\title{
Brain derived neurotrophic factor (BDNF) - Untersuchungen zur Expression und Regulation in vitro sowie zur funktionellen Relevanz in der experimentellen autoimmunen Enzephalomyelitis (EAE)
}

\author{
Dissertation \\ zur Erlangung des Doktorgrades \\ der Mathematisch-Naturwissenschaftlichen Fakultäten \\ der Georg-August-Universität zu Göttingen
}

vorgelegt von

Seray Demir, geb. Cetin

aus Rotenburg a.d. Fulda

Göttingen 2010 
Referent: Herr Prof. Dr. E. Wimmer Korreferent: Herr Prof. Dr. D. Doenecke

Tag der mündlichen Prüfung: 30.04.2010 
für Kemal Hilmi 
1. Einleitung 7

$\begin{array}{lll}1.1 & \text { Neurotrophine } & 7\end{array}$

1.2 Neurotrophine im Immunsystem $\quad 8$

$\begin{array}{lll}1.3 & \text { Neurotrophe Zytokine } & 11\end{array}$

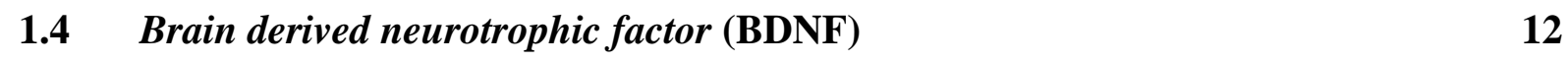

1.5 Die Multiple Sklerose (MS) und das Tiermodell der experimentellen autoimmunen Enzephalomyelitis (EAE) 16

$\begin{array}{ll}1.6 & \text { Neuroprotektive Autoimmunität } \\ & 20\end{array}$

$\begin{array}{lll}1.7 & \text { Zielsetzung } & 22\end{array}$

2. Materialien 23

2.1 Geräte 23

2.2 Labormaterialien $\quad 24$

$\begin{array}{lll}2.3 & \text { Chemikalien } & 25\end{array}$

2.4 Lösungen und Puffer

2.5 Medien und Medienzusätze $\quad 28$

2.5.1 Medienzusätze 28

2.5.2 Medien 28

2.6 Enzyme, Farbstoffe, Neurotrophine, Seren, Zellstimulanzien 29

$\begin{array}{lll}2.7 & \text { Kits } & 29\end{array}$

2.8 Antikörper 29

2.9 Komponenten der Immunisierung 30

$\begin{array}{lll}2.10 & \text { Tiere } & 30\end{array}$

2.11 Komponenten der Real-Time PCR 30

2.12 Primer Proben für die Real-Time PCR 31

2.13 Bakterienstamm 31

2.14 Plasmide $\quad 31$

2.15 Restriktionsenzyme 32

2.16 Längenstandards 32

2.17 Radioaktivität $\quad 32$

$\begin{array}{lll}2.18 & \text { Software } & 32\end{array}$ 
3. Methoden 33

3.1 Molekularbiologische Methoden 33

3.1.1 Isolation von RNA 33

3.1.2 Umschreiben von mRNA in cDNA 33

3.1.3 Quantifizierung von mRNA-Transkripten mittels Real-Time PCR 34

3.1.4 Klonierung / Ligation / Transformation 38

3.1.5 Plasmidaufreinigung 39

3.1.6 Restriktionsverdau $\quad 39$

3.1.7 DNA-Agarose Gelelektrophorese $\quad 40$

3.1.8 BDNF-ELISA 40

3.2 Zellbiologische Methoden $\quad 42$

3.2.1 Herstellung von Einzelzellsuspensionen aus primären und sekundären lymphatischen Organen $\quad 42$

3.2.2 Restimulation von T-Zellen aus einer Zelllinie $\quad 42$

3.2.3 Aufreinigung von Zellen mittels Dichtegradientenzentrifugation 43

3.2.4 Astrozyten- / Mikrogliapräparation 43

3.2.5 Isolation von mononukleären Leukozyten aus dem Rückenmark 44

3.2.6 Magnetische Zellsortierung (MACS) 45

3.2.7 Aufreinigung von T-Zellen 45

3.2.8 Zellstimulationen $\quad 46$

3.2.9 Bestimmung der Zellzahl 46

3.2.10 Durchflusszytometrie $\quad 47$

3.2.10.1Extrazelluläre Färbungen 47

3.2.11 Transfektion $\quad 48$

3.2.12 Proliferationsassay 49

3.2.13 Überlebensassay mit murinen Dorsalwurzelganglien Zellen 49

3.2.14 Herstellung lentiviraler Partikel 50

3.2.15 Lentivirale Transduktion 51

3.3 Tierexperimentelle Methoden $\quad 51$

3.3.1 Tiere 51

3.3.2 Induktion und klinische Evaluation einer aktiven $\mathrm{MOG}_{35-55}$-EAE 52

3.3.3 intra venöse (i.v.) Injektion $\quad 52$

3.4 Histologie und Immunzytochemie $\quad 53$

3.4.1 CD3 / Mac-3 / GFP Färbung 53 
3.4.2 iNOS Färbung 54

3.4.3 Anti-BDNF Färbung von Mäuse - Cytospins 55

3.4.4 Silberimprägnation nach Bielschowsky 56

3.4.5 pTrkB Fluoreszenzfärbung 57

4. Ergebnisse $\quad 58$

4.1 BDNF Expression und Regulation in vitro 58

4.1.1 Expression und Quantifizierung der mBDNF mRNA Splice-Varianten im Gehirn 58

4.1.2 Expression und Quantifizierung der mBDNF mRNA Splice-Varianten in peripheren lymphatischen Organen und Immunzellen $\quad 60$

4.1.3 Expression und Quantifizierung der mBDNF mRNA Splice-Varianten in Mikroglia und Astrozyten $\quad 64$

4.2 BDNF und dessen funktionelle Relevanz in der EAE 67

4.2.1 Generierung BDNF überexprimierender T-Zellen mittels lentiviraler Transduktion 68

4.2.2 Testen des codierenden BDNF Proteins auf Bioaktivität $\quad 73$

4.2.3 Testen der Überlebensrate i.v. injizierter T-Zellen in vivo 75

4.2.4 Prüfung des Eintritts injizierter T-Zellen in das ZNS 76

4.2.5 Einfluss der BDNF überexprimierenden T-Zellen auf die $\mathrm{MOG}_{35-55}$-EAE $\quad 78$

4.2.6 iNOS Expression $\quad 82$

4.2.7 pTrkB Expression $\quad 83$

4.2.8 Aktivierungsstatus i.v. injizierter T-Zellen in vivo 85

5. Diskussion $\quad 89$

5.1 BDNF Expression und Regulation in vitro - Splice-Varianten 89

5.2 BDNF und dessen funktionelle Relevanz in der MOG $35-55-E A E \quad 92$

$\begin{array}{ll}\text { 6. Zusammenfassung } & 108\end{array}$

$\begin{array}{ll}\text { 7. Literaturverzeichnis } & 110\end{array}$

8. Anhang 125

$\begin{array}{lll}8.1 & \text { Abkürzungsverzeichnis } & 125\end{array}$

$\begin{array}{lll}8.2 & \text { Abbildungsverzeichnis } & 129\end{array}$

$\begin{array}{lll}8.3 & \text { Danksagung } & 131\end{array}$

$\begin{array}{lll}8.4 & \text { Eidesstattliche Erklärung } & 132\end{array}$

$\begin{array}{lll}8.5 & \text { Lebenslauf } & 133\end{array}$ 


\section{Einleitung}

\section{$1.1 \quad$ Neurotrophine}

Neurotrophine sind eine Familie von Polypeptiden, die ihre Funktion zwar überwiegend, aber nicht ausschließlich im Nervensystem ausüben. Sie wurden ursprünglich als Überlebensfaktoren für neuronale Zellen beschrieben (Oppenheim et al., 1991; Purves et al., 1988). Im zentralen Nervensystem (ZNS) regulieren Neurotrophine wichtige Funktionen wie die neuronale Differenzierung und neuronales Überleben, Neuriten-Wachstum und Plastizität, synaptische Struktur und Verbindungen, sowie Neurotransmittersektretion und synaptische Plastizität (Huang and Reichardt, 2001). Zahlreiche spätere Arbeiten zeigen neben den genau untersuchten Effekten der Neurotrophine auf Neuronen auch ein weit gefächertes Wirkungsfeld von Neurotrophinen außerhalb des Nervensystems, vor allem auf Zellen des Immunsystems (Sariola, 2001; Tessarollo, 1998; Vega et al., 2003).

Das 1952 zuerst entdeckte Neurotrophin ist der Nervenwachstumsfaktor (Nerve growth factor) NGF (Levi-Montalcini, 1952), daneben gehören zu dieser Familie noch das in dieser Arbeit untersuchte Brain derived neurotrophic factor (BDNF) (Barde et al., 1982), das Neurotrophin-3 (NT-3) (Maisonpierre et al., 1991) und das Neurotrophin-4/5 (NT-4/5) (Ip et al., 1992). Außerdem wurden noch zwei weitere weniger untersuchte Neurotrophine, das Neurotrophin-6 und Neurotrophin-7, beschrieben. Diese konnten aber bislang nur bei Fischen nachgewiesen werden (Gotz et al., 1994; Nilsson et al., 1998).

Alle Neurotrophine werden zunächst als glykosylierte Neurotrophin-Vorläufer exprimiert (Pro-Neurotrophin, 31-35 kDa), die durch spezielle Konvertasen an hochkonservierten Schnittstellen in reife Neurotrophine (13.2-15.9 kDa) gespalten werden (Chao and Bothwell, 2002). Diese reifen Neurotrophine bilden dann stabile nicht-kovalent gebundene Homodimere (Wiesmann and de Vos, 2001).

Neurotrophine können an zwei verschiedene Typen von Rezeptoren mit unterschiedlicher Affinität binden. Der niedrig affine Rezeptor $\mathrm{p} 75^{\mathrm{NTR}}$ gehört zur Familie der Tumornekrosefaktor-Rezeptor-Superfamilie und dient als pan-Neurotrophin-Rezeptor (Caroleo et al., 2001; Hempstead, 2002). Die funktionelle Rolle von p75 ${ }^{\text {NTR }}$ ist noch nicht ganz aufgeklärt (Lee et al., 2001), aber es wird vermutet, dass dieser Rezeptor als CoRezeptor für die hochaffinen Rezeptoren (Esposito et al., 2001; Roux and Barker, 2002) und als Mediator des Apoptoseprogramms dient, welches durch NGF induziert wird (Chao and 
Bothwell, 2002; Meldolesi et al., 2000; Miller and Kaplan, 2001). Darüber hinaus vermittelt der $\mathrm{p} 75^{\mathrm{NTR}}$ Rezeptor die Migration von Schwann Zellen (Bentley and Lee, 2000) und ist an der Entscheidung über das Zellschicksal einiger nicht-neuronaler Zellen, wie den Makrophagen (Caroleo et al., 2001) und den glatten Gefäßmuskelzellen (Wang et al., 2000) beteiligt. Die Protein Tyrosin Kinase (Trk) Rezeptoren TrkA, TrkB und TrkC stellen die spezifischen und hochaffinen Neurotrophin Rezeptoren dar (Huang and Reichardt, 2001; Lewin and Barde, 1996). Diese Trk Rezeptoren besitzen eine extrazelluläre Domäne, an die die unterschiedlichen Neurotrophine binden, und eine zytosolische Domäne, dessen Tyrosinkinase Aktivität essenziell für die Signaltransduktion ist. Jedes Mitglied der Trk Familie besitzt einen bevorzugten Liganden unter den Neurotrophinen (Ip and Yancopoulos, 1994). An den TrkA Rezeptor bindet bevorzugt das NGF (Kaplan et al., 1991; Klein et al., 1991a), aber auch NT-3 und NT4/5 können an diesen Rezeptor, jedoch mit geringerer Affinität, binden. TrkB ist der spezifische Rezeptor für BDNF und NT-4 und in geringerem Maße auch für NT-3 (Ip et al., 1992; Klein et al., 1991b), während TrkC nur einen Liganden hat, und zwar das NT-3 (Lamballe et al., 1991). Die Gene, die für die Trk Rezeptoren codieren stammen vermutlich aus einem gemeinsamen Ursprungsgen (Hallbook, 1999), da alle Trk Rezeptoren in allen Wirbeltieren vorhanden und ihre Sequenz hochkonserviert ist.

\subsection{Neurotrophine im Immunsystem}

Neurotrophine sind hauptsächlich im ZNS vorzufinden, jedoch wurden sie und ihre Rezeptoren auch in primären und sekundären lymphatischen Organen, sowie Immunzellen detektiert (Aloe et al., 1999), wodurch diese potenzielle Ziele von Neurotrophinen darstellen. Interessanterweise konnten in allen untersuchten Wirbeltieren, von Mensch bis zum Fisch, Neurotrophine und bzw. oder deren Rezeptoren in lymphoiden Organen detektiert werden (Ciriaco et al., 1996; Hannestad et al., 1997; Hannestad et al., 2000). Im Thymus beispielsweise konnte die mRNA aller Neurotrophine und deren Rezeptoren nachgewiesen werden (Labouyrie et al., 1997; Laurenzi et al., 1994; Timmusk et al., 1993). In Säugertieren wurde der TrkA Rezeptor hauptsächlich in subkapsulären und medullären Epithelzellen lokalisiert (Garcia-Suarez et al., 2001; Hannestad et al., 1997; Parrens et al., 1999; Yoon et al., 2003), während die Expression in Thymozyten nicht detektiert werden konnte (Hannestad et al., 1997; Maroder et al., 1996; Parrens et al., 1999). Die Hauptfunktion des thymischen TrkA Rezeptors scheint die Regulierung des NGF Neurotrophins zu sein, welches zu einer 
epithelialen Zellhypertrophie in vivo führt (Abramchik et al., 1988) und die IL-6 Transkription in den Epithelzellen in vitro erhöht (Screpanti et al., 1992). Die Expression der mRNA des full-length (Laurenzi et al., 1994; Maroder et al., 1996) sowie der verkürzten, truncated, (Lomen-Hoerth and Shooter, 1995) Isoform des TrkB Rezeptors im Thymus konnte in beiden Fällen nachgewiesen werden. Auf Proteinebene konnte die Expression des TrkB Rezeptors in Thymozyten (Besser and Wank, 1999; Maroder et al., 1996), sowie in den Stromazellen detektiert und dort als ED1+ bzw. F4/80+ Makrophagen in der Ratte und der Maus (Garcia-Suarez et al., 2002) identifiziert werden. Der TrkC Rezeptor hingegen konnte bislang nicht im Thymus von Säugetieren detektiert werden, während die mRNA des p75 Neurotrophinrezeptors dort lokalisiert wurde, und zwar hauptsächlich im Stroma (LomenHoerth and Shooter, 1995), in den medullären Epithelzellen und den dendritischen Zellen (Garcia-Suarez et al., 2001; Parrens et al., 1999). Im Fall der Neurotrophine, konnte das NGF z.B. im Thymus, hauptsächlich in der Medulla, nachgewiesen werden, wo es womöglich auch lokal vor Ort synthetisiert wird (Aloe and Tuveri, 1997; Katoh-Semba et al., 1993; Turrini et al., 2001). Da man bereits weiß, dass auch T-Zellen NGF produzieren (Ehrhard et al., 1993; Lambiase et al., 1997; Santambrogio et al., 1994), könnte man davon ausgehen, dass dieses Neurotrophin auf parakrine Art und Weise seine Funktion auf die TrkA exprimierenden Epithelzellen ausübt. Die mRNA für das Neurotrophin BDNF hingegen wurde im Thymus detektiert, wo es von Stomazellen exprimiert wurde (Laurenzi et al., 1994; Timmusk et al., 1999; Yamamoto et al., 1996), außerdem scheint dieses Neurotrophin durch die Bindung an seinen spezifischen TrkB Rezeptor, welches auf unreifen Thymozyten exprimiert wird, für das Überleben der Thymozyten in bestimmten Entwicklungsstadien notwendig zu sein (Maroder et al., 1996). Im Thymus konnten außerdem die Neurotrophine NT-3 (Katoh-Semba et al., 1996; Laurenzi et al., 1994) und NT-4/5 (Laurenzi et al., 1994; Timmusk et al., 1993) auf mRNA und auch auf Proteinebene nachgewiesen werden. Die zelluläre Quelle dieser Neurotrophine, sowie ihre Rolle im Thymus sind bisher nicht aufgeklärt.

In der Milz konnten alle Neurotrophine (Laurenzi et al., 1994; Timmusk et al., 1993; Yamamoto et al., 1996), sowie die Neurotrophinrezeptoren p75 und die spezifischeren Trk Rezeptoren detektiert werden (Laurenzi et al., 1994; Yamamoto et al., 1996). In der Milz der Ratte wurde die $\mathrm{p} 75^{\mathrm{NTR}}$ Expression in den dendritischen Zellen im PALS (periarterielle lymphatische Scheiden) detektiert (Perez-Perez et al., 2003), während die TrkA Expression bislang nicht detektiert werden konnte. Der TrkB Rezeptor hingegen wurden mit Hilfe der Immunhistochemie in Subpopulationen von Makrophagen des Menschen (Shibayama and Koizumi, 1996), der Ratte und der Maus (Perez-Perez et al., 1999) identifiziert. 
Dass Neurotrophine auch einen Einfluss auf Lymphozyten haben, wurde erstmals durch Dean et al. (1987) berichtet. Dieser beobachtete, dass NGF die blastogene Antwort der Milzzellen der Maus erhöhte. Die Expression von Neurotrophinen und deren Rezeptoren auf Lymphozyten ist teilweise abhängig von ihrer Zellaktivierung (Kerschensteiner et al., 1999; Moalem et al., 2000). Die Expression von NGF und seinem spezifischen Rezeptor TrkA wird durch die Mitogenaktivierung der CD4+ T-Zellen induziert (Ehrhard et al., 1993), und der TrkA Rezeptor scheint deswegen funktionell zu sein, da die NGF Wirkung auf Antigen stimulierte CD4+ T Zellen die Expression von c-fos, einem Transkriptionsfaktor, induziert (Ehrhard et al., 1994). Sowohl CD4+ als auch CD8+ T-Zellen produzieren NGF, welches nach Antigenstimulation in der Th2 Untergruppe erhöht wird (Santambrogio et al., 1994). In diesem Zusammenhang ist zu erwähnen, dass unstimulierte humane CD4+ Th1 und Th2 Zellen, aber nicht die Th0 Zellen, NGF und TrkA exprimieren (Lambiase et al., 1997). Th1 Zellen exprimieren zusätzlich das full-length TrkB und geringe Mengen des TrkC Rezeptors (Besser and Wank, 1999). CD4+ und CD8+ T-Zellen transkribieren sowohl BDNF mRNA und produzieren bioaktives BDNF (Braun et al., 1999; Kerschensteiner et al., 1999; Kruse et al., 2007) als auch NT-3 und NT-4/5 (Moalem et al., 2000). Im Gegensatz dazu ist die Expression von $\mathrm{p} 75^{\mathrm{NTR}}$ in T-Zellen kontrovers (Ehrhard et al., 1993; Kittur et al., 1992).

In B-Zellen wurde die Expression von TrkA (D'Onofrio et al., 2000; Torcia et al., 1996) und p75 ${ }^{\text {NTR }}$ (Brodie et al., 1996) beobachtet. Schenone et al. (1996) jedoch berichteten, dass BZellen weder auf mRNA noch auf Proteinebene $\mathrm{p} 75^{\mathrm{NTR}}$ oder TrkA exprimieren. Dafür beobachteten diese Autoren, dass B-Zellen TrkB auf mRNA und Proteinebene exprimieren und dass dieser Rezeptor durch das Neurotrophin BDNF aktiviert wird. Die Unterschiede zwischen diesen beiden Ergebnissen könnten auf den Aktivierungsstatus der Zellen zurückzuführen sein. Die Expression von TrkB auf B-Zellen konnte durch eine weitere Arbeitsgruppe bestätigt werden (D'Onofrio et al., 2000), und eine mögliche Expression des TrkC Rezeptors auf B-Zellen wurde angedeutet (D'Onofrio et al., 2000). Im Fall der Neurotrophinexpression wurde in B-Zellen die Expression von NGF (Santambrogio et al., 1994; Torcia et al., 1996) und NT-3 (Besser and Wank, 1999) beobachtet. Interessanterweise scheint NGF auch im Überleben der B-Zellen eine wichtige Rolle zu spielen, da es in der Lage ist diese Zellen von der induzierten Apoptose zu schützen (Kronfeld et al., 2002).

Im Fall der Monozyten wurde beobachtet, dass diese den TrkA Rezeptor exprimieren, und dass die Expression nach Aktivierung erhöht ist, aber während der Differenzierung zu den Gewebsmakrophagen herunterreguliert wird (Ehrhard et al., 1993a). Was die Neurotrophine betrifft konnte die Expression von NGF, BDNF und NT4/5 in den Makrophagen detektiert 
werden (Braun et al., 1999; Caroleo et al., 2001). Es wurde gezeigt, dass NGF und BDNF sowohl das Zytokinexpressionsmuster in mononukleären Zellen des peripheren Bluts beeinflussen als auch in antigenspezifischen T-Zellen die Produktion von IL-4, TGF- $\beta$, TNF$\alpha$ und INF- $\gamma$ modulieren (Bayas et al., 2003).

Zusammengefasst scheinen die Neurotrophin/Rezeptor Systeme eine wichtige Rolle in der Tund B-Zellphysiologie zu spielen. Des Weiteren scheint jede Lymphozyten Untergruppe ihr ganz eigenes charakteristisches Muster an Neurotrophinen und deren spezifischen Rezeptoren $\mathrm{zu}$ exprimieren.

\subsection{Neurotrophe Zytokine}

Eine andere Familie von Wachstumsfaktoren ist die Familie der neurotrophen Zytokine. Sie umfasst die Moleküle, die ursprünglich als Zytokine identifiziert wurden, die von Lymphozyten freigesetzt werden und die Proliferation fördern, wozu auch das Interleukin-6 zählt (IL-6). Diese Moleküle wirken auch auf das neuronale Überleben und deren Differenzierung, in diesem Zusammenhang wurde das neurotrophe Zytokin ciliary neurotrophic factor (CNTF) identifiziert. Diese Wachstumsfaktoren üben ihre biologischen Effekte über einen Rezeptorkomplex aus, der aus einer ubiquitär exprimierten gp130 und zytokinspezifischen Untereinheiten, wie z.B. CNTF-Rezeptor- $\alpha$ oder LIF Rezeptor $\beta$, besteht. Die Aktivierung des Rezeptorkomplexes ist in der Lage eine intrazelluläre Kaskade an Proteinkinasen, wie der JAK und MAP Kinase, zu aktivieren. Diese Kinasen wiederum kontrollieren die Aktivität der Transkriptionsfaktoren, die der STAT Familie angehören (Bravo and Heath, 2000).

Das neurotrophe Zytokin CNTF scheint offensichtlich einen Einfluss auf die autoimmune Demyelinisierung auszuüben und wird im Folgenden näher erläutert. CNTF ist ein $25 \mathrm{kDa}$ Polypeptid und wurde ursprünglich als Überlebensfaktor für ziliäre Ganglienneurone identifiziert (Adler et al., 1979). Dem CNTF fehlt eine hydrophobe Sekretionssequenz, wodurch es im Zytoplasma lokalisiert ist und da es nur nach einem Gewebeschaden freigesetzt wird auch als Läsionsfaktor betrachtet wird (Sleeman et al., 2000; Stockli et al., 1989). Die Expression des CNTF ist in der Peripherie auf Schwannzellen und im zentralen Nervensystem auf Astrozyten begrenzt. Der CNTF Rezeptor hingegen konnte hauptsächlich in neuralem Gewebe und dem Skelletmuskel detektiert werden, zeigte aber auch eine geringe Expression in der Nebenniere, Haut, Leber, Nieren und Hoden (Oppenheim et al., 1991; 
Sleeman et al., 2000; Stockli et al., 1991). CNTF ist in vitro ein wirksamer Überlebens- und Differenzierungsfaktor für viele Zelltypen des Nervensystems, wie Neuronen und Oligodendrozyten (Adler et al., 1979; Arakawa et al., 1990; D'Souza et al., 1996; Stankoff et al., 2002). In vivo verhindert es die Degeneration von axotomierten Neuronen und vermindert Motordefizite in verschiedenen Mausstämmen mit neuromuskulären Mängeln (Curtis et al., 1993; Mitsumoto et al., 1994; Sendtner et al., 1990; Sendtner et al., 1992). In CNTF defizienten Mäusen konnte ein schwererer Erkrankungsverlauf im Vergleich zu Kontrolltieren nach Induktion einer experimentellen autoimmunen Enzephalomyelitis (EAE), einem Tiermodell der Multiplen Sklerose, beobachtet werden (Linker et al., 2002). In der späten Phase der Erkrankung litten CNTF defiziente Mäuse immer noch an Paraplegie, während bei den Kontrolltiere nur noch eine Gangataxie zu erkennen war. Auf der histologischen Ebene kann die erhöhte Suszeptibilität der CNTF defizienten Mäuse durch eine $60 \%$-ige Verminderung der proliferierenden Vorläuferzellen der Oligodendrozyten zu erklären sein. In einer anderen Studie wurde ganz im Gegensatz zur vorangegangenen die systemische Applikation von CNTF in Wildtyp BL/6 Mäusen untersucht (Kuhlmann et al., 2006). Die Verabreichung von niedrigen Dosen des Zytokins während der akuten Phase einer MOG induzierten EAE, führte nicht zu systemischen Nebenwirkungen, wie Änderungen in der peripheren Immunantwort, zeigte aber einen verminderten Krankheitsverlauf. Es wurde beobachtet, dass die Zahl an perivaskulären Infiltraten und die Menge an aktivierten Mikroglia im Rückenmark reduziert waren. Dieser benefizielle Effekt konnte jedoch nach dem Absetzen der Applikation nicht mehr gehalten werden, wodurch die Inflammation und die Symptome wieder das Niveau der Kontrolltiere einnahmen.

Da CNTF scheinbar ein Schlüsselmolekül in der autoimmunen Demyelinisierung in experimentellen Modellen darstellt, so liegt es Nahe, dass dieses Zytokin auch eine funktionelle Relevanz in der MS haben könnte.

\subsection{Brain derived neurotrophic factor (BDNF)}

Im Jahre 1982 wurde BDNF als zweites Mitglied der Neurotrophinfamilie entdeckt (Barde et al., 1982). Das reife, biologisch aktive BDNF hat ein Molekulargewicht von $14 \mathrm{kDa}$ und stammt aus dem $32 \mathrm{kDa}$ großen pro-BDNF (Matsumoto et al., 2008). BDNF bildet meist Homodimere, die durch drei Disulfidbrücken miteinander verbunden werden, aber auch Heterodimere mit NT3 und NT4/5 wurden beschrieben (Robinson et al., 1995; Wiesmann and 
de Vos, 2001). Im Gegensatz zum konstitutiv sezernierten NGF, wird die Sekretion dieses Proteins nur durch einen Aktivitäts-abhängigen Signalweg reguliert. Das Sortieren des Proteins in den sekretorischen Signalweg hängt von der Sortierungssequenz in der Tertiärstruktur ab. Auch die Carboxy-Peptidase E ist kritisch für die Sekretion (Lou et al., 2005).

Auf molekularer Ebene umfasst das BDNF Gen ca. $50 \mathrm{~kb}$ an genomischer DNA und besteht aus 8 verschiedenen Exons. Obwohl die ersten sieben Exons unterschiedliche Promotoren besitzen, codiert nur Exon 8 die Proteinsequenz für BDNF (Liu et al., 2006). Dennoch werden durch alternatives Splicing und die Verwendung von Polyadenylierungs-Stellen mehrere alternative Splicevarianten generiert (Abb. 1.1), woraus man ableitet, dass die verschiedenen Promotoren unterschiedlich reguliert werden bzw. auf die verschiedenen Stimuli unterschiedlich antworten. Im ZNS können alle Splicevarianten auf unterschiedlichen Ebenen detektiert werden, einige unter Ihnen sind sogar auch in peripherem Geweben, wie der Lunge, dem Herzen, dem Dünndarm, den Nieren und den Hoden aktiv (Liu et al., 2006). Diese unterschiedliche Expression des BDNF könnte auf getrennte regulatorische Netzwerke dieses Proteins im ZNS und im Immunsystem zurückzuführen sein. Die genaue Regulation ist bisher jedoch noch ungeklärt.

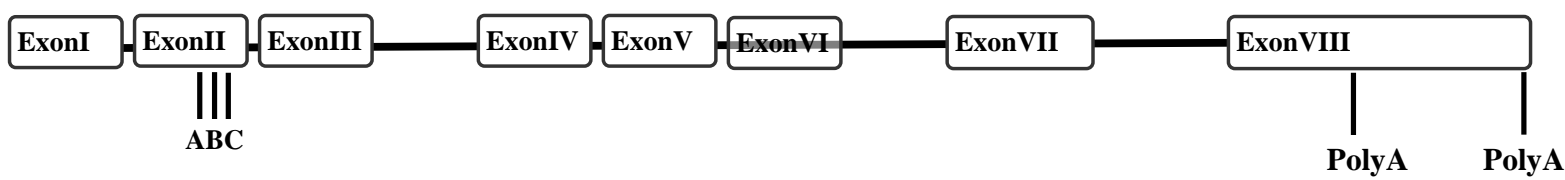

\begin{tabular}{ll|l|} 
BDNF 1 & ExonI & ExonVIII \\
BDNF 2A & ExonIIA & ExonVIII \\
BDNF 2B ExonIIB & ExonVIII \\
BDNF 2C ExonIIC & ExonVIII \\
BDNF 3 ExonIII ExonVIII
\end{tabular}

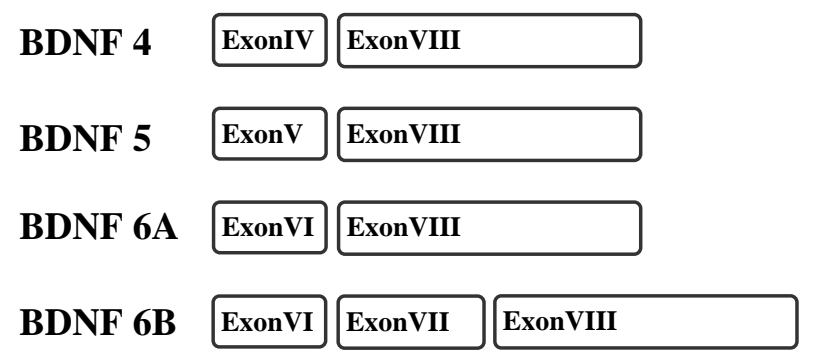

Abb. 1.1: Maus BDNF Genstruktur und Splice-Varianten. Die Rechtecke repräsentieren die unterschiedlichen Exons. Die senkrechten Linien deuten auf Splice-Stellen innerhalb der Exons und auf alternative Polyadenylierungs-Stellen hin. 
Der biologische Effekt von BDNF wird durch die Bindung an spezifische Rezeptoren vermittelt. Dabei unterscheidet man zwischen dem hoch affinen TrkB Rezeptor und den weniger affinen $\mathrm{p} 75^{\mathrm{NTR}}$ Rezeptor, an den auch alle anderen Neurotrophine binden können. Für den TrkB Rezeptor wurden alternative Isoformen nachgewiesen. So kann der full-length TrkB Rezeptor noch seine komplette Signalfunktion ausüben, während die verkürzte und sog. truncated Isoform nur eine limitierte Signalfunktion besitzt und sogar durch die Bildung von Heterodimeren die Funktion der TrkB Rezeptoren inhibieren kann (Eide et al., 1996). BDNF hat einen direkten Einfluss auf axonales Wachstum (Markus et al., 2002), ist beteiligt an der Modulation von neuronalen Aktivitäten und beeinflusst das Gedächtnis und die Lernfähigkeit (Gorski et al., 2003; Linnarsson et al., 1997). Des Weiteren hat BDNF auch Einfluss auf die synaptische Plastizität durch die Bindung an den prä- und postsynaptischen TrkB-Rezeptor. Dadurch stimuliert es vermutlich die Glutamatausschüttung und inhibiert die GABAerge synaptische Transmission an der Postsynapse (Wardle and Poo, 2003). Im ZNS ist BDNF verantwortlich für das Überleben und die Differenzierung von zahlreichen Neuronenpopulationen, wie z.B. auch im Striatum (Lewin and Barde, 1996). Die Bedeutung des BDNF für die Funktionalität des Gehirns und dessen Erhalt wurde durch den frühen Tod von BDNF-defizienten Mäusen betont, da diese durch den Untergang von viscero-afferenten Neuronen und dementsprechend auch dem Versagen der Aspiration in einem Alter von 2-3 Wochen versterben. Zudem wurde in heterozygoten $\mathrm{BDNF}^{+/}$Mäusen starke Verhaltensstörungen, wie ein hohes Maß an Aggressivität und Hyperaktivität, beobachtet. Weiterhin wurde bei diesen Tieren Hyperphagia, Obesität, Verlust der Mechanosensitivität und der Untergang von Neuronen aus dem PNS beschrieben (Carroll et al., 1998; Ernfors et al., 1994; Kernie et al., 2000; Rios et al., 2001).

Im ZNS ist die BDNF Expression nicht nur auf Neuronen begrenzt, sondern wurde auch in glialen Zellen beobachtet. BDNF mRNA Expression z.B. wurde auch in Mikroglia detektiert (Elkabes et al., 1996; Kruse et al., 2007), außerdem ist berichtet worden, dass BDNF die Proliferation von Mikroglia auslöst (Elkabes et al., 1996; Kruse et al., 2007). In Astrozyten hingegen bindet BDNF an den verkürzten TrkB Rezeptor und führt $\mathrm{zu}$ einer Kalziumausschüttung aus intrazellulären Kompartimenten (Rose et al., 2003). Durch derartige Studien entwickelt sich das BDNF als ein potenzieller Mediator für Neuronen-GliaInteraktionen im ZNS.

Im Immunsystem wird BDNF sowohl in primären als auch in sekundären lymphatischen Organen exprimiert. Auf zellulärer Ebene wurde die BDNF mRNA Expression in thymischen Stromazellen detektiert, was eventuell auf einen Einfluss des BDNF auf das Überleben von 
Thymozyten in bestimmten Entwicklungsstufen in der Thymozytenreifung zurückzuführen ist (Maroder et al., 1996). Zudem wurde sowohl BDNF mRNA als auch das BDNF Protein in TZellen, B-Zellen und Monozyten nachgewiesen (Kerschensteiner et al., 1999; Kruse et al., 2007). Da unreife Thymozyten (Maroder et al., 1996) und Th1 Zellen (Besser and Wank, 1999) den TrkB Rezeptor exprimieren und der BDNF Gehalt in aktivierten T-Zellen erhöht ist (Kerschensteiner et al., 1999), wird in diesen Zellen eine auto- bzw. parakrine Wirkungsweise des BDNF vermutet, dies ist jedoch noch nicht bewiesen. Im Fall der B-Zellen wurde eine Blockierung der B-Zellentwicklung in der Prä-BII Phase in jungen BDNF knock-out Mäusen beobachtet (Schuhmann et al., 2005). Dieser Block führt zu einem drastischen Abfall der BZellzahl in bestimmten Reifestadien sowie zur Minimierung der Zellzahl an reifen B-Zellen in der Peripherie und demonstrierte zugleich die bedeutende Funktion des BDNF in der Entwicklung dieses Zelltyps. Zusätzlich zu seiner Expression im Immunsystem, könnte BDNF auch zu immunologischen Veränderungen im ZNS führen. Diese Auswirkungen beinhalten die Hemmung der MHC-Klasse-II Induktion und der kostimulatorischen Moleküle auf Mikroglia, was einen Einfluss auf die Antigenpräsentation hätte (Neumann et al., 1998). In den vergangenen Jahren hat sich immer deutlicher herausgestellt, dass Neurotrophine auch in der Pathogenese vieler neurodegenerativer Erkrankungen eine wichtige Rolle spielen, wodurch sie sich auch gleichzeitig als vielversprechende therapeutische Ziele anbieten. Bei der Parkinson Erkrankung z.B. handelt es sich um eine neurodegenerative Erkrankung, die durch die Degeneration von dopaminergen Neuronen in der Substantia nigra und des Striatums charakterisiert wird. Das Neurotrophin BDNF wird von dopaminergen Neuronen exprimiert und für deren Entwicklung und Erhalt benötigt. Genau aus diesem Grund scheint BDNF auch in der Pathogenese von Parkinson beteiligt zu sein. Man konnte feststellen, dass die BDNF mRNA Menge in der Substantia nigra von Parkinson Patienten reduziert war (Howells et al., 2000). Im Tiermodell des Parkinson führte die Applikation von BDNF mit Hilfe einer Injektion ins Striatum bzw. der Zufuhr von transplantierten Fibroblasten, die in der Lage sind humanes BDNF zu sezernieren, zu einer geringeren Zerstörung der dopaminergen Neuronen (Frim et al., 1994; Shults et al., 1995). Im Gegenteil dazu zeigte eine Studie, in der die BDNF Expression inhibiert wurde, dass dopaminerge Neurone vermehrt zerstört wurden (Porritt et al., 2005). Diese Untersuchungen zeigen, dass die neuroprotektiven Eigenschaften des BDNF immer stärker in den Vordergrund treten. So auch z.B. in der am häufigsten auftretenden Demenzerkrankung bei älteren Menschen, der Alzheimer Erkrankung. Diese zeichnet sich neuropathologisch durch Neuronenverlust, extrazelluläre Einlagerungen von Amyloid Plaques, intrazellulären Einlagerungen von hyperphosphoryliertem tau, 
neurofibrillären Verwicklungen und lokalen Entzündungsreaktionen aus. Die neuropsychologischen und neuropsychiatrischen Symptome der Alzheimer Erkrankung resultieren womöglich aus einer verminderten cholinergen Funktion, die mit dem Verlust von cholinergen Neuronen einhergeht (Davies and Maloney, 1976; Winblad et al., 1993). An dieser Stelle wird eine Funktion des BDNF in der Pathogenese dieser Erkrankung vorgeschlagen, da dieses Neurotrophin in der Lage ist auf cholinerge Neurone zu wirken. Zudem reguliert BDNF die synaptische Plastizität und spielt deshalb eine Schlüsselrolle in der Gedächtnisformation und dessen Speicherung (Hellweg and Jockers-Scherubl, 1994). So ist es nicht verwunderlich, dass im Hippocampus und im Neocortex von Alzheimer Patienten die BDNF mRNA (Connor et al., 1997; Garzon et al., 2002; Holsinger et al., 2000; Phillips et al., 1991) und das BDNF Protein (Ferrer et al., 1999; Hock et al., 2000; Michalski and Fahnestock, 2003; Peng et al., 2005) sowie der spezifische Rezeptor TrkB (Allen et al., 1999; Ferrer et al., 1999) geringer exprimiert werden. Zu den Funktionen von BDNF zählt die Dephosphorylierung des tau Proteins (Elliott et al., 2005), wodurch eine Verbindung zwischen BDNF und der tau Pathologie als sehr wahrscheinlich erscheint.

Auch BDNF Genpolymorphismen scheinen eine Rolle in degenerativen Erkrankungen zu spielen. So führt eine G zu A Substitution dazu, dass am Codon 66 des BDNF Gens die Aminosäure Valin (Val) durch Methionin (Met) ersetzt wird (Huang et al., 2007). Dieser Polymorphismus wird mit der Anfälligkeit für einige psychische und neurologische Erkrankungen wie z.B. der Schizophrenie, in Verbindung gebracht (Rosa et al., 2006). Zwischen der Anfälligkeit für die MS und diesem Polymorphismen konnte bislang keine eindeutige Verbindung hergestellt werden (Lindquist et al., 2005). Dennoch wurde beobachtet, dass in Anwesenheit des Met Allels in MS Patienten die graue Substanz stärker erhalten blieb, ohne jedoch einen signifikanten Einfluss auf neuropsychologische Parameter zu nehmen (Zivadinov et al., 2007).

Um jedoch die genaue Funktion des BDNF in neurodegenerativen Erkrankungen zu erfassen, sind weitere Studien erforderlich.

\subsection{Die Multiple Sklerose (MS) und das Tiermodell der experimentellen autoimmunen Enzephalomyelitis (EAE)}

MS ist die häufigste chronische neurologische Erkrankung im jungen Erwachsenenalter, und betrifft häufiger Frauen in einem Verhältnis von circa 3:2. Die charakteristischen frühen 
Symptome des schubförmigen Erkrankungsverlaufs sind sensorischen Störungen sowie die optische Neuritis, während die Verschlechterung der motorischen Fähigkeiten erst in den späteren Erkrankungsstufen auftauchen und zu starken Einschränkungen im fortschreitenden MS-Verlauf führen (Noseworthy et al., 2000). In den vergangenen 15 Jahren wurde verstärkt versucht erkrankungslindernde Therapien zu entwickeln, vor allem für die frühe Phase der Erkrankung. Jedoch ist die Effizienz solcher Therapieansätze bis heute noch unbefriedigend und eine vollständige Heilung ist noch nicht in Sicht. Ein komplexes Zusammenspiel von genetischen- und Umweltfaktoren tragen zu dieser vermutlich autoimmunen Pathogenese der MS bei, bei der die genaue Ätiologie noch ungeklärt ist.

Die klassischen histopathologischen Eigenschaften der MS-Läsionen sind die Inflammation, Demyelinisierung und die Gliose in der weißen Substanz (Frohman et al., 2006), wobei sich die neueren Untersuchungen auch auf die Pathologie der grauen Substanz konzentrieren (Stadelmann et al., 2008). Die Krankheitssymptome, die mit den MS-Läsionen einhergehen sind Koordinationsschwierigkeiten, Spastizität, visuelle und sensorische Beeinträchtigungen, Gedächtnisstörungen, Probleme in der kognitiven Verarbeitung von Information sowie Depressionen (Hauser and Oksenberg, 2006). Mit 85 - $90 \%$ ist die häufigste Art der Multiplen Sklerose die schubförmig remittierende Form der Erkrankung, die doppelt so viele Frauen betrifft als Männer. Charakteristisch dafür ist, dass die Betroffenen abwechselnde Phasen der Erkrankung und Erholung durchlaufen, bei der in der Erholungsphase die Symptome teilweise wieder abklingen. Bei den meisten Patienten, die unter der schubförmig remittierenden Form von MS leiden, geht die Erkrankung nach einigen Jahren in die sekundär progredient verlaufende Form über, bei der die Erholungsphasen ausbleiben und sich die Symptome kontinuierlich verstärken. Ähnlich der sekundär progredienten Form der Erkrankung verläuft auch die zweithäufigste Form der Multiplen Sklerose, nämlich die primär progrediente Form, die ca. $10-15 \%$ der Patienten betrifft. Hierbei zeichnet sich die Erkrankung durch eine kontinuierliche Verschlechterung des Krankheitsbildes von Anfang an der Erkrankung aus, ohne dass der Patient jegliche Erholungsphasen durchläuft. Diese Form der Erkrankung bricht zu einem späteren Zeitpunkt aus und ist stärker unter Männern verbreitet als unter Frauen (Sospedra and Martin, 2005).

Die Ätiologie der Multiplen Sklerose ist zwar unbekannt, jedoch geht man davon aus, dass sich die Anfälligkeit für diese Erkrankung aus genetischen und Umweltfaktoren zusammensetzt. So wurde z.B. beobachtet, dass die Erkrankung unter Trägern der Allele HLA-DR*1501 und HLA-DQ*0601 häuft (Olerup and Hillert, 1991). Was den eventuellen Beitrag von Umweltfaktoren zur Erkrankung betrifft, so wurde interessanterweise beobachtet, 
dass sich die Multiple Sklerose hauptsächlich auf die Nordhemisphäre konzentriert. Dies kann natürlich auch auf ein genetisch prädispositionierten Genpool zurückzuführen sein, aber auch Umweltfaktoren wie z.B. Infektionen können das erhöhte Erkrankungsrisiko begründen. Zudem konnten Migrationsstudien zeigen, dass Menschen, die vor dem 15. Lebensalter aus einem Gebiet mit einem hohen Anfälligkeitsrisiko in ein Gebiet umziehen, welches ein niedrigeres Risiko besitzt, das geringere Erkrankungsrisiko erwerben (Sospedra and Martin, 2005).

Es ist allgemein akzeptiert, dass die Multiple Sklerose durch CD4+ T-Zellen vermittelt wird (Hafler, 2004). Durch den Kontakt mit Antigen beladenen APC's werden autoreaktive TZellen aktiviert, dabei ist allerdings noch umstritten wo das erste Antigenpriming stattfindet, im ZNS oder den peripheren lymphatischen Organen (McMahon et al., 2005). Für die Initiation der Erkrankung konnte jedoch gezeigt werden, dass autoreaktive T-Zellen die Bluthirnschranke passieren und im ZNS auf Myelinantigene reagieren. Die genauen Antigene, die für das Priming der autoreaktiven T-Zellen verantwortlich sind, sind unbekannt, jedoch konnten Tiermodelle zeigen, dass vor allem MBP (Myelinbasisches Protein), PLP (Proteolipoprotein) und MOG (Myelin Oligodendrozyten Glykoprotein) mögliche Kandidaten sind. Aber auch andere T-Zellspezifitäten, wie z.B. MAG (Myelin assoziiertes Protein), MOBP (Myelin assoziiertes Oligodendrozytenbasisches Protein) oder OSP (Oligodendrozyten spezifisches Protein) konnten identifiziert werden (Sospedra and Martin, 2005). Nach der T-Zellaktivierung wird der ganze Entzündungsprozess durch die Freisetzung von Zytokinen und anderen proinflammatorischen Mediatoren, die zur Aktivierung von ansässigen Makrophagen und Mikroglia führt, in Gang gesetzt. Daraufhin kommt es zu einer verstärkten Permeabilität der Bluthirnschranke, was zum Einstrom von T-Zellen, Antikörpern und Komponenten des angeborenen Immunsystems wie Makrophagen, NK Zellen, Granulozyten und Komplement führt. Die Folge ist Schädigung von Axonen und Oligodendrozyten, die schließlich zu den bereits beschriebenen Symptomen der Multiplen Sklerose führt (Keegan and Noseworthy, 2002). Das Ausmaß dieser Schädigung zwischen den unterschiedlichen Formen der Multiplen Sklerose ist variabel (Hemmer et al., 2006). Neben autoreaktiven CD4+ T-Zellen scheinen auch CD8+ $\mathrm{T}$ und B Lymphozyten an der Pathogenese der Multiplen Sklerose beteiligt zu sein. In diesem Zusammenhang wird ein Erklärungsmodell vorgeschlagen, bei dem die CD4+ T-Zellen zwar für die Initiation der Multiplen Sklerose verantwortlich sind, aber dass hauptsächlich CD8+ T-Zellen für Zellschädigung während den Schüben und chronischen Phasen der Multiplen Sklerose verantwortlich sind (Friese and Fugger, 2005). Die genaue Rolle der B Lymphozyten in der 
Pathogenese der MS ist umstritten und noch nicht ganz geklärt. Eins der wichtigsten Diagnosekriterien der MS ist das Vorhandensein von myelinspezifischen Antikörpern im Liquor (CSF; Cerebrospinale Flüssigkeit) der MS Patienten (Hemmer et al., 2006), deren Anstieg mit der Verschlechterung von Krankheitssymptomen während der Schübe korrelierte. Diese Antikörper konnten auch in MS Plaques und Gebieten mit aktiver Demyelinisierung nachgewiesen werden (Sospedra and Martin, 2005). Diese Beobachtungen sprechen für eine Beteilung von B Lymphozyten an der Pathogenese der MS, wobei das Ausmaß ihrer Beteiligung immer noch ungeklärt ist.

Der Erkrankungsverlauf sowie die histopathologischen Merkmale der MS können in einigen Tiermodellen nachgestellt werden, wobei das wohl wichtigste Tiermodell die experimentelle autoimmune Enzephalomyelitis (EAE) ist (Gold et al., 2006). EAE kann in anfälligen Tieren, meist Inzuchtnagerstämme, durch die Immunisierung mit einem ganzen Myelinprotein oder einem speziellen (Myelin) Antigen in Adjuvant ausgelöst werden. Dafür wurden in den letzten Jahrzehnten spezielle enzephalitogene Epitope von potenziellen Autoantigenen identifiziert, dazu zählen das Myelin Oligodendrozyten Glykoprotein Aminosäure (AS) 35-55 $\left(\mathrm{MOG}_{35-55}\right)$ und das Proteolipid Protein AS 139-151 (PLP $\left.{ }_{139-151}\right)$. Durch die Immunisierung von verschiedenen Mausstämmen wie z.B. die C57BL/6 Mäuse mit MOG oder SJL Mäuse mit PLP können unterschiedliche Aspekte der MS Erkrankung nachgeahmt werden. So führt z.B. die Induzierung der MOG-EAE in C57BL/6 Mäusen zu einem ersten Schub, dem ein chronischer Erkrankungsverlauf folgt, und der durch Demyelinisierung und degenerative Entwicklungen gekennzeichnet ist (Herrero-Herranz et al., 2008). Die meisten Studien in diesen Modellen sind auf die Hauptakteure ausgerichtet, die an der Immunpathogenese beteiligt sind, wie z.B. die „Th1/Th17“ Immunantworten oder die regulatorischen Elemente. Nur einige wenige Studien behandeln die Bedeutung von Suszeptibilitätsfaktoren für den Gewebeschaden oder dessen Wiederherstellung. In diesem Zusammenhang gewinnen Neurotrophine durch ihren Einfluss auf neuronale und gliale Zellen an Bedeutung und es wird immer stärker bewusst, dass Neurotrophine nicht nur das Zielgewebe beeinflussen, sondern auch die Immunreaktion selbst und somit eine enge Verknüpfung zwischen Nervensystem und Immunsystem schaffen. 


\subsection{Neuroprotektive Autoimmunität}

Neuronen und Gliazellen sind die Hauptquelle für neurotrophe Faktoren. Auch BDNF wird hauptsächlich von Neuronen gebildet, wobei neuere Studien zeigen, dass bioaktives BDNF auch von Immunzellen exprimiert wird (Kerschensteiner et al., 1999). Diese BDNF exprimierenden Immunzellen, sowie der BDNF-spezifische Rezeptor TrkB wurden um verschiedene Läsionen herum in MS Patienten detektiert und gaben Grund zur Annahme, dass das von Immunzellen sezernierte BDNF auch in den Läsionen aktiv sein könnte und dort seine potenziell neuroprotektiven Fähigkeiten ausübt (Kerschensteiner et al., 1999; Stadelmann et al., 2002). In diesem Zusammenhang keimte das so genannte „Konzept der neuroprotektiven Autoimmunität“ auf (Schwartz et al., 1999). Dieses Konzept besagt, dass in entzündlichen Erkrankungen des ZNS, die infiltrierenden Zellen eine ambivalente Funktion ausüben. Auf der einen Seite führt die Infiltration der Leukozyten zum Gewebeschaden, entweder direkt durch die Antigenerkennung und der anschließenden Zelllyse oder indirekt durch die Sekretion von inflammatorischen Zytokinen, die entweder zur Apoptose führen und bzw. oder andere schädlichere Effektorzellen aktivieren. Auf der anderen Seite führt die Infiltration der Leukozyten zur Sekretion von regulatorischen Zytokinen sowie Neurotrophinen, wie das BDNF, die potenziell neuroprotektiv wirken können (Stadelmann et al., 2002; Ziemssen et al., 2002). Diese neurotrophen Faktoren können dann in das umliegende entzündete Gewebe eindringen und möglicherweise den Grad des axonalen bzw. neuronalen Schadens begrenzen.

Dieses Konzept wird durch weitere Beobachtungen in Tiermodellen, wie die des experimentellen Modells der Sehnervquetschung und des Rückenmarktraumas unterstützt. In diesen Modellen erhöht die Entzündung das axonale Überleben und verbessert sogar deren Funktionalität (Schwartz and Kipnis, 2001). Solch positive Effekte werden den endogenen TZellabhängigen Immunantworten zugesprochen (Yoles et al., 2001). Es existieren ähnliche Arbeiten, die dieses Konzept unterstützen, wie z.B. im Modell der partiellen Quetschung des Sehnervs, wo infiltrierende autoreaktive T-Zellen die Neuronen vor einer sekundären Degeneration schützen (Moalem et al., 1999). In diesen früheren Studien wurden aktivierte TZellen systemisch verabreicht, um den protektiven Effekt der autoimmunen Infiltrationen zu untersuchen. Mittlerweile führt eine aktive Immunisierung mit einem Myelin Antigen (z.B. MBP) $\mathrm{zu}$ einer angemessenen Immunantwort, die zu einer Protektion in verschiedenen Läsionen führt (Hauben et al., 2000). Ganz im Gegensatz dazu führt die neonatale Immunisierung mit einem Myelin Antigen zur immunologischen Toleranz und verhindert 
Protektion, was zu einem verschlimmerten Zustand nach einer Sehnervsverletzung oder Rückenmarksprellung führt (Kipnis et al., 2002). Interessanterweise scheinen natürlich vorkommende regulatorische T-Zellen die neuroprotektive Autoimmunität zu beeinflussen, denn die Eliminierung dieser regulatorischen Zellen verbessert das Ergebnis nach einer Verletzung, wobei die Injektion dieser Zellen direkt nach einer Verletzung den neuronalen Zelltod erhöht (Kipnis et al., 2002). In einem Ratten EAE-Modell wurden erhöhte BDNF und NT-3 Mengen in infiltrierten Lymphozyten gefunden (Hammarberg et al., 2000; Muhallab et al., 2002), die Menge dieser Neurotrophine in den Bystander Zellen war jedoch mindestens genauso hoch manchmal sogar noch höher. Diese Daten deuten darauf hin, dass nach einem demyelinisierenden Angriff die schädigenden Lymphozyten durch die vermehrte Ausschüttung von Neurotrophinen neutralisiert werden. Dieses Konzept wird auch durch das faziale Motoneuronen Transsektionsmodell unterstützt. In diesem Modell ist die CD4+ TZellpopulation verantwortlich für den neuroprotektiven Effekt (Serpe et al., 2003), und sowohl residente Mikrogliazellen als auch periphere Antigen-präsentierende Zellen (APC) aus dem Knochenmark fungieren als kritische APCs (Byram et al., 2004). Dennoch sollte eine Verstärkung der so genannten protektiven Immunantwort für die neuronale Protektion nicht favorisiert werden, denn auch Gegenteiliges wurde z.B. nach einer Rückenmarksverletzung bei T-Zellrezeptortransgenen Mäusen, deren T-Zellrezeptor spezifisch für MBP ist, beobachtet. In diesem Ansatz war die Precursorfrequenz der Antigenspezifischen T-Zellen sehr viel höher als im Vergleich zu Wildtyp Mäusen, deswegen war die neurologische Dysfunktion nach Immunisierung mit MBP nicht verringert, sondern sehr viel gravierender als in Wildtyp Mäusen. Die Ursache dafür könnte in der vermehrten Ausschüttung von proinflammatorischen Zytokinen liegen, welche den neuroprotektiven Effekt der Neurotrophine überwiegen (Jones et al., 2002).

Dennoch kann man zusammenfassen, dass sowohl endogenes als auch exogen appliziertes BDNF das Potenzial hat neuronales und axonales Überleben $\mathrm{zu}$ unterstützen, die Remyelinisierung zu verstärken und Immunfunktionen während der autoimmunen Entzündung im ZNS zu regulieren (Hohlfeld et al., 2000). 


\subsection{Zielsetzung}

Im Zentrum dieser Arbeit stehen grundlagenorientierte und klinisch relevante Untersuchungen zum Brain derived neurotrophic factor (BDNF).

Im ersten Ansatz sollte das BDNF auf genetischer Ebene untersucht werden. Die Gruppe von Liu konnte kürzlich zeigen, dass das murine BDNF-Gen verschiedene Splice-Varianten besitzt und in verschiedenen Gehirnarealen bzw. peripheren Organen unterschiedlich exprimiert wird. Ziel dieser Untersuchungen ist zu prüfen, ob sich das Expressionsmuster der Splice-Varianten im Gehirn von denen in den Immunzellen unterscheidet.

In Ergänzung $\mathrm{zu}$ den grundlagenorientierten Untersuchungen sollte auch die klinische Bedeutung des BDNF näher betrachtet werden, denn aufgrund zahlreicher Untersuchungen wird angenommen, dass das von Immunzellen sezernierte BDNF Protein eine neuroprotektive Rolle in der Multiplen Sklerose spielt. Dieser benefizielle Effekt von BDNF soll in der vorliegenden Arbeit vorerst an der experimentellen autoimmunen Enzephalomyelits (EAE), der experimentellen Form der Multiplen Sklerose, mit Hilfe von T-Zellen, die BDNF überexprimieren, untersucht werden. Diese T-Zellen sollen C57BL/6 Mäusen, bei denen eine EAE induziert wurde, injiziert werden. Eine anschließende Milderung der EAE-Symptome würde die These des neuroprotektiven Charakters von BDNF unterstützen. Für diesen Ansatz sollte die codierende Sequenz des BDNF-Gens in einen lentiviralen Vektor kloniert und dieser anschließend durch lentivirale Transduktion in Zellen einer Myelin Oligodendrozyten Glykoprotein (MOG)-spezifischen T-Zelllinie bzw. in antigenspezifische T-Zellen aus einer MOG-spezifischen T-Zellrezeptor-transgenen Maus gebracht werden. Diese Ergebnisse können Hinweise auf die funktionelle Relevanz geben bzw. hilfreich für spätere therapeutische Zwecke sein.

Diese Arbeit soll zusammenfassend die grundlegende Bedeutung des BDNF-Moleküls (Splice-Varianten/Regulation) sowie dessen klinische Relevanz im Tiermodell der Multiplen Sklerose untersuchen. 


\section{Material}

\subsection{Geräte}

Beta-Counter, MikroBeta Trilux

Brutschrank, Incubator IS-2

Brutschrank $\mathrm{CO}_{2}$, Hera cell 240 und Hera cell 150

Durchflusszytometer, BD Facs Calibur

Elektronische Präzisionswaage, Basic lite

BL3100

Elektrophoresekammer, Agagel Maxi/Mini

Feinwaage, CP 124S und BL3100

Fluoreszenzmikroskop, Axiovert 200M

Gasbrenner, flammy S

Gefrierschrank $\left(-80^{\circ} \mathrm{C}\right)$, HFU 586Top

Gewebeinfiltrationsautomat, LeicaTP 1020

$\mathrm{H}_{2} \mathrm{O}$-Bidestgerät, Arium ${ }^{\circledR} 611$

Heizblock, Bio TDB-100 Dry Block Heating

Thermostat

Kühlschrank $\left(4^{\circ} \mathrm{C}\right)$, Liebherr Premium

Kühlschrank $\left(-20^{\circ} \mathrm{C}\right)$, Liebherr Premium

no-frost

Lichtmikroskop

Magnetrührer, MR 3001

Mikrotiter Plattenphotometer, Sunrise

Mikrowellengerät, 5001 AKB279/PH

Mixer, Vor-Tex-Genie 2 ${ }^{\mathrm{TM}}$

Multikanalpipette, Research

Nanodrop, Spectralphotometer ND-100

Netzgerät für die Elektrophorese, Elite 300 Plus

Paraffinausgießstation, Leica EG 1160

PCR-Gerät, Mastercyler Gradient

PH-Meter, inoLab Level 3

Phasenkontrastmikroskop, Axioskop 40

Pipetten, Typ Research $(2,5 ; 10 ; 20 ; 100 ; 200$;

$1000 \mu 1$ Hubvolumen)

Pipettierhilfe, Pipetus ${ }^{\circledR}$

Pipettierhilfe, Accu-Jet ${ }^{\circledR}$

Real-Time-PCR-Gerät, 7500 Real Time PCR

System

Schlittenmikrotom, Leica SM2000R

Sterilbank, Klasse II HS 18

Tischzentrifuge, MiniSpinPlus 5415R

UV-Tisch für Agarose-Gele, TCP-20-M

Wasserbad, A100

Zellerntegerät, FilterMate

Zentrifuge, Multifuge $1 \mathrm{~S}-\mathrm{R}$
Perkin Elmer, Rodgau-Jügesheim Incutec, Mössingen

Heraeus Instruments, Hanau

BD Biosciences, Heidelberg

Sartorius, Göttingen

Schütt, Göttingen

Sartorius, Göttingen

Carl Zeiss Mikroskopie, Oberkochen

Schütt Labortechnik, Göttingen

Heraeus Instruments, Hanau

Leica-microsystems, Bensheim

Sartorius, Göttingen

Biosan, Riega, Lettland

Liebherr, Ochsenhausen

Liebherr, Ochsenhausen

Carl Zeiss Mikroskopie, Jena Heidolph Instruments, Schwabach

Tecan, Crailsheim

Philips, Eindhoven, Niederlande

Scientific Industries, Vertrieb: Schütt

Labortechnik, Göttingen

Eppendorf AG, Hamburg

Peqlab, Erlangen

Schütt Labortechnik, Göttingen

Leica-microsystems, Bensheim

Eppendorf AG, Hamburg

Wissenschaftlich-technische Werkstätten,

Weilheim

Carl Zeiss Mikroskopie, Jena Eppendorf, Hamburg

Hirschmann Laborgeräte, Eberstadt Brand, Wertheim

Applied Biosystems, Foster City, USA

Leica-microsystems, Bensheim Heraeus Instruments, Hanau Eppendorf AG, Hamburg

LTF Labortechnik, Wasserburg Lauda, Lauda-Königshofen Perkin Elmer, Rodgau-Jügesheim Heraeus Instruments, Hanau 
Zytozentrifuge, Shandon Cytospin 4

\subsection{Labormaterialien}

Deckgläser, $24 * 60 \mathrm{~mm}$

Einwegspritzen, $1 \mathrm{ml}, 5 \mathrm{ml}, 10 \mathrm{ml}, 20 \mathrm{ml}, 50 \mathrm{ml}$ ELISA-Platten, F96 MicroWell Platten, MaxiSorp

Flüssigkeits-Blocker-Stift (PapPen), Liquid-Blocker Super PAP pen

Glasfaserfilter, printed FiltermatA

Glaspipetten, $5 \mathrm{ml}, 10 \mathrm{ml}, 20 \mathrm{ml}$

Klebefolien für Real-Time-PCR-Platten, MicroAmp ${ }^{\mathrm{TM}}$ Optical Adhesive Film Laborhandschuhe, Peha-soft Powderfree MACS Seperation Columns, LS+MS

Nitril-Handschuhe, Nitra-Tex® EP Objektträger, Super Frost Plus, 25 x 75 mm

Gewebekulturschalen, $\varnothing 5 \mathrm{~cm}, 10 \mathrm{~cm}$

Gewebekulturflaschen, $75 \mathrm{~cm}^{2}$

Gewebekulturflaschn, BD Primaria, $75 \mathrm{~cm}^{2}$

Kanülen, Sterican, Ø 0,4 x 20 mm, $27 \mathrm{G}$ grau; Ø

$0,45 \times 12 \mathrm{~mm}, 26 \mathrm{G}$ braun

Pasteurpipetten

PCR-Reaktionsgefäße $(0,2 \mathrm{ml})$

Pipettenspitzen, Gilson gelb und blau,

Kristallpipettenspitzen

Plastikröhrchen, steril, $50 \mathrm{ml}$ und $15 \mathrm{ml}$

Reaktionsgefäß, $1,5 \mathrm{ml} / 2 \mathrm{ml}$

Round-Bottom-Tube für Durchflusszytometrie, $5 \mathrm{ml}$ Polystyrene

Sterilfilter, 0,22 $\mu \mathrm{m}$ GP Express Plus Membran

Sterilfilter

Szintillationswachsblatt, MeltiLexA

Well-Platten, Multidish (6, 12, 24, 48),

Microwell (96)

Zählkammer, Typ Neubauer Improved

Zellsiebe, $40 \mu \mathrm{m}$

96-Vertiefungsplatten für Real Time PCR,

ABgene $\AA$ PCR Plates Thermo Fast ${ }^{\circledR} 69$

Detection Plate
Thermo Fisher Scientific, Waltham, USA

Menzel-Gläser, Braunschweig

B.Braun, Melsungen

Nunc, Wiesbaden

SCI Science Services, München

Wallac, Turku, Finnland

Schütt, Göttingen

Applied Biosystems, Foster City, USA

Hartmann, Heidenheim

Miltenyi Biotec, Bergisch Gladbach

Ansell, München

Thermo Fisher Scientific, Waltham, USA

Sarstedt, Nümbrecht

BD Biosciences, Heidelberg

BD Biosciences, Heidelberg

B.Braun, Melsungen

WU, Mainz

Sarstedt, Nümbrecht

Sarstedt, Nümbrecht

Sarstedt, Nümbrecht

Sarstedt, Nümbrecht

BD Biosciences, Heidelberg

Millipore, Schwalbach

Wallac, Turku, Finnland

Nunc, Wiesbaden

Krannich, Göttingen

BD Biosciences, Heidelberg

Thermo Fisher Scientific, Waltham, USA 


\subsection{Chemikalien}

Agarose

$\mathrm{AgNO}_{3}$ (Silbernitrat)

Ampicillin

Aquadex

BSA (Rinderserumalbumin)

$\beta$-Mercaptoethanol

$\mathrm{CaCl}_{2}$ (Kalziumchlorid)

DAB (Diaminobenzidin)

EDTA (Ethylendiamintetraessigsäure)

Ethidiumbromid

Entellan

Ethanol

Fluoromount-G, $25 \mathrm{ml}$

Glucose

Hämalaun

$\mathrm{HCl}$ (Salzsäure)

$\mathrm{HNO}_{3}$ (Salpetersäure)

$\mathrm{H}_{2} \mathrm{O}_{2}$ (Wasserstoffperoxid)

Isopropanol

$\mathrm{KCl}$ (Kaliumchlorid)

LB

LB-Agar

Lymphoprep

Methanol

$\mathrm{NaN}_{3}$ (Natriumazid)

Natriumbicarbonat

Natriumcarbonat

$\mathrm{NaCl}$ (Natriumchlorid)

$\mathrm{NaCl}$ (Natriumchlorid) 0,9\%

$\mathrm{Na}_{2} \mathrm{HPO}_{4}$ (Natriumhydrogenphosphat)

$\mathrm{NaH}_{2} \mathrm{PO}_{4} \mathrm{XH}_{2} \mathrm{O}$ (Natriumhydrogenphophat

Monohydrat)

$\mathrm{NH}_{3}$ (Ammoniak)

$\mathrm{NH}_{4} \mathrm{Cl}$ (Ammoniumchlorid)

Paraformaldehyd $37 \%$

Percoll

Polybrene

Tris base

Tris- $\mathrm{HCl}$

Triton-X-100

Trypsin, 0,05\% Trypsin / EDTA

Tween 20

UltraPure Destilliertes Wasser DNase,

RNase frei

Xylol

Zitronensäure Monohydrat
Roth, Karlsruhe

Roth, Karlsruhe

Sigma-Aldrich Chemie, Taufkirchen

Merck, Darmstadt

Roth, Karlsruhe

Roth, Karlsruhe

Roth, Karlsruhe

Merck, Darmstadt

Roth, Karlsruhe

Roth, Karlsruhe

Merck, Darmstadt

Roth, Karlsruhe

Southern Biotech, Alabama, USA

Roth, Karlsruhe

Roth, Karlsruhe

Roth, Karlsruhe

Roth, Karlsruhe

Roth, Karlsruhe

Roth, Karlsruhe

Roth, Karlsruhe

Roth, Karlsruhe

Roth, Karlsruhe

PAA, Pasching, Österreich

Roth, Karlsruhe

Roth, Karlsruhe

Roth, Karlsruhe

Roth, Karlsruhe

Roth, Karlsruhe

B.Braun, Melsungen

Roth, Karlsruhe

Roth, Karlsruhe

Sigma-Aldrich Chemie, Taufkirchen

Roth, Karlsruhe

Merck, Darmstadt

GE Healthcare, Uppsala, Schweden Sigma-Aldrich Chemie, Taufkirchen Sigma-Aldrich Chemie, Taufkirchen

Roth, Karlsruhe

Roth, Karlsruhe

Gibco, Invitrogen Karlsruhe

Roth, Karlsruhe

Gibco, Invitrogen, Karlsruhe

Roth, Karlsruhe

Roth, Karlsruhe 


\section{$2.4 \quad$ Lösungen und Puffer}

\section{Annexin Puffer}

$\begin{array}{ll}150 \mathrm{mM} & \mathrm{HEPES} \mathrm{pH} 7,4 \\ 150 \mathrm{mM} & \mathrm{NaCl} \\ 5 \mathrm{mM} & \mathrm{KCl} \\ 2 \mathrm{mM} & \mathrm{CaCl}_{2} \\ \text { in } \mathrm{H}_{2} \mathrm{O} & \end{array}$

Coating Puffer für BDNF-ELISA

$0,025 \mathrm{M} \quad$ Natriumbicarbonat

$0,025 \mathrm{M} \quad$ Natriumcarbonat

in $\mathrm{H}_{2} \mathrm{O}$

pH 9,7

\section{DAB Entwicklerlösung}

$\begin{array}{ll}1 \text { Tablette } & \text { DAB } \\ 75 \mu 1 & 3 \% \mathrm{H}_{2} \mathrm{O}_{2} \\ \text { ad. } 10 \mathrm{ml} & \mathrm{PBS}\end{array}$

\section{EDTA Puffer}

$\begin{array}{ll}3,3 \mathrm{ml} & \text { EDTA }(0,3 \mathrm{M}) \\ \text { ad. } 1000 \mathrm{ml} & \mathrm{H}_{2} \mathrm{O} \\ \text { pH } 8,0 & \end{array}$

\section{Entwicklerlösung für Versilberung nach Bielschowsky}

$5,4 \mathrm{ml} \quad$ Paraformaldehyd (37\%)

1 Tropfen konz. $\mathrm{HNO}_{3}(65 \%)$

$0,5 \mathrm{~g} \quad$ Zitronensäure

ad. $120 \mathrm{ml} \quad \mathrm{H}_{2} \mathrm{O}$

\section{Erythrozyten-Lyse-Puffer}

$0,1 \mathrm{M} \quad \mathrm{NH}_{4} \mathrm{Cl}$

in $\mathrm{H}_{2} \mathrm{O}$

\section{FACS Puffer}

$0,1 \%$

BSA

$0,1 \% \quad$ Natriumazid

in $1 \mathrm{x}$ PBS

\section{MACS Puffer}

$\begin{array}{ll}100 \mathrm{ml} & 10 \mathrm{x} \text { PBS } \\ 6,7 \mathrm{ml} & 0,3 \mathrm{M} \text { EDTA } \\ 5 \mathrm{~g} & \text { BSA } \\ \text { ad } 1000 \mathrm{ml} & \mathrm{H}_{2} \mathrm{O}\end{array}$




\section{PBS-Puffer (10x)}

$400 \mathrm{~g} \quad \mathrm{NaCl}$

$10 \mathrm{~g} \quad \mathrm{KCl}$

$71 \mathrm{~g} \quad \mathrm{Na}_{2} \mathrm{HPO}_{4}$

$69 \mathrm{~g} \quad \mathrm{NaH}_{2} \mathrm{PO}_{4} \mathrm{xH}_{2} \mathrm{O}$

ad. $5000 \mathrm{ml} \quad \mathrm{H}_{2} \mathrm{O}$

pH 6,7

\section{PBS-Puffer (1x)}

$\begin{array}{ll}100 \mathrm{ml} & 10 \times \text { PBS Puffer } \\ \text { ad. } 1000 \mathrm{ml} \quad \mathrm{H}_{2} \mathrm{O}\end{array}$

Percoll-Verdünnungspuffer

$\begin{array}{ll}0,02 \mathrm{~g} & \text { BSA } \\ 0,2 \mathrm{~g} & \text { Glucose } \\ \text { ad. } 20 \mathrm{~g} & 1 \mathrm{x} \text { PBS }\end{array}$

POD-Blockierlösung

$\begin{array}{ll}8 \mathrm{ml} & \text { Methanol } \\ 1,2 \mathrm{ml} & \text { Natriumazid (2M) } \\ 2 \mathrm{ml} & \mathrm{H}_{2} \mathrm{O}_{2}(3 \%)\end{array}$

Rückenmark-Resuspensionspuffer

$\begin{array}{ll}0,02 \mathrm{~g} & \text { BSA } \\ 0,2 \mathrm{~g} & \text { Glucose } \\ 200 \mu \mathrm{l} & \text { DNAseI }(10 \mathrm{mg} / \mathrm{ml}) \\ \text { ad. } 20 \mathrm{~g} & 1 \times \text { PBS }\end{array}$

TBS 50 mM

$12,1 \mathrm{~g} \quad$ Tris base

$18 \mathrm{~g} \quad \mathrm{NaCl}$

ad. $2000 \mathrm{ml} \quad \mathrm{H}_{2} \mathrm{O}$

$\mathrm{pH} 7,5$

\section{TBST Waschpuffer für BDNF-ELISA}

$\begin{array}{ll}150 \mathrm{mM} & \mathrm{NaCl} \\ 20 \mathrm{mM} & \text { Tris } \mathrm{HCl} \mathrm{pH} \mathrm{7,6} \\ 0,05 \% & \text { Tween } \\ \text { in } \mathrm{H}_{2} \mathrm{O} & \end{array}$

\section{Thymidinlösung}

$1 \mathrm{ml} \quad$ Thymidin $(6,7 \mathrm{Ci} / \mathrm{mmol})$

ad. $100 \mathrm{ml}$ R0 Medium

\section{Zitratpuffer}

2,1 g Zitronensäure-Monohydrat ad $1000 \mathrm{ml} \quad \mathrm{H}_{2} \mathrm{O}$

pH 6,0 


\subsection{Medien und Medienzusätze}

\subsubsection{Medienzusätze}

BME (Basal Medium Eagle)

ConA Überstand

DMEM (Dulbecco's Modified Eagle Medium)

FCS (Fötales Kälberserum)

HEPES (2-(4-(2-Hydroxyethyl)-1-

piperazyinyl)-ethansulfonsäure

L-Glutamin

Natriumpyruvat

NEAA (Nicht essentielle Aminosäuren)

Penicillin/Streptomycin

RPMI 1640

$\mathrm{X}$-vivo
Sigma-Aldrich, Chemie, Taufkirchen Eigenherstellung, IMSF, Göttingen Gibco, Invitrogen, Karlsruhe PAA, Pasching, Österreich Gibco, Invitrogen, Karlsruhe

Gibco, Invitrogen, Karlsruhe Gibco, Invitrogen, Karlsruhe Gibco, Invitrogen, Karlsruhe Biochrom AG, Berlin Gibco, Invitrogen, Karlsruhe Lonza, Verviers, Belgien

\subsubsection{Medien}

\section{EH Medium}

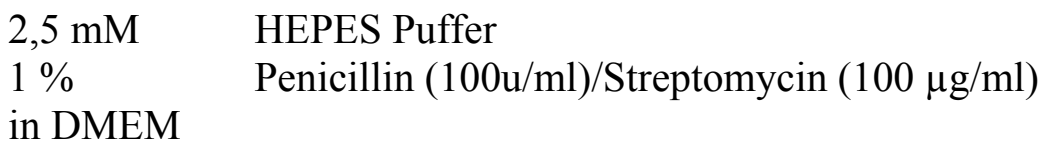

\section{Medium Mikroglia/Astrozyten}

$\begin{array}{ll}10 \% & \text { FCS } \\ 1 \% & \text { L-Glutamin } \\ 1 \% & \text { Penicillin }(100 \mathrm{u} / \mathrm{ml}) / \text { Streptomycin }(100 \mu \mathrm{g} / \mathrm{ml}) \\ \text { in BME } & \end{array}$

\section{R0 Medium}

$\begin{array}{ll}1 \% & \text { Penicillin }(100 \mathrm{u} / \mathrm{ml}) / \text { Streptomycin }(100 \mu \mathrm{g} / \mathrm{ml}) \\ 1 \% & \text { L-Glutamine } \\ 1 \% & \text { NEAA } \\ 1 \% & \text { Natrium-Pyruvat }\end{array}$

in RPMI 1640

R10 Medium

$10 \% \quad$ FCS

in R0 Medium

\section{ReMed Medium}

$5 \% \quad$ FCS

$400 \mu 1 / 100 \mathrm{ml} \beta$-Mercaptoethanol $(0,2 \%$ in A.dest vorverdünnt)

in R0 Medium

\section{TCGF Medium}

$\begin{array}{ll}\text { R10 } & \text { Medium } \\ 6-10 \% & \text { ConA Überstand }\end{array}$




\subsection{Enzyme, Farbstoffe, Neurotrophine, Seren, Zellstimulanzien}

BDNF

BSA (Rinderserumalbumin)

ConA (Concanavalin A)

DAPI (6-diaminidino-2-phenylindole,

dihydrochloride)

DNaseI

IFN- $\gamma$ (Interferon-gamma)

Ionomycin

LPS (Lipopolysaccharid)

NDS (Normales Eselserum)

NGF

Pferdeserum

PMA (Phorbol mystrate acetate)

Propiumiodid

Trypanblau

\section{$2.7 \quad$ Kits}

AB-Komplex

BDNF $E_{\text {Max }}$ Immunoassay Kit

Jetstar Kit

Nanofectin Kit

New Fuchsin Kit

Pan-T-Cell-Kit

RNeasy Mini Kit

\section{$2.8 \quad$ Antikörper}

Alexa Fluor488 Ziege-anti-Ratte IgG $(\mathrm{H}+\mathrm{L})$

Alexa Fluor594 Ziege-anti-Kanninchen IgG

$(\mathrm{H}+\mathrm{L})$

Hamster-anti-Maus CD3e-biotinyliert

Hamster-anti-Maus CD69-PE

Kanninchen-anti-BDNF, polyklonal

Kanninchen-anti-Maus-biotinyliert $\operatorname{IgG}(\mathrm{H}+\mathrm{L})$

Kanninchen-anti-Maus iNOS

Kanninchen-anti-pTrkB, polyklonal

Kanninchen-anti-Ratte-biotinyliert IgG $(\mathrm{H}+\mathrm{L})$

Maus-anti-APP

Ratte-anti-Human CD3

Ratte-anti-Maus CD4-PECy5

Ratte-anti-Maus CD8-biotinyliert

Ratte-anti-Maus CD25-biotinyliert

Ratte-anti-Maus CD62L-biotinyliert

Ratte-anti-Maus CD44-PE

Ratte-anti-Maus Mac3

Streptavidin-APC
PreProtech, Frankfurt

Roth, Karlsruhe

Sigma-Aldrich Chemie, Taufkirchen

Moleculare Probes, Oregon, USA

Roche, Mannheim

Pan Biotec, Aidenbach

Sigma-Aldrich Chemie, Taufkirchen

Sigma-Aldrich Chemie, Taufkirchen Jackson Immuno Research, Suffolk, UK

PreProtech, Frankfurt

Molecular Probes, Oregon, USA

Sigma-Aldrich Chemie, Taufkirchen

Sigma-Aldrich Chemie, Taufkirchen

Merck, Darmstadt

Dako, Hamburg

Promega, Mannheim

Genomed, Löhne

PAA, Pasching, Österreich

Dako, Hamburg

Milteny Biotec, Bergisch Gladbach

Qiagen, Hilden

Molecular Probes, Oregon, USA

Molecular Probes, Oregon, USA

BD Biosciences, Heidelberg

BD Biosciences, Heidelberg

Chemicon, Hofheim

Dako, Hamburg

Biomol, Hamburg

Bereitgestellt von M. Chao

Vector via Linaris, Wertheim

Chemicon, Hofheim

Serotec, Wiesbaden

BD Biosciences, Heidelberg

BD Biosciences, Heidelberg

BD Biosciences, Heidelberg

BD Biosciences, Heidelberg

BD Biosciences, Heidelberg

BD Biosciences, Heidelberg

BD Biosciences, Heidelberg 
Ziege-anti-Kanninchen-biotinyliert $\operatorname{IgG}(\mathrm{H}+\mathrm{L})$

Ziege-anti-Kanninchen IgG $(\mathrm{H}+\mathrm{L})$

\subsection{Komponenten der Immunisierung}

IFA (Inkomplettes Freundsches Adjuvant)

$\mathrm{MOG}_{35-55}$ Peptid

Mycobacterium tuberculosis H37RA

Pertussistoxin

\section{Komplette Freundsche Adjuvant (CFA)}

$100 \mathrm{mg} \quad$ Mycobacterium tuberculosis H37RA

$10 \mathrm{ml}$ Inkomplettes Freundsches Adjuvant
Vector via Linaris, Wertheim Linaris, Wertheim

Becton Laboratories, Baltimore, USA

Charité, Berlin

Becton Laboratories, Baltimore, USA

List Biomedicals, Campbell, USA

\subsection{Tiere}

2D2

C57BL/6

GFP

TTIкB+LTH bereitgestellt durch V.Kuchroo, Boston, USA

Harlan, Borchen

Jackson Laboratories, Bar Harbor, USA bereitgestellt durch D. Mathis, Boston, USA und C. Kaltschmidt, Witten-Herdecke

\subsection{Komponenten der Real-Time PCR}

ABgene Absolute QPCR SYBR Green Mix dNTP

OligodT-Nukleotide

Platinum ${ }^{\circledR q P C R}$ SuperMix-UDG

qRT-Puffer

ROX

SuperScript ${ }^{\mathrm{TM}}$ II Reverse Transkriptase
Thermo Fisher Scientific, Waltham, USA Invitrogen, Karlsruhe Invitrogen, Karlsruhe Invitrogen, Karlsruhe Invitrogen, Karlsruhe Thermo Fisher Scientific, Waltham, USA Invitrogen, Karlsruhe 


\subsection{Primer Proben für die Real-Time PCR}

Alle Primer wurden von Microsynth bezogen.

\section{Oligonukleotid}

$\beta$-actin S

$\beta$-actin AS

$\beta$-actin probe mBDNF1 S

mBDNF2a $S$

mBDNF2b S

mBDNF2c $S$

mBDNF3 S

mBDNF4 S

mBDNF5 $\mathrm{S}$

mBDNF6a S

mBDNF6b S

mBDNF AS

mBDNF AS2

mBDNF probe

mBDNF CDS S

mBDNF CDS AS
Sequenz $\left(5^{\prime}->3^{\prime}\right)$

ATTGCCGACAGGATGCAGAA GCTGATCCACATCTGCTGGAA FAM-CAAGATCATTGCTCCTCCTGAGCGCA-TAMRA GCAAAGCCGAACTTCTCACAT

ACAGAGCCAGCGGATTTGTC AGTTGGCTTCCTAGCGGTGTAG TGCAAGTGTTTATCACCAGGATCTA GGGCCGGATGCTTCCTT

CTGCCTTGATGTTTACTTTGACAAG GGGATCCGAGAGCTTTGTG

TCCTGAGGAAGTGAAAGTTTTGACT

GATTGCTGAAAATGGTGTCGTAAA GCAACCGAAGTATGAAATAACCATAG

CGTGGACGTTTACTTCTTTCATG

FAM-TTCCACCAGGTGAGAAGAGTGATGACCAT-TAMRA

ACTTGGCCTACCCAGGTGTG GCATCACCCGGGAAGTGTAC

\subsection{Bakterienstamm}

Zur Klonierung wurde der Escherichia coli Stamm HB101: F', hsd S20( $\left.\mathrm{r}_{\mathrm{B}}{ }^{-}, \mathrm{m}_{\mathrm{B}}{ }^{-}\right)$, recA13, ara14, proA2, LacY1, galK2, rpsL20 (str), xyl-5, mtl-1, supE44, leuB6, thi-1 der Firma Takara verwendet.

\subsection{Plasmide}

Für die BDNF Überexpression wurde der lentivirale Vektor pLenti-PGK-EGFP verwendet, der von Prof. Harald Neumann (Universität Bonn) zur Verfügung gestellt wurde. Die zur Generierung des Lentivirus notwendigen Plasmide pMD2-VSV-G, pMDLg, pRSV-rev und pLenti6/V wurden freundlicherweise von Dr. Ellen Gerhard (Universität Göttingen) bereit gestellt. 


\subsection{Restriktionsenzyme}

Der Restriktionsverdau erfolgte mit den Restriktionsenzymen BamHI und XhoI in den entsprechenden Puffern der Firma Fermentas.

\subsection{Längenstandards}

Bei der Agarose-Gelelektrophorese von DNA wurden die Längenstandards O'GeneRuler Low Range DNA Ladder und O'GeneRuler 100bp Plus DNA Ladder der Firma Fermentas verwendet.

\subsection{Radioaktivität}

Für den Proliferationsassay wurde radioaktiv markiertes Thymidin (Methyl-3H) der Firma MP Biomedicals verwendet.

\subsection{Software}

Für die Anfertigung der Dissertation wurden folgende Softwareprogramme verwendet.

EndNote 7.0.0

Software für die RT-PCR und deren Auswertung. Sequence Detection Software Version 1.3.1., 7500 System SDS-Software Software zur Messung von RNAKonzentrationen, Nano Drop ND-100 V.3.1.2. Software für die Durchflusszytometrie, Cell Quest $^{\mathrm{TM}}$ pro Version 5.1.1.

Software zur Aufnahme von Bildern am Fluoreszenzmikroskop, Image-Pro®MDA Version 5.1.2.59

Software zur Erstellung von Grafiken, GraphPad Prism 4.03 für Windows Microsoft ${ }^{\circledR O f f i c e} 2003$
Researchsoft, London, England Applied Biosystems, Foster City, USA

Coleman Technologies Inc., Orlando, USA BD Biosciences, Heidelberg

Media Cybernetics, Inc., Bethesda, USA GraphPad Software Inc., La Jolla, USA Microsoft Corporation, Redmont, USA 


\section{Methoden}

\subsection{Molekularbiologische Methoden}

\subsubsection{Isolation von RNA}

Bei einer RNA-Isolation erhält man eine Gesamt-RNA bestehend aus ribosomaler- (rRNA), transfer- (tRNA) und messenger RNA (mRNA). Die Ausbeute kann dabei von Gewebe zu Gewebe variieren, wobei der Anteil an mRNA lediglich ca. $2 \%$ der Gesamt-RNA ausmacht. Dieser Gehalt ist jedoch ausreichend für viele Anwendungen, wie z.B. Reverse TranskriptasePCR (RT-PCR).

Die RNA-Aufreinigung wurde mit dem RNeasy Mini Kit (Quiagen, Hilden) durchgeführt. Dafür wurden die Zellen bzw. das Gewebe in je $350 \mu$ RLT-Puffer (Kitkomponente, versetzt mit 1\% $\beta$-Mercaptoethanol) aufgenommen und durch mehrmaliges Auf- und Abpipettieren homogenisiert. Nach Zugabe von $350 \mu 170$ \%-igem Ethanol (hergestellt mit RNase-freiem Wasser) wurde der Ansatz auf eine RNeasy Säule überführt und zentrifugiert (30 Sekunden, Raumtemperatur, $10.000 \mathrm{rpm}$ ). Die Säule wurde auf ein frisches Auffanggefäß gesteckt und einmal mit $700 \mu \mathrm{l}$ RWI (Kitkomponente) und zweimal mit $500 \mu \mathrm{l}$ RPE (Kitkomponente) gewaschen (30 Sekunden, Raumtemperatur, 10.000 rpm). Der Durchfluss wurde dabei jedes Mal verworfen. Um die RNA wieder aus der Säule zu eluieren, wurde diese mit 30-50 $\mu 1$ RNase-freiem Wasser beladen und zentrifugiert (60 Sekunden, Raumtemperatur, 10.000 rpm). Die RNA-Konzentration und Reinheit wurde mittels Spektralphotometrie durch die Absorption bei $260 \mathrm{~nm}$ ermittelt. Zur Quantifizierung der Konzentration fand folgende Formel Anwendung:

RNA ng/ $\mu \mathrm{l}=\mathrm{OD}_{260 \mathrm{~nm}} \mathrm{x}$ Verdünnung $\mathrm{x} 40$

\subsubsection{Umschreiben von mRNA in cDNA}

Bei der Reversen Transkription wird RNA in DNA, die so genannte complementary DNA (cDNA), umgeschrieben, dabei macht man sich zu Nutze, dass eukaryotische mRNA am 3' Ende einen polyA-Schwanz besitzt. An dieses Ende können oligodT-Nukleotide binden und als Primer für die RNA-abhängige DNA-Polymerase, der Reversen Transkriptase, dienen. Das Enzym ist dann anschließend in der Lage mRNA in cDNA umzuschreiben.

Für den Ansatz vereinigt man zunächst folgende Komponenten: 


$\begin{array}{ll}200 \mathrm{ng} \text { RNA } & \mathrm{x} \mu \mathrm{l} \\ 500 \mathrm{ng} / \mu \mathrm{l} \text { OligodT-Nukleotide } & 1 \mu \mathrm{l} \\ 10 \mathrm{mM} \text { dNTPs } & 1 \mu \mathrm{l} \\ \text { Wasser } & \mathrm{x} \mu \mathrm{lad} 12 \mu 1 \text { Endvolumen }\end{array}$

Dieser Ansatz wird für 5 Minuten bei $65^{\circ} \mathrm{C}$ inkubiert, wobei die Sekundärstrukturen der RNA aufschmelzen und der Primer an die RNA hybridisieren kann. Um diesen Zustand zu halten wird die Probe anschließend auf Eis gelegt und noch folgende Komponenten hinzugefügt:

$\begin{array}{ll}5 \text { x First strand Puffer } & 4 \mu 1 \\ 200 \mathrm{U} / \mathrm{ml} \text { Superskript II Reverse Transkriptase } & 1 \mu 1 \\ \text { Wasser } & 3 \mu 1\end{array}$

Die Reverse Transkription findet nun für 50 Minuten bei $42^{\circ} \mathrm{C}$ statt und wird dann anschließend durch Inaktivierung der Reversen Transkriptase bei $75^{\circ} \mathrm{C}$ für 15 Minuten beendet.

\subsubsection{Quantifizierung von mRNA-Transkripten mittels Real-Time PCR}

Die Polymerasekettenreaktion (Polymerase Chain Reaction, PCR) ist ein Verfahren zur invitro Amplifikation von DNA. Die PCR-Technik unterteilt sich in drei Schritte:

1) Denaturierungs-Phase

In diesem Schritt wird die doppelsträngige DNA bei $92-95^{\circ} \mathrm{C}$ denaturiert, wobei die Wasserstoffbrückenbindungen zwischen den Basenpaaren gespalten werden.

\section{2) Annealing-Phase}

In dieser Phase lagern sich die Oligonukleotide (Primer) komplementär an die Einzelstränge an. Wichtig dabei ist, dass die Temperatur auf eine für die Primer spezifische Temperatur abgesenkt wird. Diese spezifische Temperatur (Schmelztemperatur) hängt von der unterschiedlichen Basenzusammensetzung und Länge der Primer ab. 
Sie lässt sich annäherungsweise mit folgender Formel berechnen:

$\mathrm{Tm}=(\mathrm{G}+\mathrm{C}) \times 4^{\circ} \mathrm{C}+(\mathrm{A}+\mathrm{T}) \times 2^{\circ} \mathrm{C}$

\section{3) Elongations-Phase}

Die Elongation erfolgt über eine hitzestabile DNA-Polymerase (Taq-DNA-Polymerase), die aus dem thermophilen Prokaryonten Thermus aquaticus isoliert wird. Sie hat ihr Aktivitätsoptimum bei $72^{\circ} \mathrm{C}$ und benötigt zusätzlich zur zu amplifizierenden DNA Primer mit freien 3' OH-Gruppen, Desoxyribonukleotide (dATP, dTTP, dGTP, dCTP) und $\mathrm{Mg}^{2+}$.

Diese drei Phasen werden ca. 25-40-mal wiederholt, wobei die DNA-Menge exponentiell vervielfältigt wird.

Ein finaler Elongationsschritt von fünf Minuten gewährleistet einen vollständigen Abschluss der Polymeraseaktivität, anschließend wird die Reaktion durch das Herabkühlen auf $4^{\circ} \mathrm{C}$ beendet.

Das Besondere an der Real-Time PCR ist, dass man mit dieser Methode die Menge an mRNA Transkripten quantifizieren kann. Die Quantifizierung erfolgt mit Hilfe von FluoreszenzMessungen, die während eines PCR-Zyklus erfasst werden, dabei nimmt die Fluoreszenz proportional mit der Menge an PCR-Produkten zu.

Die einfachste Möglichkeit der Quantifizierung der PCR-Produkte erfolgt durch den Einsatz von DNA-interkalierenden Farbstoffen, wie z.B. dem SYBR Green, welches an jede doppelsträngige DNA binden kann und somit nur eine geringe Spezifität aufweist. Diesem Nachteil kann durch eine zusätzliche Schmelzkurvenanalyse entgegenwirkt werden, da jedes DNA-Fragment einen spezifischen Schmelzpunkt hat. Bei dieser Analyse wird die DNA aufgeschmolzen, indem die Temperatur kontinuierlich von $50^{\circ} \mathrm{C}$ bis $\mathrm{zu} 95^{\circ} \mathrm{C}$ erhöht wird. Jedes Fragment hat je nach Basenlänge einen spezifischen Schmelzpunkt, an dem der Doppelstrang denaturiert und dabei den interkalierten Fluoreszenzfarbstoff freisetzt. Diese Fluoreszenzabnahme wird registiert und dem Schmelzpunkt zugeordnet. Mehrere Peaks an unterschiedlichen Schmelzpunkten würden unspezifische Amplifikationen bedeuten.

Wesentlich spezifischer hingegen sind sogenannte TaqMan-Sonden. Dabei handelt es sich um genspezifische Sonden, die an einem Ende mit einem „Quencher“ und am anderen Ende mit einem Reporter-Fluoreszenzfarbstoff (z.B. TAMRA und FAM) markiert sind. Solange der "Quencher“ an dieser Sonde hängt, wird die Fluoreszenz des Reporter-Fluorophors unterdrückt. Wird aber diese Sonde an die DNA synthetisiert, so wird dieser „Quencher“ durch die 5'-3'-Exonukleaseaktivität der Taq-Polymerase entfernt. Die Fluoreszenz des 
Reporters wird nun nicht mehr durch den „Quencher“ unterdrückt und kann gemessen werden.

In dieser Arbeit wurden Real-Time-PCR Analysen sowohl mit SYBR Green als auch mit Taq-Man-Sonden durchgeführt. Beta-Aktin diente dabei als endogene Kontrolle für die relative Quantifizierung nach der $\Delta \Delta$-Ct-Methode.

Folgende Primer wurden bei Mikrosynth (Lindau, Deutschland) erworben und für die RealTime-PCR verwendet:

$\begin{array}{ll}\text { Oligonukleotid } & \text { Sequenz (5'> }{ }^{\prime}{ }^{\prime} \text { ) } \\ \beta \text {-actin S } & \text { ATTGCCGACAGGATGCAGAA } \\ \beta \text {-actin AS } & \text { GCTGATCCACATCTGCTGGAA } \\ \beta \text {-actin probe } & \text { FAM-CAAGATCATTGCTCCTCCTGAGCGCA-TAMRA } \\ \text { mBDNF1 S } & \text { GCAAAGCCGAACTTCTCACAT } \\ \text { mBDNF2a S } & \text { ACAGAGCCAGCGGATTTGTC } \\ \text { mBDNF2b S } & \text { AGTTGGCTTCCTAGCGGTGTAG } \\ \text { mBDNF2c S } & \text { TGCAAGTGTTTATCACCAGGATCTA } \\ \text { mBDNF3 S } & \text { GGGCCGGATGCTTCCTT } \\ \text { mBDNF4 S } & \text { CTGCCTTGATGTTTACTTTGACAAG } \\ \text { mBDNF5 S } & \text { GGGATCCGAGAGCTTTGTG } \\ \text { mBDNF6a S } & \text { TCCTGAGGAAGTGAAAGTTTTGACT } \\ \text { mBDNF6b S } & \text { GATTGCTGAAAATGGTGTCGTAAA } \\ \text { mBDNF AS } & \text { GCAACCGAAGTATGAAATAACCATAG } \\ \text { mBDNF AS2 } & \text { CGTGGACGTTTACTTCTTTCATG } \\ \text { mBDNF probe } & \text { FAM-TTCCACCAGGTGAGAAGAGTGATGACCAT-TAMRA } \\ \text { mBDNF CDS S } & \text { ACTTGGCCTACCCAGGTGTG } \\ \text { mBDNF CDS AS } & \text { GCATCACCCGGGAAGTGTAC }\end{array}$


Der Ansatz für die Real-Time PCR bestand aus folgenden Komponenten:

Für Taq-Man Sonden:

2 x Invitrogen's Platinum SuperMix-UDG

$12,5 \mu 1$

Primer (sense und antisense, $10 \mathrm{pM}$ )

je $1 \mu 1$

Taq-Man Sonde

$1 \mu 1$

ROX

$1 \mu 1$

Für SYBR Green:

2 x ABgene Absolute QPCR SYBR Green Mix

$12,5 \mu 1$

Primer (sense und antisense, $10 \mathrm{pM}$ )

je $1 \mu 1$

ROX 1/1000 verdünnt

$1 \mu 1$

Alle Proben wurden als Triplikate in eine für die Real-Time PCR spezielle 96-Loch-Platte angesetzt. Dafür wurden je $15 \mu 1$ des PCR-Ansatzes mit $10 \mu 1$ der cDNA (1:25 verdünnt) in ein well gegeben. Als Referenzgen wurde bei jeder PCR das Maus Beta-Aktin mitgeführt. Die Amplifikation erfolgte mit Hilfe einer Real-Time-PCR Maschine (7500 Sequence Detection System, Applied Biosystems, Darmstadt, Deutschland).

Das PCR-Programm für die Taq-Man Sonden lautete wie folgt:

$\left.\begin{array}{ll}2 \text { Minuten } & 50^{\circ} \mathrm{C} \\ 2 \text { Minuten } & 95^{\circ} \mathrm{C} \\ 15 \text { Sekunden } & 95^{\circ} \mathrm{C} \\ 1 \text { Minute } & 60^{\circ} \mathrm{C}\end{array}\right] \quad 40-50$ Zyklen

Das PCR-Programm für den SYBR Green Assay unterschied sich lediglich im zweiten PCRSchritt, in dem die DNA-Polymerase nicht 2 Minuten bei $95^{\circ} \mathrm{C}$ für die Aktivierung benötigt, sondern 15 Minuten. Außerdem wurde bei diesem Ansatz stets nach dem PCR-Lauf noch die Dissoziationskurve bestimmt. 


\subsubsection{Klonierung / Ligation / Transformation}

Unter Klonierung versteht man die Integration eines DNA-Fragments in einen Vektor, welcher anschließend zur Vervielfältigung in Bakterien transformiert wird. Der Vorgang der Integration wird auch Ligation genannt, wobei entweder überstehende Enden (sticky ends) oder glatte Enden (blunt ends) miteinander ligiert werden.

In diesem Ansatz wurde das BDNF-Gen aus dem pT7T3D-PacI Vektor (RZPD Deutsches Ressourcenzentrum für Genomforschung $\mathrm{GmbH}$, Berlin) herausamplifiziert. Dabei wurden Primer eingesetzt, die jeweils an den 5'-Enden eine Restriktionsschnittstelle für die Endonukleasen BamHI und XhoI besitzen. Nach der Amplifikation wurden die Enden des BDNF Gens sowie der lentivirale Vektor pLenti6/V5 (Invitrogen, Karlsruhe, Deutschland) mit diesen beiden Endonukleasen geschnitten (siehe Kap. 3.1.6) und so für die nachfolgende Ligation vorbereitet.

Der Ligationsansatz setzte sich zusammen aus:

$\begin{array}{ll}\text { pLenti6/V5 Vektor } & 95 \mathrm{ng} / \mathrm{ml} \\ \text { Insert } & 100-150 \mathrm{ng} / \mathrm{ml} \\ \text { 10x T4 DNA Ligase Puffer } & 1 \mu \mathrm{l} \\ \text { T4 DNA Ligase } & 1 \mu \mathrm{l} \\ \text { Wasser } & \mathrm{ad} 10 \mu \mathrm{l}\end{array}$

Der Ansatz wurde über Nacht bei $4^{\circ} \mathrm{C}$ inkubiert und die Ligase am nächsten Tag 10 Minuten bei $65^{\circ} \mathrm{C}$ inaktiviert.

Für die Transformation der kompetenten HB101 E.coli Zellen wurden $5 \mu 1$ des Ligationsansatzes verwendet. Die Hitzeschocktransformation wurde mit $25 \mu 1$ E.coli Zellen und $5 \mu 1$ Ligationsansatz durchgeführt. Dieser Ansatz wurde zunächst für ca. 20 Minuten in einem $50 \mathrm{ml}$ Reaktionsgefäß auf Eis inkubiert. Anschließend wurde das Reaktionsgefäß für 45 Sekunden in ein $42^{\circ} \mathrm{C}$ warmes Wasserbad überführt und schließlich 2 Minuten auf Eis inkubiert. Nach Zugabe von $300 \mu \mathrm{S}$ SOC-Medium wurde der Ansatz bei $37^{\circ} \mathrm{C}$ für 1 Stunde auf einem Rundschüttler geschüttelt. Die Ausplattierung erfolgte auf je zwei LB-Agar-Platten mit $50 \mu \mathrm{g} / \mathrm{ml}$ Ampicillin. Die Platten wurden über Nacht bei $37^{\circ} \mathrm{C}$ inkubiert.

Der Erfolg der Ligation bzw. Transformation wurde durch einen Restriktionsverdau im Anschluss an eine Plasmidaufreinigung überprüft. 


\subsubsection{Plasmidaufreinigung}

Bakterienklone wurden von der LB-amp Platte ausgewählt und über Nacht in $3 \mathrm{ml}$ LBMedium (versetzt mit $50 \mu \mathrm{g} / \mathrm{ml}$ Ampicillin) bei $37{ }^{\circ} \mathrm{C}$ auf einem Rundschüttler inkubiert. Diese Vorkultur wurde genutzt um weitere $50 \mathrm{ml}$ LB-amp-Medium anzuimpfen, die ebenfalls über Nacht bei $37^{\circ} \mathrm{C}$ im Rundschüttler inkubiert wurden. Für die Plasmidaufreinigung wurde das Jetstar Kit (Genomed, Löhne) benutzt. Die Bakterienkultur wurde abzentrifugiert (4600 rpm, 10 Minuten, Raumtemperatur) und in $4 \mathrm{ml}$ E1 (Kitkomponente, enthält RNase A) resuspendiert. Nach Zugabe von $4 \mathrm{ml}$ E2 (Kitkomponente) wurde der Ansatz für 5 Minuten bei Raumtemperatur inkubiert. Anschließend wurden 4 ml E3 (Kitkomponente) hinzugegeben und das Reaktionsgefäß wurde invertiert. Die in diesem Schritt ausgefällten Kalium-SDSFlocken, präzipitierten Proteinen und chromosomale DNA, die über einen weiteren Zentrifugationsschritt (4600 rpm, 10 Minuten, Raumtemperatur) pelletiert wurden. Der Überstand wurde auf eine bereits mit $10 \mathrm{ml}$ E4 Puffer (Kitkomponente) äquilibrierte Midisäule überführt. Nach dem der Überstand durch die Säule geflossen war, wurde diese zweimal mit 10 ml E5 Puffer (Kitkomponente) gewaschen, dabei wurde der Durchfluss jedes Mal verworfen. Zur Elution der Plasmid-DNA wurden $5 \mathrm{ml}$ E6 (Kitkomponente) auf die Säule gegeben, der Durchfluss in einem frischen Reaktionsgefäß gesammelt und mit 0,7 Volumen Isopropanol versetzt. Die Plasmid-DNA wurde bei $13.000 \mathrm{rpm}$ und $4^{\circ} \mathrm{C}$ für 30 Minuten pelletiert und anschließend mit 70\%-igem Ethanol gewaschen.

Das Pellet wurde luftgetrocknet und in 20-50 $\mu 1 \mathrm{H}_{2} \mathrm{O}$ aufgenommen.

\subsubsection{Restriktionsverdau}

Restriktionsendonukleasen sind katalytisch aktive Enzyme, die die Fähigkeit haben doppelsträngige DNA an spezifischen Sequenzen spalten zu können. Falls beide Stränge an der gleichen Stelle geschnitten werden, so entstehen glatte Enden (blunt ends), werden die Stränge jedoch an unterschiedlichen Stellen geschnitten so entstehen 5'- bzw. 3'- Überhänge (sticky ends). Laut Definition schneidet eine Einheit (unit) einer Endonuklease $1 \mu \mathrm{g}$ DNA in einer Stunde, dabei hängt die katalytische Aktivität auch stark von der Reinheit der DNA ab, da diese durch Verunreinigungen gehemmt wird. 
Der Ansatz eines Restriktionsverdaus, der in dieser Arbeit standardmäßig angewandt wurde, war:

DNA

Enzym

10x dazugehöriger Restriktionspuffer

Wasser
$1 \mu \mathrm{g}$

10 Einheiten

$2 \mu 1$

ad $20 \mu 1$

Der Restriktionsverdau wurde für 1 Stunde bei $37^{\circ} \mathrm{C}$ inkubiert.

\subsubsection{DNA-Agarose Gelelektrophorese}

Bei der sogenannten Gelelektrophorese wandern geladene Moleküle in einem elektrischen Feld, dabei variiert die Wanderungsgeschwindigkeit je nach Größe und Form der Moleküle sowie ihrer elektrischen Ladung. Die Porengröße eines Agarosegels wird durch die Konzentration der Agarose bestimmt, in dieser Arbeit wurden hauptsächlich $1 \%$-ige Gele verwendet.

Zur Sichtbarmachung der aufgetragenen DNA, wird dem Gel Ethidiumbromid hinzugefügt, welches zwischen die Basen der DNA interkaliert und unter UV-Licht sichtbar wird. Die elektrophoretische Trennung der Nukleinsäuren wurde über ein digitales Bildverarbeitungssystem dokumentiert.

Die Größe der DNA-Fragmente wurde durch das Auftragen eines Längenstandards (O'Generuler Low Range bzw. O'Generuler 100bp DNA Plus, Fermentas) ermittelt.

\subsubsection{BDNF ELISA}

Der Enzymgekoppelte Immunadsorptionstest (EIA) bzw. Enzyme Linked Immunosorbent Assay (ELISA) dient als immunologisches Nachweisverfahren für Proteine, Viren aber auch niedermolekulare Verbindungen wie Hormone und Toxine. Dabei bedient man sich spezifischer Enzym-gekoppelter Antikörper, die an den nachzuweisenden Stoff (Antigen) binden und durch eine vom Enzym katalysierte Reaktion das Vorhandensein des Antigens nachweisen. Das Reaktionsprodukt führt üblicherweise zu einem Farbumschlag, dessen 
Signalstärke die Antigenkonzentration widerspiegelt und somit auch quantitative Aussagen möglich macht.

Bei dem so genannten Sandwich ELISA werden zwei Antikörper verwendet, die an das nachzuweisende Antigen binden. Der erste Antikörper (coating Antikörper) wird an eine spezielle 96-Loch-Mikrotiterplatte gebunden. Die zu untersuchende Probe wird anschließend in die Vertiefungen gegeben, so dass das spezifische Antigen an den Antikörper binden kann. Der Detektions (detection)-Antikörper ist ebenfalls spezifisch und bildet durch die Bindung an das Antigen den Antikörper-Antigen-Antikörper Komplex, und somit das so genannte Sandwich. Das zusätzliche Hinzufügen eines Enzym- (hier Meerrettichperoxidase, HRP) gekoppelten sekundären Antikörpers ermöglicht die Spaltung eines anschließend applizierten Substrats (Chromogen), welches zu einem Farbumschlag führt. Für eine quantitative Analyse, wird neben den eigentlichen Proben auch eine Serie mit bekannten Antigenkonzentrationen auf die 96-Loch-Mikrotiterplatte gegeben, die als Kalibrierungskurve für das gemessene Signal dient.

Für den Nachweis des BDNF Proteins, wurde das BDNF $\mathrm{E}_{\mathrm{Max}}$ Immunoassay Kit (Promega, Mannheim) verwendet. Zunächst wurde der coating Antikörper 1:1000 mit dem coating Puffer verdünnt und je $100 \mu 1$ in eine spezielle 96-Loch-Mikrotiterplatte pipettiert und über Nacht bei $4^{\circ} \mathrm{C}$ inkubiert. Der mitgelieferte 5 x Block \& Sample Puffer wurde 1:5 mit A.dest verdünnt und auf die zuvor mehrmals mit Waschpuffer gewaschene Platte gegeben. Mit diesem Puffer wurde der Plattenboden $1 \mathrm{~h}$ lang bei Raumtemperatur geblockt, um unspezifische Bindungen zu vermeiden. Nach einem weiteren Waschschritt wurden je $100 \mu 1$ des Standards und der Proben aufgetragen. Der Standard setzte sich dabei zusammen aus einer Verdünnungsreihe des humanen BDNF Proteins (Kitkomponente) in 1x Block \& Sample Puffer (500 pg/ml, 250 pg/ml, 125 pg/ml, 62,5 pg/ml, 31,3 pg/ml, 15,6 pg/ml, 7,8 $\mathrm{pg} / \mathrm{ml}, 0 \mathrm{pg} / \mathrm{ml}$ ), während die eigentlichen Proben nicht verdünnt wurden. Die Platte wurde für $2 \mathrm{~h}$ bei Raumtemperatur auf einem Rundschüttler inkubiert und anschließend erneut gewaschen. Der Detektions-Antikörper (Anti-Human BDNF pAb, Kitkomponente) wurde 1:500 in 1 x Block \& Sample Puffer verdünnt und je $100 \mu 1$ pro Vertiefung auf die Platte gegeben. Nach einer Inkubationszeit von $2 \mathrm{~h}$ bei Raumtemperatur auf einem Rundschüttler wurde die Platte erneut gewaschen. Der Enzym-gekoppelte sekundäre Antikörper (Anti-IgY HRP Conjugate, Kitkomponente) wurde 1:200 in 1x Block \& Sample Puffer verdünnt, wovon je $100 \mu \mathrm{l}$ pro Vertiefung auf die Platte gegeben wurde. Die Platte wurde $1 \mathrm{~h}$ bei Raumtemperatur auf einem Rundschüttler inkubiert und anschließend gewaschen. Für die Farbreaktion wurden jeweils $100 \mu \mathrm{l}$ des Substrats (TMB One Solution, Kitkomponente) pro 
Vertiefung der Platte gegeben und 10-15 Minuten bei Raumtemperatur auf einem Rundschüttler inkubiert. Die Reaktion wurde durch die Zugabe von je $100 \mu 11 \mathrm{M} \mathrm{HCl}$ pro Vertiefung gestoppt. Die Absorption wurde mittels Mikrotiterplatten-Photometer (Sunrise, Tecan) bei $450 \mathrm{~nm}$ bestimmt. Die absoluten Proteinmengen wurden mit Hilfe einer Standardkurve und des Software Programms GraphPad Prism (GraphPad Software, Inc.,San Diego,USA) ermittelt.

\subsection{Zellbiologische Methoden}

\subsubsection{Herstellung von Einzelzellsuspensionen aus primären und sekundären lymphatischen Organen}

Zur Herstellung einer Einzelzellsuspension aus primären (Thymus) und sekundären lymphatischen Organen (Lymphknoten und Milz) wurden die Organe mit Hilfe eines $5 \mathrm{ml}$ Spritzenstempels durch ein Zellsieb $(40 \mu \mathrm{m})$ gerieben. Das Sieb sowie der Stempel wurden mehrer Male mit EH-Medium gespült. Die Zellen wurden anschließend in EH-Medium aufgenommen und zweimal gewaschen (1200 rpm, 8 Minuten, $4^{\circ} \mathrm{C}$ ). Nach Resuspension der Zellen in frischem Medium, wurde die Zellzahl bestimmt.

\subsubsection{Restimulation von T-Zellen aus einer Zelllinie}

MOG-spezifische T-Zellen einer Zelllinie müssen stets nach 6-7 Tagen in Kultur restimuliert werden. Hierfür wurde die Milz einer C57Bl/6 Maus entnommen, welches zur Zellvereinzelung mit Hilfe eines Spritzenstempels durch ein Zellsieb gerieben wurde. Die Zellen, die als Antigenpräsentierende Zellen fungieren sollen, wurden in EH Medium aufgenommen und zentrifugiert (1200 rpm, 8 Minuten, $\left.4^{\circ} \mathrm{C}\right)$. Nach einem weiteren Waschschritt wurde der Überstand verworfen und das Zellpellet für 13 Minuten mit 30 Gy bestrahlt. Die Zellen wurden anschließend in ReMed Medium aufgenommen. Parallel dazu wurden auch die MOG-spezifischen T-Zellen abzentrifugiert (1200 rpm, 8 Minuten, $\left.4^{\circ} \mathrm{C}\right)$ und in ReMed Medium aufgenommen. Nach Bestimmung der Zellzahlen wurden die Zellen im Verhältnis von $0,4 \times 10^{6} \mathrm{~T}$-Zellen $+2,5 \times 10^{6}$ Milzzellen $/ \mathrm{ml}$ zueinander gegeben, mit 20 $\mu \mathrm{g} / \mathrm{ml}$ MOG versetzt und für $48 \mathrm{~h}$ kultiviert $\left(37^{\circ} \mathrm{C}, 5 \% \mathrm{CO}_{2}\right)$. Nach Zugabe von $1 / 2$ Volumen TCGF Medium wurden die Zellen weitere $24 \mathrm{~h}$ kultiviert $\left(37^{\circ} \mathrm{C}, 5 \% \mathrm{CO}_{2}\right)$. Um in Anschluss 
daran die Milzzellen von den MOG-spezifischen T-Zellen $\mathrm{zu}$ trennen wurde eine Dichtegradientenzentrifugation durchgeführt (siehe Kap. 3.2.3).

Diese Zellen wurden entweder zur Expansion in TCGF Medium weiterkultiviert oder für Zellkulturexperimente verwendet.

\subsubsection{Aufreinigung von Zellen mittels Dichtegradientenzentrifugation}

Nach der Restimulation von T-Zellen (siehe Kap. 3.2.2) einer MOG-spezifischen T-Zelllinie wurden diese von den unerwünschten Zellen in der Zellkultur (APCs etc.) mit Hilfe einer Dichtegradientenzentrifugation abgetrennt. Dafür wurde das Zellgemisch zentrifugiert (1200 $\mathrm{rpm}, 8$ Minuten, $4^{\circ} \mathrm{C}$ ) und anschließend in $6 \mathrm{ml} \mathrm{R} 10$ Medium aufgenommen. Dieser Zellsuspension wurden $3 \mathrm{ml}$ Lymphoprep untergeschichtet und erneut zentrifugiert (3000 rpm, 30 Minuten, $4^{\circ} \mathrm{C}$, ohne Bremse). Die in der Interphase lokalisierten T-Zellen wurden abgenommen und erneut mit R10 Medium gewaschen (1200 rpm, 8 Minuten, $4^{\circ} \mathrm{C}$ ). Das Zellpellet wurde anschließend je nach Verwendungszweck in das entsprechende Medium aufgenommen.

\subsubsection{Astrozyten- / Mikrogliapräparation}

Mikroglia und Astrozyten wurden aus primären Glia Cokulturen gewonnen. Dafür wurde neugeborenen Mäusen (1-3 Tage alt) das Gehirn entnommen und mit Hilfe einer $5 \mathrm{ml}$ Pipette eine Zellsuspension erzeugt. Nach einem Waschschritt mit PBS, wurde die Zellsuspension von jeweils zwei Tieren in eine $75 \mathrm{~cm}^{2}$ Primariakulturflasche (Falcon, Becton/Dickinson, Heidelberg) überführt und mindestens 9-14 Tage in Kultur gehalten.

Die Isolation von Mikroglia aus dieser Cokultur wurde durch das so genannte Abschütteln erreicht, wobei die Zellkultur 7 Stunden lang bei $37^{\circ} \mathrm{C}$ und $150 \mathrm{rpm}$ geschüttelt wird. Nach dieser Inkubationszeit wurden die Mikrogliazellen mit dem Überstand abgenommen, in ein 50 $\mathrm{ml}$ Reaktionsgefäß überführt und 10 Minuten bei $4^{\circ} \mathrm{C}$ und $1200 \mathrm{rpm}$ abzentrifugiert. Nach einem Waschschritt mit dem entsprechenden Medium wurden die Zellen in $7 \mathrm{ml}$ Medium aufgenommen und in eine vorher mit FCS beschichtete $75 \mathrm{~cm}^{2}$ Primariaflasche überführt. In dieser Phase wurde durch eine Einstündige Inkubation bei $37^{\circ} \mathrm{C}$ die Adhäsion der Mikrogliazellen auf die Flaschenoberfläche bewirkt. Dieser Schritt sollte zu einer reineren 
Zellpopulation führen, da Mikroglia in der Lage sind schneller auf die beschichtete Oberfläche zu binden als die restlichen Zellen der Mischkultur. Im Anschluss wurde der Überstand abgesaugt und die Mikrogliazellen von der Flaschenoberfläche mit $1 \mathrm{x}$ Trypsin/EDTA und einer Inkubation von 3-4 Minuten bei $37^{\circ} \mathrm{C}$ abgenommen. Nach einem finalen Waschschritt mit dem entsprechenden Medium wurden die Zellen in einer angemessenen Menge Medium aufgenommen und die Zellzahl bestimmt.

Die Isolation der Astrozyten aus dieser Cokultur erfolgte nach dem Abschütteln und Entfernen der Mikroglia mit dem Überstand. Die adhärenten Astrozyten wurden mit $1 \mathrm{x}$ Trypsin/EDTA und einer Inkubation von 3-4 Minuten bei $37^{\circ} \mathrm{C}$ von der Plastikoberfläche abgelöst. Nach einem Waschschritt mit Medium und einer Zentrifugation von 10 Minuten bei $4^{\circ} \mathrm{C}$ und $1200 \mathrm{rpm}$ wurden die Zellen in $10 \mathrm{ml}$ Medium aufgenommen und in eine $10 \mathrm{~cm}$ Petrischale ausplattiert. Bei einer Inkubation von 20 Minuten bei Raumtemperatur adhärierten noch mögliche Mikrogliakontaminationen auf der Plastikoberfläche und ermöglichten so eine reinere Astrozytenpopulation. Dieser Aufreinigungsschritt wurde ein zweites Mal durchgeführt, bevor der Überstand bei $1200 \mathrm{rpm}$ und $4^{\circ} \mathrm{C}$ für 10 Minuten abzentrifugiert wurde. Die Zellen wurden abschließend in einer angemessenen Menge Medium aufgenommen und die Zellzahl bestimmt. Nach dem Ausplattieren wurde den Astrozytenzellen die Möglichkeit gegeben über Nacht zu adhärieren, bevor sie in einem Experiment verwendet wurden.

\subsubsection{Isolation von mononukleären Leukozyten aus dem Rückenmark}

Die Isolation mononukleärer Leukozyten aus dem Rückenmark wurde mittels Dichtegradientenzentrifugation durchgeführt.

Zunächst wurden die zu untersuchenden Tiere mit $0,9 \% \mathrm{NaCl}$ perfundiert und anschließend das Rückenmark herauspräpariert. Diese wurden mit einem Spritzenstempel zerkleinert, in 20 ml Rückenmarksresuspensionspuffer aufgenommen und zentrifugiert (1600 rpm, 10 Minuten, $\left.4^{\circ} \mathrm{C}\right)$. Währendessen wurden die Percollgradienten hergestellt, indem $4 \mathrm{ml} 45 \%$ Percoll in ein $15 \mathrm{ml}$ Röhrchen pipettiert und mit $2 \mathrm{ml} 70 \%$ Percoll mit Hilfe einer $2 \mathrm{ml}$ Spritze unterlegt wurde. Zuletzt wurde die Rückenmarkssuspension, die zuvor in $6 \mathrm{ml} 30 \%$ Percoll aufgenommen wurde, vorsichtig mit einer $2 \mathrm{ml}$ Spritze auf den Gradienten aufgetragen und zentrifugiert (2300 rpm, 20 Minuten, $4^{\circ} \mathrm{C}$, ohne Bremse). Dabei setzte sich das Myelin oben auf dem Gradienten ab und konnte problemlos abgesaugt werden. Die Leukozyten hingegen 
sammelten sich in den beiden Interphasen an und wurden vorsichtig mit einer $2 \mathrm{ml}$ Spritze abgenommen und in ein $50 \mathrm{ml}$ Röhrchen überführt. Die Leukozyten wurden mit FACS-Puffer aufgefüllt und zentrifugiert (1600 rpm, 10 Minuten, $\left.4^{\circ} \mathrm{C}\right)$. Das Zellpellet wurde in $1 \mathrm{ml}$ PBS aufgenommen und die Zellzahl bestimmt.

\subsubsection{Magnetische Zellsortierung (MACS)}

Die magnetische Zellsortierung dient zur Aufreinigung von spezifischen Leukozytensubpopulationen aus verschiedensten Ausgangsmaterialen. Dabei nutzt man Antikörper, die an magnetische Kügelchen (beads) gekoppelt sind und entweder direkt an Zellepitope binden oder an Antikörper, die bereits an die Zellen gebunden haben. Die markierten Zellen können dann mittels eines Magneten von den restlichen Zellen abgetrennt werden. Dafür wird die Zellsuspension auf eine Säule gegeben, deren Matrix aus ferromagnetischen Stahlpartikeln besteht. Nach Anlegen des magnetischen Feldes, bleiben alle magnetisch markierten Zellen in der Säule hängen, während die übrigen unmarkierten Zellen hindurchfließen können. Nach Entfernung des Magneten, können auch die magnetisch markierten Zellen eluiert werden. Je nach Bedarf kann entweder eine negative Depletion (unmarkierte Zellen) oder eine positive Selektion (markierte Zellen) durchgeführt werden.

\subsubsection{Aufreinigung von T-Zellen}

Die Aufreinigung der T-Zellen wurde in diesem Fall über eine negative Depletion mit dem PAN-T-Cell-Kit (Qiagen, Hilden) durchgeführt. Dafür wurden die Milzen von C57BL/6 Tieren entnommen und vereinzelt (siehe Einzelzellgewinnung). Je 1 x $10^{7}$ Milzzellen wurden mit $40 \mu \mathrm{l}$ MACS Puffer und $10 \mu 1$ biotinyliertem Antikörper Cocktail (anti-CD11b, CD45R, CD5 und Ter-119) 10 Minuten bei $4^{\circ} \mathrm{C}$ inkubiert. Anschließend wurden erneut pro $1 \times 10^{7}$ Milzzellen $30 \mu \mathrm{l}$ MACS Puffer und $20 \mu \mathrm{l}$ anti-Biotin MicroBeads hinzugegeben und 15 Minuten bei $4^{\circ} \mathrm{C}$ inkubiert. Danach wurden die Zellen mit MACS Puffer aufgefüllt, zentrifugiert (1200 rpm, 10 Minuten, $4^{\circ} \mathrm{C}$ ) und je $1 \times 10^{8}$ Zellen wurden in $500 \mu$ MACS Puffer aufgenommen. Zur Trennung der markierten Zellen von den unmarkierten T-Zellen wurden LS Säulen verwendet, die eine Kapazität von ca. 1 x $10^{5}-10^{8}$ Zellen haben. Die Säulen wurden an einen Magneten gespannt und vor Gebrauch mit 3 ml MACS Puffer prä- 
äquilibriert. Je 1 x $10^{8}$ Zellen wurden auf eine Säule gegeben, wobei der Durchfluss gesammelt wurde. Die Säule wurde anschließend 3-mal mit je 3 ml MACS Puffer gewaschen. Der Durchfluss mit den unmarkierten T-Zellen wurde bei jedem Schritt gesammelt. Nach einem abschließenden Zentrifugationsschritt (1200 rpm, 8 Minuten, $4^{\circ} \mathrm{C}$ ) wurde die Zellzahl bestimmt.

Die Reinheit der T-Zellen wurde bei jeder Aufreinigung mittels Durchflusszytometrie überprüft und lag durchschnittlich bei ca. $90 \%$.

\subsubsection{Zellstimulationen}

Da die verwendeten Zelltypen zum Teil unterschiedlich stimuliert wurden, ist im Folgenden eine Übersicht der verschiedenen Stimulationen aufgeführt.

Makrophagen wurden in dieser Arbeit mit PBS aus dem Peritoneum der Maus ausgewaschen. Nach 2 Waschschritten mit PBS (1200 rpm, 8 Minuten, $4^{\circ} \mathrm{C}$ ) wurden die Zellen in einer Konzentration von $1 \times 10^{6} / \mathrm{ml}$ in R10 Medium aufgenommen und über Nacht anwachsen lassen. Nach einem Medienwechsel am nächsten Tag wurden die Zellen mit 10 ng/ml LPS über Nacht stimuliert. Auch Mikroglia (siehe Kap. 3.2.4) wurden ebenso wie Makrophagen mit $10 \mathrm{ng} / \mathrm{ml}$ LPS über Nacht stimuliert. Astrozyten (siehe Kap. 3.2.4) hingegen wurden über Nacht mit 100 u/ml IFN- $\gamma$ stimuliert. Für die Stimulation von T-Zellen (siehe Kap. 3.2.7) und Thymozyten (siehe Kap. 3.2.1) wurden 50 ng/ml PMA und 500 ng/ml Ionomycin verwendet. Die Stimulation der T-Zellen erfolgte über 2-3 Tage, während Thymozyten lediglich über Nacht stimuliert wurden.

\subsubsection{Bestimmung der Zellzahl}

Die Zellzahl einer Zellsuspension wurde mit Hilfe einer Neubauer-Zählkammer bestimmt. Dafür wurde der Zählansatz je nach Bedarf mit Trypanblau verdünnt. $10 \mu 1$ der Verdünnung wurden dann unter das Deckgläschen der Neubauer-Zählkammer gegeben und 4 x 16 Felder ausgezählt. Für die Bestimmung der Zellzahl pro ml wurde folgende Formel verwendet: (gezählte Zellzahl/4) x Verdünnung x $10^{4}$ (Kammerfaktor) 


\subsubsection{Durchflusszytometrie}

Die Durchflusszytometrie oder auch fluoreszenzaktivierte Zellanalyse (FACS) genannt dient zur Detektion, Messung und Analyse von Signalen, die von einzelnen Zellen enthalten werden, wenn sie in einem Flüssigkeitsstrom durch einen Lichtstrahl treten. Hierdurch erhält man die Möglichkeit gleichzeitig mehrere physikalische und Fluoreszenzparameter einer einzelnen Zelle in einer größeren Zellpopulation quantitativ $\mathrm{zu}$ bestimmen. Der Durchflusszytometer misst wie Zellen das Licht absorbieren und reflektieren und welche Fluoreszenz sie emittieren, wodurch die relative Größe und die optische Dichte berechnet werden kann. Des Weiteren ermöglicht der Gebrauch von spezifischen Antikörpern, die mit unterschiedlichen fluoreszierenden Farbstoffen markiert sind, den Nachweis der Expression von bestimmten Molekülen auf und in der Zelle. Durch den Einsatz von Nukleinsäurebindenden fluoreszierenden Farbstoffen kann zusätzlich der DNA-Gehalt in einer Zelle festgestellt werden.

Alle FACS-Messungen wurden mit dem FACSCalibur (BD Biosciences, Heidelberg) durchgeführt und die Daten mit dem Programm CellQuest ${ }^{\mathrm{TM}}$ analysiert.

\subsubsection{Extrazelluläre Färbungen}

In dieser Arbeit wurden alle im Anschluss aufgeführten Antikörper und Reagenzien bei BD Biosciences erworben und für extrazelluläre Färbungen eingesetzt:

CD8-bio, CD4-PECy5, CD3e-bio, CD44-PE, CD25-bio, CD62L-bio, CD69-PE, Propiumiodid

Pro Färbung wurden ca. 2,5 x $10^{5}-1 \times 10^{6}$ Zellen in $100 \mu$ l FACS-Puffer aufgenommen und in ein FACS-Röhrchen gegeben. Die gewünschte Antikörperkombination wurde in einer 1:500 Verdünnung zu den Zellen gegeben und 15 Minuten bei $4{ }^{\circ} \mathrm{C}$ im Dunkeln inkubiert. Nach Ablauf der Inkubationszeit wurden die Zellen mit 4 ml FACS-Puffer gewaschen und 5 Minuten bei $1200 \mathrm{rpm}$ und $4^{\circ} \mathrm{C}$ zentrifugiert. Falls die Antikörper Biotingekoppelt waren, war ein weiterer Färbeschritt notwendig, da Biotin kein Fluorochrom enthält und somit alleine nicht im Durchflusszytometer detektierbar ist. In diesem Fall war ein weiterer Inkubationsschritt mit Fluorochromassoziiertem Streptavidin notwendig, welches an das Biotin bindet. Dafür wurden nach dem Waschschritt die Zellen erneut in $100 \mu 1$ FACS-Puffer aufgenommen und eine 1:500 Verdünnung des zweiten Antikörpers dazugegeben. Nach einer 
Inkubation von 15 Minuten bei $4^{\circ} \mathrm{C}$ im Dunkeln wurden die Zellen mit 4 ml FACS-Puffer aufgefüllt und bei $1200 \mathrm{rpm}$ und $4^{\circ} \mathrm{C}$ für 5 Minuten abzentrifugiert. Der Überstand wurde verworfen und das Zellpellet in $200 \mu$ FACS-Puffer aufgenommen und im Durchflusszytometer analysiert. Eine Ausnahme $\mathrm{zu}$ diesem Protokoll bildete die Apoptosefärbung mit Propiumiodid. Hier wurden die Zellen in $100 \mu$ l Annexin-Puffer aufgenommen und mit $20 \mu 1$ Propiumiodid $(50 \mu \mathrm{g} / \mathrm{ml})$ versetzt. Nach einer Inkubation von 15 Minuten bei $4^{\circ} \mathrm{C}$ im Dunkeln wurde dem Ansatz weitere $250 \mu$ Annexin-Puffer hinzugefügt und ohne einen weiteren Waschschritt wurden die Proben im Durchflusszytometer analysiert.

\subsubsection{Transfektion}

Durch die Transfektion kann Fremd-DNA in eine eukaryotische Zelle transferiert werden. Falls die transfizierte DNA schnell wieder abgebaut wird, wie in diesem Fall, so spricht man von einer transienten Transfektion. Die Transfektion erfolgte nach dem Prinzip der Lipofektion, bei dem kationische Lipide verwendet werden, an die die negativ geladene Plasmid-DNA bindet. Dabei entstehen größere Komplexe, die von den Zielzellen aufgenommen werden.

Für die Lipofektion wurde das Kit Nanofectin (PAA, Pasching, Österreich) verwendet, dafür wurden HEK-Zellen in eine 6-Loch-Platte ausgesät und so lange kultiviert $\left(37^{\circ} \mathrm{C}, 5 \% \mathrm{CO}_{2}\right)$ bis sie eine Konfluenz von ca. 60-70 \% aufwiesen. Wenn dies der Fall war, wurde 2 Stunden vor der Transfektion ein Mediumwechsel durchgeführt und die Zellen in je $2 \mathrm{ml} \mathrm{R} 10$ pro Loch aufgenommen. Zur Vorbereitung des DNA-Lipid-Komplexes wurden 2-3 $\mu \mathrm{g}$ DNA in $100 \mu \mathrm{NaCl}(150 \mathrm{mM})$ aufgenommen, während 9,6 $\mu \mathrm{l}$ des Nanofectins in ebenfalls $100 \mu 1$ $\mathrm{NaCl}(150 \mathrm{mM})$ aufgenommen wurden. Nachdem die Ansätze separat vermischt und kurz abzentrifugiert wurden, wurde zum Nanofectin-Gemisch die DNA-Lösung hinzugegeben, gut vermischt und für 30 Minuten bei Raumtemperatur inkubiert. Anschließend wurde das Nanofectin/DNA-Gemisch tröpfchenweise auf die HEK-Zellen pipettiert, nochmals geschwenkt und für 4 Stunden kultiviert $\left(37^{\circ} \mathrm{C}, 5 \% \mathrm{CO}_{2}\right)$. Nach Ablauf dieser 4 Stunden wurde die Transfektion mit einem Medienwechsel gestoppt. Nach 24-48 Stunden wurde der Erfolg mittels eines Reporter-Fluoreszenzgens bzw. dem Nachweis des Zielgens überprüft. 


\subsubsection{Proliferationsassay}

Der Proliferationsassay dient zur Bestimmung der Proliferationsrate von Zellen, die durch den Einbau von radioaktiv markierten $\left[{ }^{3} \mathrm{H}\right]$-Thymidin in die neu synthetisierte DNA gemessen wird. Demnach ergibt sich, dass je mehr Radioaktivität gemessen wird, umso mehr $\left[{ }^{3} \mathrm{H}\right]-$ Thymidin eingebaut wurde bzw. umso stärker die Zellen proliferiert haben.

Der Proliferationsassay wurde routinemäßig mit der Restimulation von T-Zellen mitgeführt, um sicherzustellen, dass die Restimulationen erfolgreich waren und die Zellen weiterhin proliferieren. Dafür wurden $2 \times 10^{4}$ T-Zellen mit $1,25 \times 10^{5}$ Milzzellen (vorher mit $30 \mathrm{~Gy}$ bestrahlt) in $100 \mu \mathrm{l}$ ReMed aufgenommen und in die Vertiefungen einer 96-Loch-Platte gegeben. In jeweils 3 Vertiefungen wurden $10 \mu 1 \mathrm{R} 0, \mathrm{MOG}_{35-55}$ (Endkonzentration $2 \mu \mathrm{g} / \mathrm{ml}$ ) bzw. ConA (Endkonzentration $125 \mathrm{ng} / \mathrm{ml}$ ) hinzupipettiert und für $48 \mathrm{~h}$ kultiviert $\left(37^{\circ} \mathrm{C}, 5 \%\right.$ $\mathrm{CO}_{2}$ ). Nach dieser Kultivierungszeit wurde pro Vertiefung der 96-Loch-Platte jeweils $25 \mu 1$ (entspricht 1,25 $\mu \mathrm{Ci}$, verdünnt in R0) der [ $\left.{ }^{3} \mathrm{H}\right]$-Thymidin-Lösung hinzugefügt und der Ansatz für weitere $16 \mathrm{~h}$ weiterkultiviert. Nach Beendigung der Kultivierungszeit wurden die Zellen mit Hilfe eines Zellerntegerätes (FilterMate, Perkin Elmer, Rodgau-Jügesheim, Deutschland) auf Glasfaserfilter (printed FiltermatA, Wallac, Turku, Finnland) geerntet, während nicht eingebaute Radioaktivität heraus gewaschen wurde. Nach der Trocknung der Glasfaserfilter bei $60^{\circ} \mathrm{C}$ für 1 Stunde, wurde ein Szintillationswachsblatt (MeltiLexA, Wallac, Turku, Finnland) auf dem Filter geschmolzen (kurz bei $60^{\circ} \mathrm{C}$ ) und bei Raumtemperatur wieder abgehärtet. Die Radioaktivität wurde mittels eines Beta-Counters (MikroBeta, Trilux, Perkin Elmer, Rodgau-Jügesheim, Deutschland) gemessen.

\subsubsection{3 Überlebensassay mit murinen Dorsalwurzelganglien Zellen}

Der Überlebensassay wurde mit Hilfe von Prof. Dr. Stefan Wiese (Ruhr-Uni-Bochum) durchgeführt. Im Anschluss wird die Vorgehensweise kurz zusammengefasst.

Zur Isolation der Wurzelganglienzellen wurden Mausembryonen von Tag 12,5 verwendet. Nach Präparation der Neuronen wurden diese mit Trypsin (0,1\% Endkonzentration) für 30 Minuten bei $37^{\circ} \mathrm{C}$ behandelt. Der Verdau wurde mit serumhaltigem Medium (DMEM, 10\% Pferdeserum) gestoppt, in eine $10 \mathrm{~cm}$ Kulturschale ausplattiert und für 4 Stunden bei $37^{\circ} \mathrm{C}$ inkubiert $\left(5 \% \mathrm{CO}_{2}\right)$. Nach der Inkubationszeit wurde die Zellsuspension wieder von der Kulturplatte aufgenommen, gezählt und auf 4-Loch Kulturplatten (Greiner) mit einer Zellzahl 
von 3000 Zellen pro Loch ausplattiert. Eine Stunde nach dem Ausplattieren wurden neurotrophe Faktoren (NGF $10 \mathrm{ng} / \mathrm{ml}$, BDNF $10 \mathrm{ng} / \mathrm{ml}$ und 0,1 ng/ml) hinzu gegeben. Die erste Auszählung der ausplattierten Zellen erfolgte nachdem alle Zellen auf der Oberfläche der Kulturschale angeheftet waren, was nach ca. 4 Stunden erfolgte. Die zweite Auszählung erfolgte an Tag 1. An beiden Zeitpunkten wurden 5 Gesichtsfelder $\left(1,9 \mathrm{~mm}^{2} /\right.$ Feld $)$ pro Loch im Lichtmikroskop ausgezählt.

\subsubsection{Herstellung lentiviraler Partikel}

Die lentiviralen Partikel wurden von Dr. Ellen Gerhardt (Universitätsmedizin Göttingen) generiert. Im Anschluss erfolgt eine kurze Beschreibung der Vorgehensweise.

Zur Generierung lentiviraler Partikel wurden zunächst 293T Zellen in einer $15 \mathrm{~cm}$ Kulturschale so expandiert, dass sie 24 Stunden vor Transfektion eine Konzentration von ca. 1, $25 \times 10^{7} / 15 \mathrm{~cm}$ Kulturschale besaßen. 2 Stunden vor Transfektion wurde ein Medienwechsel durchgeführt. Pro $15 \mathrm{~cm}$ Kulturschale wurde folgender Transfektionsansatz pipettiert:

$9 \mu \mathrm{g} \quad$ pMD2-VSV-G (Hülle)

$16,25 \mu \mathrm{g} \quad$ pMDLg (Kernverpackungsplasmid)

$6,25 \mu \mathrm{g} \quad$ pRSV-rev (Reverese Transkriptase)

$25 \mu \mathrm{g} \quad$ pLenti6/V (Transfer Vektorplasmid)

Dies wurde zusammen mit $0,1 \times \mathrm{TE} / \mathrm{H}_{2} \mathrm{O}$ (Verhältnis 2:1) auf $1125 \mu$ l aufgefüllt. Nach Zugabe von $125 \mu \mathrm{l}$ 2,5 M CaCl2 und kurzem vortexen, wurde dem Transfektionsansatz tröpfchenweise $1250 \mu 12 \times$ HBS hinzugefügt, während auf höchster Stufe auf einem Vortexer der Ansatz vermischt wurde. Sofort nach 2 x HBS Zugabe wurde der komplette Ansatz auf die $293 \mathrm{~T}$ Zellen gegeben und für 14-16 Stunden in Kultur gehalten $\left(37^{\circ} \mathrm{C}, 5 \%\right.$ $\mathrm{CO}_{2}$ ). Nach dieser Kultivierungszeit wurde ein Medienwechsel durchgeführt und nach 48-72 Stunden nach Transfektion die Überstände eingesammelt. Die viralen Überstände wurden über einen Filter gegeben und bei 50.000 x g für 2 Stunden zentrifugiert. Nach einem Waschschritt mit PBS und anschließender Zentrifugation (50.000 x g, 2 Stunden) wurden die viralen Partikel in einer angemessenen Menge x-vivo Medium aufgenommen und in Aliquots bei $-80^{\circ} \mathrm{C}$ gelagert. 


\subsubsection{Lentivirale Transduktion}

Lentivirale Partikel (ca. $1 \mu 1$ pro $1 \times 10^{6}$ Zellen) wurden zusammen mit $10 \mu \mathrm{g} / \mathrm{ml}$ Polybrene (Sigma-Aldrich, München) zur MOG spezifischen T-Zellsuspension (ca. 1 x 10\% $/ \mathrm{ml}$ ) hinzu gegeben und für 1 Stunde bei $37{ }^{\circ} \mathrm{C}$ in x-vivo Medium (Cambrex Bio Science, Verviers, Belgien) inkubiert. Anschließend wurde die T-Zellsuspension in $15 \mathrm{ml}$ Reaktionsgefäße überführt und für 90 Minuten bei $2200 \mathrm{rpm}$ und $32^{\circ} \mathrm{C}$ zentrifugiert. Nach der Zentrifugation wurde der Überstand verworfen und die Zellen 2-mal mit Medium gewaschen (2200 rpm, 5 Minuten, $32^{\circ} \mathrm{C}$ ). Nach dem Waschschritt wurden für die nachfolgende i.v. Injektion je $10 \mathrm{x}$

$10^{6}$ Zellen in $200 \mu$ PBS aufgenommen. Im Fall der in vitro Experimente wurden die Zellen nach dem Waschschritt in TCGF Medium in einer Konzentration von 1 x $10^{6} / \mathrm{ml}$ aufgenommen, in eine entsprechende Kulturschale ausplattiert und für 4 bis 6 Tage kultiviert $\left(37^{\circ} \mathrm{C}, 5 \% \mathrm{CO}_{2}\right)$.

Die HEK Zellen wurden anders als die T-Zellen in DMEM Medium mit $10 \%$ FCS aufgenommen und mit den Lentiviralen Partikeln zusammen für 24 Stunden in Kultur gehalten $\left(37^{\circ} \mathrm{C}, 5 \% \mathrm{CO}_{2}\right)$. Anschließend wurden die Zellen zweimal mit Medium gewaschen und weitere 4 bis 6 Tage kultiviert.

Die BDNF Überexpression wurde im Überstand der Zellkultur mittels ELISA (Promega, Heidelberg) ermittelt, während die GFP Expression mit Hilfe der Fluoreszenzmikroskopie kontrolliert wurde.

\subsection{Tierexperimentelle Methoden}

\subsubsection{Tiere}

C57BL/6 Mäuse wurden bei Harlan (Borchen) erworben, transgene 2D2 Mäuse (Bettelli et al., 2003), die einen $\mathrm{MOG}_{35-55}$ spezifischen T-Zellrezeptor beherbergen wurden durch V.K. Kuchroo (Boston, USA) bereitgestellt und Grün Fluoreszenz Protein transgene (GFP) Tiere wurden über Jackson Laboratories (Bar Harbor, ME, USA) bezogen. C57B1/6 Tiere, in denen

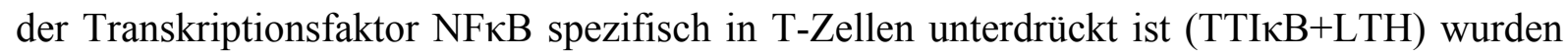
durch D. Mathis (Boston, USA) (Labrecque et al., 2001) und C. Kaltschmidt (WittenHerdecke) (Fridmacher et al., 2003; Kaltschmidt et al., 2006) bereitgestellt. Alle Mäuse wurden in der Tierhaltung des Instituts für Multiple Sklerose Forschung in Göttingen gehalten 
bzw. weitergezüchtet. Sämtliche Experimente wurden durch die Regierung von Niedersachsen genehmigt und durch autorisierte Personen überwacht.

\subsubsection{Induktion und klinische Evaluation einer aktiven MOG $_{35-55}-\mathrm{EAE}$}

Für die Induktion einer aktiven $\mathrm{MOG}_{35-55}$-EAE wurde den Mäusen subcutan rechts und links neben dem Schwanzansatz eine Emulsion aus 50 $\mu \mathrm{g} \mathrm{MOG}_{35-55}$ Peptid (Charité, Berlin) in PBS und der gleichen Menge an Mycobacterium tuberculosis H37RA enthaltendem CFA injiziert. Den Tieren wurde zusätzlich am Tag der Immunisierung und 48 Stunden später intraperitoneal Pertussis toxin (400ng pro Maus) verabreicht. Die Tiere wurden täglich gewogen und auf klinische Symptome der EAE hin untersucht. Die Stärke der EAE wurde an Hand einer zehnstufigen Skala ermittelt:

0 = gesund; 1 = reduzierter Schwanztonus; $2=$ schlaffe Schwanzlähmung, $3=$ Fehlen reflektorischer Ausgleichbewegungen beim Gehen; 4 = Gangataxie; 5 = leichte Lähmung der Hinterbeine; $6=$ Plegie eines Beines oder mittelgradige Lähmung beider Hinterbeine; $7=$ Paraplegie mit kompletter Lähmung beider Hinterbeine; $8=$ Tetraperese mit (leichter) Lähmung auch der vorderen Extremitäten; $9=$ moribund; $10=$ tot.

Die Tiere wurden spätestens bei einem Score von 7 aus tierschutzrechtlichen Gründen aus dem Versuch genommen.

\subsection{3 intra venöse (i.v.) Injektion}

Für die i.v. Injektionen wurden je 10 Millionen T-Zellen pro Tier aufgereinigt, mit dem Lentivirus infiziert und anschließend in $200 \mu \mathrm{l}$ PBS aufgenommen. Die Zellsuspension wurde in eine $1 \mathrm{ml}$ Spritze aufgezogen und mit einer 27G (0,4 x $20 \mathrm{~mm})$ Kanüle in die Schwanzvene appliziert. 


\subsection{Histologie und Immunzytochemie}

Für alle histologischen Untersuchungen wurden die Mäuse zunächst mit Paraformaldehyd perfundiert und anschließend das Rückenmark herauspräpariert. Das Rückenmark wurde in gleichgroße Stücke zerteilt, im Gewebeinfiltrationsautomat (LeicaTP 1020) entwässert, in Paraffin eingebettet und als $3 \mu \mathrm{m}$ dicke Querschnitte auf Objektträger aufgebracht. Die Schnitte wurden über Nacht bei $56^{\circ} \mathrm{C}$ fixiert und bis zur Färbung bei Raumtemperatur gelagert.

\subsubsection{CD3 / Mac-3 / GFP Färbung}

Direkt vor der Färbung wurden die Schnitte wieder deparaffiniert und durch eine absteigende Alkoholreihe gegeben, indem sie 2-mal für 10 Minuten in Xylol und anschließend für jeweils 2 Minuten 2-mal in $99 \%, 96 \%$ und $70 \%$ Ethanol und zuletzt in A.dest eingetaucht wurden. Um die Proteine, die in ihrer räumlichen Struktur durch die Fixierung verändert wurden, wieder zu renaturieren war eine Mikrowellenvorbehandlung vor der Färbung notwendig. Dafür wurden die Schnitte in ein mikrowellengeeignetes, hitzestabiles Gefäß gestellt, welches mit EDTA-Puffer (1mM, pH 8,0) gefüllt war. Nach einer Kochzeit von 38 Minuten wurden die Schnitte zunächst 3-mal in A.dest danach 3-mal in PBS gewaschen. Nach Blockierung der unspezifischen Bindungen mit 10 \% BSA/PBS für 30 Minuten bei Raumtemperatur, wurden die Schnitte mit dem jeweiligen Primärantikörper über Nacht bei $4^{\circ} \mathrm{C}$ in $1 \% \mathrm{BSA} / \mathrm{PBS}$ in einer Feuchtekammer inkubiert. Anschließend wurden die Objektträger 3-mal mit PBS gewaschen. Zur Inaktivierung endogener Peroxidasen (POD) wurden die Schnitte 13 Minuten lang mit einer POD-Blockierlösung ( $8 \mathrm{ml} \mathrm{Methanol,} \mathrm{1,2} \mathrm{ml} 2 \mathrm{M} \mathrm{NaN}_{3}$ und $2 \mathrm{ml} 3 \% \mathrm{H}_{2} \mathrm{O}_{2}$ ) behandelt und erneut mit PBS gewaschen. Die Sekundärantikörper wurden wie unten aufgeführt eingesetzt und jeweils in $1 \%$ BSA/PBS verdünnt und 45 Minuten bei Raumtemperatur in einer Feuchtekammer inkubiert. Nach drei weiteren PBS Waschschritten wurden die Schnitte mit dem Peroxidase basierten AB-Komplex (DAKO, Hamburg, 1:100 verdünnt in PBS) für 35 Minuten bei Raumtemperatur behandelt. Nach 3-maligem Waschen in PBS wurden die Schnitte etwa 10 Minuten (Mac-3, CD3 und GFP Färbung) bzw. 5 Minuten (APP Färbung) in Diaminobenzidin (DAB) Entwicklerlösung inkubiert und anschließend in A.dest überführt. Die Gegenfärbung erfolgte durch Hämalaun für ca. 30 Sekunden und einer anschließenden Inkubation in A.dest für 10-15 Minuten. Um die Schnitte 
abschließend zu entwässern wurden sie durch eine aufsteigende Alkoholreihe (je 2-mal für 2 Minuten in $70 \%, 96 \%, 99 \%$ Ethanol und je zweimal für 10 Minuten in Xylol) gegeben und mit Entellan eingedeckt.

Für die T-Zellfärbung wurde als Primärantikörper ein Ratte anti-Maus CD3 Antikörper (Serotec, Wiesbaden, 1:300) eingesetzt, während für die Makrophagen/Mikroglia Färbung ein Ratte anti-Maus Mac-3 Antikörper (BD Biosciences, 1:200) verwendet wurde. In beiden Fällen diente ein biotinylierter Kanninchen anti-Ratte Antikörper (Vector via Linaris, Wertheim, 1:100) als Sekundärantikörper. Axonaler Schaden wurde mit Hilfe eines APP spezifischen Antikörpers (MAB348, Chemicon, Hofheim, 1:1000) ermittelt, welcher mit einem biotinylierten Kanninchen anti-Maus Sekundärantikörper (DAKO, 1:100) kombiniert wurde. GFP positive Zellen wurden mit einem Huhn anti-GFP Antikörper (Chemicon, 1:300) und einem biotinylierten Esel anti-Huhn Sekundärantikörper detektiert (Jackson, 1:200). Im Gegensatz zu den restlichen Färbungen wurde in der GFP Färbung vor der Blockierung die Schnitte zusätzlich mit 0,2 \% Triton-X-100 und $2 \%$ BSA in PBS für 20 Minuten bei Raumtemperatur inkubiert und anschließend 3-mal mit PBS gewaschen. Die Spezifität der Färbungen wurde durch eine Negativkontrolle bestätigt, in der der Primärantikörper ausgelassen wurde.

\subsection{2 iNOS Färbung}

Für die iNOS Färbung wurden die Schnitte sofort nach Anfertigung an Stelle von $56^{\circ} \mathrm{C}$ über Nacht bei $37^{\circ} \mathrm{C}$ über Nacht und anschließend noch 1 Stunde bei $60^{\circ} \mathrm{C}$ inkubiert. Zum entparaffinieren wurden die Schnitte 4-mal für 10 Minuten in Xylol und dann für je 3 Minuten in $50 \%$ / 50 \% Xylol-Isopropanol, $100 \%, 90 \%, 70 \%, 50 \%$ Isopropanol und zuletzt in A.dest eingetaucht. Für die Mikrowellenbehandlung wurden die Schnitte in Zitratpuffer (10 $\mathrm{mM}, \mathrm{pH}$ 6,5) für 38 Minuten gekocht und anschließend in A.dest und TBS gewaschen. Als nächstes wurden die Schnitte in $3 \% \mathrm{H}_{2} \mathrm{O}_{2}$ (verdünnt in TBS) für 20 Minuten bei $4^{\circ} \mathrm{C}$ inkubiert. Nach mehreren Waschschritten mit TBS wurden die Schnitte in eine Feuchtekammer überführt und mit $10 \%$ Normales Eselserum (Normal-Donkey-Serum, NDS) / TBS für 20 Minuten bei Raumtemperatur blockiert. Die Blockierlösung wurde ohne weiteren Waschschritt von den Schnitten entfernt und der erste Antikörper anti-iNOS (Kanninchen polyklonal, Assay designs) in einer 1:500 Verdünnung in 1\% NDS / TBS auf die Schnitte gegeben. Nach der Inkubationszeit über Nacht bei $4^{\circ} \mathrm{C}$, wurden die Schnitte mit 
TBS gewaschen und für 1 Stunde bei Raumtemperatur mit dem Sekundärantikörper (biotinyliert anti Kanninchen, 1:200 in TBS) inkubiert. Die Schnitte wurden mehrmals mit TBS gewaschen und 1 Stunde bei Raumtemperatur mit POX (ExtrAvidin Peroxidase, 1:1000 in TBS) behandelt. Nach mehrmaligen Waschschritten mit TBS wurden die Schnitte für ca. 5 Minuten in DAB Entwicklerlösung eingetaucht. Die Reaktion wurde durch Waschschritte in TBS und A.dest gestoppt. Die Gegenfärbung erfolgte durch Hämalaun für ca. 15 Sekunden und einer anschließenden Inkubation in A.dest für 10-15 Minuten. Zur Entwässerung wurden die Schnitte durch eine aufsteigende Alkoholreihe (je 1-mal für 3 Minuten in $50 \%, 70 \%, 90$ \%, 100 \% Isopropanol, 50 \% / 50 \% Xylol/Isopropanol und je 4-mal für 10 Minuten in Xylol) gegeben und mit Entellan eingedeckt.

Inkubation in A.dest für 10-15 Minuten. Um die Schnitte abschließend zu entwässern wurden sie durch eine aufsteigende Alkoholreihe (je 2-mal für 2 Minuten in $70 \%, 96 \%, 99 \%$ Ethanol und je zweimal für 10 Minuten in Xylol) gegeben und mit Entellan eingedeckt.

\subsubsection{Anti-BDNF Färbung von Mäuse - Cytospins}

Für die BDNF Lymphozytenfärbung wurden zunächst je $2 \times 10^{5}$ Zellen mittels Cytospin (1200 rpm, 10 Minuten, RT) auf einen Objektträger gebracht und kurz luftgetrocknet. Zur Fixierung wurden die Zellen für 20 Minuten bei Raumtemperatur mit 4 \% PFA/PBS inkubiert und mit TBS gewaschen. Anschließend wurden die Zellen mit 0,2\% Triton-X-100 in $2 \%$ BSA/TBS für 20 Minuten bei Raumtemperatur permeabilisiert. Nach einem weiteren Waschgang mit TBS wurden die Zellen für 60 Minuten bei Raumtemperatur mit $10 \%$ BSA/TBS blockiert und über Nacht in einer Feuchtekammer bei $4^{\circ} \mathrm{C}$ mit dem Primärantikörper (Kanninchen anti-BDNF, Chemicon) in einer 1:100 Verdünnung in $1 \%$ BSA/TBS inkubiert. Am nächsten Tag wurden die Zellen mit TBS gewaschen, während der Sekundärantikörper (Ziege anti-Kanninchen $\operatorname{IgG}(\mathrm{H}+\mathrm{L})$, Vector) präabsorbiert wurde, indem $1 \mu l$ von diesem mit $1 \mu 1$ Mausserum für 10 Minuten bei Raumtemperatur inkubiert wurden. Der Sekundärantikörper wurde anschließend mit einer 1:800 Verdünnung in $1 \% \mathrm{BSA} / \mathrm{TBS}$ verdünnt und für 60 Minuten bei Raumtemperatur auf die Zellen gegeben. Während dieser Inkubationszeit wurde der Alkalische Phosphatase basierter AB-Komplex (DAKO) angesetzt, indem $5 \mu 1$ der Lösung A des Kits mit $500 \mu$ TBS vermischt und anschließend noch $5 \mu 1$ der Lösung B des Kits dazugefügt wurden. Dieser Ansatz wurde vor der Hinzugabe 30 Minuten bei Raumtemperatur präinkubiert. Nach dem Sekundärantikörper wurden die Zellen mit TBS 
gewaschen und mit dem AB-Komplex versetzt. Nach einer Inkubationszeit von 45 Minuten wurden die Zellen erneut mit TBS gewaschen. Für die Farbentwicklung wurde das Kit New Fuchsin (Dako) verwendet. Dafür wurden $60 \mu 1$ des Fuchsin Chromogens (Kitkomponente) mit $60 \mu \mathrm{l}$ des Fuchsin Activating Agents (Kitkomponente) vermischt und 1 Minute bei Raumtemperatur inkubiert bevor $880 \mu \mathrm{l}$ Puffer aus dem Kit hinzugefügt wurden. Die Entwicklerlösung wurde für ca. 10 Minuten auf die Zellen gegeben, bevor die Reaktion mit A.dest gestoppt wurde. Nach weiteren Waschschritten mit A.dest wurden die Zellen mit Aquadex (Merck) wässrig eingedeckt.

\subsubsection{Silberimprägnation nach Bielschowsky}

Bei der Imprägnation mit Metallsalzen können Bindegewebsfasern selektiv braunschwarz dargestellt werden. Bielschowsky nutzte dieses Verfahren zur Darstellung von Nervenfasern durch Imprägnation der Neurofibrillen. Dafür wurden die Querschnitte zunächst entparaffiniert und durch eine absteigende Alkoholreihe gegeben (je 2-mal für 10 Minuten in Xylol und 2 Minuten in $99 \%, 96 \%, 70 \%$ Ethanol und A.dest), anschließend folgte eine Inkubation der Schnitte in vorgewärmten $20 \%$-igem $\mathrm{AgNO}_{3}$ für 15 Minuten bei $37^{\circ} \mathrm{C}$. Nach dieser Inkubation wurden die Schnitte für jeweils 5 Minuten in A.dest gewaschen, währenddessen wurde zur $\mathrm{AgNO}_{3}$-Lösung tröpfchenweise $25 \%$-iges $\mathrm{NH}_{3}$ zugegeben bis sich ein brauner Niederschlag bildete, der sich unter weiterer $\mathrm{NH}_{3}$-Zugabe wieder auflöste und dabei Ag-Hydroxid entstand. Die Schnitte wurden nach dem Waschschritt 10 Minuten bei $37^{\circ} \mathrm{C}$ im Dunkeln in der zuvor beschriebenen Ag-Hydroxid-Lösung inkubiert und anschließend zweimal in $0,1 \% \mathrm{NH}_{3}$ gewaschen bevor sie wieder in die Ag-Hydroxid-Lösung eingetaucht wurden. Dieses Mal wurden der Lösung 11 Tropfen Entwicklerlösung hinzugeben und gut vermischt. Nach einer Entwicklungszeit von 4 Minuten unter konstantem Schütteln wurden die Schnitte erneut zweimal in $0,1 \% \mathrm{NH}_{3}$ und anschließend in A.dest gewaschen. Die Schnitte wurden entwässert (je 2-mal für 2 Minuten in $70 \%, 96 \%, 99 \%$ Ethanol und je 2-mal für 10 Minuten in Xylol) und mit Entellan eingedeckt. 


\subsection{5 pTrkB Fluoreszenzfärbung}

Bei der pTrkB Fluoreszenzfärbung wurden erneut die Querschnitte deparaffiniert, durch eine absteigende Alkoholreihe gegeben und anschließend einer Mikrowellenbehandlung in Zitratpuffer (10 mM, pH 6,5) für 38 Minuten unterzogen. Nach mehreren Waschschritten mit A.dest und PBS, wurden die Schnitte mit $10 \%$ BSA/PBS/0,1 \% Triton-X-100 für 30 Minuten bei Raumtemperatur geblockt. Anschließend wurde der Primärantikörper (anti-pTrkB) 1:50 in $1 \%$ BSA/PBS/0.01 \% Triton-X-100 verdünnt und mit den Schnitten zusammen in der Feuchtekammer über Nacht bei $4^{\circ} \mathrm{C}$ inkubiert. Nach der Inkubation wurden die Schnitte erneut in PBS gewaschen und mit dem Sekundärantikörper (Ziege anti-Kaninchen 594, Molecular Probes) versetzt. Dieser wurde $1: 100$ in $1 \%$ BSA/PBS/0,01 \% Triton-X-100 verdünnt und auf den Schnitten 1 Stunde bei Raumtemperatur inkubiert. Bei einer Einzelfärbung wurden die Schnitte ab diesem Schritt mit PBS gewaschen, anschließend mit DAPI (1:50.000 verdünnt) 45 Sekunden gegengefärbt und erneut mit PBS gewaschen. Abschließend wurden die Schnitte mit Fluoromount (SouthernBiotech) eingedeckt.

Bei einer Doppelfärbung hingegen wurden die Schnitte nach dem Sekundärantikörper mit PBS gewaschen und mit dem zweiten Primärantikörper (Ratte anti-Maus CD3, Serotec bzw. Ratte anti-Maus Mac-3, BD Biosciences) behandelt. Dieser wurde 1:200 mit $1 \%$ BSA/PBS/Triton-X-100 verdünnt und 1 Stunde auf den Schnitten bei Raumtemperatur inkubiert. Nach 3-maligem Waschen in PBS, wurden die Schnitte mit dem zweiten Sekundärantikörper (Ziege anti-Ratte 488, Molecular Probes, 1:100 in 1\% BSA/PBS/TritonX-100 verdünnt) 1 Stunde bei Raumtemperatur inkubiert. Nach mehreren Waschschritten mit PBS, wurden die Schnitte wie bereits beschrieben mit DAPI gegengefärbt und eingedeckt. 


\section{Ergebnisse}

\subsection{BDNF Expression und Regulation in vitro}

Die transkriptionelle Regulation von BDNF ist komplex und immer noch nicht vollständig aufgeklärt. Das murine BDNF Gen (mBDNF), welches ca. 50 Kilobasen an genomischer DNA umspannt, besteht aus 8 verschiedenen Exons, wobei lediglich Exon 8 das codierende Exon darstellt. Die anderen am 5' Ende gelegenen Exons beinhalten voneinander unabhängige Promotoren, exprimieren jedoch alle durch das direkte Splicing zu Exon 8 das gleiche BDNF Protein. Es ist dem alternativen Splicing und der Verwendung von Polyadenylierungs-Stellen zuzuschreiben, dass aus diesen Acht Exons Neun verschiedene Splice-Varianten exprimiert werden. Daher ist es gut möglich, dass durch diese transkriptionelle Komplexität eine sehr genaue Regulation des BDNF in verschiedenen Zelltypen möglich ist.

Ausgehend von dieser Hypothese wurden die verschiedenen Splice-Varianten des mBDNF Gens in Zellen des Immunsystems sowie des zentralen Nervensystems (ZNS) untersucht und miteinander verglichen.

\subsubsection{Expression und Quantifizierung der mBDNF mRNA Splice-Varianten im Gehirn}

Zunächst wurde die Expression der mBDNF mRNA Splice-Varianten im zentralen Nervensystem (ZNS) untersucht. Dafür wurde ein Real-Time-PCR Ansatz etabliert, der es ermöglichte alle neun Splice-Varianten $\mathrm{zu}$ amplifizieren. $\mathrm{Zu}$ diesem Zweck wurde ein gemeinsamer reverse Primer eingesetzt, welcher mit forward Primern kombiniert wurde, die alle spezifisch für ein nichtcodierendes Exon waren. Zusätzlich wurde eine für alle Ansätze einsetzbare TaqMan probe verwendet. Dieser Ansatz war erfolgreich für alle untersuchten Splice-Varianten, mit Ausnahme von Exon 5, wofür separate forward und reverse Primer eingesetzt werden mussten.

Die erste Analyse erfolgte mit dem Gehirngewebe einer C57Bl/6N Maus, die in fast allen Fällen das erwartete einzelne Amplifikat (Abb. 4.1) aufzeigte. Eine Ausnahme dabei bildete Exon 2, welche nach der Amplifikation bis zu drei unterschiedliche Produkte aufwies (Abb. 4.1). Die Ursache dafür lag vermutlich in den beiden internen Splice-Stellen im Exon von mBDNF 2, welche zu diesem unterschiedlichen splicing führt. Demnach führt je nach 
verwendeter Splice-Stelle der Einsatz des forward Primers für mBDNF $2 \mathrm{~A}$ zu drei verschiedenen Amplifikationsprodukten. Falls die erste Splice-Stelle benutzt wird, wird ein Amplifikationsprodukt von 109 bp erwartet, während die Benutzung der zweiten und dritten Splice-Stelle zu jeweils einem Amplifikationsprodukt von 321 bp bzw. 404 bp führen würde. Diese drei Produkte wurden auch tatsächlich nach der Amplifikation erhalten. Der Gebrauch des forward Primers für mBDNF 2B führte zur Amplifikation von 116 bp und 199 bp langen Produkten (Abb. 4.1), die durch die unterschiedliche Verwendung der beiden Splice-Stellen entstanden. Die Verwendung des forward Primers für mBDNF 2C führte zum erwarteten Amplifikationsprodukt von 121 bp Länge (Abb. 4.1). Somit war die Berechnung der relativen mRNA Expression nur im Fall von mBDNF 1, 3, 4, 5 und 6 möglich.

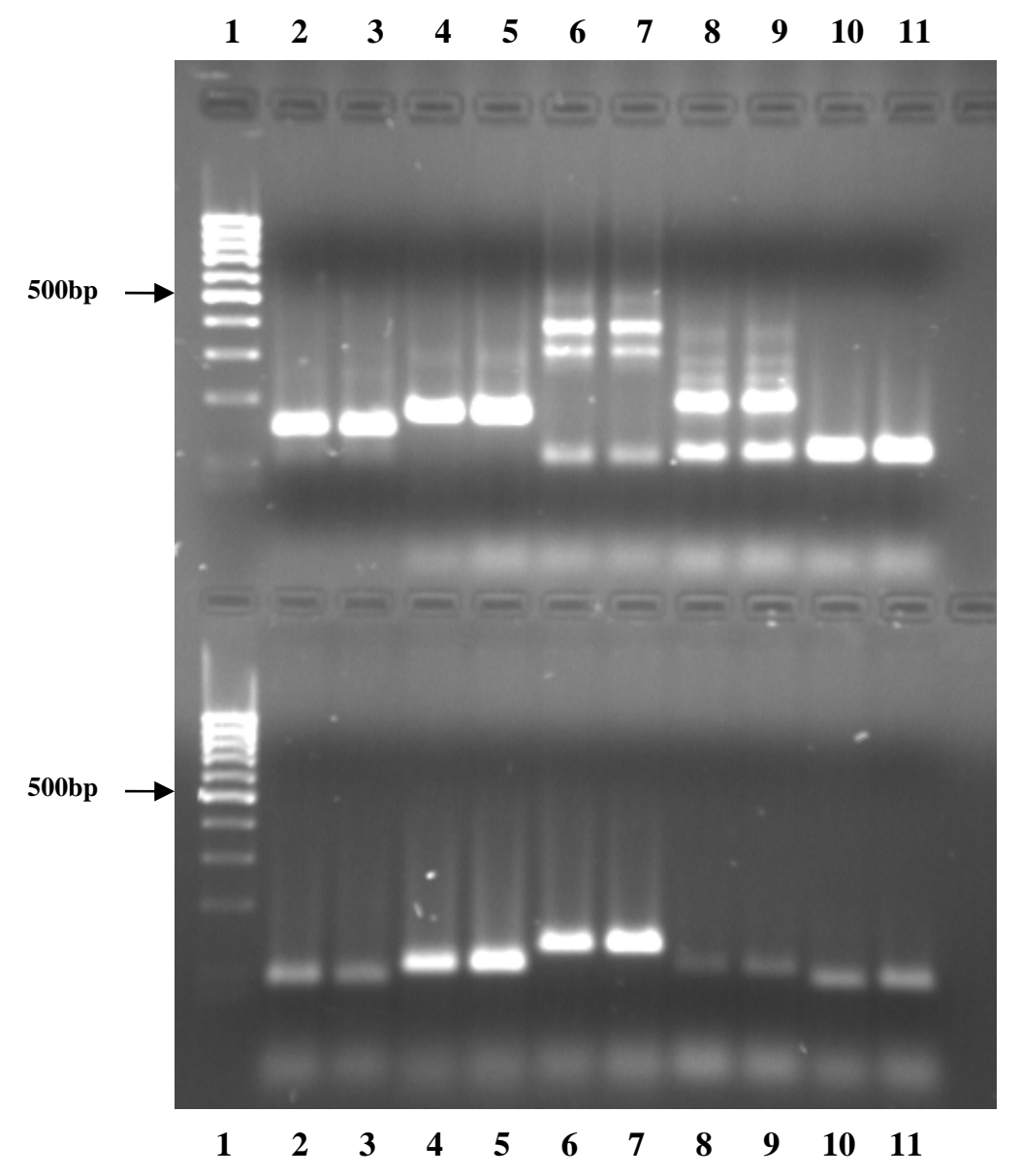

Abb. 4.1: Amplifikation der mBDNF mRNA Splice-Varianten im Gehirn von C57Bl/6 Mäusen. Agarosegel nach elektrophoretischer Auftrennung der PCR Produkte. oberes Bild: 1) MassRuler, O'GeneRuler LowRange,Fermentas, 2,3) Beta-Aktin, 4,5) mBDNF1, 6,7) mBDNF2a, 8,9) mBDNF2b, 10,11) mBDNF2c; unteres Bild: 1) MassRuler, O'GeneRuler LowRange, Fermentas, 2,3) mBDNF3, 4,5) mBDNF4, 6,7) mBDNF5, 8,9) mBDNF6a, 10,11) mBDNF6b. 
Für die Kalkulation der relativen mRNA Expression wurde in diesem Ansatz die Expression der mBDNF 1 mRNA willkürlich auf $100 \%$ gesetzt und die restlichen Splice-Varianten damit verglichen. Daraus ergab sich, dass im Mausgehirn die mRNA von mBDNF 1 und 4 in vergleichbar hohen Mengen exprimiert wurde. Im Vergleich dazu war die Expression der Splice-Variante 5 ca. 10-mal und die mRNA der Splice-Variante 3 ca. 60-mal niedriger als die Expression der mRNA von mBDNF 1 bzw. 4. Die Expression von mBDNF mRNA 6A und 6B hingegen konnte nur in sehr geringen Mengen detektiert werden und lag bei circa $0,05 \%$ bzw. 0,9\% (Abb. 4.2).

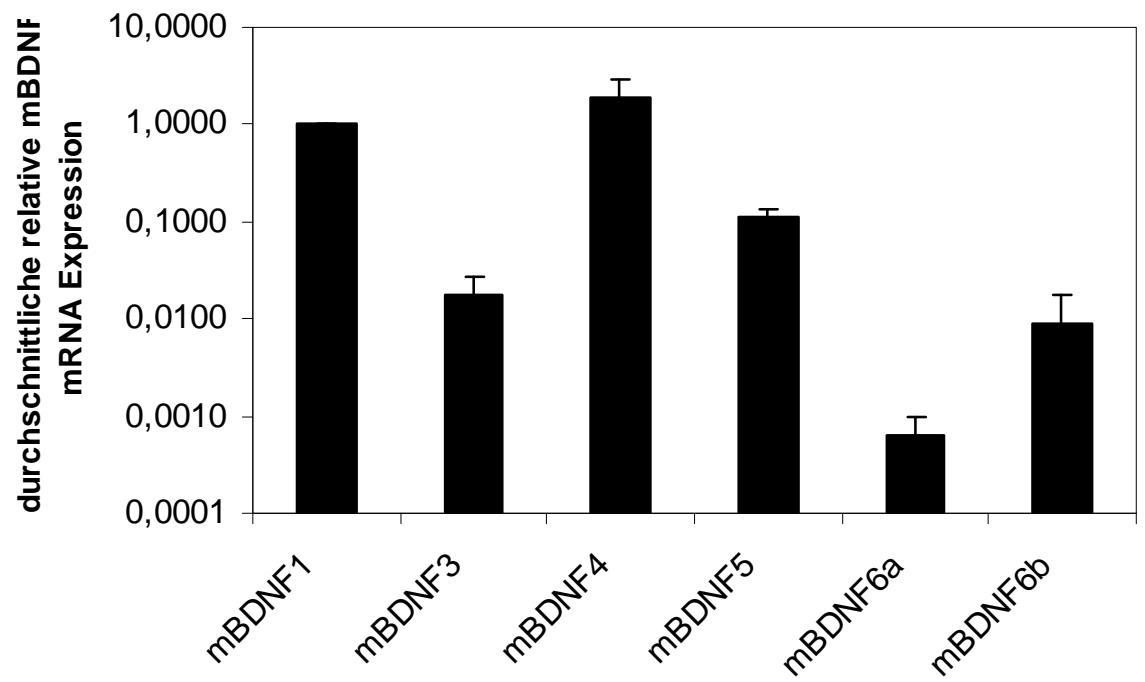

Abb. 4.2: Durchschnittliche relative Expression der mBDNF mRNA Splice-Varianten im Gehirn von C57Bl/6 Mäusen. Die relative Expression der mBDNF mRNA Splicevarianten wurde mit Hilfe der $\Delta \triangle \mathrm{CT}$ Methode berechnet, wobei die Expression des mBDNF 1 als Kalibrator auf $100 \%$ gesetzt wurde. Der Mittelwert und die Standardabweichung setzen sich zusammen aus 5 unabhängigen Experimenten mit unterschiedlichen Tieren.

\subsubsection{Expression und Quantifizierung der mBDNF mRNA Splice-Varianten in peripheren lymphatischen Organen und Immunzellen}

Als nächstes sollte untersucht werden, ob die unterschiedlichen mBDNF mRNA SpliceVarianten auch in peripherem lymphatischem Gewebe sowie Immunzellen vorzufinden sind. Tatsächlich konnte in den Proben aus Thymus, Milz und Lymphknoten von C57Bl/6N 
Mäusen nur mBDNF 3 mRNA amplifiziert werden, während keine andere Splice-Variante, die im Gehirn nachgewiesen wurde, detektierbar war. Quantitative Analysen zeigten eine ähnlich hohe Expression von mBDNF 3 mRNA in den untersuchten lymphatischen Gewebeproben, die jedoch verglichen mit der Expression von mBDNF 3 mRNA im Gehirn deutlich höher war (Abb. 4.3).

Da die BDNF Proteinexpression in T-Zellen und Makrophagen (Kerschensteiner 1999) sowie in T-Zellklonen (Besser und Wank, 1999) bereits beschrieben war, sollte auch in diesen Zelltypen die Expression der mBDNF Splice-Varianten untersucht werden. Dafür wurden TZellen aus der Milz und peritoneale Makrophagen isoliert. Die Analyse ergab auch in diesem Fall nur die Expression von mBDNF 3 mRNA, dessen Expressionsrate in T-Zellen vergleichbar mit dem in lymphatischen Organen war und somit vermutlich die Hauptquelle für BDNF in diesen Organen darstellt. Die Expression von mBDNF 3 mRNA in Makrophagen hingegen lag bei nur circa 20 \% der Expression im Gehirn (Abb. 4.3).

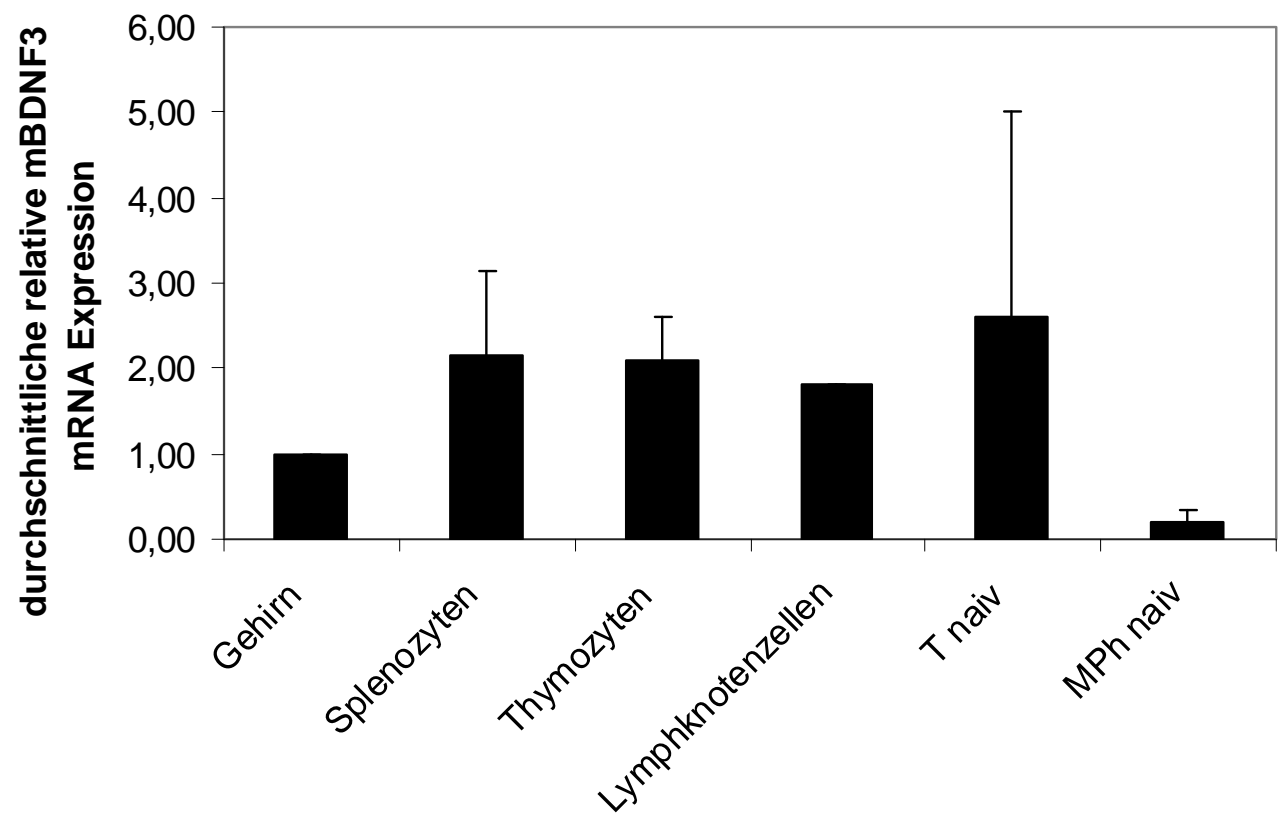

Abb. 4.3: Durchschnittliche relative Expression der mBDNF 3 mRNA in peripherem lymphatischem Gewebe und in Immunzellpopulationen von C57BI/6 Mäusen. Die relative Expression wurde mit Hilfe der $\Delta \Delta \mathrm{CT}$ Methode berechnet, wobei die mBDNF3 Expression im Gehirn als Kalibrator diente und auf $100 \%$ gesetzt wurde. $\mathrm{n}=1$ für Lymphknotenzellen, $\mathrm{n}=3$ für alle anderen Proben. Der Fehlerbalken repräsentiert die Standardabweichung. 
Weiterhin wurde berichtet, dass die Aktivierung von T-Zellen zu einer Erhöhung der BDNF Proteinexpression führt. Dies kann entweder an der quantitativen Erhöhung der detektierten mBDNF 3 mRNA Expression liegen oder an einer zusätzlichen Aktivierung anderer BDNF mRNA Splice-Varianten. Um eine dieser Erklärungsansätze zu bestätigen bzw. auszuschließen, wurden aus einer C57B1/6 Maus Thymozyten und T-Zellen aus der Milz isoliert und mit PMA/Ionomycin stimuliert. Die Analyse der BDNF mRNA Splice-Varianten ergab eine 10fache Erhöhung der mBDNF 3 mRNA Expression in Thymozyten und 17 fache Erhöhung der Expression dieser Splice-Variante in T-Zellen aus der Milz (Abb. 4.4 A). Andere Splice-Varianten waren auch nach der Stimulation nicht detektierbar. Peritoneale Makrophagen wurden für 24 Stunden mit LPS stimuliert und zeigten anschließend ebenso nur die Expression von mBDNF 3 mRNA, die jedoch diesmal im Vergleich zu unbehandelten Makrophagen um ein 4faches reduziert war (Abb. 4.4 B). Um zudem zu untersuchen, welche Transkriptionsfaktoren bei der Hochregulierung von mBDNF 3 mRNA verantwortlich sein könnten, wurde ein tet induzierbares System verwendet, bei dem der Transkriptionsfaktor NF$\kappa \mathrm{B}$ spezifisch in T-Zellen runterreguliert ist. Von diesen doppelttransgenen Tieren wurden Thymozyten entnommen und mit Wildtyp Thymozyten verglichen (Abb. 4.4 A). Dabei stellte sich heraus, dass die Expression von mBDNF 3 mRNA nach Stimulation der Thymozyten beider Genotypen vergleichbar war. Aus diesem Grund konnte eine entscheidende Rolle des Transkriptionsfaktor NF- $\kappa \mathrm{B}$ in der Regulation von mBDNF 3 in T-Zellen ausgeschlossen werden.

A

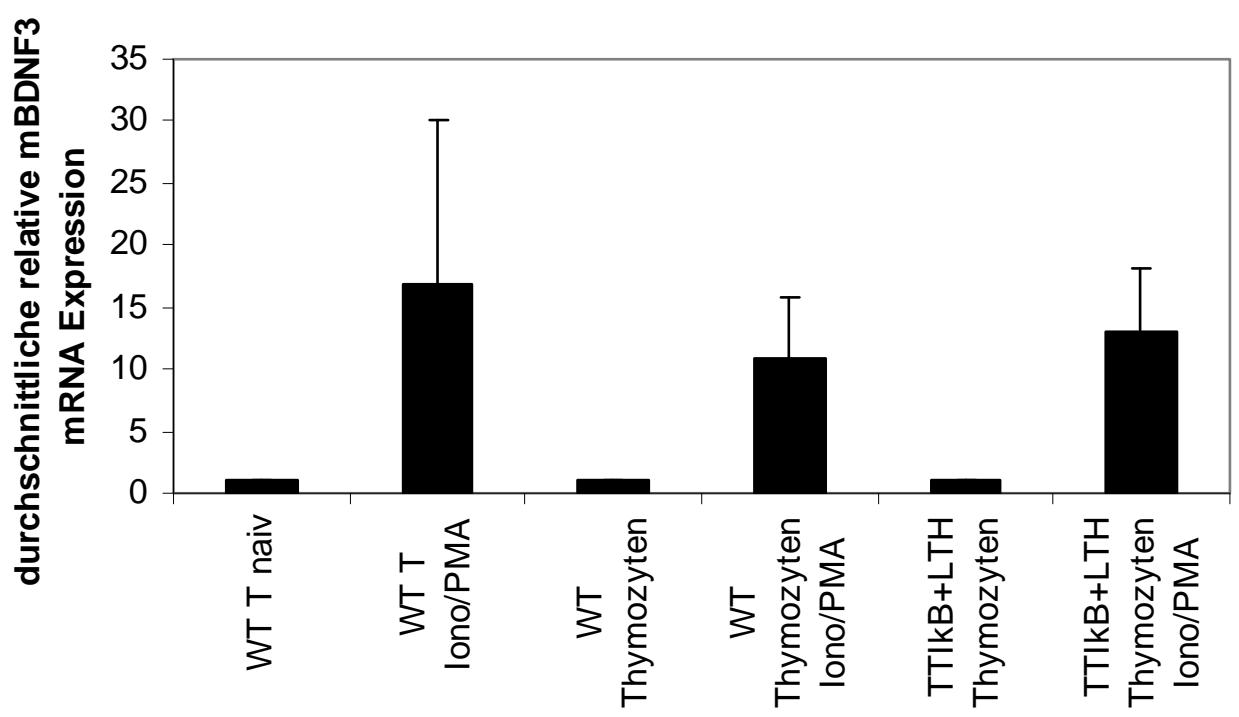


B

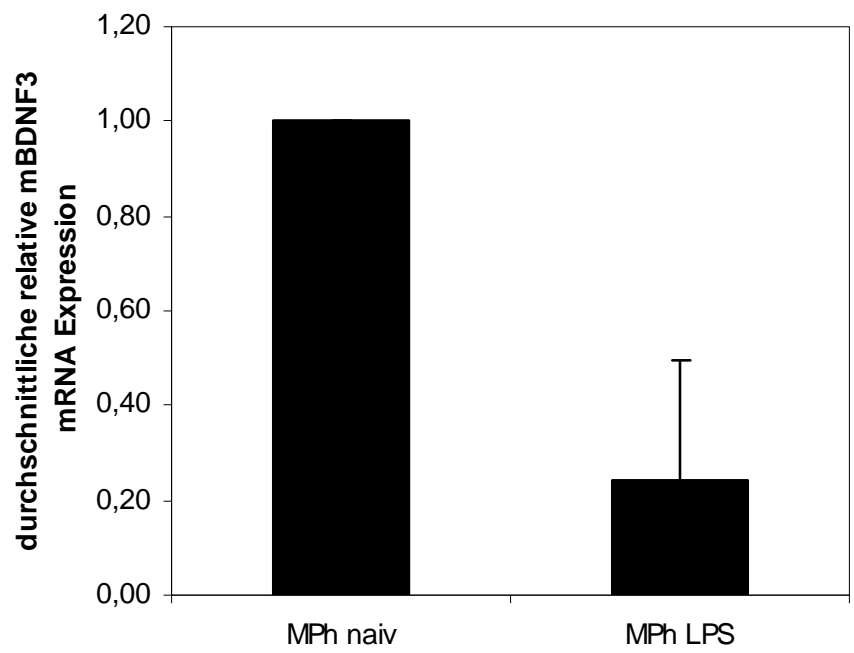

Abb. 4.4: Durchschnittliche relative Expression der mBDNF 3 mRNA. Die mBDNF mRNA Expression wurde in A. stimulierten und aufgereinigten T-Zellen und Thymozyten von Wildtyp C57B1/6 Tieren, sowie in Thymozyten von C57B1/6 Tieren, in denen der Transkriptionsfaktor NFkB spezifisch in T-Zellen unterdrückt ist (TTIкB+LTH) B. und in stimulierten Makrophagen von C57Bl/6 Tieren untersucht. Die relative Expression wurde mit Hilfe der $\Delta \Delta \mathrm{CT}$ Methode berechnet, wobei die mBDNF 3 Expression in A. unstimulierten T-Zellen oder B. unstimulierten Makrophagen als Kalibrator diente und auf $100 \%$ gesetzt wurde. A. $n=4$ für Wildtyp Thymozyten, $n=2$ für aufgereinigte T-Zellen und $n=2$ für TTIкB+LTH Thymozyten. B. n=3. Der Fehlerbalken repräsentiert die Standardabweichung.

Um auszuschließen, dass die erzielten Ergebnisse nur für den C57Bl/6N Mausstamm gelten, wurden auch weitere Zuchtstämme mit anderen MHC Haplotypen (Balb/c-MHC ${ }^{\mathrm{d}}$ und FVB/N-MHC ${ }^{q}$ ) in die Versuche mit einbezogen. Die Analyse der beiden Stämme resultierte in vergleichbaren Ergebnissen, die die Expressionsrate der BDNF mRNA Splice-Variante im Gehirn und speziell die Expression von mBDNF 3 mRNA in T-Zellen und Makrophagen betreffen.

Demnach kann man zusammenfassen, dass in peripheren murinen lymphatischen Organen und isolierten T-Zellen sowie Makrophagen nur die mRNA der Splice-Variante mBDNF 3 exprimiert wird, und dass die Stimulation von T-Zellen zu einer Erhöhung der mBDNF 3 mRNA Expression führt, jedoch nicht zur Expression weiterer Splice-Variante. 


\subsubsection{Expression und Quantifizierung der mBDNF mRNA Splice-Varianten in Mikroglia und Astrozyten}

Mikroglia und Astrozyten spielen eine bedeutende Rolle in der Pathogenese und im Erkrankungsverlauf der EAE und MS. Zudem sind Mikroglia und Makrophagen nah miteinander verwandt und teilen gleiche Immunfunktionen sowie Oberflächenmoleküle, was die Untersuchung der mBDNF Splice-Varianten in diesen Zelltypen sehr attraktiv machte.

Beide Zelltypen wurden dafür aus einer gemischten Gliazellkultur aus dem Gehirn von Neugeborenen C57B1/6N Mäusen gewonnen. Nach der Aufarbeitung wurden routinemäßig Mikrogliakulturen von 97 \%-iger Reinheit gewonnen, die nur wenig Astrozytenkontaminationen enthielten.

Die Analyse der mBDNF Splice-Varianten ergab, dass in Astrozyten alle Splice-Varianten exprimiert werden, und dass die Expressionsrate von mBDNF mRNA 1, 4, 6A und 6B vergleichbar mit dem im Gehirn ist (Abb. 4.5). Ganz deutlich war eine Überrepresentation von mBDNF 5 mRNA erkennbar, dessen relative mRNA Expression 5 fach höher war als die Expression der mBDNF 1 mRNA. Die relative mBDNF 3 mRNA Expression hingegen war im Vergleich zur Expression im Gehirn doppelt so hoch und erreichte circa $4 \%$ der Expression von mBDNF 1 mRNA. Im Fall der Mikroglia konnte nur die mRNA der SpliceVariante mBDNF 3 detektiert werden (Abb. 4..7.).

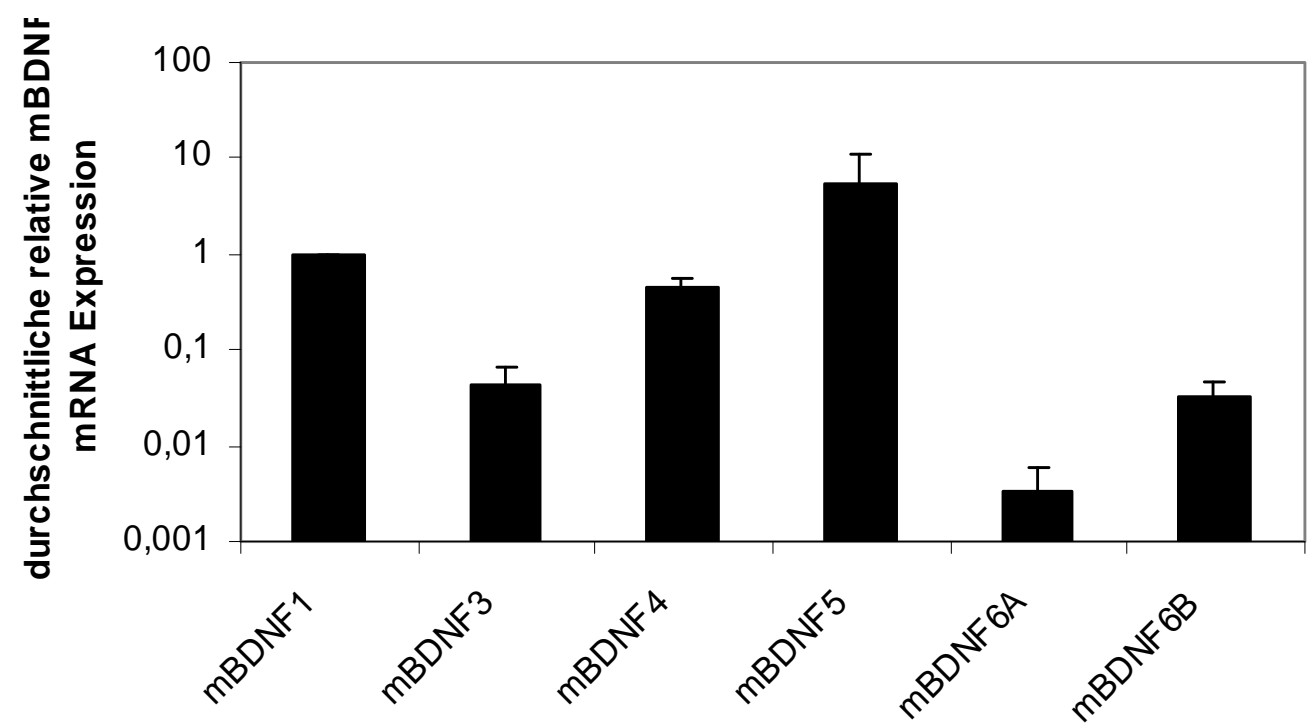

Abb. 4.5: Durchschnittliche relative Expression der mBDNF mRNA Splice-Varianten in Astrozyten von C57Bl/6 Mäusen. Die relative mBDNF mRNA Expression in Astrozyten wurde mit Hilfe der $\Delta \Delta C T$ Methode berechnet, wobei die mBDNF 1 Expression als Kalibrator diente und auf $100 \%$ gesetzt wurde. $\mathrm{n}=3$. Der Fehlerbalken repräsentiert die Standardabweichung. 
Um die relative mRNA Expression der unterschiedlichen Splice-Varianten in Astrozyten und Mikroglia mit der Expression im Gesamthirn zu vergleichen, wurde die Expression der jeweiligen Splice-Variante im Gehirn auf $100 \%$ gesetzt und die übrigen damit verglichen (Abb. 4.6).

Im Fall der Astrozyten war die mRNA Expression von mBDNF 5 in ähnlich hoher Menge exprimiert wie im Gehirn. Im Gegensatz dazu, erreichte die relative mRNA Expression von mBDNF 3 und 6A nur circa $10 \%$ der Expression im Gehirn. Die Expression von mBDNF 1 und 4 mRNA war in Astrozyten noch geringerer und erreichte nur 1-5\% der Expression im Gehirn (Abb. 4.6). In Mikroglia lag die Expression von mBDNF 3 bei nur circa $15 \%$ von der im Gehirn beobachteten Expression (Abb. 4.7).

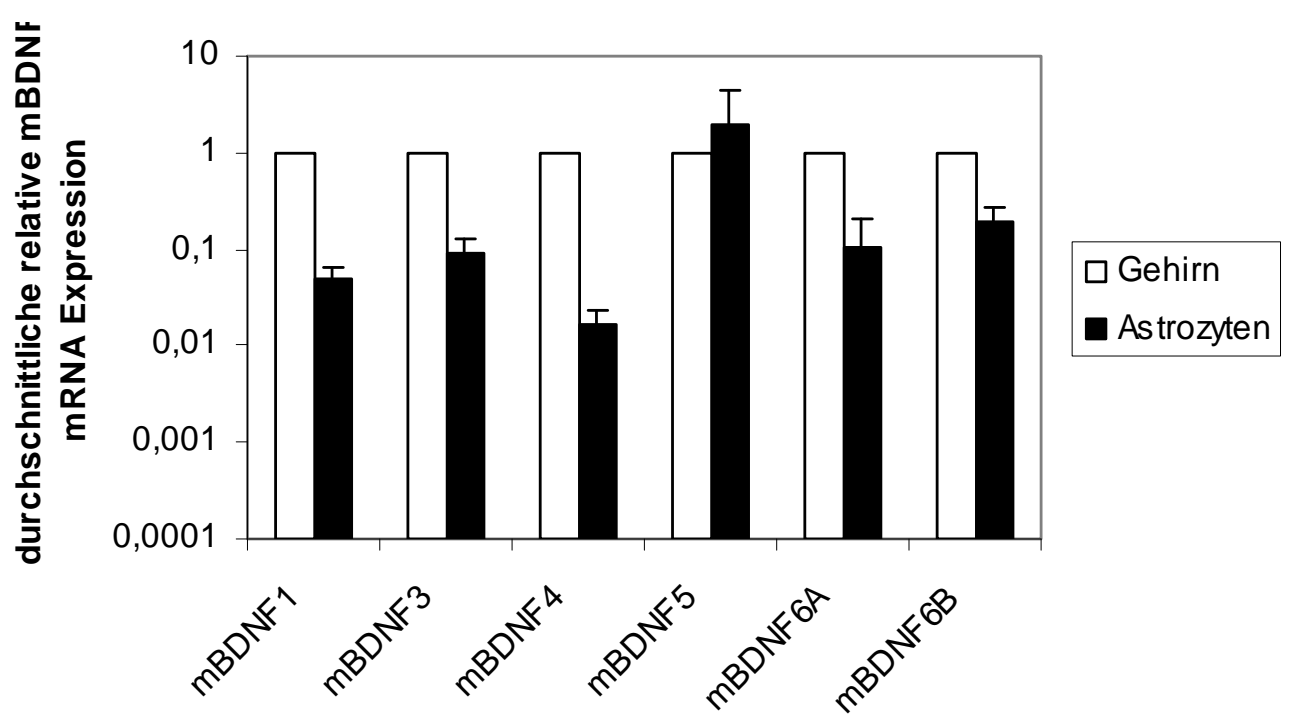

Abb. 4.6: Durchschnittliche relative Expression der mBDNF mRNA Splice-Varianten in Astrozyten im Vergleich zum Gesamthirn von C57BI/6 Mäusen. Die relative mBDNF mRNA Expression in Astrozyten wurde mit Hilfe der $\Delta \Delta \mathrm{CT}$ Methode berechnet, wobei die Expression der entsprechenden mBDNF Splice-Variante aus dem Gesamthirn als Kalibrator diente und auf $100 \%$ gesetzt wurde. $\mathrm{n}=2$. Der Fehlerbalken repräsentiert die Standardabweichung.

Diese Ergebnisse zeigten, dass in Astrozyten zwar mBDNF 5 im Vergleich zum Gesamtgehirn überrepräsentiert ist, aber dass diese nicht die einzige Splice-Variante ist, während in Mikroglia nur mBDNF 3 exprimiert wurde, was vergleichbar mit peritonealen Makrophagen ist (Abb. 4.7).

Die Stimulation der Mikroglia und Astrozyten mit LPS bzw. IFN- $\gamma$ zeigte keine signifikante Veränderung der Expression der mBDNF Splice-Varianten in Astrozyten, während die 
mBDNF 3 mRNA Expression nach Stimulation der Mikroglia mit LPS um die Hälfte reduziert war (Abb. 4.7), was vergleichbar war mit den Ergebnissen, die für peritoneale Makrophagen erzielt wurden.

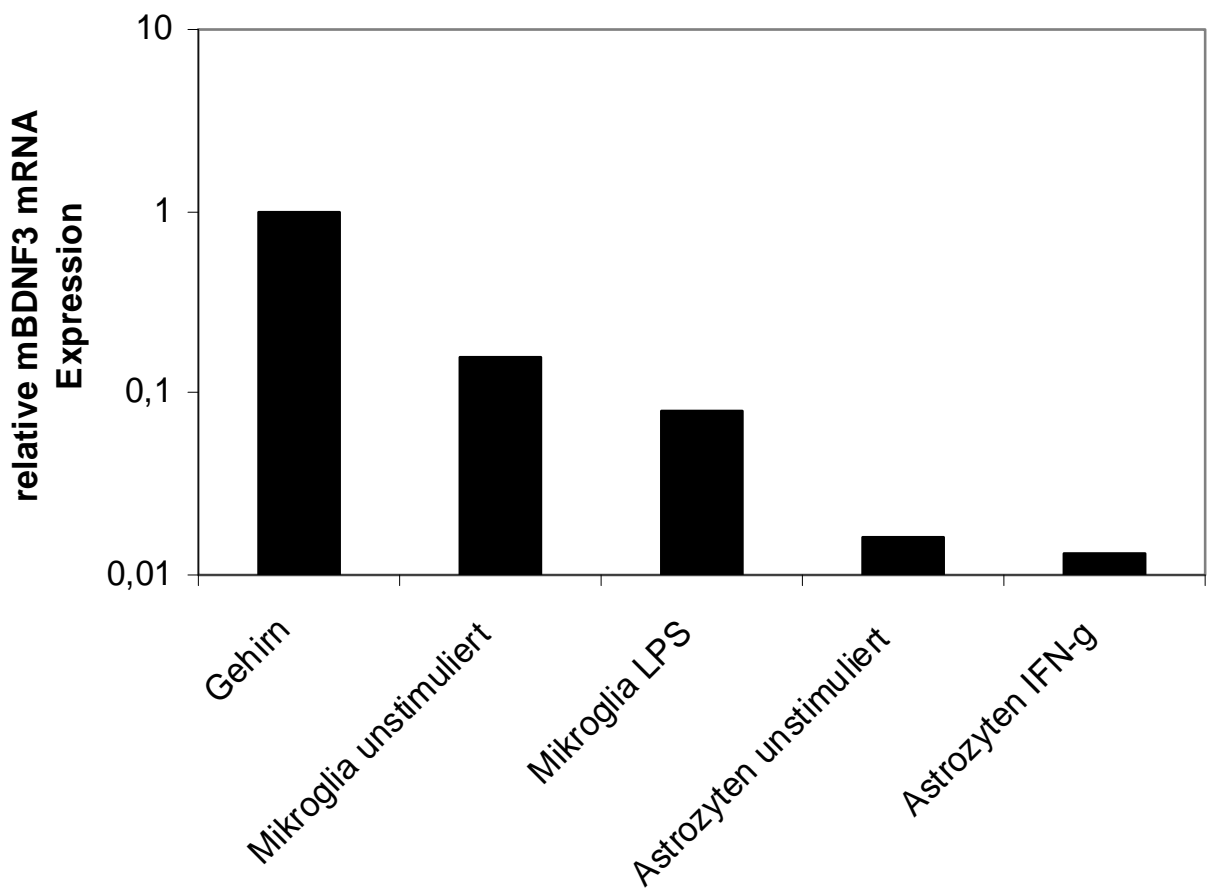

Abb. 4.7: Durchschnittliche relative Expression der mBDNF 3 mRNA Splice-Varianten in gereinigten Astrozyten und Mikroglia von C57BI/6 Mäusen. Die relative mBDNF 3 mRNA Expression in unstimulierten und stimulierten Mikroglia und Astrozyten wurden mit Hilfe der $\Delta \Delta C T$ Methode berechnet, wobei die mBDNF 3 Expression im Gesamthirn als Kalibrator diente und auf $100 \%$ gesetzt wurde. Der Fehlerbalken repräsentiert die Standardabweichung. 


\subsection{BDNF und dessen funktionelle Relevanz in der EAE}

BDNF ist ein Mitglied der Neurotrophinfamilie und spielt eine Schlüsselrolle im neuronalen Überleben sowie deren Differenzierung und Plastizität (Lewin and Barde, 1996). Zudem konnte in einigen Studien gezeigt werden, dass dieses Neurotrophin axonprotektive Eigenschaften besitzt (Gravel et al., 1997; Kobayashi et al., 1997; McTigue et al., 1998; Sendtner et al., 1992; Yan et al., 1992). Zwar bilden Neuronen die Hauptquelle für BDNF, aber auch Immunzellen können bioaktives BDNF exprimieren (Kerschensteiner et al., 1999). Diese BDNF-exprimierenden Immunzellen wurden auch in entzündlichen Läsionen im ZNS von MS-Patienten detektiert, was $\mathrm{zu}$ der Annahme geführt hat, dass infiltrierende Immunzellen nicht nur destruktive sondern durch die BDNF Expression auch neuroprotektive Eigenschaften besitzen könnten (Stadelmann et al., 2002). Schon in früheren Studien konnte gezeigt werden, dass die Applikation von BDNF in einem Mausmodell der Motorneuronendegeneration erfolgreiche Therapieergebnisse brachte (Mitsumoto et al., 1994). Die exogene Applikation von freiem BDNF in einem Modell der experimentellen autoimmunen Neuritis war jedoch nicht sehr effizient (Felts et al., 2002). Um den potenziell benefiziellen Effekt des BDNF in der EAE, dem Tiermodell der MS, zu untersuchen, wurde ein lentivirales Transduktionssystem gewählt, in das die BDNF Gensequenz einkloniert wurde. Mit Hilfe dieses Transduktionssystems sollte eine BDNF Überexpression in den Zielzellen erzeugt werden, um die Funktion des BDNF zu verstärken. Als geeignete Vehikel für den BDNF Transport wurden MOG T-Zellrezeptortransgene und GFP positive T-Zellen ausgewählt. Diese boten den Vorteil, dass das BDNF die Möglichkeit bekam mit Hilfe der TZellen in das ZNS einzudringen, um die Läsionen zu erreichen, in denen es durch die Überexpression seine potenziell therapeutische Funktion ausüben konnte. Das GFP Transgen sollte die Detektion der applizierten T-Zellen in vivo vereinfachen. 
Hier eine schematische Darstellung des Versuchsaufbaus:

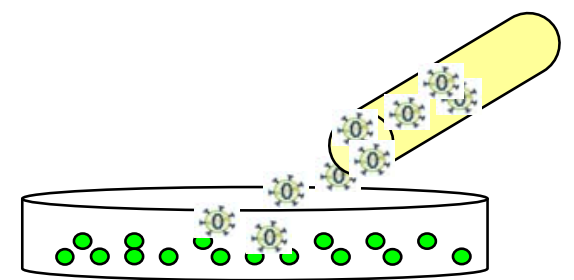

1. Generierung BDNF überexprimierender T-Zellen mittels lentiviraler Transduktion

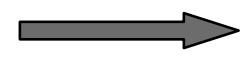

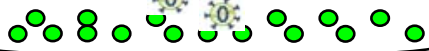

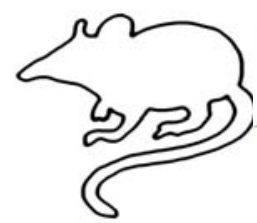

2. i.v. Injektion von BDNF überexprimierenden T-Zellen in C57Bl/6 Wildtyp Mäuse, in denen zuvor eine EAE induziert wurde
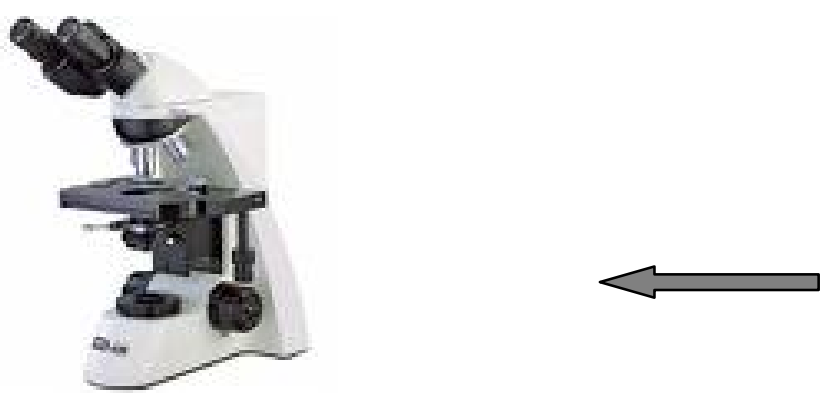

4. Histologische Analyse, um mögliche Auswirkungen der Injektion zu detektieren

3. Perfusion und Präparation des Rückenmarks nach einigen Wochen

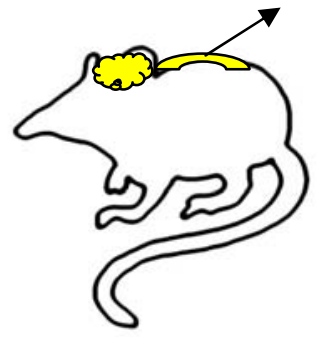

Abb. 4.8: Schematische Darstellung des Versuchsaufbaus. Diese schematische Darstellung zeigt den Versuchsaufbau für die funktionellen Untersuchungen der Überexpression des BDNF in T-Zellen in vivo.

\subsubsection{Generierung BDNF überexprimierender T-Zellen mittels lentiviraler Transduktion}

Um BDNF überexprimierende T-Zellen $\mathrm{zu}$ generieren wurde das lentivirale

Transduktionssystem verwendet, da Lentiviren die Fähigkeit haben das zu transferierende 
Gen in das Wirtsgenom stabil zu integrieren und vor allem auch ruhende Zellen zu infizieren. Somit wäre eine Aktivierung der T-Zellen vor der Infektion nicht notwendig und ein eventuell negativer Einfluss der zusätzlichen Aktivierung auf die EAE wäre ausgeschlossen. Ein weiterer Grund für die Wahl der lentiviralen Transduktion für die BDNF Überexpression war, dass T-Zellen resistent gegen andere Transfermöglichkeiten der DNA sind. So war es bisher nicht möglich T-Zellen z.B. mittels Lipofektion (siehe Kap. 3.2.11) zu transfizieren.

Um einen BDNF-codierenden lentiviralen Vektor $\mathrm{zu}$ generieren, wurde ein lentiviraler Ausgangsvektor verwendet, der von Prof. Harald Neumann (Universität Bonn) zur Verfügung gestellt wurde und pLenti-PGK-EGFP heißt. Dieser Vektor besitzt einen Phosphoglyceratkinase (PGK) Promoter, der die konstitutive Expression des nachfolgenden Gens befähigt. Die EGFP-Sequenz im Vektor, die direkt an die Promotersequenz angrenzt, wurde über die Restriktionsschnittstellen BamHI und XhoI durch die murine BDNF-Sequenz ersetzt (Abb. 4.9).
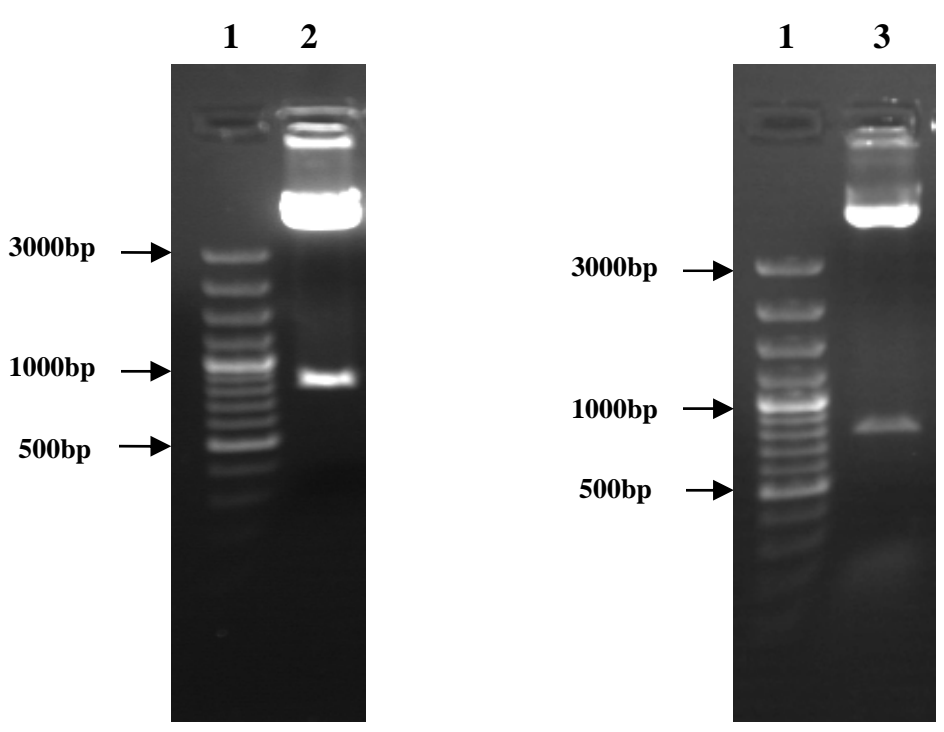

Abb. 4.9: Restriktionsverdau lentiviraler Vektoren. Agarosegel nach elektrophoretischer Auftrennung des Restriktionsverdaus. 1) Generuler 100pb plus, Fermentas 2) plenti-PGK-EGFP verdaut mit BamHI und XhoI, erwartete Fragmentgröße Vektor $=6859$ bp und Insert $=724 \mathrm{bp} 3$ ) plenti-PGK-BDNF verdaut mit BamHI und XhoI, erwartete Fragmentgröße Vektor $=6850$ bp und Insert $=750 \mathrm{bp}$.

Um die Klonierungseffizienz und die Expression des BDNF in dem neuen Vektor zu testen, wurden humane embryonale Nierenzellen (HEK) mit diesem lentiviralen Vektor transfiziert. Der Überstand dieser Zellkultur wurde in einem BDNF-ELISA gestestet und zeigte, dass bei 
einer Transfektion mit $3 \mu \mathrm{g}$ DNA, mehr als $2 \mathrm{ng} / \mathrm{ml}$ des BDNF Proteins in den Überstand sezerniert wurde, während die Expression dieses Proteins in nicht-transfizierten bzw. nur mit dem Transfektionsreagenz (Nanofectin) transfizierten Zellen mit nur 78 pg/ml im Überstand zu detektieren war (Abb. 4.10 A). Dieses Ergebnis zeigte, dass das murine BDNF Gen in den lentiviralen Vektor richtig einkloniert wurde und, dass das BDNF Protein exprimiert werden konnte.

Nachdem die Funktionalität des Vektors geklärt war, wurde der Vektor zur Generierung des Lentivirus verwendet. Der Lentivirus wurde zunächst an HEK-Zellen getestet. Um zu überprüfen, ob die Transduktionseffizienz durch Polybrene, einem kationischen Polymer, gesteigert wird, wurde zusätzlich jeweils einem Ansatz dieses Reagenz hinzugefügt. Die Analyse der HEK-Zellen erfolgte auf Proteinebene und da das Virus mindestens 3 Tage benötigt bis es das Zielgen exprimiert wurden speziell die Tage 4 bis 6 nach der Infektion beobachtet. Der BDNF-ELISA zeigte, dass die infizierten Zellen mehr BDNF Protein exprimieren als die unbehandelten Zellen (Abb. 4.10 B). Die Expressionsrate lag nach 4 Tagen bei den Ansätzen ohne Polybrenebehandlung bei circa $30 \mathrm{pg} / \mathrm{ml}$ und stieg an Tag 6 bis auf 93 pg/ml auf. Der Vergleich zu den Ansätzen mit Polybrenebehandlung zeigte geringere BDNF-Proteinkonzentrationen im Überstand, woraus sich schließen ließ, dass Polybrene im Fall der Transduktion von HEK-Zellen nicht besonders effizient ist. Der Lentivirus war aber in HEK-Zellen funktionell und führt zu einer Überexpression des BDNF nach Transduktion.

A

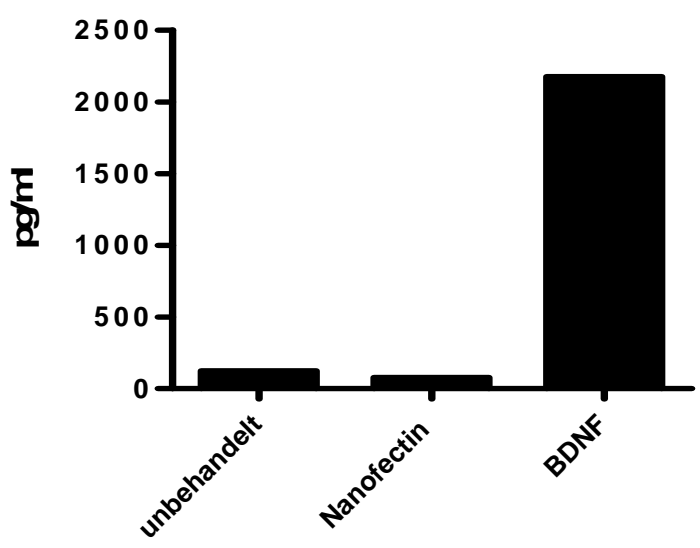

B

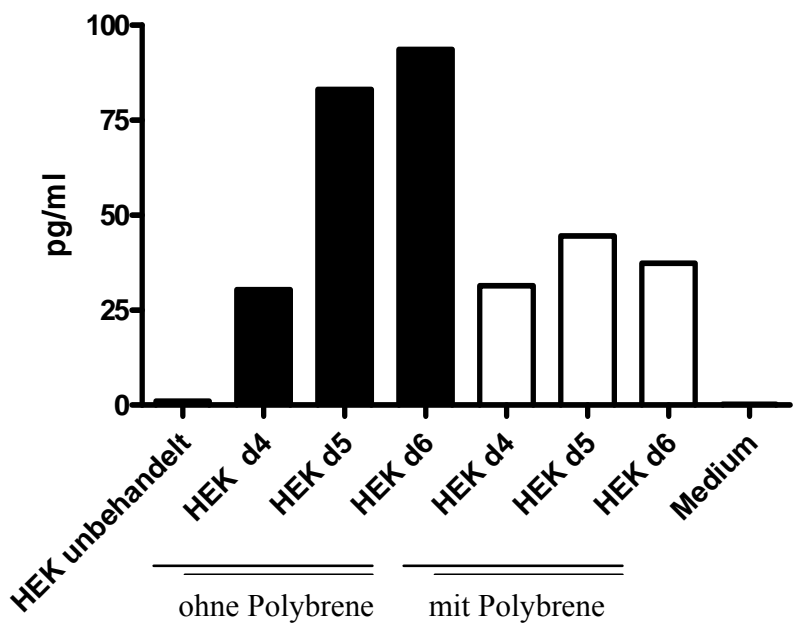

Abb. 4.10: Austestung des lentiviralen BDNF Vektors sowie des BDNF Virus an HEK-Zellen. BDNF Expression detektiert im Überstand der Zellkultur mittels BDNF ELISA nach A. Transfektion von HEK-Zellen mit dem lentiviralen BDNF Vektor und B. nach Transduktion von HEK-Zellen mit dem BDNF Lentivirus. 
Um tatsächlich BDNF-überexprimierende T-Zellen zu erhalten, wurden anfangs primäre, naive T-Zellen verwendet. Dieser Ansatz stellte sich jedoch für die in vitro Experimente als nicht durchführbar heraus, da primäre T-Zellen nicht länger als 3 Tage in Kultur zu halten sind, auch wenn sie relativ stark stimuliert werden. Da aber die Effizienz der Transduktion erst nach frühestens 4 Tagen zu detektieren ist, konnten primäre T-Zellen für die in vitro Versuche nicht verwendet werden. Aus diesem Grund wurde das Virus an einer MOGspezifischen T-Zelllinie, die aus C57BL/6 Mäusen gewonnen wurden, getestet (Abb. 4.11). Auch hier wurden die Tage 3-6 näher betrachtet und die Transduktion auf mRNA und Proteinebene analysiert. Auf mRNA-Ebene war ein Anstieg des BDNF im Laufe der beobachteten 3 Tage zu detektieren. Zur quantitativen Analyse des Anstiegs wurden die Expression der BDNF mRNA in den unbehandelten Zellen gleich 1 gesetzt und die relative Expression der infizierten Zellen dazu ermittelt. Das Ergebnis zeigte, dass die infizierten Zellen an Tag 6 circa 60-mal mehr BDNF mRNA exprimieren als die unbehandelten Zellen. Die Analyse der BDNF Proteinexpression wurde mit Hilfe eines BDNF-ELISAs durchgeführt und zeigte im Fall der Proben ohne die Zugabe von Polybrene eine sehr geringe BDNFKonzentration im Überstand, die sich im Laufe der 3 Tage kaum erhöhte. Während die Proben, die mit Polybrene behandelt wurden einen Anstieg der BDNF-Konzentration im Überstand zeigten, der an Tag 5 eine Konzentration von circa 26 pg/ml erreichte. Diese Analysen zeigen, dass nicht nur der lentivirale Vektor funktionell ist, sondern auch das daraus generierte Lentivirus sowohl HEK- als auch T-Zellen infizieren kann und zu einer BDNF Überexpression führt.

A

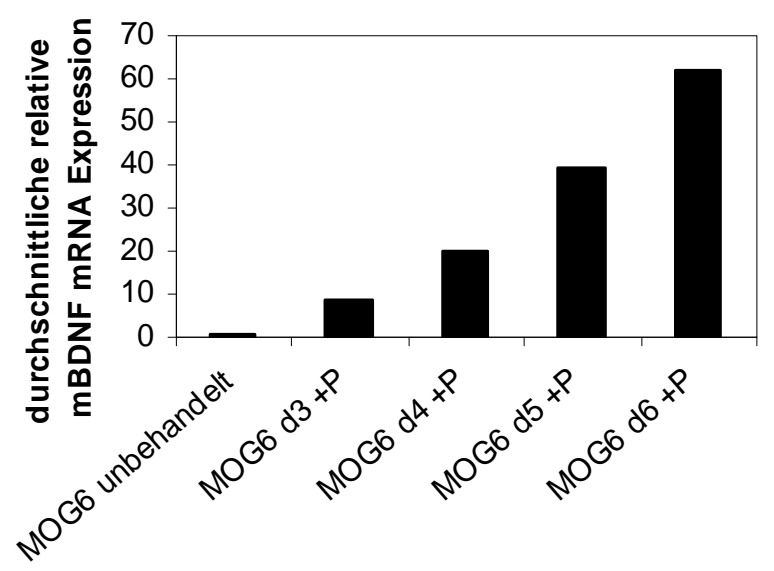

B

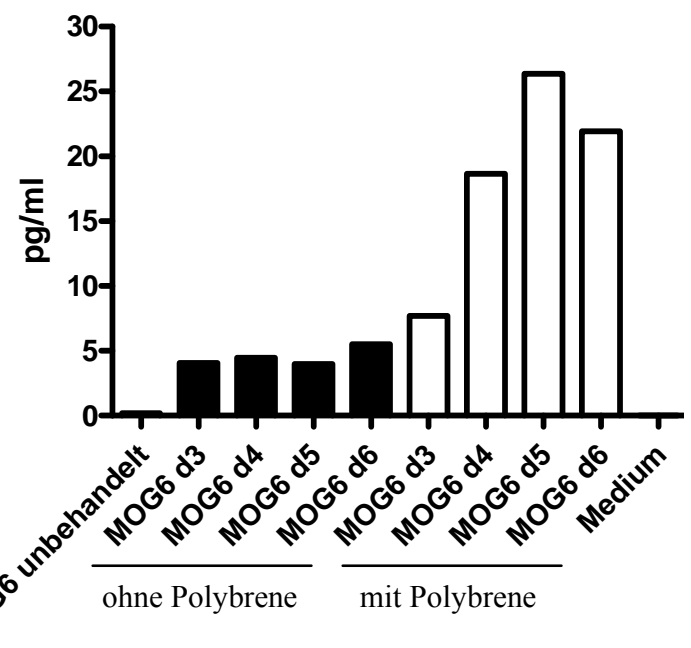

Abb. 4.11: Lentivirale Transduktion von T-Zellen einer MOG-spezifischen Zelllinie. BDNF Expression in MOG-spezifischen T-Zellen einer Zelllinie nach lentiviraler Transduktion mit dem BDNF Lentivirus detektiert A. im Überstand der T-Zellkultur mittels BDNF-ELISA und B. auf mRNA Ebene mittels Real-Time PCR. 
Um auszuschließen, dass die Virusinfektion an sich eine erhöhte BDNF-Expression verursacht und um in den in vivo Experimenten eine adäquate Kontrolle zu besitzen, wurde ein Kontrollvirus mit Hilfe des pLenti-PGK-EGFP Originalvektors generiert. Die Funktionalität dieses Virus wurde auch an HEK- und T-Zellen getestet, die in Fluoreszenzmikroskopischen Analysen stets nach Infektion mit dem Kontrollvirus eine grüne Fluoreszenz aufzeigten und somit das Virus als funktionell bestätigten (Abb. 4.12). Der Überstand der GFP-Virus infizierten T-Zellen wurde auf BDNF Proteinexpression hin untersucht, mit dem Ergebnis, dass keine detektierbare Konzentration des BDNF Proteins im ELISA nachgewiesen werden konnte. Damit wurde eine Erhöhung der BDNF-Expression allein durch eine Virusinfektion ausgeschlossen.

A

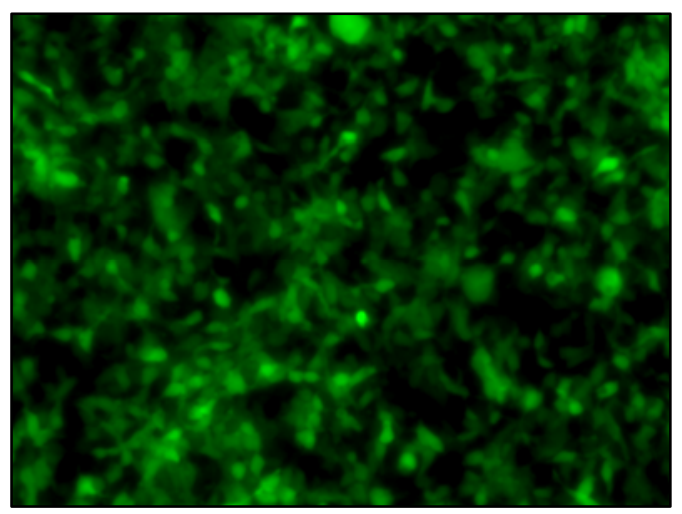

B

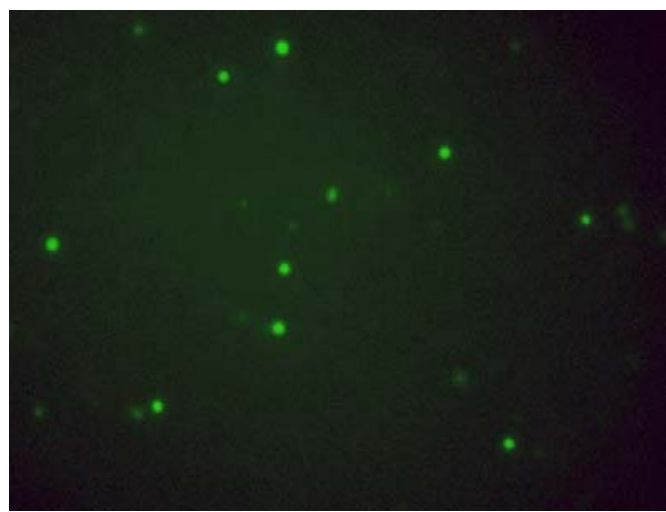

Abb. 4.12: Lentivirale Transduktion mit dem GFP Virus. Fluoreszenzmikroskopische Analyse nach GFP Virusinfektion von A. HEK-Zellen und B. MOG-spezifischen T-Zellen einer Zelllinie. Die Aufnahmen wurden mit einem 20x Objektiv angefertigt.

Als nächstes sollte die Expression von BDNF in transduzierten T-Zellen nach i.v. Applikation nachgewiesen werden. Dafür wurden GFP positive T-Zellen aus einer GFP transgenen Maus isoliert. Für jedes Empfängertier wurden 10 x $10^{6}$ T-Zellen aufgereinigt und mit dem BDNF Lentivirus transduziert. Die Zellen wurden für die i.v. Injektion in je $200 \mu 1$ PBS pro Tier aufgenommen und i.v. in die Schwanzvene der C57B1/6 Empfängertiere appliziert. 21 Tage nach i.v. Applikation wurden die lentiviral mit BDNF transduzierten GFP positiven T-Zellen aus der Milz der Empfängertiere mittels FACS nach GFP Fluoreszenz sortiert und durch Cytospin (1200 rpm, 10 Minuten) auf Objektträger aufgebracht. Nach immunhistochemischer Färbung für BDNF wurde eine deutlich intensivere Färbung im Fall der mit BDNF transduzierten T-Zellen im Vergleich zu Wildtyp T-Zellen nachweisbar (Abb. 4.13). Um zu 
zeigen, dass die aus der Milz der Empfängertiere sortierten und auf Objektträger gebrachten Zellen auch GFP positiv sind, wurden diese fluoreszenzmikroskopisch untersucht und zeigten die erwartete grüne Fluoreszenz. Demnach kann davon ausgegangen werden, dass nach lentiviraler Transduktion mit dem BDNF Virus mehr BDNF exprimiert wird als in unbehandelten T-Zellen und dass diese BDNF-Überexpression auch noch längere Zeit in vivo anhält.

A
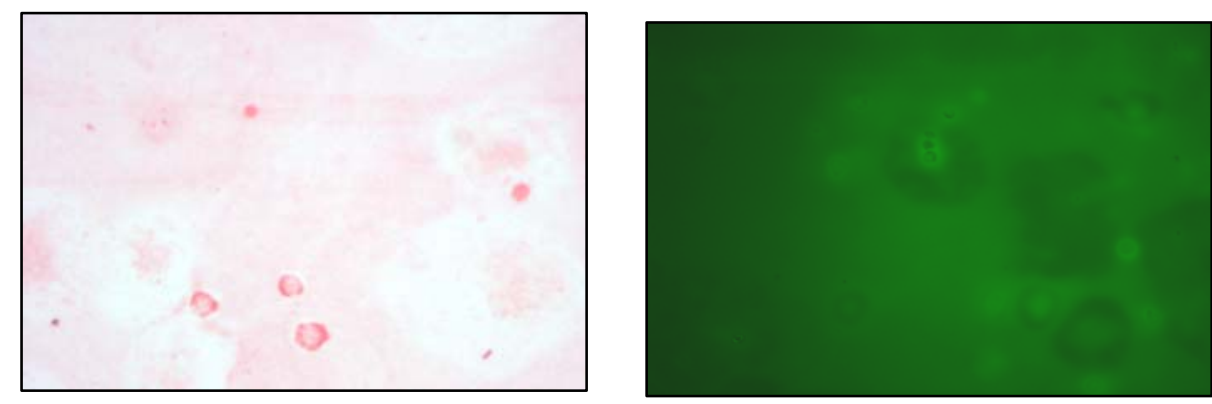

B
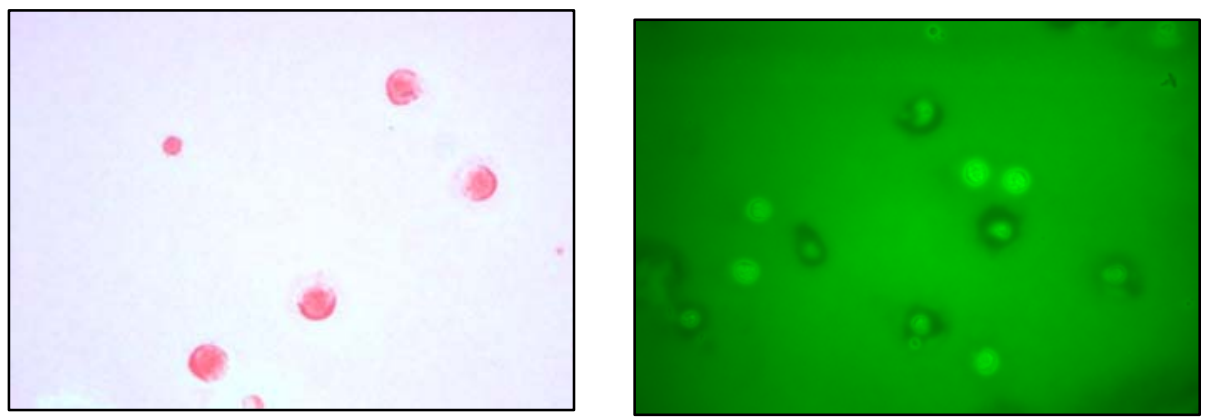

Abb. 4.13: BDNF Cytospins unbehandelter und lentiviral transduzierter T-Zellen. Immunhistochemische Färbung von T-Zell Cytospins mit BDNF, sowie fluoreszenzmikroskopische Analysen der GFP Expression von A. unbehandelten T-Zellen einer C57BL/6 Maus und B. mit dem BDNF Lentivirus transfizierten GFP positive T-Zellen nach 22 Tagen der i.v. Applikation in C57BL/6 Mäusen. Die Aufnahmen wurden mit einem 40x Objektiv angefertigt.

\subsubsection{Testen des codierenden BDNF Proteins auf Bioaktivität}

Die vorangegangen Experimente zeigten zwar, dass das murine BDNF Gen korrekt einkloniert und auch, dass das BDNF Protein exprimiert wurde. Jedoch bestätigte dies nicht, dass das BDNF Protein auch tatsächlich bioaktiv war. Um das zu überprüfen wurde ein BDNF Bioassay mit den Überständen des BDNF Virus und mit Hilfe von Prof. Stefan Wiese (Universität Bochum) durchgeführt. Dabei wurde von der Eigenschaft der murinen dorsalen 
Wurzelganglien Gebrauch gemacht, dass diese ohne das BDNF Protein nicht in der Lage sind zu überleben. Falls nun bioaktives BDNF in den Virusüberständen vorhanden sein sollte, so sollten die Ganglien, denen der Überstand zugegeben wurde, überleben. Das Ergebnis zeigte auf signifikante Art und Weise $(* * p<0,01)$, dass nach Zugabe einer 1:1000 Verdünnung des BDNF-Virusüberstandes circa $9 \%$ der Ausgangszellen überlebt haben (Abb. 4.14). Zudem zeigte der ELISA, indem der Gehalt des BDNF Proteins in diesen Überständen getestet bei einer Verdünnung von 1:1000 eine Konzentration von $300 \mathrm{pg} / \mathrm{ml}$. Wenn man nun die Überlebensrate der getesteten Ganglien mit denen der Kontrolle vergleicht, so sollte die BDNF Proteinkonzentration der getesteten Probe zwischen 0,1-1 ng/ml sein, was auch dem im ELISA gemessenen Wert entspricht. In der 1:10.000 Verdünnung des Virusüberstandes hingegen scheint die BDNF Konzentration so stark herunterverdünnt zu sein, dass es zum Überleben der Ganglien nicht mehr ausgereicht hat. Als Kontrolle wurde der Überstand des GFP Virus mit der gleichen Verdünnung (1:1000) in den Überlebensassay eingesetzt und erzielte nur eine sehr geringe Überlebensrate vergleichbar mit der unbehandelten Kontrolle. Dadurch konnten unspezifische Effekte der Virusüberstände ausgeschlossen werden, die zum Überleben der Ganglien geführt haben könnten.

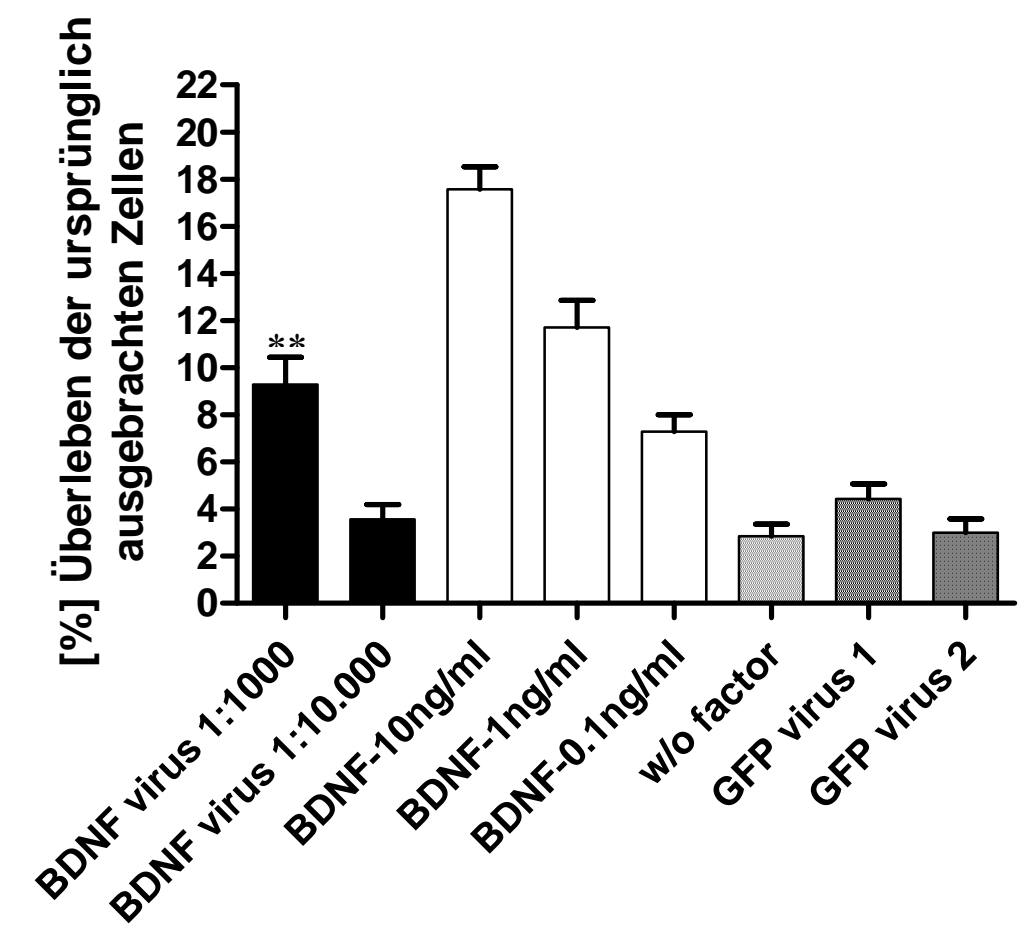


Abb. 4.14: BDNF Bioaktivitätstest mittels Überlebensassay mit murinen dorsalen Wurzelganglien. Überlebensrate der Ganglien nach Applikation von unterschiedlichen Verdünnungen der BDNF bzw. GFP Virusüberstände, sowie verschiedene Konzentrationen des BDNF Proteins (dienen als Standard) und eine unbehandelte Probe. $\mathrm{n}=7$. Die Fehlerbalken repräsentieren die Standardabweichung. $(* * \mathrm{p}<0,01)$.

\subsubsection{Testen der Überlebensrate i.v. injizierter T-Zellen in vivo}

Nach erfolgreicher Generierung der BDNF-überexprimierenden T-Zellen, sollte das Überleben dieser T-Zellen nach i.v. Injektion in vivo untersucht werden. Dafür wurden TZellen aus einer GFP transgenen Maus isoliert. Der Einsatz von GFP positiven Zellen sollte zur besseren Detektion in einer C57BL/6 Wildtyp Maus dienen. Ein Teil dieser isolierten Zellen wurde wieder unbehandelt in C57BL/6 Wildtyp Mäuse i.v. injiziert, während der andere Teil mit dem BDNF Virus infiziert wurde. Diese beiden Bedingungen sollten dabei helfen, festzustellen, ob die Virusinfektion einen Einfluss auf das Überleben der injizierten TZellen hat und ob die Überlebensdauer injizierter Zellen lange genug ist, um spätere therapeutische Behandlungen durchführen zu können. Pro Tier wurden je 10 x $10^{6}$ Zellen in $200 \mu 1$ PBS aufgenommen und in C57B1/6 Empfängermäuse i.v. in die Schwanzvene injiziert. Die Mäuse wurden ohne weitere Behandlung 14 bzw. 21 Tage im Versuch gehalten bis Ihnen zur Auswertung die Milzen entnommen wurden. Nach den Einzelzellsuspensionen wurden die Zellen ohne weitere Färbung im Durchflusszytometer nach GFP positiven Zellen untersucht. Die Auswertung ergab, dass nach 14 aber auch nach 21 Tagen noch GFP positive Zellen detektierbar waren, und dass die Virusinfektion keinen Nachteil auf das Überleben der T-Zellen ausübt (Abb. 4.15). Um die erzielten Daten $\mathrm{zu}$ stützen wurde dieser Ansatz wiederholt und zeigte vergleichbare Ergebnisse, die im Folgenden zusammengefasst sind. Von den injizierten $10 \times 10^{6}$ T-Zellen konnten nach 14 Tagen noch im Fall der unbehandelten T-Zellen $1,8 \times 10^{5}( \pm 1,8)$ GFP positive Zellen und im Fall der BDNF virusinfizierten TZellen noch 2,6 x $10^{5}( \pm 1,1)$ GFP positive Zellen in der Milz detektiert werden. Nach 21 Tagen waren in den Milzen der Tiere, denen die unbehandelten T-Zellen gespritzt wurden noch 3,3 x $10^{5}( \pm 1,0)$ GFP positive Zellen und in den Milzen der mit den virusinfizierten TZellen behandelter Tiere noch 2,3 x 10 $( \pm 0,9)$ GFP positive Zellen detektierbar.

Aus diesem Versuchsansatz lässt sich zusammenfassen, dass injizierte T-Zellen mindestens 21 Tage in vivo überleben und in der Milz nachweisbar sind. Dies ist ein ausreichender Zeitraum für die nachfolgenden Therapieversuche durch die i.v. Injektion der transduzierten 
T-Zellen. Zusätzlich war zu erkennen, dass die Virusinfektion keinen negativen Einfluss auf das Überleben der injizierten T-Zellen darstellte und somit keine weiteren Vorkehrungen für das vermehrte Überleben der T-Zellen getroffen werden mussten.

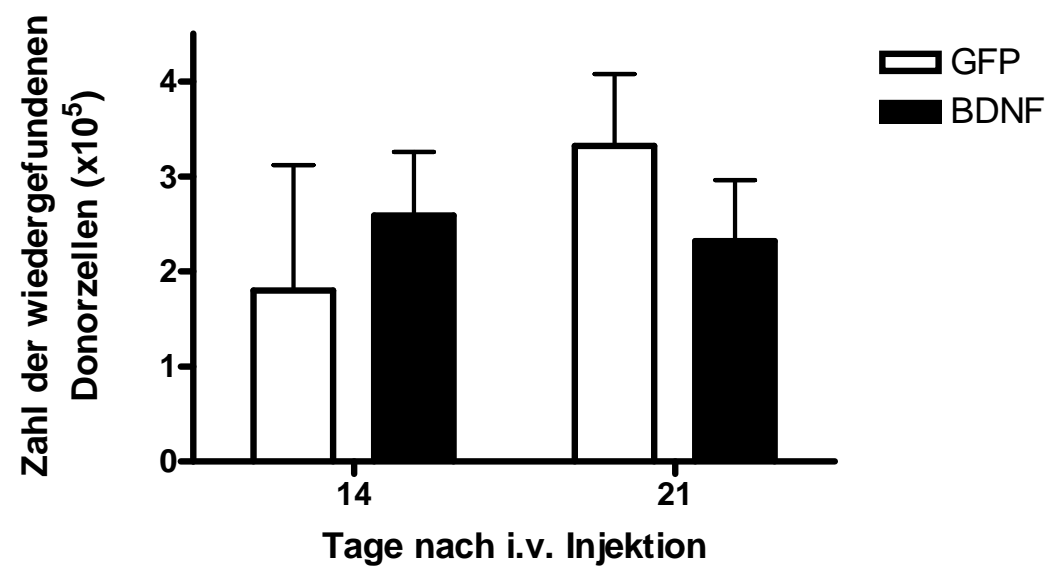

Abb. 4.15: Detektion der GFP positiven T-Zellen in der Peripherie nach i.v. Injektion in C57BL/6 Mäusen. GFP positive T-Zellen einer GFP transgenen Maus wurden entweder unbehandelt (weißer Balken) bzw. nach Infektion mit dem BDNF Virus (schwarzer Balken) in C57BL/6 Mäuse i.v. injiziert und nach 14 bzw. 21 Tagen die Milzen mittels FACS nach GFP positiven Zellen detektiert. $\mathrm{n}=2$, die Fehlerbalken repräsentieren die Standardabweichung.

\subsubsection{Prüfung des Eintritts injizierter T-Zellen in das ZNS}

Im vorangegangenen Abschnitt wurde zwar gezeigt, dass die injizierten T-Zellen in einer gesunden $\mathrm{C} 57 \mathrm{Bl} / 6$ Maus mindestens 3 Wochen überleben, dennoch ist damit nicht bewiesen, dass die Zellen auch die Blut-Hirn-Schranke passieren und in das entzündete Gewebe des ZNS nach EAE Induktion gelangen, um dort einen Effekt auszuüben. Um zu untersuchen, ob T-Zellen tatsächlich das ZNS erreichen, wurden zunächst MOG-spezifische T-Zellen aus den Milzen der 2D2 T-Zellrezeptor transgenen Mäuse, die auch noch zusätzlich ein Transgen für GFP ubiquitär exprimieren, isoliert. Der Einsatz von MOG-spezifischen T-Zellen war von besonderer Bedeutung, da MOG das Antigen ist, welches in dem EAE-Modell dieser Arbeit angegriffen wird und dadurch die Wahrscheinlichkeit erhöht, dass die injizierten Zellen auch tatsächlich die Läsionen erreichen. Um dies zu überprüfen wurde in C57Bl/6 Mäusen eine MOG-EAE mit $50 \mu \mathrm{g} \mathrm{MOG}_{35-55}$ und $50 \mu \mathrm{g}$ CFA induziert und an Tag 2 und Tag 7 nach Immunisierung wurden MOG-spezifische T-Zellen den EAE induzierten Wildtyp Mäusen i.v. 
injiziert. Die unterschiedlichen Zeitpunkte wurden bewusst gewählt, um den Zeitpunkt der optimalen Injektionszeit einzugrenzen. 15 Tage nach Immunisierung wurden die Tiere mit Paraformaldehyd perfundiert und histologisch bzw. mit dem Durchflusszytometer nach GFP positiven Zellen hin untersucht. Die Auswertungen der GFP Immunhistochemie zeigten, dass nur im Fall der an Tag 7 injizierten MOG-spezifischen T-Zellen eine positive Färbung vorzufinden war (Abb. 4.16 A). Auch im Durchflusszytometer konnte nach Lymphozytenisolation aus dem Rückenmark und nach zusätzlicher CD4 Färbung (spezifisch für T-Zellen) eine deutliche CD4/GFP doppelt positive Zellpopulation detektiert werden (Abb. 4.16 B). Die Mäuse, denen an Tag 2 die MOG-spezifischen T-Zellen injiziert wurden zeigten in der Immunhistologie keinerlei GFP positive Färbung und im Durchflusszytometer konnten lediglich 0,1 \% GFP positive Zellen in der aus dem Rückenmark gewonnenen Lymphozytenpopulation wiedergefunden werden (Daten nicht abgebildet).

A
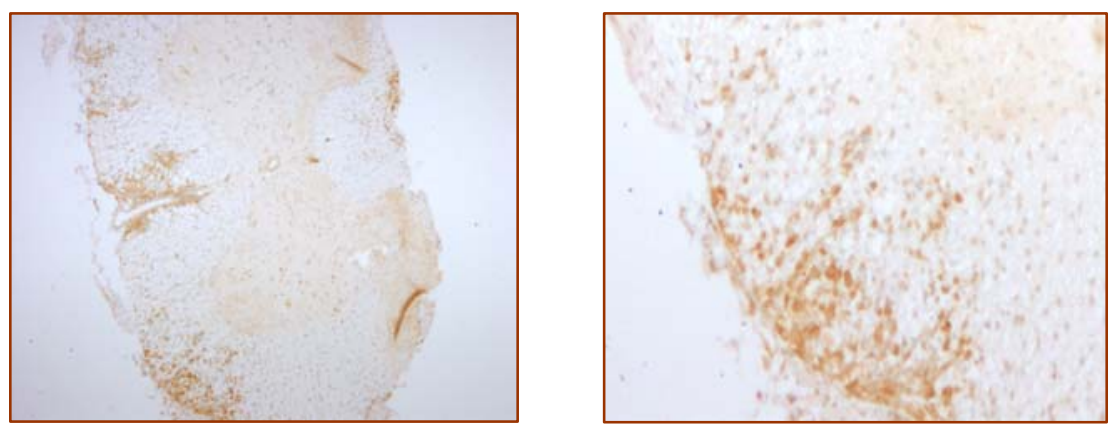

B

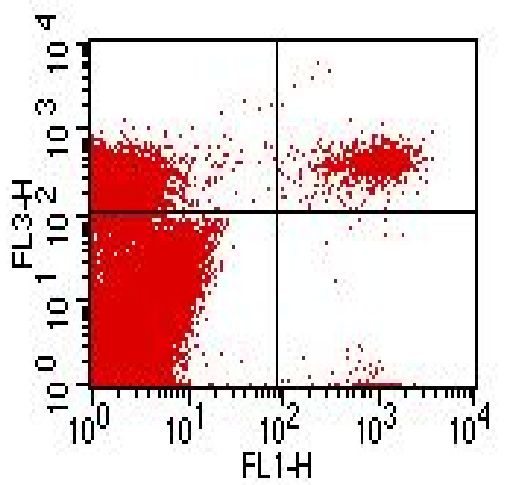

Abb. 4.16: Nachweis der GFP positiven T-Zellen im ZNS nach i.v. Injektion in C57BL/6 Mäusen. In C57B1/6 Tiere wurde eine MOG-EAE induziert und an Tag 7 MOG-spezifische und GFP positive T-Zellen i.v. injiziert. Die Aufarbeitung der Tiere erfolgte an Tag 15 nach Immunisierung. A. Immunhistochemischer Nachweis der GFP positiven T-Zellen in Rückenmarksschnitten. Die Aufnahmen wurden mit einem 20x bzw. 40x Objektiv angefertigt. B. FACS Auswertung der Lymphozyten isoliert aus dem Rückenmark und untersucht nach GFP Fluoreszenz (FL1-H) und CD4 positiven Zellen (FL3-H) nach zusätzlicher Färbung. 
Um zu untersuchen, ob auch GFP positive T-Zellen allein aus einer GFP transgenen Maus ohne einen MOG transgenen T-Zellrezeptor das ZNS nach Immunisierung erreichen würden, wurden $\mathrm{C} 57 \mathrm{Bl} / 6$ Tiere mit $50 \mu \mathrm{g} \mathrm{MOG}_{35-55}$ und $50 \mu \mathrm{g}$ CFA immunisiert und da sich die i.v. Injektion an Tag 7 als effektivste Injektionszeit darstellte, wurden den Empfängertieren je 10 Millionen GFP positive T-Zellen 7 Tage nach Immunisierung i.v injiziert. Die Tiere wurden an Tag 19 perfundiert und immunhistochemische Untersuchungen zeigten keinerlei positive GFP Färbung im Rückenmark. Dieses Ergebnis unterstützte die Bedeutung des Einsatzes der MOG-spezifischen GFP positiven T-Zellen in diesem Versuchsvorhaben.

Um auszuschließen, dass MOG-spezifische T-Zellen aus der T-Zellrezeptor transgenen Maus nach Transfer und ohne Immunisierung mit MOG eine EAE auslösen, was einen negativen Effekt auf den Versuchsaufbau hätte, wurden ca. 10 Millionen T-Zellen aus diesen transgenen Tieren in C57B1/6 Empfängertiere i.v. injiziert. Die Tiere wurden ohne weitere Behandlung 21 Tage im Versuch gehalten. Unter normalen Bedingungen treten die ersten Symptome einer EAE nach aktiver Immunisierung mit MOG nach ca. 8-10 Tagen auf. In diesem Ansatz wurden jedoch auch nach 21 Tagen nach i.v. Injektion keinerlei Anzeichen einer EAE beobachtet. Auch immunhistochemische Untersuchungen zeigten keine Infiltration von TZellen und Makrophagen im ZNS.

Dies lässt schlussfolgern, dass MOG-spezifische T-Zellen aus den T-Zellrezeptor transgenen Mäusen unter diesen Bedingungen selbst nicht in der Lage sind eine EAE auszulösen.

\subsubsection{Einfluss der BDNF überexprimierenden T-Zellen auf die MOG $_{35-55}-\mathrm{EAE}$}

Nach Abschluss der Voruntersuchungen, die zeigten, dass nach lentiviraler Transduktion MOG-spezifische T-Zellen aus den T-Zellrezeptor transgenen Mäusen vermehrt bioaktives BDNF bzw. GFP exprimieren und dass diese mindestens 3 Wochen in der Milz der Empfängertiere und ebenso nach EAE Induktion im ZNS nachzuweisen sind konnten die eigentlichen funktionellen Untersuchungen starten. Dafür wurde in zwei voneinander unabhängigen Ansätzen in jeweils $18 \mathrm{C} 57 \mathrm{Bl} / 6$ Tieren eine $\mathrm{MOG}_{35-55}$-EAE mit $50 \mu \mathrm{g}$ $\mathrm{MOG}_{35-55}$ und $50 \mu \mathrm{g}$ CFA ausgelöst. Wie bereits festzustellen war stellte die Injektion an Tag 7 den effektivsten Zeitpunkt dar. Dafür wurden T-Zellen aus den Milzen von MOGspezifischen T-Zellrezeptor-transgenen GFP positiven C57Bl/6 Tieren isoliert. Je 60 Millionen T-Zellen wurden entweder mit dem BDNF oder dem GFP Virus transduziert, daraus ergab sich, dass jeweils 6 Tiere mit je 10 Millionen BDNF bzw. GFP Virus 
transduzierten MOG-spezifischen GFP positiven T-Zellen behandelt wurden. Die mit dem GFP Virus infizierten T-Zellen dienten als Kontrollgruppe, die einen eventuellen Einfluss der lentiviralen Transduktion selbst auf den Verlauf der EAE aufzeigen sollte. Eine dritte Kontrollgruppe bestehend aus weiteren 6 C57Bl/6 Tieren wurde lediglich mit PBS behandelt. Die Tiere wurden über einen Zeitraum von 22 Tagen nach Immunisierung täglich beobachtet und die Schwere der Erkrankung bewertet. Der Krankheitsbeginn fand in allen 3 Gruppen an Tag 12 statt und verlief in den beiden Kontrollgruppen (PBS und GFP Virus behandelt) schwerer als in der mit den BDNF transduzierten T-Zellen behandelter Mäuse (Abb. 4.17). Der klinische EAE-Verlauf der beiden Kontrollgruppen verlief sehr ähnlich. Der Krankheitsverlauf der PBS behandelten Gruppe fand seinen Höhepunkt an Tag 16 und ging dann in die chronische Phase über, während die Gruppe, die mit den GFP transduzierten TZellen behandelt wurde, seinen klinischen Höhepunkt an Tag 18 bei einem Score von ungefähr 6 fand und auch in die chronische Phase überging. Der klinische EAE-Verlauf der BDNF behandelten Tiere hingegen verlief sehr viel milder und über die Dauer von 6 Tagen um bis zu 2 Scorepunkte vermindert. Der größte signifikante Unterschied $(* p<0,05)$ im klinischen Verlauf zwischen den Kontrollgruppen und der BDNF behandelten Tiere konnte an Tag 13 und 14 beobachtet werden. Dieser Effekt legte sich nach ca. 6 Tagen nach denen sich die EAE-Kurve der BDNF behandelten Tiere langsam dem Verlauf der Kontrollgruppen annäherte. Im Fall der PBS behandelten Tiere erreichte unsere BDNF behandelten Tiere auch tatsächlich dessen Grad an Erkrankung, während zur eigentlichen Kontrollgruppe, nämlich der mit den GFP behandelten T-Zellen, an Tag 22 immer noch ein Unterschied von einem Scorepunkt existierte. In den histologischen Untersuchungen wurden auch nur diese beiden Gruppen miteinander verglichen.

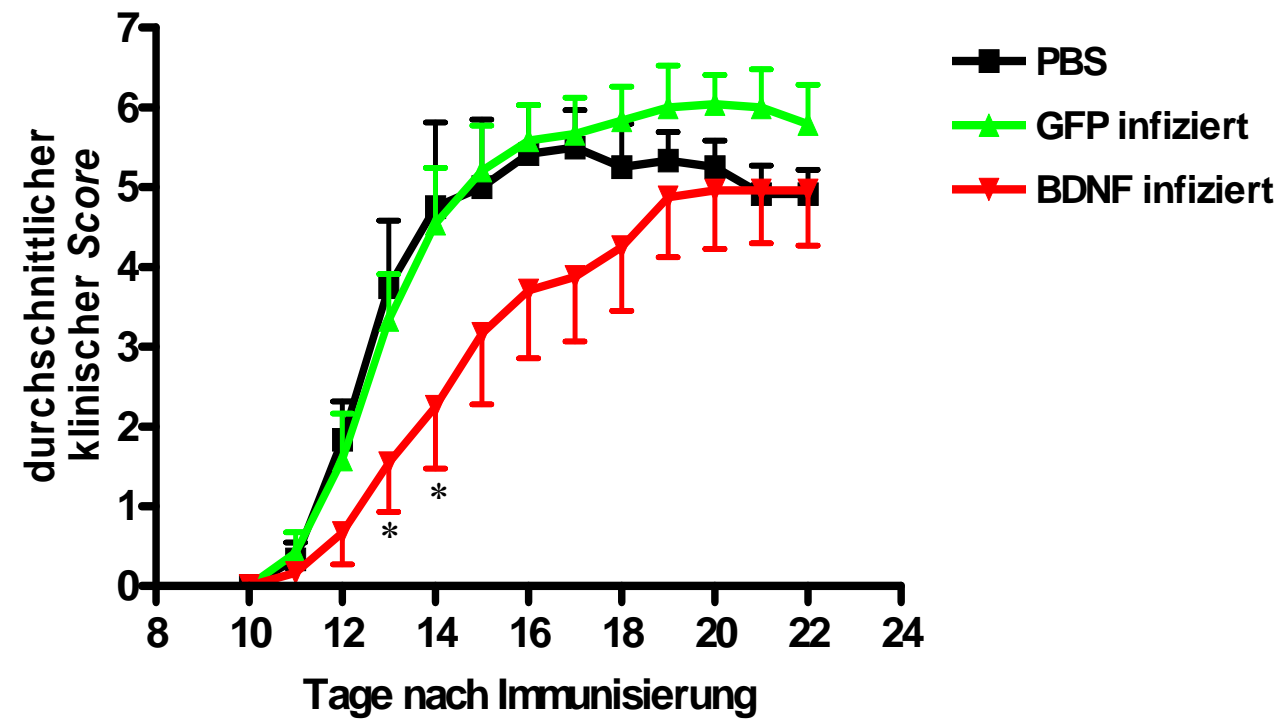


Abb. 4.17: EAE Krankheitsverlauf i.v. injizierter und mit $\mathrm{MOG}_{35-55}$ immunisierter $\mathrm{C57BI} / 6$ Mäuse. Tiere wurden an Tag 7 nach Immunisierung mit BDNF Virus transduzierten T-Zellen (rote Linie), GFP Virus transduzierten T-Zellen (grüne Linie) bzw. PBS (schwarze Linie) i.v. injiziert. Der Erkrankungszustand wurde täglich überprüft und der Versuch wurde an Tag 22 nach Immunisierung beendet. $\mathrm{n}=12$ aus zwei unabhängigen Experimenten. $\left({ }^{*} \mathrm{p}<0,05\right)$.

In den ersten immunhistochemischen Untersuchungen wurden die Rückenmarksschnitte der mit GFP und BDNF behandelten Tiere standardmäßig nach T-Zell (CD3+) und Makrophagen (Mac-3+) Infiltrationen untersucht. In beiden Fällen zeigten beide Gruppen vergleichbare Zahlen an infiltrierten T-Zellen und Makrophagen (Abb. 4.18). Die Zahl der T-Zellinfiltrate bei den GFP behandelten Tieren lag bei $397( \pm 48,9)$ Zellen $/ \mathrm{mm}^{2}$, während sie bei den BDNF behandelten Tieren bei $386( \pm 39,0)$ Zellen $/ \mathrm{mm}^{2}$ lag. Im Fall der Makrophageninfiltrate kamen Zellzahlen in Höhe von $519( \pm 79,1)$ Zellen/mm $\mathrm{mm}^{2}$ bei den GFP behandelten Tieren und $540( \pm 62,9)$ Zellen $/ \mathrm{mm}^{2}$ bei den BDNF behandelten Tieren zustande.

A

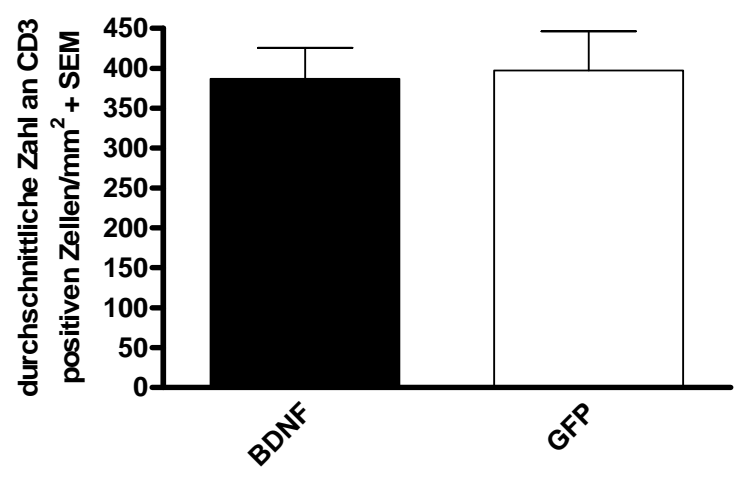

B

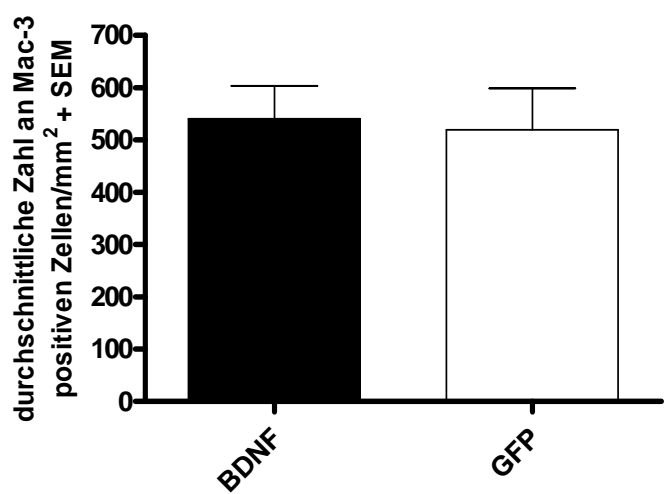

Abb. 4.18: Immunhistochemische Auswertung von Immunzellinfiltraten in C57Bl/6 Mäusen nach i.v. Injektion. C57Bl/6 Tiere wurden an Tag 7 nach Immunisierung mit BDNF bzw. GFP Virus transduzierten T-Zellen i.v. behandelt. Die Tiere wurden an Tag 22 perfundiert und die Rückenmarkschnitte nach CD3 (T-Zellspezifisch) bzw. Mac-3 (Makrophagenspezifisch) gefärbt. n=6. Fehlerbalken repräsentieren den Standardfehler des Mittelwertes.

Da dem BDNF Protein axonprotektive Eigenschaften zugesprochen werden, ist die in diesem Zusammenhang interessantere Färbung, die Versilberung nach Bielschowsky gewesen, die 
spezifisch Axone anfärbt und durch die Axondichten den Axonerhalt bestimmen kann. Die beiden Vergleichsgruppen zeigten in diesen Untersuchungen wesentliche Unterschiede untereinander. In der Auswertung wurden axonale Dichten in vier verschiedenen Regionen der Rückenmarksschnitte miteinander verglichen. Diese waren die Läsionen, die Periläsionen, Normal erscheinende weiße Substanz und graue Substanz. In den Läsionen und Periläsionen sollten die meisten Unterschiede zu erkennen sein, da dort die Immunreaktion abläuft und die infiltrierenden Zellen hauptsächlich dort vorgefunden werden. Auch die i.v. injizierten Virus transduzierten Zellen wandern $\mathrm{zu}$ den Läsionen und könnten dort ihre potenzielle neuroprotektive Funktion ausüben. Die Auswertung zeigte, dass die axonalen Dichten beider Gruppen in der grauen Substanz und der normal erscheinenden weißen Substanz vergleichbare Werte aufzeigten, während es beim Vergleich dieser beiden Gruppen in den Läsionen und Periläsionen doch signifikante Unterschiede gab (Abb. 4.19). Diese Unterschiede zeigten sich insbesondere in einer ca. $70 \%$-igen signifikanten Reduktion $\left({ }^{*} \mathrm{p}<0,01\right)$ der axonalen Dichte in den Läsionen der GFP behandelten Tiere im Gegensatz zu den BDNF behandelten Tieren. Auch die Axone in den Periläsionen waren in den BDNF behandelten Tieren signifikant $\left({ }^{*} p<0,05\right)$ stärker erhalten als in der Kontrollgruppe. Die Auswertung der Färbung für APP unterstütze die vorangegangen Daten zum axonalen Schaden und deckte eine um 36 \% geringere Akkumulation von APP positiven Elementen in den BDNF behandelten Tieren auf, was ebenso auf einen geringeren axonalen Schaden hindeutet. Der Unterschied in der APP Akkumulation verglichen mit der Kontrollgruppe war zwar nicht signifikant, was aber darauf zurückzuführen ist, dass zu dem Zeitpunkt der Analyse womöglich die Zahl der APP positiven Elemente bereits insgesamt verringert war.

A

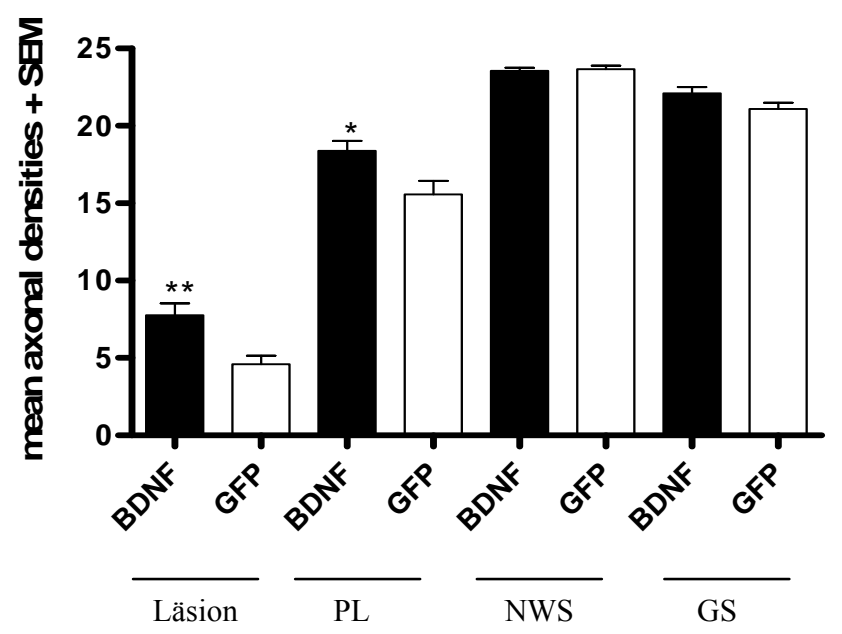

B

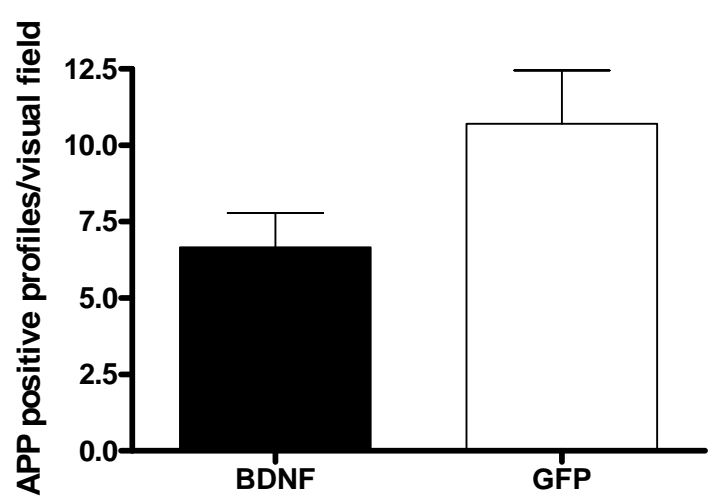


Abb. 4.19: Immunhistochemische Auswertung von axonalen Dichten und APP Akkumulationen in C57BI/6 Mäusen nach i.v. Injektion. C57B1/6 Tiere wurden an Tag 7 nach Immunisierung mit BDNF bzw. GFP Virus transduzierten T-Zellen i.v. behandelt. Die Tiere wurden an Tag 22 perfundiert und die Rückenmarkschnitte A. nach Bielschowsky versilbert ( $\mathrm{PL}=$ Periläsion, NWS=normal erscheinende weiße Substanz, GS=graue Substanz) $\left({ }^{*} \mathrm{p}<0,01 ;{ }^{*} \mathrm{p}<0,05\right)$ bzw. B. nach APP gefärbt. $\mathrm{n}=6$. Fehlerbalken repräsentieren den Standardfehler des Mittelwertes.

\subsection{6 iNOS Expression}

Ein Hauptakteur, der für die Entstehung von axonalem Schaden mitverantwortlich ist, ist das von Makrophagen und Mikroglia produzierte Stickstoffmonoxid (NO). Es wird nach Aktivierung dieser beiden Zelltypen über die induzierbare NO Syntethase (iNOS) synthetisiert und wirkt zytotoxisch. Daher kann die Untersuchung der iNOS Expression einen weiteren Hinweis für den axonalen Schaden und bei einem differenziellen Ergebnis zwischen den Kontrollgruppen eventuell auch für die neuroprotektive Funktion des BDNF vermittelt durch BDNF überexprimierende i.v. injizierte T-Zellen sprechen. Für das Auszählen der iNOS positiven Zellen wurde eine semi-quantitative Methode bevorzugt, weil die iNOS Expression am Höhepunkt der Erkrankung am höchsten ist und die Aktivität in der chronischen Phase abnimmt. Da die Versuchstiere bereits in der chronischen Phase waren, als sie aufgearbeitet wurden, konnte durch die semi-quantitative Analyse ein aussagekräftigeres Ergebnis erzielt werden. Die immunhistochemische Auswertung der Rückenmarksschnitte beider Vergleichsgruppen zeigte auf signifikante $\left({ }^{*} p<0,05\right)$ Art und Weise, dass die iNOS Expression in den BDNF behandelten Tieren im Vergleich zu der GFP Kontrollgruppe um die Hälfte reduziert war (Abb. 4.20). Die verminderte iNOS Expression in BDNF behandelten Tieren unterstützt die Daten zum axonalen Schaden und könnte ein Erklärungsansatz für den stärkeren Axonerhalt in BDNF behandelten Tieren sein.

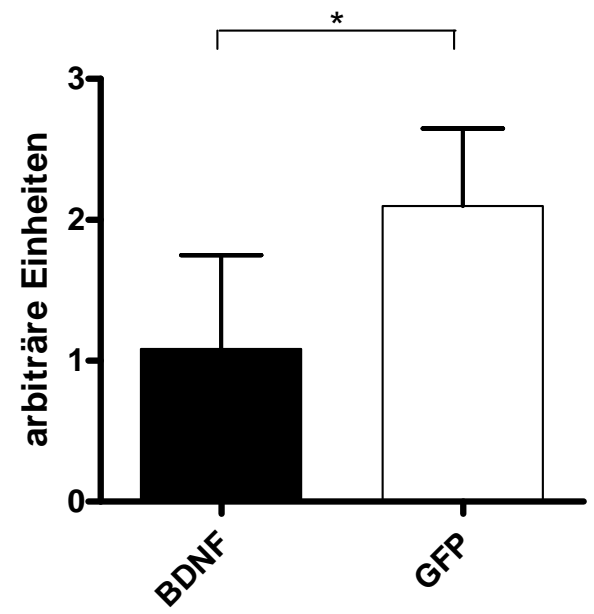


Abb. 4.20: Immunhistochemische Auswertung der iNOS Expression in C57BI/6 Mäusen nach i.v. Injektion. C57B1/6 Tiere wurden an Tag 7 nach Immunisierung mit BDNF bzw. GFP Virus transduzierten T-Zellen i.v. behandelt. Die Tiere wurden an Tag 22 perfundiert und die Rückenmarkschnitte nach iNOS gefärbt $(* \mathrm{p}<0,05)$. Definition arbiträrer Einheiten: $1=$ geringe iNOS Expression, $2=$ mittlere iNOS Expression, $3=$ hohe iNOS Expression. $n=6$. Fehlerbalken repräsentiert die Standardabweichung.

\subsection{7 pTrkB Expression}

Da die BDNF Überexpression in den Läsionen aus technischen Gründen nicht direkt nachgewiesen werden konnte, so wurde versucht den Nachweis der Überexpression und die Funktionalität des Systems durch den BDNF spezifischen Rezeptor TrkB zu erbringen. Dieser Rezeptor wird nach Bindung an seinen Liganden, dem BDNF Protein, phosphoryliert und kann so mit Hilfe eines phosphoTrkB (pTrkB) spezifischen Antikörpers detektiert werden. Für diese Untersuchungen wurden mit den Rückenmarksschnitten der mit BDNF und GFP transduzierten T-Zellen behandelter Tiere eine Fluoreszenzdoppelfärbung mit dem pTrkB und dem T-Zell (CD3) bzw. Makrophagen (Mac-3) spezifischen Antikörper durchgeführt. Dadurch sollte neben der pTrkB Expression auch eine mögliche Colokalisation des BDNF spezifischen Rezeptors mit den infiltrierenden Immunzellen detektiert werden. Was zunächst besonders auffiel, war, dass die pTrkB Expression nur auf die Läsionen begrenzt war, für die die Infiltration von T-Zellen und Makrophagen charakteristisch ist und mit deren Hilfe auch detektiert werden kann (Abb. 4.21). Des Weiteren war deutlich zu erkennen, dass die pTrkB Expression in den BDNF behandelten Tieren wesentlich stärker war als in der GFP Kontrollgruppe. In der Doppelfärbung mit T-Zell und Makrophagen spezifischen Antikörpern konnte jedoch kaum eine Colokalisation von pTrkB und den infiltrierenden T-Zellen und Makrophagen detektiert werden. 
A

pTrkB

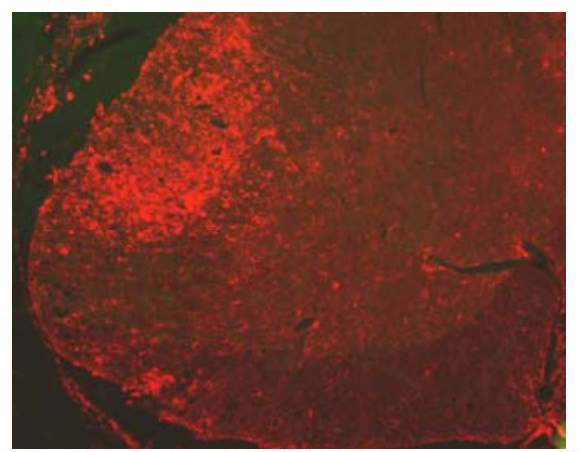

B
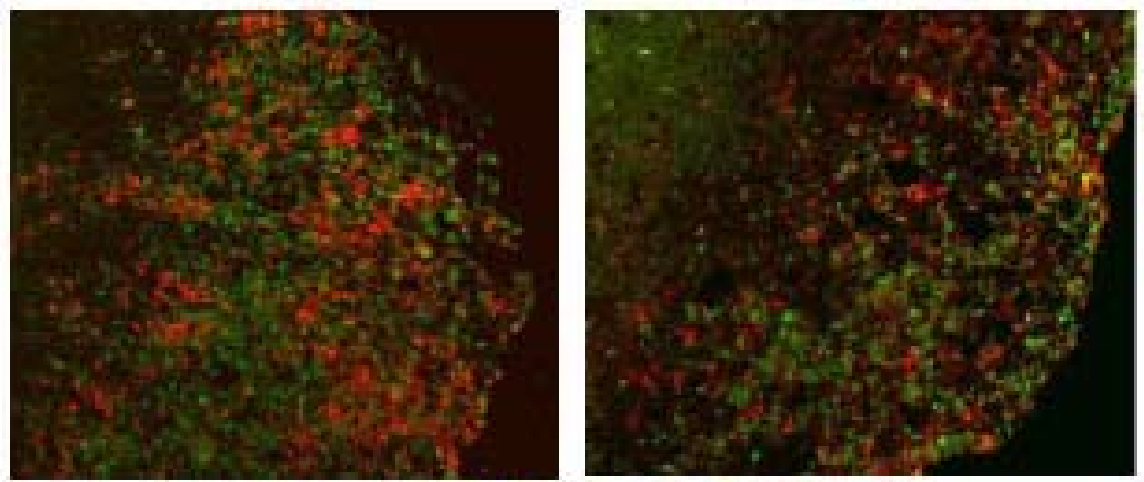

C

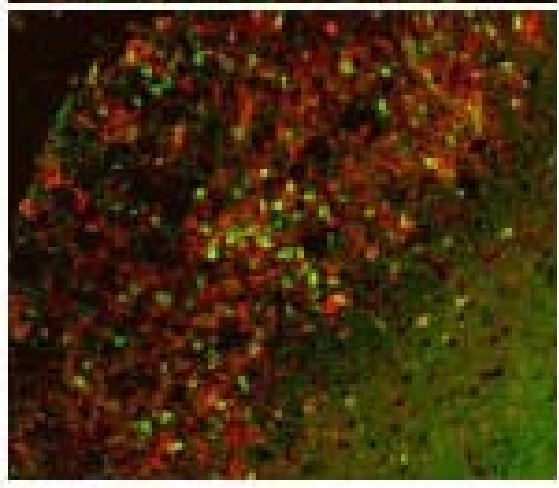

BDNF

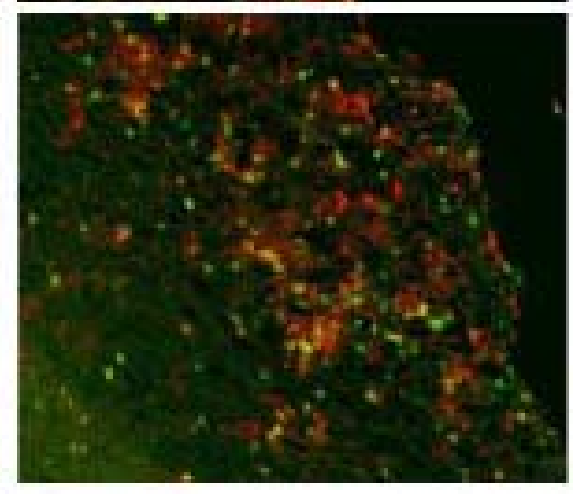

GFP

Abb. 4.21: Funktionelle Relevanz der BDNF Überexpression in situ anhand Fluoreszenzmikroskopischer Analysen der pTrkB Färbung. C57B1/6 Tiere wurden an Tag 7 nach Immunisierung mit BDNF bzw. GFP Virus transduzierten T-Zellen i.v. behandelt. Die Tiere wurden an Tag 22 perfundiert und die Rückenmarkschnitte nach pTrkB (rote Fluoreszenz) gefärbt. A. pTrkB Färbung in der Übersicht. Die Aufnahme wurde mit einem 20x Objektiv angefertigt. B. pTrkB Doppelfärbung mit Mac-3 (grüne Fluoreszenz, spezifisch für Makrophagen und aktivierte Mikroglia. C. pTrkB Doppelfärbung mit CD3 (grüne Fluoreszenz, spezifisch für T-Zellen). Die Aufnahmen in B und $\mathrm{C}$ wurden mit einem 40x Objektiv angefertigt. 


\subsubsection{Aktivierungsstatus i.v. injizierter T-Zellen in vivo}

Der Aktivierungsstatus i.v. injizierter T-Zellen wurde ermittelt, um festzustellen inwieweit die applizierten T-Zellen in vivo aktiviert werden. Es ging vor allem darum zu sehen, ob diese Zellen soweit aktiviert werden, dass sie eventuell auch am Entzündungsprozess beteiligt sein könnten, oder ob sie wie vermutet lediglich als sog. Bystander Zellen mit den entzündlichen Komponenten in das ZNS einströmen.

Dafür wurden MOG-spezifische und GFP positive T-Zellen aus transgenen 2D2 Mäusen, die zusätzlich noch ein Transgen für GFP besitzen, isoliert. Pro Empfängertier wurden je 10 Millionen dieser naiven T-Zellen mit dem BDNF bzw. GFP Virus infiziert und in C57BL/6 Tiere, in denen zuvor eine EAE ausgelöst wurde, i.v. injiziert. Die Injektion erfolgt wie bereits zuvor an Tag 7 nach Immunisierung. Die Tiere wurden am Höhepunkt ihrer Erkrankung aufgearbeitet. Dafür wurde das Rückenmark und die Milz der Tiere entnommen. Mit dem Rückenmark wurde eine Dichtegradientenzentrifugation durchgeführt, um die infiltrierten Lymphozyten zu isolieren. Die Milzen wurden mit Erythrozyten-Lyse-Puffer versetzt, um die Erythrozyten aus dem Zellgemisch zu entfernen. Anschließend wurden die Lymphozyten aus dem Rückenmark und im Vergleich dazu die Milzzellen mit verschiedenen Antikörpern gefärbt, um diese letztlich im Durchflusszytometer zu analysieren. Um die applizierten T-Zellen aus dem Zellgemisch zu identifizieren, wurden diese mit dem TZellspezifischen Antikörper CD4 gefärbt und ergaben mit der GFP Fluoreszenz, die die applizierten T-Zellen durch ihr Transgen konstitutiv exprimieren, die gewünschte Zellpopulation. Des Weiteren wurden die Zellen mit verschiedenen Aktivierungsmarkern, wie CD25, CD44, CD62L und CD69, gefärbt, um den Aktivierungsstatus zu ermitteln. Durch die GFP Fluoreszenz der applizierten Zellen konnte auch eine Unterscheidung zu den endogenen T-Zellen getroffen werden, was einen Vergleich zwischen beiden Populationen ermöglichte. Die Messungen im Durchflusszytometer ergaben, dass in der Milz ca. 14 \% der endogenen TZellen den frühen Aktivierungsmarker CD25 exprimieren, während die Expression bei den applizierten BDNF und GFP Virus infizierten T-Zellen um ein Vierfaches geringer war (Abb. 4.22). Die Expression im Rückenmark hingegen lag bei den BDNF Virus infizierten T-Zellen bei ca. $10 \%$, während fast doppelt so viele endogene T-Zellen CD25 auf ihrer Oberfläche exprimierten. Bei den GFP infizierten T-Zellen lag die Expressionsrate bei $5 \%$ und betrug somit nur ein Drittel der Expression der endogenen T-Zellen. Die Expression des späten CD44 Memory Markers zeigte in den applizierten T-Zellen in der Milz keinen sehr großen Unterschied zu den endogenen T-Zellen und lag ca. bei $20 \%$. Lediglich die GFP infizierten 
T-Zellen zeigten eine nicht signifikante Verringerung der Expression verglichen mit den Kontrollzellen. Im Rückenmark hingegen war die Expression in den applizierten T-Zellen, die mit dem BDNF Virus infiziert wurden, signifikant $(* * * p<0,001)$ um mehr als die Hälfte reduziert und lag nur noch bei $21 \%$. Die GFP infizierten Zellen zeigten zwar auch eine geringere Expression dieses Oberflächenmoleküls, welches aber nicht signifikant war. Die Expression des Aktivierungsmarkers, CD62L, welches auch gleichzeitig ein Adhäsionsmolekül ist, zeigte in allen untersuchten T-Zellpopulation in der Milz eine hohe Expression von ca. 40-60 \%. Lediglich in den applizierten BDNF infizierten T-Zellen konnte eine signifikante Verringerung $(* * p<0,01)$ von ca. $20 \%$ gegenüber den endogenen T-Zellen beobachtet werden. Im Rückenmark ging die Expression des CD62L stark herab und konnte lediglich in ca. $4 \%$ der endogenen T-Zellen detektiert werden d.h. alle T-Zellen waren aktiviert. Die Expression in den applizierten T-Zellen war noch geringer und lag nur noch bei 1-2 \%. Im Fall von CD69, welches ein früher Aktivierungsmarker ist war in der Milz die Expression in den BDNF infizierten T-Zellen fünfmal so hoch wie in den endogenen T-Zellen und betrug somit ca. $26 \%(* * \mathrm{p}<0,01)$, während die Expression in den GFP infizierten TZellen ebenfalls signifikant $\left({ }^{*} p<0,05\right)$ erhöht war und ca. $17 \%$ dieser Zellen CD69 exprimierten. Im Rückenmark war die Expression von CD69 sogar noch stärker erhöht und konnte in ca. $78 \%$ der applizierten T-Zellen detektiert werden $\left({ }^{*} p<0,01 ;{ }^{*} p<0,05\right)$, wobei die Expression in den endogenen T-Zellen signifikant um mehr als die Hälfte verringert war.

Milz

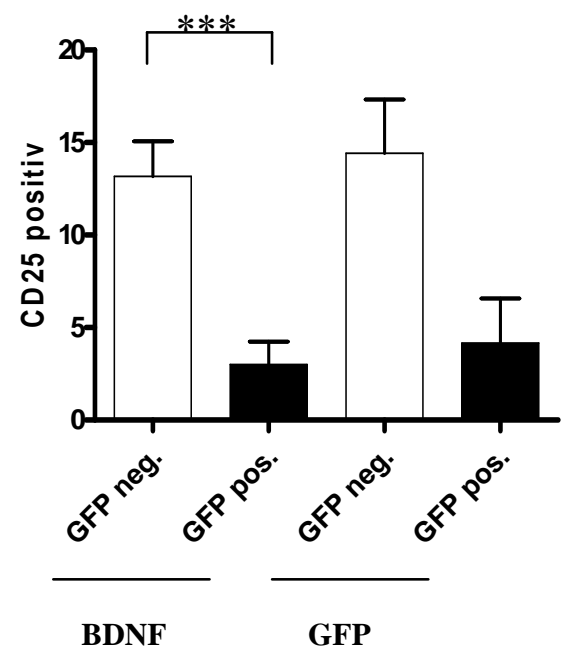

Rückenmark

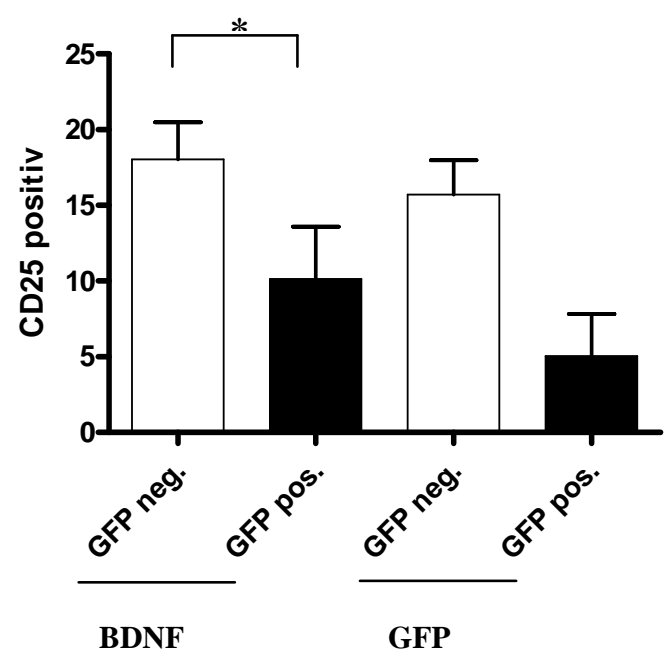


Milz
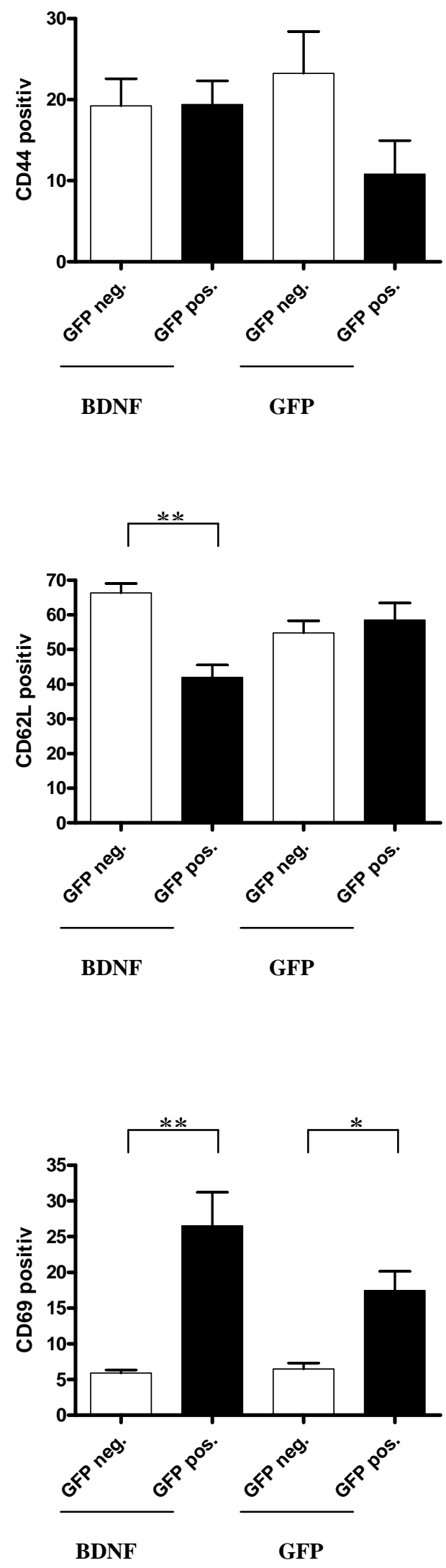

Rückenmark
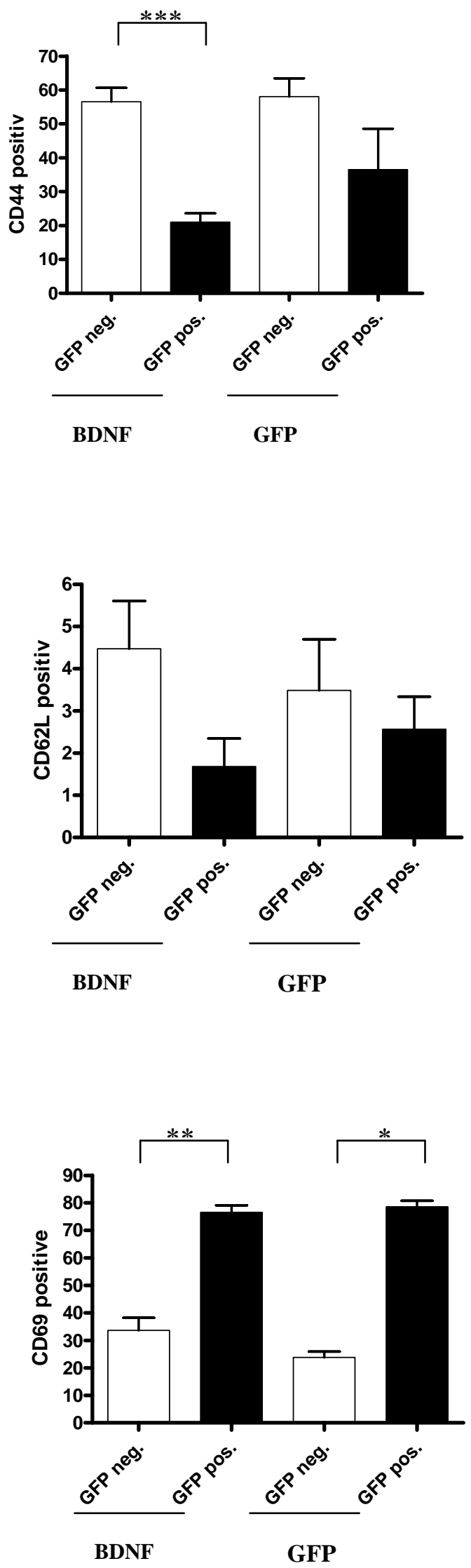
Abb. 4.22.: FACS Analyse der Aktivierungsmarker applizierter BDNF und GFP Virus transduzierter T-Zellen im Vergleich zu endogenen T-Zellen. C57BL/6 Tiere wurden an Tag 7 nach Immunisierung mit BDNF bzw. GFP Virus transduzierten T-Zellen i.v. behandelt. Am Höhepunkt der Erkrankung wurden die Lymphozyten aus dem Rückenmark und der Milz isoliert und mit den Aktivierungsmarkern CD25, CD44, CD62L und CD69 gefärbt und im Durchflusszytometer analysiert. GFP pos. Balken (schwarz) repräsentieren die jeweils applizierten T-Zellen, während die GFP neg. Balken (weiß) die endogenen T-Zellen darstellen. CD25+CD44 n=11, CD62L+CD69 n=6. Der Fehlerbalken repräsentiert die Standardabweichung. (***p<0,001; $\left.{ }^{* *} \mathrm{p}<0,01 ;{ }^{*} \mathrm{p}<0,05\right)$. 


\section{Diskussion}

\subsection{BDNF Expression und Regulation in vitro - Splice-Varianten}

Das BDNF Protein wird durch ein einzelnes Exon codiert, deswegen sind auch keine anderen Isoformen auf Proteinebene bekannt, die auf alternatives Splicing zurückzuführen sind. Auf mRNA-Ebene jedoch wurden bereits mehrere Splice-Varianten in der 5'nichttranslatierten Region in Ratten (Altieri et al., 2004; Bishop et al., 1994; Timmusk et al., 1993) und Menschen (Aoyama et al., 2001; Liu et al., 2005) beschrieben, die auf ein hohes Maß an Regulation auf Promoter bzw. Enhancer Ebene hinweisen.

In einer parallel $\mathrm{zu}$ dieser Arbeit entstandenen Veröffentlichung wurde eine detaillierte Analyse der BDNF Splice-Varianten in der Maus durchgeführt, um die genomische Struktur des BDNF und seine differentielle Regulation besser zu verstehen (Liu et al., 2006). Es wurde gezeigt, dass analog zu Ratte und Mensch, in den verschiedenen Regionen des Gehirns viele Splice-Varianten gefunden wurden, während die Expression der Splice-Varianten in den peripheren Organen beschränkter war (Liu et al., 2006).

In der vorliegenden Arbeit wurde sich auf das Immunsystem fokussiert und ein Vergleich mit dem ZNS angestellt. Es wurde eine detaillierte Analyse der unterschiedlichen mBDNF SpliceVarianten in peripheren lymphatischen Organen, sowie speziellen Immunzellen, und aufgereinigten Zellpopulationen im Vergleich zum Gehirn angefertigt. Die Anwesenheit aller bekannten Splice-Varianten im Gehirn und die eingeschränktere Expression in der Peripherie konnte bestätigt werden. In allen untersuchten peripheren lymphatischen Organen war nur mBDNF 3 mRNA detektierbar. Liu et al. (2006) hingegen konnten in ihrer Arbeit auch die Splice-Varianten mBDNF 4 und 5 in der Milz nachweisen. Zwar wurde in der vorliegenden Arbeit der gleiche Mausstamm benutzt, auch identische Primer wurden ausgetestet, jedoch waren diese Ergebnisse nicht reproduzierbar. Somit bleibt der Grund für diese Diskrepanz in der Milz ungeklärt. Weiterhin konnte in der vorliegenden Arbeit gezeigt werden, dass auch aufgereinigte T-Zellen und Makrophagen ausschließlich mBDNF 3 mRNA exprimieren. Quantitative Analysen zeigten, dass mBDNF 3 im Gehirn mit nur $1 \%$ der Expression von mBDNF 1 mRNA unterrepräsentiert war. In peripheren lymphatischen Organen hingegen war die Expression von mBDNF 3 mRNA circa 2-3-mal höher als im Vergleich zum Gehirn. Da dieses Ergebnis auch in aufgereinigten T-Zellen erzielt wurde, könnte man vermuten, dass in diesen Organen T-Zellen die Hauptquelle für mBDNF 3 mRNA sind. Im Gegensatz dazu exprimieren unbehandelte Makrophagen nur circa $20 \%$ der mBDNF 3 mRNA Menge im 
Gehirn. Dieser Unterschied in der Detektion der verschiedenen mBDNF Splice-Varianten in der Peripherie bleibt noch ungeklärt. Um Mausstammspezifische Unterschiede auszuschließen wurden die Experimente zusätzlich mit Balb/c und FVB/N Mäusen durchgeführt, die aber zu den gleichen Ergebnissen führten. Mikroglia und Astrozyten werden durch ihre vielseitigen Funktionen als Antigenpräsentierende Zellen, Effektorzellen in der MS und phagozytotische Zellen für beschädigte Neuronen (Ambrosini and Aloisi, 2004; Jack et al., 2005) als immunologisch relevante Zellen im ZNS betrachtet. Aus diesem Grund erschien es als sehr interessant, die Expression der mBDNF mRNA auch in diesen spezialisierten Zellen des ZNS zu untersuchen. Es stellte sich heraus, dass diese beiden Zelltypen ein sehr unterschiedliches Expressionsmuster der mBDNF mRNA hatten. In Astrozyten konnten alle mBDNF Splice-Varianten wiedergefunden werden. Zwar mit einigen quantitativen Unterschieden, aber dem gleichen Verteilungsmuster wie im Gehirn. Die zwei bedeutendsten Splice-Varianten hierbei waren die beiden Splice-Varianten mBDNF 1 und 4, die zwar die Mehrheit im Gehirn bildeten, jedoch in Astrozyten nur etwa 1-5 \% erreichten, dafür war aber mBDNF5 in diesen Zellen überrepräsentiert. Ein ganz anderes Expressionsmuster zeigte sich in Mikroglia, Makrophagen und anderen peripheren Immunzellen, denn dort wurde ausschließlich mBDNF 3 exprimiert. Es wird angenommen, dass Makrophagen und Mikrogliazellen einen gemeinsamen Ursprung in hämatopoetischen Stammzellen haben und damit im Gegensatz zu Neuronen und anderen Gliazellen dem Mesoderm und nicht dem Neuroektoderm entstammen (Jordan and Thomas, 1988; Oemichen, 1978). Zudem besitzen beide Zelltypen die gleichen Oberflächenmoleküle und immunologischen Funktionen, auch in Bezug auf die Expression von mBDNF Splice-Varianten scheinen Mikroglia eher die peripheren Makrophagen wiederzuspiegeln als andere gliale Zellen, ein Unterschied, der auch auf eine potentielle funktionelle Relevanz hindeutet. Diese Ansicht wurde auch durch die Beobachtung unterstützt, dass nach Stimulation von Mikroglia sowie peripheren Makrophagen mit LPS eine verminderte Expression von mBDNF 3 mRNA zu detektieren war, während die Stimulation von Astrozyten keinen Einfluss auf die Expression der mBDNF Splice-Varianten hatte.

Die physiologische Relevanz der unterschiedlichen mBDNF Splice-Varianten und deren exakte Regulation sind bisher kaum aufgeklärt. Es wurde berichtet, dass die unterschiedlichen Promotoren für die verschiedenen Splice-Varianten in zwei verschiedenen Clustern lokalisiert sind. Das erste Cluster umfasst die Exons I, II, und III (beinhaltet Splice-Varianten 1, 2A, 2B, 2C und 3), während das zweite Cluster Exon IV, V und VI (beinhaltet Splice-Varianten 4, 5, 6A und 6B) umfasst (Liu et al., 2006). Für das zweite Cluster wurden einige transkriptionelle 
Elemente, die CaRF (Calcium-responsive transcription factor), CREB (cAMP/calciumresponsive element binding protein) und $\mathrm{MeCP} 2$ (methyl-CpG binding protein 2) erkennen, beschrieben (Chen et al., 2003; Martinowich et al., 2003; Tao et al., 2002). Das Zusammenspiel der unterschiedlichen Transkriptionsfaktoren und der daraus resultierenden Expression der unterschiedlichen BDNF Splice-Varianten wurde bisher noch nicht untersucht. Auch insbesondere die Regulation der einzelnen Splice-Varianten in den unterschiedlichen Geweben ist noch sehr unklar. In dieser Arbeit wurde daraufhin die Hypothese untersucht, ob NF- $\kappa B$, ein Transkriptionsfaktor, welches eine zentrale Rolle in der T-Zellaktivierung spielt, in der Regulation von mBDNF 3 mRNA involviert ist, vor allem, weil mBDNF 3 nach TZellaktivierung hochreguliert wird. Dafür wurde ein tet-induzierbares Modellsystem gewählt, bei dem der Transkriptionsfaktor NF- $\mathrm{BB}$ in Thymozyten runterreguliert wird. Die Ergebnisse zeigten, dass nach Stimulation die Hochregulierung der mBDNF 3 mRNA in den Thymozyten dieses Modellsystems nicht anders war als in Wildtyp Thymozyten, was eine entscheidende Rolle dieses Transkriptionsfaktors in der mBDNF mRNA Regulation ausschließt. Die Regulation der BDNF mRNA in aktivierten T-Zellen bleibt somit auf molekularer Ebene immer noch ungeklärt.

In früheren Studien wurde bereits gezeigt, dass die BDNF Expression in Immunzellen nach deren Aktivierung ansteigt (Barouch et al., 2001; Besser and Wank, 1999; Kerschensteiner et al., 1999). In der vorliegenden Arbeit konnten diese Beobachtungen in T-Zellen (Thymozyten sowie reifen T-Zellen aus der Milz) auf mRNA-Ebene bestätigt werden. Ganz speziell konnte hier gezeigt werden, dass der Anstieg der mBDNF mRNA ausschließlich auf die Hochregulierung der Splice-Variante mBDNF 3 zurückzuführen ist, und nur diese durch bisher noch unbekannte Transkriptionsfaktoren positiv reguliert wird, da durch die Aktivierung keine weiteren mBDNF Splice-Varianten exprimiert werden. Wenn Makrophagen mit LPS stimuliert werden, so sinkt überraschenderweise die Expressionsrate der mBDNF 3 mRNA. Diese Ergebnisse sprechen gegen frühere Befunde, bei denen die BDNF mRNA Expression nicht in naiven, aber in LPS stimulierten peritonealen Makrophagen detektierbar war (Barouch et al., 2001). Dieser Unterschied könnte aus methodischen Unterschieden resultieren, da in der zuvor erwähnten Studie keine Real-Time PCR sowie Splice-Varianten-spezifische Oligonukleotide eingesetzt wurden. Weiterhin haben Kerschensteiner et al. (1999) z.B. lediglich von einem geringen Expressionsniveau in Monozyten berichtet, ohne dabei einen Vergleich zwischen unbehandelten und stimulierten Zellen anzustellen. Die Hypothese, dass infiltrierende Immunzellen neuroprotektiv wirken könnten (Schwartz and Kipnis, 2001; Schwartz et al., 1999), wird durch die vorliegenden 
Ergebnisse unterstützt, da stimulierte T-Zellen vermehrt BDNF exprimieren, welches wiederum auf neuronenschädigende Prozesse limitierend wirken könnte. Die Rolle des aus Makrophagen gewonnen BDNF Proteins hingegen muss noch geklärt werden. Zusätzlich sind weitere Studien notwendig, die den genauen Mechanismus der Regulation der mBDNF 3 mRNA in Immunzellen aufdecken.

Zusammengefasst ist $\mathrm{zu}$ sagen, dass mBDNF mRNA im CNS und im Immunsystem unterschiedlich reguliert wird, was die Möglichkeit einer spezifischen Intervention in die BDNF Expression in Immunzellen bietet, ohne dabei systemisch auch das BDNF im ZNS zu beeinflussen. Dieser Signalweg könnte als potenzielles Ziel für neuroprotektive Therapien in neuroinflammatorischen Krankheiten, wie der MS, verwendet werden.

\subsection{BDNF und dessen funktionelle Relevanz in der EAE}

Neurotrophe Faktoren, wie BDNF, sind essenziell für die Entwicklung und den Erhalt des Nervensystems. Dem BDNF speziell werden potenzielle Effekte auf den Neuronenerhalt und dessen Plastizität während der Entwicklung und nach Verletzungen zugesprochen. Es ist bereits seit langem bekannt, dass im Nervensystem Neuronen die größte zelluläre BDNFQuelle sind, zudem haben Kerschensteiner et al. (1999) zeigen können, dass auch aktivierte T-Zellen, B-Zellen und Monozyten BDNF exprimieren. Diese Erkenntnis erlangte noch größeres Interesse als Stadelmann et al. (2002) in Gehirnschnitten von Multiple Sklerose Patienten BDNF um verschiedene Läsionen herum detektieren konnten. Weiterhin konnte diese Gruppe zeigen, dass das detektierte BDNF vermehrt in Immunzellen vorzufinden war. Auch der BDNF-Rezeptor gp145trkB konnte in Neuronen in unmittelbarer Umgebung der Läsionen nachgewiesen werden. Aufgrund dieser Untersuchungen wird angenommen, dass das von Immunzellen sezernierte BDNF-Protein eine neuroprotektive Rolle in der Multiplen Sklerose spielt.

Die Behandlung der Multiplen Sklerose konzentriert sich auf zwei Hauptbereiche. Zum Einen wird versucht die Entzündung einzudämmen und zum Anderen gliale und neuronale Funktionen wiederherzustellen bzw. direkt zu schützen. Zu den Therapieansätzen, die der Eindämmung der Entzündung dienen, zählen z.B. die zytokinbasierten Immuntherapien, die grundsätzlich auf zwei Methoden aufbauen. Zum Einen versucht man die Entzündung durch die Applikation von anti-inflammatorischen Zytokinen, wie z.B. IFN- $\beta$, IL-10, IL-4 oder TGF- $\beta$, runterzuregulieren oder man benutzt Inhibitoren von pro-inflammatorischen 
Zytokinen. Vorsicht ist bei diesem Ansatz jedoch geboten, da es eigentlich keine Zytokinprototypen mit ausschließlich anti- oder pro-inflammatorischen Eigenschaften gibt. Die Wirkungsweise hängt vielmehr vom Zeitpunkt der Applikation bzw. dem momentanen Erkrankungsstatus ab. Außerdem gehören Zytokine einem sehr komplexen und hoch organisierten Netzwerk an, bei dem das Hinzufügen oder die Blockade einzelner Zytokine das Gleichgewicht empfindlich stören kann. Eine weitere Strategie zur Eindämmung der Entzündung ist die Verabreichung von Substanzen, die die Adhäsionsmoleküle blockieren. Adhäsionsmoleküle auf Endothelzellen spielen eine wichtige Rolle beim Einwandern von Leukozyten in das ZNS (Charo and Ransohoff, 2006). Leukozyten haften sich über Selektine (E-Selektin, P-Selektin, L-Selektin) an die Endothelzellen an, wonach es durch Integrininteraktionen zu einer festen Adhäsion der Leukozyten an das Endothel kommt. Gegen diese Interaktion greifen die Substanzen, die die Adhäsionsmoleküle blockieren, indem sie den pathogenetisch wichtigen Schritt der Leukozytenmigration unterbinden. Ein berühmter Kandidat unter den Antiadhäsionsmolekülen ist das Natalizumab, welches ein monoklonaler humanisierter Antikörper ist, der gegen das $\alpha_{4} \beta_{1}$-Integrin (VLA-4) auf der Oberfläche von Lymphozyten gerichtet ist. Studien mit MS Patienten zeigten, dass es nach einer Monotherapie mit Natalizumab zu einer Reduktion der Schübe um 67 \% kam und, dass das Voranschreiten der Behinderung nach 2 Jahren deutlich verzögert war (Polman et al., 2006). Dieser Effekt konnte durch die Kombination von Natalizumab und intramuskulär verabreichtem IFN- $\beta$ sogar noch verstärkt werden. Trotz überzeugender Studien gab es doch einen so schwerwiegenden Zwischenfall, dass die Anwendung dieses Mittels gründlich überdacht werden musste. Denn es wurde veröffentlicht, dass zwei Patienten, die Natalizumab in Kombination mit IFN- $\beta$ erhalten hatten, eine durch das JC-Virus (Humanes Polyomavirus 2) hervorgerufene progressive multifokale Leukenzephalopathie (PML) entwickelten, wonach als Folge einer der Patienten starb (Kleinschmidt-DeMasters and Tyler, 2005). Zwar ist noch nicht ganz klar, ob die Reaktivierung bzw. De-novo-Infektion des JC-Virus durch eine generelle Immunsuppression (Niino et al., 2006) oder durch einen spezifischen Effekt von Natalizumab (Ransohoff, 2005) hervorgerufen wurde, aber dieses Beispiel zeigt, dass auch dieser Therapieansatz nur sehr eingeschränkt und erst nach endgültigem Ausschluss einer möglichen JC-Virusinfektion anwendbar ist. Peroxysomproliferationsaktivierter Rezeptor $\gamma$ (PPAR- $\gamma$ )-Agonisten, wie z.B. Thiazolidinedione, stellten sich in einigen Studien auch als potenzielle Kandidaten für die MS Therapie heraus. Thiazolidinedione sind insulinsensibilisierende Verbindungen, die ursprünglich für die Therapie des Diabetes Typ 2 zugelassen wurden und wirken über die Aktivierung des nukleären Transkriptionsfaktors 
PPAR $\gamma$ (Pershadsingh et al., 2004). Neben ihren glukosesenkenden Eigenschaften haben diese Substanzen auch entzündungs- und wachstumshemmende Fähigkeiten. So können sie die TZellaktivierung verhindern, die Produktion von pro-inflammatorischen Zytokinen reduzieren und die Resistenz gegenüber Zytotoxizität erhöhen (Dello Russo et al., 2003). In der EAE konnten Thiazolidinedione den klinischen Verlauf und die Gewebeschädigung verbessern (Storer et al., 2005), weiterhin deuten vorläufige experimentelle Untersuchungen darauf hin, dass diese Substanzen auch den Krankheitsverlauf von MS-Patienten positiv beeinflussen (Pershadsingh et al., 2004). Allerdings wurde in einer anderen Studie mit einem anderen Mitglied der Thiazolidinedione, als das in der zuvor berichteten Studie, gezeigt, dass die Behandlung mit dem PPAR- $\gamma$-Agonisten keine Unterschiede in verschiedenen MRTParameteren als auch im klinischen Verlauf zeigte. Somit muss auch dieser Therapieansatz erst einmal gründlich nach seiner Effektivität hin ausgetestet werden. Eine andere Möglichkeit zur Therapie der Multiplen Sklerose ist der Versuch gliale und neuronale Funktionen wiederherzustellen bzw. direkt zu schützen. Viele der anti-inflammatorischen Medikamente, die bereits in der MS Therapie eingesetzt werden, vermindern zwar die Schubrate, jedoch haben sie nur geringen Einfluss auf die Progression der Behinderung und die Gewebedegeneration. Daher steigt die Nachfrage nach Substanzen, die auf Neuroprotektion und Remyelinisierung abzielen. Zurzeit laufen interessante und vielversprechende Laborstudien zu diversen Neuroprotektiva. In diesem Zusammenhang wird zum Beispiel das Erythropoetin (Epo) untersucht, welches ein hämatopoetischer Wachstumsfaktor der Erythropoese ist. Neben dieser Funktion besitzt Epo bemerkenswerte neuroprotektive Eigenschaften, die unter bestimmten pathophysiologischen Bedingungen im ZNS wie Ischämie, Hypoxie oder Inflammation zum Vorschein kommen (Genc et al., 2004). Epo und sein Rezeptor (EpoR) werden auf Neuronen exprimiert (Genc et al., 2006). Eine Untersuchung an EAE-Mäusen zeigte, dass die therapeutische Gabe von Epo die Schwere der Erkrankung deutlich abschwächte. Man geht davon aus, dass dieser Effekt auf die Reduktion des axonalen Schadens und der Demyelinisierung, eine verringerte Anzahl infiltrierender inflammatorischer Zellen und eine verminderte Durchlässigkeit der Blut-Hirn-Schranke zurückzuführen ist ( $\mathrm{Li}$ et al., 2004). Zudem konnte gezeigt werden, dass Epo die Differenzierung von Oligodendrozytenvorläuferzellen fördert, die Neurogenese im Striatum und der subventrikulären Zone stimuliert und die BDNF Ausschüttung erhöht (Agnello et al., 2002). In Schlaganfallpatienten konnte bereits eine Reduktion des neurologischen Defizits und der glialen Schädigung nach intravenös verabreichtem Epo beobachtet werden (Ehrenreich et al., 2004), während eine Studie mit MS-Patienten momentan in Planung ist. 
Das einzige Medikament, dem eine neuroprotektive Eigenschaft zugesprochen wird und das tatsächlich auch schon auf den Markt eingeführt wurde, ist das Laquinimod. Diese innovative Substanz zeichnet sich zunächst durch die orale und damit sehr praktikable Anwendung aus. Eine große Studie konnten deutlich zeigen, dass Laquinimod die Anhäufung von Läsionen in Multiple Sklerose Patienten um bis zu 40 \% verhindert (Comi et al., 2008). Zudem besitzt diese Substanz auch eine anti-inflammatorische Eigenschaft, die vermutlich auf eine Th1 zu Th2 Verschiebung basiert (Zou et al., 2002).

Neuronale und axonale Degeneration werden auch stark von den Ionenkanälen beeinflusst. So führt z.B. die axonale Demyelinisierung zu Veränderungen in der zellulären und subzellulären Expression und Lokalisation von Natriumkanälen $\left(\mathrm{Na}_{\mathrm{v}}\right)$. Studien, die solche pathophysiologischen Veränderungen aufzeigen, deuten darauf hin, dass subtypenspezifische Inhibitoren bestimmter Ionenkanäle die neuronale bzw. axonale Degeneration abschwächen könnten. In Tiermodell konnte bereits gezeigt werden, dass der Natriumkanalblocker Phenytoin die Demyelinisierung des Sehnervs und des Rückenmarks reduziert (Lo et al., 2003). Neuere Befunde geben Hinweise darauf, dass die Aktivierung von Mikrogliazellen und infiltrierenden Makrophagen während der Entzündung des ZNS wesentlich durch $\mathrm{Na}_{\mathrm{v}} 1.6$ beeinflusst wird. Diese Hypothese wird unterstützt durch die Beobachtung, dass Phenytoin die Anzahl infiltrierender Entzündungszellen bei der EAE reduziert (Craner et al., 2005). Weitere wichtige Faktoren, die zur Neuroprotektion beitragen sollen sind neurotrophe Faktoren, diese sind wie bereits beschrieben Proteine, die das Überleben und die Differenzierung von Nervenzellen regulieren (Thoenen and Sendtner, 2002) und über spezifischen Neurotrophinrezeptoren wirken (Bothwell, 1995). Scheinbar können neurotrophe Faktoren das Zytokingleichgewicht im ZNS durch bisher noch unbekannte Mechanismen in Richtung anti-Inflammation verlagern (Villoslada et al., 2000), zudem fördern sie möglicherweise das Überleben von Neuronen in MS-Läsionen (Kerschensteiner et al., 2003). Aus diesem Grund scheint die exogene Anwendung neurotropher Faktoren prinzipiell ein viel versprechender therapeutischer Ansatz zu sein. In einem Tiermodell der EAE wurde bereits die systemische Applikation von CNTF in Wildtyp BL/6 Mäusen untersucht (Kuhlmann et al., 2006). Die intraperitoneale Verabreichung von niedrigen Dosen des CNTF während der akuten Phase einer MOG induzierten EAE, führte nicht zu systemischen Nebenwirkungen, wie Änderungen in der peripheren Immunantwort, zeigte aber einen verminderten Krankheitsverlauf. Es wurde beobachtet, dass die Zahl an perivaskulären Infiltraten und die Menge an aktivierten Mikroglia im Rückenmark reduziert waren. Dieser Effekt des CNTF auf die Entzündung im Rückenmark kann höchstwahrscheinlich nicht direkt mit einem Effekt 
dieses Zytokins auf die T-Zellen in Verbindung gebracht werden, da diese Zellen nicht die Rezeptoruntereinheiten CNTFR $\alpha$ und LIFR $\beta$ exprimieren (Hilton et al., 1988; Hilton et al., 1991; Sleeman et al., 2000). Es ist eher möglich, dass das CNTF die Immunantwort im Rückenmark über immunmodulierende Moleküle, die von Mikroglia produziert werden, beeinflusst, da bereits bekannt ist dass CNTF auf diese Zellpopulation eine Wirkung hat (Hagg et al., 1993; Kahn et al., 1995). Oder CNTF könnte einen direkten neuroprotektiven Effekt ausüben, der den initialen Myelin- bzw. Axonschaden verhindert und dadurch auch die sekundäre entzündliche Antwort blockiert (Aboul-Enein et al., 2004). Neben dieser Studie, die einen verbesserten EAE-Verlauf nach CNTF Applikation aufweist, wurde auch ein gegenteiliges Experiment durchgeführt, bei dem der EAE-Verlauf in CNTF defizienten Mäusen untersucht wurde (Linker et al., 2002). Diese Studie ergab, dass die Mäuse, die kein CNTF exprimierten einen schwereren Erkrankungsverlauf im Vergleich zu Kontrolltieren nach Induktion einer experimentellen autoimmunen Enzephalomyelitis (EAE), aufwiesen (Linker et al., 2002). In der späten Phase der Erkrankung litten CNTF defiziente Mäuse immer noch an Paraplegie, während bei den Kontrolltiere nur noch eine Gangataxie zu erkennen war. Auf der histologischen Ebene könnte die erhöhte Suszeptibilität der CNTF defizienten Mäuse durch eine 60 \%ige Verringerung der proliferierenden Vorläuferzellen der Oligodendrozyten zu erklären sein. Diese beiden Untersuchungen zeigen deutlich die Bedeutung neurotropher Faktoren in den entzündlichen, demyelinisierenden Erkrankungen, wie der MS bzw. seinem Tiermodell, der EAE. So liegt es auch nahe, weitere neurotrophe Faktoren, wie das BDNF, in dieser Erkrankung zu erforschen, um mögliche ähnliche neuroprotektive Effekte aufzudecken und als neue therapeutische Ziele anzubieten.

Zudem werden inflammatorischen Zellen, nicht zuletzt durch die Expression von neurotrophen Faktoren, auch eine neuroprotektive Funktion nachgesagt, deren Beachtung relevant für beide, die immunsuppressiven und neuroprotektiven, Behandlungsziele der MS ist. Denn es konnte gezeigt werden, dass die therapeutische Applikation von aktivierten autoimmunen T-Zellen nach einer partiellen Quetschung des Sehnervs eine sekundäre Degeneration verhindern konnte (Moalem et al., 1999). Der genaue Mechanismus dieser Neuroprotektion ist zwar nicht bekannt, aber Untersuchungen an einem Modell der partiellen Quetschung des Sehnervs haben gezeigt, dass nach Applikation eines Tyrosinkinaseassoziierten Inhibitors der neuroprotektive Effekt der autoimmunen T-Zellen teilweise verhindert wurde (Moalem et al., 2000). Der beschriebene Inhibitor inhibiert spezifisch die Tyrosinkinaserezeptoren, über die auch die Neurotrophinwirkung vermittelt wird, und blockiert diese TrkA, TrkB und TrkC Rezeptoren ungefähr gleichermaßen, ohne dabei andere 
Tyrosinkinase Signalwege zu beeinflussen (Berg et al., 1992; Koizumi et al., 1988; Nye et al., 1992; Tapley et al., 1992). Das Ergebnis, dass der Tyrosinkinase-assoziierte Inhibitor den Schutz vor sekundärer Degeneration vermindert, deutet darauf hin, dass die Neuroprotektion, die nach Applikation von autoimmunen T-Zellen erreicht wird, mitunter Neurotrophin vermittelt ist.

Man sollte bei der nichtselektiven immunsuppressiven MS-Therapie z.B., welches für gewöhnlich in der Multiplen Sklerose eingesetzt wird, beachten, dass womöglich nicht nur die autoaggressiven Angreifer, sondern auch die potentiell neuroprotektiven gutartigen autoimmunen Zellen eliminiert werden. Dies könnte auch den Grund für den teilweise nur sehr eingeschränkten klinischen Erfolg dieser Therapie liefern (Hohlfeld, 1997; Noseworthy et al., 1999). Daher rücken immer stärker neuere Therapieansätze in den Mittelpunkt, die sich mit der selektiven Modulation der autoimmunen Reaktion beschäftigen (Hemmer et al., 2002; Hohlfeld, 1997). Neue Behandlungsziele betreffen vor allem den Erhalt bzw. die Verstärkung der potenziell neuroprotektiven Funktion der gutartigen autoreaktiven T-Zellen, zu denen auch regulatorische T-Zellen (Treg) zählen. Treg sind CD4+ CD25+ selbstreaktive T-Zellen, die im Thymus durch die Expression des Transkriptionsfaktors Foxp3 der negativen Selektion entkommen und in die Treg Linie gelenkt werden (Ghiringhelli et al., 2005; Sakaguchi, 2005; von Boehmer, 2005). Im Gegensatz zu den aggressiven selbstreaktiven T-Zellen haben Treg Zellen, die Foxp3 exprimieren, eine Suppressorfunktion und sind daher entscheidend, um generell multiple Organe vor Autoimmunität zu schützen (Kim et al., 2007; Sakaguchi, 2005). Die Bedeutung von Treg Zellen in der Begrenzung des autoimmunen Gewebeschadens konnte im Tiermodell der Multiplen Sklerose (Kohm et al., 2002), der Typ-1-Diabetis (Herman et al., 2004; Piccirillo et al., 2005) und der rheumatoiden Arthritis (Morgan et al., 2003) gezeigt werden. Auch im Menschen konnte eine Verminderung der Treg Zellzahl bzw. ihrer suppressiven Funktion in der Multiplen Sklerose demonstriert werden (Haas et al., 2005; Viglietta et al., 2004), was einen weiteren Hinweis auf die Bedeutung dieser Zellen in der Autoimmunität liefert.

Von einem erfolgreichen Ansatz mit dem Neurotrophin BDNF und dessen mögliche therapeutische Wirkung in neurodegenerativen Erkrankungen wurde bereits in einem Mausmodell der Motorneurodegeneration berichtet (Mitsumoto et al., 1994). Bislang sind aber therapeutische Ansätze mit BDNF in humanen Motoneuronenerkrankungen misslungen (1999), was womöglich auf die limitierte Verfügbarkeit des BDNF im ZNS zurückzuführen ist (Dittrich et al., 1996). Auch die exogene Applikation von freiem BDNF war ineffizient in einem Modell der experimentellen autoimmunen Neuritis (Felts et al., 2002). Eine andere 
Möglichkeit der BDNF Applikation wurde in einem Modell der akuten Rückenmarksverletzung getestet, bei dem ein Katheder intrathekal eingesetzt und mit einer osmotischen Pumpe betrieben wurde (Kim and Jahng, 2004). Dafür wurde rekombinantes BDNF in einer künstlichen Cerebrospinalflüssigkeit gelöst und kontinuierlich verabreicht. Dieser Versuchsansatz zeigte zwar einen positiven Effekt auf die Rückenmarksverletzung, jedoch ist diese Art der Applikation nicht sehr praktikabel. Osmotische Pumpen haben den Nachteil, dass die Apparatur eventuell Infektionen von außen mit in das angebundene Gewebe bringen kann, außerdem sind die übertragenen Konzentrationen des Neurotrophins weit über den physiologischen Mengen und deshalb auch gerade für Langzeitexperimente nicht geeignet.

Aus diesem Grund wurde in der vorliegenden Arbeit für die funktionellen Untersuchungen ein Ansatz gewählt, in dem BDNF überexprimierende T-Zellen mittels lentiviraler Transduktion generiert und deren Relevanz im EAE Modell getestet wurde. Studien zur effizienteren lentiviralen Transduktion zeigten, dass nach Polybrenezugabe und Zentrifugation der T-Zellen mit den lentiviralen Partikeln eine 6fach höhere Transduktionseffizienz erzielt werden konnte verglichen mit Kontrollzellen, die unbehandelt blieben (Costello et al., 2000). Polybrene ist ein kationisches Polymer, welches durch das Herabsetzen der Oberflächenspannung die Transduktion des Virus erleichtern soll, die zusätzliche Zentrifugation schafft eine engere räumliche Nähe und somit mehr Angriffsfläche für das Virus. Auch in der vorliegenden Arbeit wurden murine T-Zellen standardmäßig mit den lentiviralen Partikeln zentrifugiert und auch mit Polybrene versetzt, was im Vergleich zu den Ansätzen ohne Polybrenezugabe zu einer 5fach höheren Transduktionseffizienz mit dem BDNF Lentivirus führte. Der Erfolg der Transduktion war jedoch sehr variabel und machte aus diesem Grund den Versuchsansatz sehr aufwendig. Eine in diesem Zusammenhang relevante Veröffentlichung (Baumann et al., 2004), die einen Vergleich zwischen der Transduktion humaner und muriner T-Zellen anstellte, gab Erklärungsansätze für die heterogenen Transfektionserfolge in unserem murinen System. Dieser Vergleich zeigte, dass primäre murine CD4+ T-Zellen im Vergleich zur humanen T-Zelllinie HuT78/CCR5 eine sehr viel geringere Suszeptibilität für die Transduktion durch HIV-1, einem Vertreter der Lentiviren, besitzen. Zum einen liegt es wohl daran, dass murinen T-Zellen notwendige Faktoren für einen erfolgreichen Eintritt des Virus in die Zelle fehlen, wie z.B. die humane Form des HIV-1 Rezeptors und Co-Rezeptormoleküle, wie CD4 und CCR5, deren murine Orthologe den HIV-1 Eintritt nicht unterstützen (Browning et al., 1997). Im Gegensatz dazu nutzen die Viren für diese Funktion die murine Form des CXCR4 als Co-Rezeptor (Bieniasz 
et al., 1997; Tachibana et al., 1997). Deswegen verläuft der Viruseintritt noch relativ effizient, während sich größere Schwierigkeiten bei der Komplettierung der reversen Transkriptase und des Kerntransfers des Präintegrationskomplexes ergeben. Auf diesen Ebenen scheinen murine T-Zellen wichtige Instrumente zu besitzen, die die virale Infektion effektiv blocken können und somit die Transduktionseffizienz stark herabsetzen. Diese Blockiermechanismen spiegelten sich auch in unseren Experimenten wieder, indem virale Transduktionen nicht immer effizient waren und auch nur geringe BDNF Proteinkonzentrationen nach viraler Transduktion detektierbar waren. Wenn man jedoch bedenkt, dass endogene BDNF Proteinexpressionen in murinen T-Zellen so gering sind, dass sie mit den derzeit verfügbaren technischen Mitteln kaum detektierbar sind, so stellen diese geringen aber detektierbaren Mengen eine doch wesentliche Steigerung der BDNF Expression in murinen T-Zellen dar. Des Weiteren ist zu Bedenken, dass in unserem System BDNF nicht systemisch verabreicht wird, sondern sehr lokal, direkt in den Läsionen, überexprimiert wird, und somit davon ausgegangen werden kann, dass die produzierte BDNF Menge ausreicht, um einen lokalen potenziell benefiziellen Effekt auszuüben.

Um sicherzustellen, dass das in den lentiviralen Vektor einklonierte BDNF auch bioaktiv war und somit seine Funktion ausüben konnte, wurde ein BDNF Bioassay durchgeführt. Dieser Assay ist ein standardisiertes Verfahren (Wiese et al., 1999; Wiese et al., 2001) und zeigte, dass in den Virusüberständen bioaktives BDNF vorhanden war. Da das Protokoll eine recht hohe Verdünnung des Virusüberstandes in der zu testenden Zellkultur vorsieht, wurden nicht die Überstände der T-Zellen nach viraler Transduktion verwendet, da dort die initialen Konzentrationen bereits sehr gering waren, sondern die Überstände der Zellen, die ursprünglich das Virus hergestellt haben, denn auch dort wurden bereits während der Virusproduktion die Produkte des lentiviralen Vektors in den Überstand sezerniert. Ein Vergleich der Überstände zeigte, dass der BDNF Virusüberstand das Überleben der Ganglien auf signifikante Art und Weise gewährleistete, während Ganglien, die mit dem GFP Virusüberstand versetzt wurden kaum überlebten.

Für die in vivo Versuche wurden MOG-spezifische T-Zellen aus T-Zellrezeptor transgenen Mäusen (2D2) verwendet, da MOG das Peptid ist, welches in unserem EAE-Modell angegriffen wird und auch die endogenen T-Zellen, die in das ZNS infiltrieren hauptsächlich MOG spezifische Epitope besitzen. Diese 2D2 T-Zellen können im naiven Zustand keine EAE auslösen, dafür müssten sie zunächst in vitro in eine Th Untergruppe polarisiert werden, die durch ihr Zytokinprofil dazu in der Lage ist den ganzen Entzündungsprozess in Gang zu setzen. Eine erst kürzlich erschienene Studie (Jager et al., 2009) hat sich mit der Polarisation 
dieser speziellen MOG-spezifischen T-Zellen und ihrer Fähigkeit der EAE Induktion beschäftigt. Die Th1 Untergruppe wurde früher als der eigentliche Verursacher der EAE betrachtet. Man kann Th1 polarisierte T-Zellen erhalten, indem man sie in vitro mit IL-12 behandelt. Das charakteristische Zytokin welches sie nach Polarisation sezernieren ist das pro-inflammatorische IFN- $\gamma$, welches bereits in entzündlichen ZNS Läsionen detektiert werden konnte und bekannt für seine Aktivierung von Makrophagen ist (Merrill et al., 1992). Neuerdings wird aber auch eine andere Th Untergruppe für die EAE Induktion verantwortlich gemacht, und zwar das Th17. Naive T-Zellen können in vitro mit Hilfe von TGF- $\beta$ und IL-6 zu Th17 Zellen polarisiert und mit IL-23 stabilisiert werden (Bettelli et al., 2006; Veldhoen et al., 2006). Charakteristische Zytokine, die von Th17 Zellen exprimiert werden sind IL-17A, IL-17F, IL-21 und IL-22. Eine weitere pathogene Untergruppe sind die Th9 Zellen, die durch TGF- $\beta$ und IL-4 polarisiert werden und danach große Mengen an IL-9 und IL-10 sezernieren (Dardalhon et al., 2008; Veldhoen et al., 2008). Die letzte Th Untergruppe bilden die Th2 Zellen, die jedoch nicht in der Lage sind eine EAE auszulösen, da sie eher antiinflammatorische Prozesse induzieren (Baron et al., 1993; Merrill et al., 1992). Die MOGspezifischen T-Zellen einer 2D2 Maus wurden in vitro $\mathrm{zu}$ den verschiedenen Untergruppen polarisiert und C57BL/6 Wildtyp Tieren injiziert. Es konnte gezeigt werden, dass nicht nur Th1 Zellen, sondern auch Th17 als auch Th9 Zellen eine EAE mit ähnlichem klinischem Ausmaß auslösen können (Jager et al., 2009). Es wurde außerdem beobachtet, dass die zu applizierenden Zellen mindestens über zwei Zyklen stimuliert werden müssen, um überhaupt eine EAE auszulösen. Die Th17 polarisierten Zellen können zwar bereits nach dem ersten Stimulationszyklus eine EAE auslösen, jedoch wird dieser Effekt durch die zusätzliche Gabe von Pertussistoxin, welches normalerweise in der aktiven Immunisierung mit dem MOG Antigen verwendet wird, verhindert (Jager et al., 2009). Nach dem zweiten Stimulationszyklus jedoch konnten die Th17 Zellen auch in Anwesenheit von Pertussistoxin eine EAE auslösen. Die in der vorliegenden Arbeit verwendeten MOG-spezifischen T-Zellen der 2D2 Mäuse wurden vor Applikation weder polarisiert noch stimuliert, außerdem wurde in dieser Arbeit gezeigt, dass lediglich die Applikation dieser naiven T-Zellen keine EAE in C57BL/6 Tieren auslösen konnte. Aus diesem Grund erscheint es eher unwahrscheinlich, dass die MOG-spezifischen T-Zellen, die in dieser Versuchsreihe verwendet wurden, zum Entzündungsprozess beitragen. Die Frage, ob die injizierten naiven MOG-spezifischen TZellen in den EAE induzierten Mäusen nach Applikation in eine aggressive Subform der Th Zellen getrieben werden kann eher ausgeschlossen werden, da die Applikation dieser Zellen den Erkrankungsverlauf nicht negativ, sondern eher positiv beeinflusst haben. 
Neben den MOG-spezifischen T-Zellen wurde auch die Injektion von lediglich GFP positiven T-Zellen einer GFP transgenen Maus mit C57B1/6 Hintergrund nach Induktion einer EAE ausgetestet. Diese injizierten T-Zellen konnten aber nicht im ZNS nachgewiesen werden, während MOG-spezifische T-Zellen sowohl immunhistochemisch als auch mit Hilfe der Durchflusszytometrie im ZNS nachweisbar waren. Dies bestätigte die bevorzugte Wahl der MOG-spezifischen T-Zellen und machte das Homing der behandelten T-Zellen zu den Läsionen wahrscheinlicher.

Zuvor wurden aber reine GFP positive T-Zellen verwendet, um die Überlebensrate i.v. injizierter und mit dem BDNF Lentivirus infizierter T-Zellen in vivo ohne EAE Induktion zu untersuchen. Die Analyse der Milzen zeigten, dass sogar nach 21 Tagen noch GFP positive TZellen in der Milz nachweisbar sind und, dass diese mehr BDNF exprimieren als unbehandelte T-Zellen, die ebenfalls i.v. injiziert wurden. Diese Ergebnisse zeigen, dass TZellen sofern sie sich nicht in einem entzündlichen Milieu befinden relativ lange in vivo überleben können, dies ändert sich jedoch, wenn T-Zellen in die entzündlichen Läsionen im ZNS gelangen. Dort wurde beobachtet, dass T-Zellen die über ihren T-Zellrezeptor aktiviert wurden, durch den AICD (activation-induced cell death) Signalweg in die Apoptose getrieben werden (Green et al., 2003; Krammer, 2000). Dieser Mechanismus dient dem Beenden der Immunantwort und wirkt somit der hohen proliferativen Kapazität der Antigen-stimulierten Lymphozyten entgegen, und versucht dadurch auch gleichzeitig die Lymphozyten Homöostase aufrecht zu erhalten. Dieser extrinsische Signalweg wird mit Hilfe von sogenannten death Rezeptoren, wie dem CD95 (Apo-1/Fas), gesteuert (Krammer, 2000; Krueger et al., 2003). In der vorliegenden Arbeit kann man davon ausgehen, dass im ZNS die endogenen Lymphozyten, die durch das Antigen relativ stark stimuliert werden und den Entzündungsprozess in Gang setzen, über diesen Apoptoseweg wieder aus dem ZNS entfernt werden. Für die injizierten T-Zellen hingegen, die im ZNS nicht so stark stimuliert sind, könnte ein zweiter, intrinsischer Apoptoseweg, das ACAD (activated T cell autonomous death), in Frage kommen (Hildeman et al., 2002). Dieser Apoptoseweg, auch passiver Zelltod genannt, benötigt keine starke T-Zellrezeptor Aktivierung und wird auch nicht über death Rezeptoren reguliert. Vielmehr resultiert dieser Signalweg aus dem Mangel an Überlebensfaktoren und wird durch die Mitglieder der Bcl-2 Familie reguliert (Strasser, 2005). Übertragen auf diese Arbeit könnte dieser Apoptoseweg eine Möglichkeit sein, durch die die weniger aktivierten applizierten Lymphozyten wieder aus dem ZNS entfernt werden. Um diese Hypothese jedoch zu bestätigen sind noch weitere Studien erforderlich, die in dieser Arbeit nicht weiter verfolgt wurden. 
Die Beobachtung, dass T-Zellen nach einer gewissen Zeit wieder aus dem ZNS entfernt werden, war auch deutlich in den in vivo Experimenten zu sehen, in denen C57B1/6 Mäusen eine EAE induziert und anschließend BDNF Lentivirus transduzierte GFP positive MOGspezifische T-Zellen injiziert wurden. Hier war am Anfang des klinischen Verlaufs noch ein verzögerter und sehr viel milderer EAE-Verlauf der BDNF behandelten Tiere zu erkennen, während dieser nach ca. einer Woche nicht mehr gehalten werden konnte und sich der Grad der Erkrankung immer mehr den Kontrollgruppen näherte. Daraus könnte man schließen, dass die injizierten T-Zellen durch die Apoptose wieder aus dem ZNS entfernt wurden und dass durch die limitierte Zahl der applizierten Zellen der Nachstrom nicht aufrecht erhalten werden konnte, wodurch der positive Effekt auf den klinischen Verlauf abgeklungen ist. Um jedoch diesen milderen Effekt in BDNF behandelten Tieren zu halten wären weitere Injektionen mit den BDNF Lentivirus transduzierten T-Zellen erforderlich, dies wiederum würde aber die Realisierbarkeit der therapeutischen Applikation in Langzeitversuchen limitieren.

Für die i.v. Injektion wurde Tag 7 nach Immunisierung favorisiert. Ein Zeitpunkt an dem die ersten axonalen Schäden in den EAE Läsionen zu erkennen sind (Herrero-Herranz et al., 2008; Jones et al., 2008), aber das initiale T-Zellpriming bereits abgeschlossen ist. Folglich können injizierte T-Zellen direkt ins ZNS zu den Läsionen wandern ohne vorher durch das Immunsystem aktiviert zu werden. Dadurch dienen injizierte Zellen lediglich als Vehikel für die BDNF Expression und tragen nicht weiter zur Entzündung bei. Anders ist es, wenn BDNF zu einem früheren Zeitpunkt appliziert wird, denn dort kann auch die Immunantwort beeinträchtigt werden, so wie es auch der Fall war nach Applikation von BDNF mittels transformierten Knochenmarksstammzellen in EAE induzierten Mäusen (Makar et al., 2009; Makar et al., 2008). Hier beobachtete man, dass die Überexpression des BDNF zu einem verzögerten Einsetzen der EAE führte und den Grad der Erkrankung während der akuten und chronischen Phase vermindern konnte. Zudem wurde in dieser Arbeit nach BDNF Behandlung eine Verschiebung des Lymphozytenphänotyps zum anti-inflammatorischen Phänotyp festgestellt. Dabei geht es darum, dass die Zytokine des Th1 und Th2 Phänotyps scheinbar eine wichtige Funktion in der Läsionsentwicklung in der Pathogenese der MS und EAE einnehmen (Makar et al., 2009; Ruddle et al., 1990). So sezernieren T-Zellen des Th1 Phänotyps wichtige pro-inflammatorische Zytokine wie IFN $\gamma$ und TNF $\alpha$ und vermitteln somit den inflammatorischen Schaden. Im Gegensatz dazu sezernieren T-Zellen des Th2 Phänotyps z.B. IL-4 und IL-10, die immunsuppressiv und immunregulatorisch wirken und mit dem Nachlassen der Erkrankung und der Genesung in Verbindung gebracht werden (Makar et al., 2009; Ruddle et al., 1990). In diesem Ansatz konnte nun festgestellt werden, dass es in den 
BDNF behandelten Tieren zu einer verminderten Expression der pro-inflammatorischen Zytokine (IFN $\gamma$ und $\mathrm{TNF} \alpha$ ) kam, während die Expression der anti-inflammatorischen Zytokine (IL-4, IL-10 und IL-11) angestiegen war und somit BDNF nicht nur neuroprotektive Eigenschaften, sondern scheinbar auch immunmodulatorische Fähigkeiten besitzt, sofern der Zeitpunkt der Applikation richtig gewählt wird.

I.v. injizierte Mäuse wurden auf verschiedensten Ebenen immunhistochemisch untersucht. Der im Zusammenhang mit der neuroprotektiven Funktion von BDNF wohl wichtigste Nachweis ist der Erhalt der Axone in BDNF behandelten Tieren, denn das zentrale Merkmal der Multiplen Sklerose, und somit auch seinem Tiermodell der EAE, ist die Demyelinisierung und der axonale Schaden. Bei der Demyelinisierung werden die Myelinscheide und auch die Oligodendrozyten selbst als Folge einer Attacke von Zellen des Immunsystems, die gegen Myelin-ähnliche Epitope gerichtete sind, angegriffen. Diese Immunattacke beinhaltet sowohl eine zelluläre Immunität, mit T-Zellen, die gegen das Myelin oder Oligodendrozyten gerichtet sind, die Phagozytose, die von Makrophagen angetrieben wird und die humorale Immunität, die durch die Sekretion von anti-Myelin Antikörpern durch B-Zellen repräsentiert wird. Es gibt unterschiedliche Möglichkeiten mit denen aktivierte Immunzellen das Myelin und Oligodendrozyten zerstören können. Zum einen kann die direkte Bindung von T-Zellen an die Myelinepitope zur Aktivierung von Makrophagen und somit zur Phagozytose der Myelinscheide kommen. Weiterhin kann die Freisetzung von zytotoxischen Zytokinen oder löslichen toxischen Mediatoren, wie dem Stickstoffmonoxid (NO) sezerniert von Mikroglia bzw. Makrophagen zur Zerstörung des Myelins führen. Oder es sind Antikörper, die gegen ein Myelinepitop gerichtet sind und von infiltrierenden B-Zellen sezerniert werden, die an das Myelin binden und die Komplementkaskade in Gang setzen, was die Opsonisierung und Phagozytose des Myelins und der Oligodendrozyten zur Folge hat. Studien haben ergeben, dass man die Demyelinisierung in der frühen, akuten Phase der MS in unterschiedliche Muster aufteilen kann (Lassmann et al., 2001). Diese Muster konnten zwar in den MS Patienten beobachtet werden, jedoch sind nicht alle vier Muster in den aktiven Läsionen eines einzelnen Patienten detektierbar. Folglich existiert auch nicht ein einziges Tiermodell, welches alle Muster der Demyelinisierung repräsentiert, sondern jedes Tiermodell spiegelt eines der vier Muster wieder. Das erste Muster ist charakterisiert durch den TZell/Makrophagen-assoziierten Myelinschaden und wird hauptsächlich im $\mathrm{MOG}_{35-55}$-EAE Modell in C57BL/6 Mäusen beobachtet (Calida et al., 2001). Das Hauptcharakteristikum des zweiten Musters ist die Präzipitation von Immunglobulinen und des Komplementsystems an den Stellen des aktiven Myelinabbaus. Das dritte Muster spiegelt die Zeichen einer 
Oligodendrozyten Dystrophie wieder mit einem unverhältnismäßigen Verlust an dem Myelinassoziiertem Glykoprotein (MAG) und der Apoptose der Oligodendrozyten (Aboul-Enein et al., 2003). Das vierte Muster ist hauptsächlich gekennzeichnet durch die Degeneration der Oligodendrozyten. Neben der Demyelinisierung ist auch der axonale Schaden und Verlust ein charakteristisches Merkmal der MS. Der axonale Schaden wird durch histologische Untersuchungen bestimmt, wobei die Akkumulation des Amyloid Precursor Proteins (APP) eine beliebte Methode ist, um den Schaden zu detektieren. Die Akkumulation des APP entsteht, wenn der axonale Transport dieses Proteins durch eine Verletzung unterbrochen ist. APP Akkumulation ist eine transiente Erscheinung, die meist in der frühen Phase der Erkrankung auftaucht und mit dem Ausmaß der Infiltration korreliert (Kuhlmann et al., 2002). Es konnte in in vitro Studien gezeigt werden, dass auch CD8+ T-Zellen direkt mit den demyelinisierten Axonen interagieren können und axonalen Schaden vermitteln (Medana et al., 2001). Auch in einer in vivo Studie führte der adoptive Transfer von CD8+ T-Zellen zu entzündlichen Gehirnläsionen mit einem hohen Maß an axonalem Schaden und Zerstörung (Huseby et al., 2001), auch wenn diese T-Zellen eigentlich gegen ein Myelinantigen und nicht gegen ein axonales Antigen gerichtet waren. Im Gegensatz dazu wurde aber auch gezeigt, dass in Mäusen, in denen die MHC Klasse-1 und CD8+ Interaktion gestört war, ein sehr viel höheres Maß an axonalem Schaden auftrat (Linker et al., 2005). Ein weiterer Mediator, der zum axonalen Schaden beiträgt, ist das Stickstoffmonoxid (NO), welches von aktivierten Makrophagen sezerniert wird und eine reversible Blockierung der Leitung in den demyelinisierten Axonen verursacht (Redford et al., 1997). Außerdem konnte gezeigt werden, dass NO Exposition mit Konzentrationen ähnlich denen, die von Makrophagen produziert werden, zu einer Wallerschen Degeneration der Axone führt, dessen Schädigung in einer Durchtrennung des Axons endete (Smith et al., 2001).

In der vorliegenden Arbeit wurde zunächst versucht den axonalen Schaden mit Hilfe der Versilberung nach Bielschowsky zu bestimmen. Diese Methode färbt spezifisch Axone an und konnte auf signifikante Art und Weise zeigen, dass die Axone in den Läsionen der BDNF behandelten Tiere deutlich besser erhalten waren. Dies lässt darauf schließen, dass die BDNF Überexpression entweder die Axone direkt vor Schädigung geschützt hat, da bereits berichtet wurde, dass das von T-Zellen exprimierte BDNF und sein spezifischer Rezeptor TrkB in den Axonen der entzündlichen Läsionen überexprimiert sind (Stadelmann et al., 2002). Somit kann das BDNF in situ direkt auf Neuronen wirken, indem es benefizielle Mechanismen in Gang setzt, die den schädlichen Effekten der Neuoinflammation entgegenwirken können. Oder aber die BDNF Überexpression in den transduzierten T-Zellen könnte zu einer 
Remyelinisierung geführt haben, denn es konnte auch gezeigt werden, dass die Applikation von BDNF in einem Modell der Rückenmarksverletzung zu einer verstärkten Proliferation der Oligodendrozyten und Remyelinisierung von Axonen geführt hat (McTigue et al., 1998).

Diese Daten wurden durch die APP Färbung unterstützt, dessen Akkumulation ein Hinweis auf axonalen Schaden ist (Bramlett et al., 1997; Li et al., 1995; Pesini et al., 1999; Yam et al., 1997) und in den BDNF behandelten Tieren ebenfalls reduzierter auftritt. Ein größerer signifikanter Unterschied ist wohl aus dem Grund nicht detektierbar, da die Analyse der Rückenmarksschnitte erst in der chronischen Phase durchgeführt wurde und APP Akkumulation in der akuten Phase am höchsten ist und mit der Zeit abnimmt (Kuhlmann et al., 2002).

Axonaler Schaden wird, wie bereits aufgeführt, auch besonders durch die Synthese von Stickstoffmonoxid (NO) begünstigt (MacMicking et al., 1997). In entzündlichen Läsionen sind es Makrophagen und Mikroglia, die durch die Expression der induzierbaren NO Synthetase (iNOS) vermehrt NO produzieren und dadurch Axone angreifen. Die Untersuchungen in der vorliegenden Arbeit zeigten, dass die iNOS Expression in den BDNF behandelten Tieren auf signifikante Art und Weise um die Hälfte reduziert war und korellierte damit gut mit den Daten des axonalen Schadens. Die Zielzellen, in denen die iNOS Expression reduziert ist, scheinen hierbei jedoch nicht die Makrophagen zu sein, da bereits gezeigt wurde das BDNF keinen Einfluss auf die NO Produktion in Makrophagen hat (Barouch et al., 2001). Aber es wurde veröffentlicht, dass die NO Produktion in Mikroglia durch BDNF reduziert wird und somit die Reduktion der iNOS Expression womöglich in Mikroglia stattfand (Nakajima et al., 2001). Eine eindeutige Zuweisung kann jedoch nicht getroffen werden, da mit der histologischen Färbung nicht zwischen den beiden Zelltypen unterschieden werden kann.

Die Inflammation hingegen wurde durch die BDNF Überexpression nicht beeinflusst und zeigte in den immunhistochemischen Untersuchungen die gleiche Anzahl an T-Zell- und Makrophageninfiltrationen in den BDNF bzw. GFP behandelten Mäusen. Für die Charakterisierung der infiltirierenden T-Zellen vor allem aber auch der injizierten mit den Lentiviren transduzierten MOG-spezifischen GFP positiven T-Zellen wurde deren Aktivierungsstatus nach typischen T-Zell-Aktivierungsmarkern hin untersucht. Dafür wurden die aus dem Rückenmark isolierten Lymphozyten mit den Lymphozyten der Milz verglichen. Es war deutlich zu erkennen, dass der frühe Aktivierungsmarker CD25 und der späte Memory Zellmarker CD44 in den transduzierten T-Zellen im Rückenmark runterreguliert war, wodurch eine aggressive Effektorfunktion der injizierten Zellen eher unwahrscheinlich 
erscheint. Im Fall von CD62L zeigten die Vergleichgruppen keine sehr großen Unterschiede untereinander. Da aber CD62L ein Adhäsionsmolekül ist, welches für das Homing der TZellen verantwortlich ist, ist die Expression dieses Moleküls womöglich nötig, um den injizierten transduzierten T-Zellen, die durch das Immunsystem nicht wie die endogenen Effektorzellen aktiviert werden, das Eindringen in das entzündete Gewebe zu ermöglichen. Eine interessante Aussage ergab sich bei der Analyse der CD69 Expression. In diesem Fall zeigten die transduzierten T-Zellen eine sehr viel stärkere Expression dieses Moleküls sowohl in der Milz als auch im Rückenmark. CD69 ist eins der am frühesten exprimierten Lymphozyten Aktivierungsmarker und wurde in früheren Studien als pro-inflammatorischer Rezeptor deklariert (Testi et al., 1990). Dennoch wurden keine fundierten in vivo Experimente durchgeführt, um die genaue Rolle und die physiologische Funktion des CD69 im Immunsystem zu untersuchen. Neuere Studien hingegen zeigen, dass dem CD69 auch eine regulatorische Funktion zugesprochen werden kann. Diese regulatorische Funktion kann hauptsächlich durch die Produktion von TGF- $\beta$ vermittelt werden. Dieses Molekül reguliert die Funktion der Antigenpräsentierenden Zellen (APC) herunter (Kulkarni et al., 1993; Shull et al., 1992) und limitiert die Aktivierung und die Polarisation der T-Zellen zum Th1 bzw. Th2 Phänotyp. Außerdem ist TGF- $\beta$ ein Überlebensfaktor für natürlich vorkommende Foxp3+ regulatorische T-Zellen und eine zentrale Komponente für deren suppressive Aktivität, vor allem durch die Suppression der IFN- $\gamma$ Antwort (Karpus and Swanborg, 1991), in vivo (Marie et al., 2005). Die signifikant höhere CD69 Expression in unseren transduzierten Zellen könnte ebenfalls keine pro-inflammatorischen Ereignisse induzieren, da sich schließlich auch der Krankheitsverlauf der EAE nicht nach Injektion der transduzierten TZellen verschlimmerte. Es könnte sogar sein, dass durch die erhöhte CD69 Expression die Expansion von regulatorischen T-Zellen ausgelöst wurde, die bekanntermaßen eine suppressive Funktion in autoimmunen Erkrankungen haben (Kim et al., 2007; Sakaguchi, 2005).

Um die BDNF Überexpression in vivo zu detektieren, wurde versucht den BDNF spezifischen TrkB Rezeptor in den Rückenmarksquerschnitten der behandelten Tiere nachzuweisen. Dieser Rezeptor wird nach Bindung mit seinem Liganden phosphoryliert (Kaplan et al., 1991). Dieser phosphorylierte Rezeptor (pTrkB) kann anschließend mit einem spezifischen Antikörper detektiert werden und die Überexpression des BDNF Proteins nachweisen. Die Ergebnisse zeigten, dass die pTrkB Expression zunächst lediglich auf die Läsionen beschränkt war, die durch die Infiltration von T-Zellen und Makrophagen charakterisiert wird. Des Weiteren führte die Injektion der BDNF überexprimierenden MOG-spezfischen TZR 
transgenen T-Zellen im Vergleich zur Kontrollgruppe zu einer vermehrten Expression des pTrkB in den Läsionen. Dadurch wurde erneut die Funktionalität des Systems in vivo bestätigt, da TrkB vermutlich in den Läsionen durch die BDNF überexprimierenden T-Zellen aktiviert wurde, was wiederum die Wirksamkeit von BDNF direkt vor Ort nachweisen würde. Da kaum eine Colokalisation der T-Zellen mit pTrkB beobachtet werden konnte, scheint BDNF in diesem Fall nicht auf autokrine Art und Weise sezerniert zu werden. Das bedeutet, dass die BDNF Überexpression scheinbar nicht die T-Zellen selbst beeinflusst, auch Makrophagen und Mikroglia scheinen in diesem Ansatz nicht die Zielzellen von BDNF zu sein. Da aber ein neuroprotektiver Effekt erzielt werden konnte, könnte BDNF direkt auf die Axone wirken, da bereits durch Andere (Meyer-Franke et al., 1998) und auch durch die eigene Arbeitsgruppe gezeigt werden konnte (Daten noch nicht veröffentlicht), dass der BDNF spezifischen TrkB Rezeptor auch auf Axonen exprimiert wird.

Abschließend ist zu sagen, dass diese Ergebnisse ganz deutlich eine funktionelle Rolle des BDNF in der EAE aufzeigen konnten. Der genaue Wirkmechanismus ist zwar nicht bekannt, aber es konnten verschiedene Ansatzpunkte, wie dem direkten Einfluss des BDNF auf Axone über die TrkB Rezeptoren oder dem indirekten Einfluss über die Runterregulierung von iNOS in Mikroglia bzw. der Expansion von regulatorischen T-Zellen, vorgeschlagen werden. Außerdem geben diese Daten, die die neuroprotektive Funktion des BDNF in der EAE darstellen konnten, Hoffnung für die weitere Erforschung der Therapeutika, die in der Multiplen Sklerose bzw. der autoimmunen Demyelinisierung des ZNS die BDNF Expression hochregulieren können. 


\section{Zusammenfassung}

Das Neurotrophin Brain derived neurotrophic factor (BDNF) ist essenziell für die Entwicklung und den Erhalt des Nervensystems. Seine Expression ist nicht nur auf Neuronen begrenzt, sondern wurde auch in Immunzellen, wie z.B. in den Infiltraten in Multiple Sklerose Läsionen, detektiert. Zahlreiche Studien deuten auf eine neuroprotektive Funktion des BDNF hin. Dass Immunzellen BDNF exprimieren, welches zudem neuroprotektiv wirken könnte wurde auch im „Konzept der neuroprotektiven Autoimmunität“ aufgegriffen. Dieses Konzept baut darauf auf, dass autoimmune T-Zellen neben ihrer aggressiv destruktiven Funktion durch die Expression von regulatorischen Molekülen, wie z.B. auch dem BDNF, axonprotektive Fähigkeiten besitzen. Ausgehend von dieser Hypothese wurde das BDNF in der vorliegenden Arbeit auf zwei verschiedenen Wegen untersucht.

Im Ersten Teil standen grundlagenorientierte Untersuchungen im Vordergrund. Dabei ging es um die Erforschung der unterschiedlichen Splice-Varianten des BDNF Gens und deren Expressionsmuster im ZNS und in den Immunzellen. Es wurden insgesamt neun verschiedene Splice-Varianten für BDNF beschrieben, die sich in ihrer Promoterregion, aber nicht in der Protein-kodierenden Sequenz unterscheiden. Real-Time Untersuchungen der mRNA ergaben, dass im Mausgehirn alle existierenden Splice-Varianten exprimiert werden, während in peripheren lymphatischen Organen (Thymus, Milz, Lymphknoten) und aufgereinigten Immunzellen (T-Zellen, Makrophagen) lediglich die Splice-Variante mBDNF 3 nachgewiesen werden konnte. Nach Stimulation der T-Zellen wurde die BDNF 3 mRNA hochreguliert, während es in Makrophagen nach Stimulation zu einer Verringerung der BDNF 3 mRNA kam. Eine weitere detaillierte Analyse von differenzierten Zellpopulationen aus dem Gehirn ergab, dass gereinigte Mikroglia wie Makrophagen nur mBDNF 3 exprimieren, während in gereinigten Astrozyten alle Splice-Varianten, ähnlich dem Gesamthirn, nachweisbar sind.

Zusammenfassend konnte gezeigt werden, dass sich die Expression von BDNF SpliceVarianten zwischen Immunsystem und Gehirn signifikant unterscheidet. Dabei scheinen unterschiedliche Regulationsmechanismen der BDNF mRNA Expression in den verschiedenen Zelltypen zu existieren. Die physiologische Relevanz dieser Splice-Varianten ist jedoch immer noch nicht aufgeklärt.

Im zweiten Teil der Arbeit ging es um die Überexpression von BDNF in T-Zellen und anschließendem adoptiven Transfer in einem Tiermodell der Experimentellen autoimmunen Enzephalomyelitis (EAE). Dadurch sollte getestet werden, ob diese Injektion den Krankheitsverlauf, aber vor allem den axonalen Schaden positiv beeinflussen kann und somit 
die Hypothese unterstützt, dass BDNF in der EAE neuroprotektiv wirkt und eventuell als potentieller Therapieansatz in Frage kommt. Dafür wurde die codierende murine BDNF Gensequenz in ein lentivirales Transfektionssystem einkloniert. Dieses lentivirale System wurde erfolgreich zur Generierung von BDNF überexprimierenden MOG-spezifische TZellrezeptor (TZR) transgenen T-Zellen verwendet, die zusätzlich GFP als Transgen ubiquitär exprimieren. Diese Lentivirus transduzierten T-Zellen wurden in C57BL/6 Mäuse i.v. injiziert, in denen zuvor eine EAE ausgelöst wurde. Die mit den BDNF transduzierten TZellen behandelten Tiere zeigten zunächst einen verzögerten und deutlich reduzierten Krankheitsverlauf, der sich jedoch allmählich den Kontrollgruppen näherte. Immunhistochemische Untersuchungen zeigten keinen Unterschied in der Infiltration von TZellen und Makrophagen zwischen den beiden Versuchsgruppen. Der Aktivierungsstatus, der die CD25 und CD44 Expression betrifft, war in den injizierten T-Zellen im Vergleich zu den endogenen T-Zellen aus dem ZNS runterreguliert. Die Charakterisierung des axonalen Schadens zeigte geringere APP Akkumulationen und höhere Axondichte in den Läsionen und Periläsionen der BDNF behandelten Tieren im Vergleich zu den GFP behandelten Kontrolltieren, was einen besseren Axonerhalt in den BDNF behandelten Tieren bezeugte. Ein Effektormolekül, dass für die Entstehung des axonalen Schadens mitverantwortlich gemacht wird, ist die induzierbare NO-Synthetase (iNOS), die auch in den BDNF behandelten Mäusen signifikant geringer exprimiert war. Auch die Signaltransduktionswege des BDNF wurden immunhistochemisch untersucht. Dafür wurde der aktivierte BDNF spezifische Rezeptor TrkB (phospho TrkB) in den beiden Vergleichgruppen angefärbt. Das Ergebnis zeigte ein sehr viel stärkeres Signal in den BDNF behandelten Tieren und die Expression war lediglich auf die Läsionen, die durch die Infiltration von T-Zellen und Makrophagen gekennzeichnet waren, begrenzt. Dies bestätigte nochmals die Funktionalität des Systems in vivo, da wahrscheinlich der TrkB Rezeptor durch die BDNF Überexpression aktiviert wurde und somit auch einen Nachweis für die Wirksamkeit von BDNF direkt vor Ort lieferte.

Die Überexpression von BDNF in T-Zellen sorgte in vivo ganz deutlich für einen besseren Axonerhalt und bestätigte damit seine funktionelle Relevanz in der EAE. Durch diese Ergebnisse wird das Neurotrophin BDNF in den Focus neuer Therapiestragien der Multiplen Sklerose und anderer Autoimmunerkrankungen gesetzt. 


\section{Literaturverzeichnis}

1999. A controlled trial of recombinant methionyl human BDNF in ALS: The BDNF Study Group (Phase III). Neurology 52, 1427-1433.

Aboul-Enein, F., Bauer, J., Klein, M., Schubart, A., Flugel, A., Ritter, T., Kawakami, N., Siedler, F., Linington, C., Wekerle, H., Lassmann, H., Bradl, M., 2004. Selective and antigen-dependent effects of myelin degeneration on central nervous system inflammation. J Neuropathol Exp Neurol 63, 1284-1296.

Aboul-Enein, F., Rauschka, H., Kornek, B., Stadelmann, C., Stefferl, A., Bruck, W., Lucchinetti, C., Schmidbauer, M., Jellinger, K., Lassmann, H., 2003. Preferential loss of myelin-associated glycoprotein reflects hypoxia-like white matter damage in stroke and inflammatory brain diseases. J Neuropathol Exp Neurol 62, 25-33.

Abramchik, G.V., Yermakova, S.S., Kaliunov, V.N., Tanina, R.M., Tumilovich, M.K., 1988. The immunomodulatory effect of nerve growth factor. J Neurosci Res 19, 349-356.

Adler, R., Landa, K.B., Manthorpe, M., Varon, S., 1979. Cholinergic neuronotrophic factors: intraocular distribution of trophic activity for ciliary neurons. Science 204, 1434-1436.

Agnello, D., Bigini, P., Villa, P., Mennini, T., Cerami, A., Brines, M.L., Ghezzi, P., 2002. Erythropoietin exerts an anti-inflammatory effect on the CNS in a model of experimental autoimmune encephalomyelitis. Brain Res 952, 128-134.

Allen, S.J., Wilcock, G.K., Dawbarn, D., 1999. Profound and selective loss of catalytic TrkB immunoreactivity in Alzheimer's disease. Biochem Biophys Res Commun 264, 648651.

Aloe, L., Simone, M.D., Properzi, F., 1999. Nerve growth factor: a neurotrophin with activity on cells of the immune system. Microsc Res Tech 45, 285-291.

Aloe, L., Tuveri, M.A., 1997. Nerve growth factor and autoimmune rheumatic diseases. Clin Exp Rheumatol 15, 433-438.

Altieri, M., Marini, F., Arban, R., Vitulli, G., Jansson, B.O., 2004. Expression analysis of brain-derived neurotrophic factor (BDNF) mRNA isoforms after chronic and acute antidepressant treatment. Brain Res 1000, 148-155.

Ambrosini, E., Aloisi, F., 2004. Chemokines and glial cells: a complex network in the central nervous system. Neurochem Res 29, 1017-1038.

Aoyama, M., Asai, K., Shishikura, T., Kawamoto, T., Miyachi, T., Yokoi, T., Togari, H., Wada, Y., Kato, T., Nakagawara, A., 2001. Human neuroblastomas with unfavorable biologies express high levels of brain-derived neurotrophic factor mRNA and a variety of its variants. Cancer Lett 164, 51-60.

Arakawa, Y., Sendtner, M., Thoenen, H., 1990. Survival effect of ciliary neurotrophic factor (CNTF) on chick embryonic motoneurons in culture: comparison with other neurotrophic factors and cytokines. J Neurosci 10, 3507-3515.

Barde, Y.A., Edgar, D., Thoenen, H., 1982. Purification of a new neurotrophic factor from mammalian brain. Embo J 1, 549-553.

Baron, J.L., Madri, J.A., Ruddle, N.H., Hashim, G., Janeway, C.A., Jr., 1993. Surface expression of alpha 4 integrin by CD4 T cells is required for their entry into brain parenchyma. J Exp Med 177, 57-68.

Barouch, R., Appel, E., Kazimirsky, G., Brodie, C., 2001. Macrophages express neurotrophins and neurotrophin receptors. Regulation of nitric oxide production by NT-3. J Neuroimmunol 112, 72-77.

Baumann, J.G., Unutmaz, D., Miller, M.D., Breun, S.K., Grill, S.M., Mirro, J., Littman, D.R., Rein, A., KewalRamani, V.N., 2004. Murine T cells potently restrict human immunodeficiency virus infection. J Virol 78, 12537-12547. 
Bayas, A., Kruse, N., Moriabadi, N.F., Weber, F., Hummel, V., Wohleben, G., Gold, R., Toyka, K.V., Rieckmann, P., 2003. Modulation of cytokine mRNA expression by brain-derived neurotrophic factor and nerve growth factor in human immune cells. Neurosci Lett 335, 155-158.

Bentley, C.A., Lee, K.F., 2000. p75 is important for axon growth and schwann cell migration during development. J Neurosci 20, 7706-7715.

Berg, M.M., Sternberg, D.W., Parada, L.F., Chao, M.V., 1992. K-252a inhibits nerve growth factor-induced trk proto-oncogene tyrosine phosphorylation and kinase activity. J Biol Chem 267, 13-16.

Besser, M., Wank, R., 1999. Cutting edge: clonally restricted production of the neurotrophins brain-derived neurotrophic factor and neurotrophin-3 mRNA by human immune cells and Th1/Th2-polarized expression of their receptors. J Immunol 162, 6303-6306.

Bettelli, E., Carrier, Y., Gao, W., Korn, T., Strom, T.B., Oukka, M., Weiner, H.L., Kuchroo, V.K., 2006. Reciprocal developmental pathways for the generation of pathogenic effector TH17 and regulatory T cells. Nature 441, 235-238.

Bettelli, E., Pagany, M., Weiner, H.L., Linington, C., Sobel, R.A., Kuchroo, V.K., 2003. Myelin oligodendrocyte glycoprotein-specific T cell receptor transgenic mice develop spontaneous autoimmune optic neuritis. J Exp Med 197, 1073-1081.

Bieniasz, P.D., Fridell, R.A., Anthony, K., Cullen, B.R., 1997. Murine CXCR-4 is a functional coreceptor for T-cell-tropic and dual-tropic strains of human immunodeficiency virus type 1. J Virol 71, 7097-7100.

Bishop, J.F., Mueller, G.P., Mouradian, M.M., 1994. Alternate 5' exons in the rat brainderived neurotrophic factor gene: differential patterns of expression across brain regions. Brain Res Mol Brain Res 26, 225-232.

Bothwell, M., 1995. Functional interactions of neurotrophins and neurotrophin receptors. Annu Rev Neurosci 18, 223-253.

Bramlett, H.M., Kraydieh, S., Green, E.J., Dietrich, W.D., 1997. Temporal and regional patterns of axonal damage following traumatic brain injury: a beta-amyloid precursor protein immunocytochemical study in rats. J Neuropathol Exp Neurol 56, 1132-1141.

Braun, A., Lommatzsch, M., Mannsfeldt, A., Neuhaus-Steinmetz, U., Fischer, A., Schnoy, N., Lewin, G.R., Renz, H., 1999. Cellular sources of enhanced brain-derived neurotrophic factor production in a mouse model of allergic inflammation. Am J Respir Cell Mol Biol 21, 537-546.

Bravo, J., Heath, J.K., 2000. Receptor recognition by gp130 cytokines. Embo J 19, 23992411.

Brodie, C., Oshiba, A., Renz, H., Bradley, K., Gelfand, E.W., 1996. Nerve growth-factor and anti-CD40 provide opposite signals for the production of IgE in interleukin-4-treated lymphocytes. Eur J Immunol 26, 171-178.

Browning, J., Horner, J.W., Pettoello-Mantovani, M., Raker, C., Yurasov, S., DePinho, R.A., Goldstein, H., 1997. Mice transgenic for human CD4 and CCR5 are susceptible to HIV infection. Proc Natl Acad Sci U S A 94, 14637-14641.

Byram, S.C., Carson, M.J., DeBoy, C.A., Serpe, C.J., Sanders, V.M., Jones, K.J., 2004. CD4positive $\mathrm{T}$ cell-mediated neuroprotection requires dual compartment antigen presentation. J Neurosci 24, 4333-4339.

Calida, D.M., Constantinescu, C., Purev, E., Zhang, G.X., Ventura, E.S., Lavi, E., Rostami, A., 2001. Cutting edge: C3, a key component of complement activation, is not required for the development of myelin oligodendrocyte glycoprotein peptide-induced experimental autoimmune encephalomyelitis in mice. J Immunol 166, 723-726.

Caroleo, M.C., Costa, N., Bracci-Laudiero, L., Aloe, L., 2001. Human monocyte/macrophages activate by exposure to LPS overexpress NGF and NGF receptors. J Neuroimmunol 113, 193-201. 
Carroll, P., Lewin, G.R., Koltzenburg, M., Toyka, K.V., Thoenen, H., 1998. A role for BDNF in mechanosensation. Nat Neurosci 1, 42-46.

Chao, M.V., Bothwell, M., 2002. Neurotrophins: to cleave or not to cleave. Neuron 33, 9-12.

Charo, I.F., Ransohoff, R.M., 2006. The many roles of chemokines and chemokine receptors in inflammation. N Engl J Med 354, 610-621.

Chen, W.G., Chang, Q., Lin, Y., Meissner, A., West, A.E., Griffith, E.C., Jaenisch, R., Greenberg, M.E., 2003. Derepression of BDNF transcription involves calciumdependent phosphorylation of MeCP2. Science 302, 885-889.

Ciriaco, E., Dall'Aglio, C., Hannestad, J., Huerta, J.J., Laura, R., Germana, G., Vega, J.A., 1996. Localization of Trk neurotrophin receptor-like proteins in avian primary lymphoid organs (thymus and bursa of Fabricius). J Neuroimmunol 69, 73-83.

Comi, G., Pulizzi, A., Rovaris, M., Abramsky, O., Arbizu, T., Boiko, A., Gold, R., Havrdova, E., Komoly, S., Selmaj, K., Sharrack, B., Filippi, M., 2008. Effect of laquinimod on MRI-monitored disease activity in patients with relapsing-remitting multiple sclerosis: a multicentre, randomised, double-blind, placebo-controlled phase IIb study. Lancet 371, 2085-2092.

Connor, B., Young, D., Yan, Q., Faull, R.L., Synek, B., Dragunow, M., 1997. Brain-derived neurotrophic factor is reduced in Alzheimer's disease. Brain Res Mol Brain Res 49, 71-81.

Costello, E., Munoz, M., Buetti, E., Meylan, P.R., Diggelmann, H., Thali, M., 2000. Gene transfer into stimulated and unstimulated T lymphocytes by HIV-1-derived lentiviral vectors. Gene Ther 7, 596-604.

Craner, M.J., Damarjian, T.G., Liu, S., Hains, B.C., Lo, A.C., Black, J.A., Newcombe, J., Cuzner, M.L., Waxman, S.G., 2005. Sodium channels contribute to microglia/macrophage activation and function in EAE and MS. Glia 49, 220-229.

Curtis, R., Adryan, K.M., Zhu, Y., Harkness, P.J., Lindsay, R.M., DiStefano, P.S., 1993. Retrograde axonal transport of ciliary neurotrophic factor is increased by peripheral nerve injury. Nature 365, 253-255.

Dardalhon, V., Awasthi, A., Kwon, H., Galileos, G., Gao, W., Sobel, R.A., Mitsdoerffer, M., Strom, T.B., Elyaman, W., Ho, I.C., Khoury, S., Oukka, M., Kuchroo, V.K., 2008. IL4 inhibits TGF-beta-induced Foxp3 + T cells and, together with TGF-beta, generates IL-9+ IL-10+ Foxp3(-) effector T cells. Nat Immunol 9, 1347-1355.

Davies, P., Maloney, A.J., 1976. Selective loss of central cholinergic neurons in Alzheimer's disease. Lancet 2, 1403.

Dello Russo, C., Gavrilyuk, V., Weinberg, G., Almeida, A., Bolanos, J.P., Palmer, J., Pelligrino, D., Galea, E., Feinstein, D.L., 2003. Peroxisome proliferator-activated receptor gamma thiazolidinedione agonists increase glucose metabolism in astrocytes. J Biol Chem 278, 5828-5836.

Dittrich, F., Ochs, G., Grosse-Wilde, A., Berweiler, U., Yan, Q., Miller, J.A., Toyka, K.V., Sendtner, M., 1996. Pharmacokinetics of intrathecally applied BDNF and effects on spinal motoneurons. Exp Neurol 141, 225-239.

D'Onofrio, M., de Grazia, U., Morrone, S., Cuomo, L., Spinsanti, P., Frati, L., Gulino, A., Ragona, G., 2000. Expression of neurotrophin receptors in normal and malignant B lymphocytes. Eur Cytokine Netw 11, 283-291.

D'Souza, S.D., Alinauskas, K.A., Antel, J.P., 1996. Ciliary neurotrophic factor selectively protects human oligodendrocytes from tumor necrosis factor-mediated injury. $\mathrm{J}$ Neurosci Res 43, 289-298.

Ehrenreich, H., Aust, C., Krampe, H., Jahn, H., Jacob, S., Herrmann, M., Siren, A.L., 2004. Erythropoietin: novel approaches to neuroprotection in human brain disease. Metab Brain Dis 19, 195-206. 
Ehrhard, P.B., Erb, P., Graumann, U., Otten, U., 1993. Expression of nerve growth factor and nerve growth factor receptor tyrosine kinase Trk in activated CD4-positive T-cell clones. Proc Natl Acad Sci U S A 90, 10984-10988.

Ehrhard, P.B., Erb, P., Graumann, U., Schmutz, B., Otten, U., 1994. Expression of functional trk tyrosine kinase receptors after T cell activation. J Immunol 152, 2705-2709.

Ehrhard, P.B., Ganter, U., Stalder, A., Bauer, J., Otten, U., 1993a. Expression of functional trk protooncogene in human monocytes. Proc Natl Acad Sci U S A 90, 5423-5427.

Eide, F.F., Vining, E.R., Eide, B.L., Zang, K., Wang, X.Y., Reichardt, L.F., 1996. Naturally occurring truncated trkB receptors have dominant inhibitory effects on brain-derived neurotrophic factor signaling. J Neurosci 16, 3123-3129.

Elkabes, S., DiCicco-Bloom, E.M., Black, I.B., 1996. Brain microglia/macrophages express neurotrophins that selectively regulate microglial proliferation and function. $\mathrm{J}$ Neurosci 16, 2508-2521.

Elliott, E., Atlas, R., Lange, A., Ginzburg, I., 2005. Brain-derived neurotrophic factor induces a rapid dephosphorylation of tau protein through a PI-3 Kinase signalling mechanism. Eur J Neurosci 22, 1081-1089.

Ernfors, P., Lee, K.F., Jaenisch, R., 1994. Mice lacking brain-derived neurotrophic factor develop with sensory deficits. Nature 368, 147-150.

Esposito, D., Patel, P., Stephens, R.M., Perez, P., Chao, M.V., Kaplan, D.R., Hempstead, B.L., 2001. The cytoplasmic and transmembrane domains of the p75 and Trk A receptors regulate high affinity binding to nerve growth factor. J Biol Chem 276, 32687-32695.

Felts, P.A., Smith, K.J., Gregson, N.A., Hughes, R.A., 2002. Brain-derived neurotrophic factor in experimental autoimmune neuritis. J Neuroimmunol 124, 62-69.

Ferrer, I., Marin, C., Rey, M.J., Ribalta, T., Goutan, E., Blanco, R., Tolosa, E., Marti, E., 1999. BDNF and full-length and truncated TrkB expression in Alzheimer disease. Implications in therapeutic strategies. J Neuropathol Exp Neurol 58, 729-739.

Fridmacher, V., Kaltschmidt, B., Goudeau, B., Ndiaye, D., Rossi, F.M., Pfeiffer, J., Kaltschmidt, C., Israel, A., Memet, S., 2003. Forebrain-specific neuronal inhibition of nuclear factor-kappaB activity leads to loss of neuroprotection. J Neurosci 23, 94039408.

Friese, M.A., Fugger, L., 2005. Autoreactive CD8+ T cells in multiple sclerosis: a new target for therapy? Brain 128, 1747-1763.

Frim, D.M., Uhler, T.A., Galpern, W.R., Beal, M.F., Breakefield, X.O., Isacson, O., 1994. Implanted fibroblasts genetically engineered to produce brain-derived neurotrophic factor prevent 1-methyl-4-phenylpyridinium toxicity to dopaminergic neurons in the rat. Proc Natl Acad Sci U S A 91, 5104-5108.

Frohman, E.M., Racke, M.K., Raine, C.S., 2006. Multiple sclerosis--the plaque and its pathogenesis. N Engl J Med 354, 942-955.

Garcia-Suarez, O., Blanco-Gelaz, M.A., Lopez, M.L., Germana, A., Cabo, R., Diaz-Esnal, B., Silos-Santiago, I., Ciriaco, E., Vega, J.A., 2002. Massive lymphocyte apoptosis in the thymus of functionally deficient TrkB mice. J Neuroimmunol 129, 25-34.

Garcia-Suarez, O., Germana, A., Hannestad, J., Ciriaco, E., Silos-Santiago, I., Germana, G., Vega, J.A., 2001. Involvement of the NGF receptors (Trka and p75lngfr) in the development and maintenance of the thymus. Ital J Anat Embryol 106, 279-285.

Garzon, D., Yu, G., Fahnestock, M., 2002. A new brain-derived neurotrophic factor transcript and decrease in brain-derived neurotrophic factor transcripts 1, 2 and 3 in Alzheimer's disease parietal cortex. J Neurochem 82, 1058-1064.

Genc, K., Genc, S., Baskin, H., Semin, I., 2006. Erythropoietin decreases cytotoxicity and nitric oxide formation induced by inflammatory stimuli in rat oligodendrocytes. Physiol Res 55, 33-38. 
Genc, S., Koroglu, T.F., Genc, K., 2004. Erythropoietin as a novel neuroprotectant. Restor Neurol Neurosci 22, 105-119.

Ghiringhelli, F., Menard, C., Terme, M., Flament, C., Taieb, J., Chaput, N., Puig, P.E., Novault, S., Escudier, B., Vivier, E., Lecesne, A., Robert, C., Blay, J.Y., Bernard, J., Caillat-Zucman, S., Freitas, A., Tursz, T., Wagner-Ballon, O., Capron, C., Vainchencker, W., Martin, F., Zitvogel, L., 2005. CD4+CD25+ regulatory T cells inhibit natural killer cell functions in a transforming growth factor-beta-dependent manner. J Exp Med 202, 1075-1085.

Gold, R., Linington, C., Lassmann, H., 2006. Understanding pathogenesis and therapy of multiple sclerosis via animal models: 70 years of merits and culprits in experimental autoimmune encephalomyelitis research. Brain 129, 1953-1971.

Gorski, J.A., Balogh, S.A., Wehner, J.M., Jones, K.R., 2003. Learning deficits in forebrainrestricted brain-derived neurotrophic factor mutant mice. Neuroscience 121, 341-354.

Gotz, R., Koster, R., Winkler, C., Raulf, F., Lottspeich, F., Schartl, M., Thoenen, H., 1994. Neurotrophin-6 is a new member of the nerve growth factor family. Nature 372, 266269.

Gravel, C., Gotz, R., Lorrain, A., Sendtner, M., 1997. Adenoviral gene transfer of ciliary neurotrophic factor and brain-derived neurotrophic factor leads to long-term survival of axotomized motor neurons. Nat Med 3, 765-770.

Green, D.R., Droin, N., Pinkoski, M., 2003. Activation-induced cell death in T cells. Immunol Rev 193, 70-81.

Haas, J., Hug, A., Viehover, A., Fritzsching, B., Falk, C.S., Filser, A., Vetter, T., Milkova, L., Korporal, M., Fritz, B., Storch-Hagenlocher, B., Krammer, P.H., Suri-Payer, E., Wildemann, B., 2005. Reduced suppressive effect of CD4+CD25high regulatory T cells on the $\mathrm{T}$ cell immune response against myelin oligodendrocyte glycoprotein in patients with multiple sclerosis. Eur J Immunol 35, 3343-3352.

Hafler, D.A., 2004. Multiple sclerosis. J Clin Invest 113, 788-794.

Hagg, T., Varon, S., Louis, J.C., 1993. Ciliary neurotrophic factor (CNTF) promotes lowaffinity nerve growth factor receptor and CD4 expression by rat CNS microglia. $\mathrm{J}$ Neuroimmunol 48, 177-187.

Hallbook, F., 1999. Evolution of the vertebrate neurotrophin and Trk receptor gene families. Curr Opin Neurobiol 9, 616-621.

Hammarberg, H., Lidman, O., Lundberg, C., Eltayeb, S.Y., Gielen, A.W., Muhallab, S., Svenningsson, A., Linda, H., van Der Meide, P.H., Cullheim, S., Olsson, T., Piehl, F., 2000. Neuroprotection by encephalomyelitis: rescue of mechanically injured neurons and neurotrophin production by CNS-infiltrating T and natural killer cells. J Neurosci 20, 5283-5291.

Hannestad, J., Garcia-Suarez, O., Huerta, J.J., Esteban, I., Naves, F.J., Vega, J.A., 1997. TrkA neutrophin receptor protein in the rat and human thymus. Anat Rec 249, 373-379.

Hannestad, J., Marino, F., Germana, A., Catania, S., Abbate, F., Ciriaco, E., Vega, J.A., 2000. Trk neurotrophin receptor-like proteins in the teleost Dicentrarchus labrax. Cell Tissue Res 300, 1-9.

Hauben, E., Butovsky, O., Nevo, U., Yoles, E., Moalem, G., Agranov, E., Mor, F., LeibowitzAmit, R., Pevsner, E., Akselrod, S., Neeman, M., Cohen, I.R., Schwartz, M., 2000. Passive or active immunization with myelin basic protein promotes recovery from spinal cord contusion. J Neurosci 20, 6421-6430.

Hauser, S.L., Oksenberg, J.R., 2006. The neurobiology of multiple sclerosis: genes, inflammation, and neurodegeneration. Neuron 52, 61-76.

Hellweg, R., Jockers-Scherubl, M., 1994. Neurotrophic factors in memory disorders. Life Sci $55,2165-2169$. 
Hemmer, B., Archelos, J.J., Hartung, H.P., 2002. New concepts in the immunopathogenesis of multiple sclerosis. Nat Rev Neurosci 3, 291-301.

Hemmer, B., Nessler, S., Zhou, D., Kieseier, B., Hartung, H.P., 2006. Immunopathogenesis and immunotherapy of multiple sclerosis. Nat Clin Pract Neurol 2, 201-211.

Hempstead, B.L., 2002. The many faces of p75NTR. Curr Opin Neurobiol 12, 260-267.

Herman, A.E., Freeman, G.J., Mathis, D., Benoist, C., 2004. CD4+CD25+ T regulatory cells dependent on ICOS promote regulation of effector cells in the prediabetic lesion. J Exp Med 199, 1479-1489.

Herrero-Herranz, E., Pardo, L.A., Gold, R., Linker, R.A., 2008. Pattern of axonal injury in murine myelin oligodendrocyte glycoprotein induced experimental autoimmune encephalomyelitis: implications for multiple sclerosis. Neurobiol Dis 30, 162-173.

Hildeman, D.A., Zhu, Y., Mitchell, T.C., Kappler, J., Marrack, P., 2002. Molecular mechanisms of activated T cell death in vivo. Curr Opin Immunol 14, 354-359.

Hilton, D.J., Nicola, N.A., Metcalf, D., 1988. Specific binding of murine leukemia inhibitory factor to normal and leukemic monocytic cells. Proc Natl Acad Sci U S A 85, 59715975.

Hilton, D.J., Nicola, N.A., Metcalf, D., 1991. Distribution and comparison of receptors for leukemia inhibitory factor on murine hemopoietic and hepatic cells. J Cell Physiol 146, 207-215.

Hock, C., Heese, K., Hulette, C., Rosenberg, C., Otten, U., 2000. Region-specific neurotrophin imbalances in Alzheimer disease: decreased levels of brain-derived neurotrophic factor and increased levels of nerve growth factor in hippocampus and cortical areas. Arch Neurol 57, 846-851.

Hohlfeld, R., 1997. Biotechnological agents for the immunotherapy of multiple sclerosis. Principles, problems and perspectives. Brain 120 ( Pt 5), 865-916.

Hohlfeld, R., Kerschensteiner, M., Stadelmann, C., Lassmann, H., Wekerle, H., 2000. The neuroprotective effect of inflammation: implications for the therapy of multiple sclerosis. J Neuroimmunol 107, 161-166.

Holsinger, R.M., Schnarr, J., Henry, P., Castelo, V.T., Fahnestock, M., 2000. Quantitation of BDNF mRNA in human parietal cortex by competitive reverse transcriptionpolymerase chain reaction: decreased levels in Alzheimer's disease. Brain Res Mol Brain Res 76, 347-354.

Howells, D.W., Porritt, M.J., Wong, J.Y., Batchelor, P.E., Kalnins, R., Hughes, A.J., Donnan, G.A., 2000. Reduced BDNF mRNA expression in the Parkinson's disease substantia nigra. Exp Neurol 166, 127-135.

Huang, E.J., Reichardt, L.F., 2001. Neurotrophins: roles in neuronal development and function. Annu Rev Neurosci 24, 677-736.

Huang, R., Huang, J., Cathcart, H., Smith, S., Poduslo, S.E., 2007. Genetic variants in brainderived neurotrophic factor associated with Alzheimer's disease. J Med Genet 44, e66.

Huseby, E.S., Liggitt, D., Brabb, T., Schnabel, B., Ohlen, C., Goverman, J., 2001. A pathogenic role for myelin-specific $\mathrm{CD} 8(+) \mathrm{T}$ cells in a model for multiple sclerosis. $\mathrm{J}$ Exp Med 194, 669-676.

Ip, N.Y., Ibanez, C.F., Nye, S.H., McClain, J., Jones, P.F., Gies, D.R., Belluscio, L., Le Beau, M.M., Espinosa, R., 3rd, Squinto, S.P., et al., 1992. Mammalian neurotrophin-4: structure, chromosomal localization, tissue distribution, and receptor specificity. Proc Natl Acad Sci U S A 89, 3060-3064.

Ip, N.Y., Yancopoulos, G.D., 1994. Neurotrophic factor receptors: just like other growth factor and cytokine receptors? Curr Opin Neurobiol 4, 400-405.

Jack, C., Ruffini, F., Bar-Or, A., Antel, J.P., 2005. Microglia and multiple sclerosis. J Neurosci Res 81, 363-373. 
Jager, A., Dardalhon, V., Sobel, R.A., Bettelli, E., Kuchroo, V.K., 2009. Th1, Th17, and Th9 effector cells induce experimental autoimmune encephalomyelitis with different pathological phenotypes. J Immunol 183, 7169-7177.

Jones, M.V., Nguyen, T.T., Deboy, C.A., Griffin, J.W., Whartenby, K.A., Kerr, D.A., Calabresi, P.A., 2008. Behavioral and pathological outcomes in MOG 35-55 experimental autoimmune encephalomyelitis. J Neuroimmunol 199, 83-93.

Jones, T.B., Basso, D.M., Sodhi, A., Pan, J.Z., Hart, R.P., MacCallum, R.C., Lee, S., Whitacre, C.C., Popovich, P.G., 2002. Pathological CNS autoimmune disease triggered by traumatic spinal cord injury: implications for autoimmune vaccine therapy. J Neurosci 22, 2690-2700.

Jordan, F.L., Thomas, W.E., 1988. Brain macrophages: questions of origin and interrelationship. Brain Res 472, 165-178.

Kahn, M.A., Ellison, J.A., Speight, G.J., de Vellis, J., 1995. CNTF regulation of astrogliosis and the activation of microglia in the developing rat central nervous system. Brain Res $685,55-67$.

Kaltschmidt, B., Ndiaye, D., Korte, M., Pothion, S., Arbibe, L., Prullage, M., Pfeiffer, J., Lindecke, A., Staiger, V., Israel, A., Kaltschmidt, C., Memet, S., 2006. NF-kappaB regulates spatial memory formation and synaptic plasticity through protein kinase A/CREB signaling. Mol Cell Biol 26, 2936-2946.

Kaplan, D.R., Martin-Zanca, D., Parada, L.F., 1991. Tyrosine phosphorylation and tyrosine kinase activity of the trk proto-oncogene product induced by NGF. Nature 350, 158160.

Karpus, W.J., Swanborg, R.H., 1991. CD4+ suppressor cells inhibit the function of effector cells of experimental autoimmune encephalomyelitis through a mechanism involving transforming growth factor-beta. J Immunol 146, 1163-1168.

Katoh-Semba, R., Kaisho, Y., Shintani, A., Nagahama, M., Kato, K., 1996. Tissue distribution and immunocytochemical localization of neurotrophin-3 in the brain and peripheral tissues of rats. J Neurochem 66, 330-337.

Katoh-Semba, R., Semba, R., Kashiwamata, S., Kato, K., 1993. An acceleration of agerelated increases in levels of the beta-subunit of nerve growth factor in selected tissues from senescence-accelerated mice (SAM-P/8). J Mol Neurosci 4, 107-115.

Keegan, B.M., Noseworthy, J.H., 2002. Multiple sclerosis. Annu Rev Med 53, 285-302.

Kernie, S.G., Liebl, D.J., Parada, L.F., 2000. BDNF regulates eating behavior and locomotor activity in mice. Embo J 19, 1290-1300.

Kerschensteiner, M., Gallmeier, E., Behrens, L., Leal, V.V., Misgeld, T., Klinkert, W.E., Kolbeck, R., Hoppe, E., Oropeza-Wekerle, R.L., Bartke, I., Stadelmann, C., Lassmann, H., Wekerle, H., Hohlfeld, R., 1999. Activated human T cells, B cells, and monocytes produce brain-derived neurotrophic factor in vitro and in inflammatory brain lesions: a neuroprotective role of inflammation? J Exp Med 189, 865-870.

Kerschensteiner, M., Stadelmann, C., Dechant, G., Wekerle, H., Hohlfeld, R., 2003. Neurotrophic cross-talk between the nervous and immune systems: implications for neurological diseases. Ann Neurol 53, 292-304.

Kim, D.H., Jahng, T.A., 2004. Continuous brain-derived neurotrophic factor (BDNF) infusion after methylprednisolone treatment in severe spinal cord injury. J Korean Med Sci 19, 113-122.

Kim, J.M., Rasmussen, J.P., Rudensky, A.Y., 2007. Regulatory T cells prevent catastrophic autoimmunity throughout the lifespan of mice. Nat Immunol 8, 191-197.

Kipnis, J., Mizrahi, T., Hauben, E., Shaked, I., Shevach, E., Schwartz, M., 2002. Neuroprotective autoimmunity: naturally occurring CD4+CD25+ regulatory T cells suppress the ability to withstand injury to the central nervous system. Proc Natl Acad Sci U S A 99, 15620-15625. 
Kittur, S.D., Song, L., Endo, H., Adler, W.H., 1992. Nerve growth factor receptor gene expression in human peripheral blood lymphocytes in aging. J Neurosci Res 32, 444448.

Klein, R., Jing, S.Q., Nanduri, V., O'Rourke, E., Barbacid, M., 1991a. The trk proto-oncogene encodes a receptor for nerve growth factor. Cell 65, 189-197.

Klein, R., Nanduri, V., Jing, S.A., Lamballe, F., Tapley, P., Bryant, S., Cordon-Cardo, C., Jones, K.R., Reichardt, L.F., Barbacid, M., 1991b. The trkB tyrosine protein kinase is a receptor for brain-derived neurotrophic factor and neurotrophin-3. Cell 66, 395-403.

Kleinschmidt-DeMasters, B.K., Tyler, K.L., 2005. Progressive multifocal leukoencephalopathy complicating treatment with natalizumab and interferon beta-1a for multiple sclerosis. N Engl J Med 353, 369-374.

Kobayashi, N.R., Fan, D.P., Giehl, K.M., Bedard, A.M., Wiegand, S.J., Tetzlaff, W., 1997. BDNF and NT-4/5 prevent atrophy of rat rubrospinal neurons after cervical axotomy, stimulate GAP-43 and Talpha1-tubulin mRNA expression, and promote axonal regeneration. J Neurosci 17, 9583-9595.

Kohm, A.P., Carpentier, P.A., Anger, H.A., Miller, S.D., 2002. Cutting edge: CD4+CD25+ regulatory $\mathrm{T}$ cells suppress antigen-specific autoreactive immune responses and central nervous system inflammation during active experimental autoimmune encephalomyelitis. J Immunol 169, 4712-4716.

Koizumi, S., Contreras, M.L., Matsuda, Y., Hama, T., Lazarovici, P., Guroff, G., 1988. K252a: a specific inhibitor of the action of nerve growth factor on PC 12 cells. J Neurosci 8, 715-721.

Krammer, P.H., 2000. CD95's deadly mission in the immune system. Nature 407, 789-795.

Kronfeld, I., Kazimirsky, G., Gelfand, E.W., Brodie, C., 2002. NGF rescues human B lymphocytes from anti-IgM induced apoptosis by activation of PKCzeta. Eur J Immunol 32, 136-143.

Krueger, A., Fas, S.C., Baumann, S., Krammer, P.H., 2003. The role of CD95 in the regulation of peripheral T-cell apoptosis. Immunol Rev 193, 58-69.

Kruse, N., Cetin, S., Chan, A., Gold, R., Luhder, F., 2007. Differential expression of BDNF mRNA splice variants in mouse brain and immune cells. J Neuroimmunol 182, 13-21.

Kuhlmann, T., Lingfeld, G., Bitsch, A., Schuchardt, J., Bruck, W., 2002. Acute axonal damage in multiple sclerosis is most extensive in early disease stages and decreases over time. Brain 125, 2202-2212.

Kuhlmann, T., Remington, L., Cognet, I., Bourbonniere, L., Zehntner, S., Guilhot, F., Herman, A., Guay-Giroux, A., Antel, J.P., Owens, T., Gauchat, J.F., 2006. Continued administration of ciliary neurotrophic factor protects mice from inflammatory pathology in experimental autoimmune encephalomyelitis. Am J Pathol 169, 584-598.

Kulkarni, A.B., Huh, C.G., Becker, D., Geiser, A., Lyght, M., Flanders, K.C., Roberts, A.B., Sporn, M.B., Ward, J.M., Karlsson, S., 1993. Transforming growth factor beta 1 null mutation in mice causes excessive inflammatory response and early death. Proc Natl Acad Sci U S A 90, 770-774.

Labouyrie, E., Parrens, M., de Mascarel, A., Bloch, B., Merlio, J.P., 1997. Distribution of NGF receptors in normal and pathologic human lymphoid tissues. J Neuroimmunol 77, 161-173.

Lamballe, F., Klein, R., Barbacid, M., 1991. trkC, a new member of the trk family of tyrosine protein kinases, is a receptor for neurotrophin-3. Cell 66, 967-979.

Lambiase, A., Bracci-Laudiero, L., Bonini, S., Starace, G., D'Elios, M.M., De Carli, M., Aloe, L., 1997. Human CD4+ T cell clones produce and release nerve growth factor and express high-affinity nerve growth factor receptors. J Allergy Clin Immunol 100, 408414. 
Lassmann, H., Bruck, W., Lucchinetti, C., 2001. Heterogeneity of multiple sclerosis pathogenesis: implications for diagnosis and therapy. Trends Mol Med 7, 115-121.

Laurenzi, M.A., Barbany, G., Timmusk, T., Lindgren, J.A., Persson, H., 1994. Expression of mRNA encoding neurotrophins and neurotrophin receptors in rat thymus, spleen tissue and immunocompetent cells. Regulation of neurotrophin- 4 mRNA expression by mitogens and leukotriene B4. Eur J Biochem 223, 733-741.

Lee, R., Kermani, P., Teng, K.K., Hempstead, B.L., 2001. Regulation of cell survival by secreted proneurotrophins. Science 294, 1945-1948.

Levi-Montalcini, R., 1952. Effects of mouse tumor transplantation on the nervous system. Ann N Y Acad Sci 55, 330-344.

Lewin, G.R., Barde, Y.A., 1996. Physiology of the neurotrophins. Annu Rev Neurosci 19, 289-317.

Li, G.L., Farooque, M., Holtz, A., Olsson, Y., 1995. Changes of beta-amyloid precursor protein after compression trauma to the spinal cord: an experimental study in the rat using immunohistochemistry. J Neurotrauma 12, 269-277.

Li, W., Maeda, Y., Yuan, R.R., Elkabes, S., Cook, S., Dowling, P., 2004. Beneficial effect of erythropoietin on experimental allergic encephalomyelitis. Ann Neurol 56, 767-777.

Lindquist, S., Schott, B.H., Ban, M., Compston, D.A., Sawcer, S., Sailer, M., 2005. The BDNF-Val66Met polymorphism: implications for susceptibility to multiple sclerosis and severity of disease. J Neuroimmunol 167, 183-185.

Linker, R.A., Maurer, M., Gaupp, S., Martini, R., Holtmann, B., Giess, R., Rieckmann, P., Lassmann, H., Toyka, K.V., Sendtner, M., Gold, R., 2002. CNTF is a major protective factor in demyelinating CNS disease: a neurotrophic cytokine as modulator in neuroinflammation. Nat Med 8, 620-624.

Linker, R.A., Rott, E., Hofstetter, H.H., Hanke, T., Toyka, K.V., Gold, R., 2005. EAE in beta2 microglobulin-deficient mice: axonal damage is not dependent on MHC-I restricted immune responses. Neurobiol Dis 19, 218-228.

Linnarsson, S., Bjorklund, A., Ernfors, P., 1997. Learning deficit in BDNF mutant mice. Eur J Neurosci 9, 2581-2587.

Liu, Q.R., Lu, L., Zhu, X.G., Gong, J.P., Shaham, Y., Uhl, G.R., 2006. Rodent BDNF genes, novel promoters, novel splice variants, and regulation by cocaine. Brain Res 1067, 112.

Liu, Q.R., Walther, D., Drgon, T., Polesskaya, O., Lesnick, T.G., Strain, K.J., de Andrade, M., Bower, J.H., Maraganore, D.M., Uhl, G.R., 2005. Human brain derived neurotrophic factor (BDNF) genes, splicing patterns, and assessments of associations with substance abuse and Parkinson's Disease. Am J Med Genet B Neuropsychiatr Genet 134B, 93-103.

Lo, A.C., Saab, C.Y., Black, J.A., Waxman, S.G., 2003. Phenytoin protects spinal cord axons and preserves axonal conduction and neurological function in a model of neuroinflammation in vivo. J Neurophysiol 90, 3566-3571.

Lomen-Hoerth, C., Shooter, E.M., 1995. Widespread neurotrophin receptor expression in the immune system and other nonneuronal rat tissues. J Neurochem 64, 1780-1789.

Lou, H., Kim, S.K., Zaitsev, E., Snell, C.R., Lu, B., Loh, Y.P., 2005. Sorting and activitydependent secretion of BDNF require interaction of a specific motif with the sorting receptor carboxypeptidase e. Neuron 45, 245-255.

MacMicking, J., Xie, Q.W., Nathan, C., 1997. Nitric oxide and macrophage function. Annu Rev Immunol 15, 323-350.

Maisonpierre, P.C., Le Beau, M.M., Espinosa, R., 3rd, Ip, N.Y., Belluscio, L., de la Monte, S.M., Squinto, S., Furth, M.E., Yancopoulos, G.D., 1991. Human and rat brainderived neurotrophic factor and neurotrophin-3: gene structures, distributions, and chromosomal localizations. Genomics 10, 558-568. 
Makar, T.K., Bever, C.T., Singh, I.S., Royal, W., Sahu, S.N., Sura, T.P., Sultana, S., Sura, K.T., Patel, N., Dhib-Jalbut, S., Trisler, D., 2009. Brain-derived neurotrophic factor gene delivery in an animal model of multiple sclerosis using bone marrow stem cells as a vehicle. J Neuroimmunol 210, 40-51.

Makar, T.K., Trisler, D., Sura, K.T., Sultana, S., Patel, N., Bever, C.T., 2008. Brain derived neurotrophic factor treatment reduces inflammation and apoptosis in experimental allergic encephalomyelitis. J Neurol Sci 270, 70-76.

Marie, J.C., Letterio, J.J., Gavin, M., Rudensky, A.Y., 2005. TGF-beta1 maintains suppressor function and Foxp3 expression in CD4+CD25+ regulatory T cells. J Exp Med 201, 1061-1067.

Markus, A., Patel, T.D., Snider, W.D., 2002. Neurotrophic factors and axonal growth. Curr Opin Neurobiol 12, 523-531.

Maroder, M., Bellavia, D., Meco, D., Napolitano, M., Stigliano, A., Alesse, E., Vacca, A., Giannini, G., Frati, L., Gulino, A., Screpanti, I., 1996. Expression of trKB neurotrophin receptor during T cell development. Role of brain derived neurotrophic factor in immature thymocyte survival. J Immunol 157, 2864-2872.

Martinowich, K., Hattori, D., Wu, H., Fouse, S., He, F., Hu, Y., Fan, G., Sun, Y.E., 2003. DNA methylation-related chromatin remodeling in activity-dependent BDNF gene regulation. Science 302, 890-893.

Matsumoto, T., Rauskolb, S., Polack, M., Klose, J., Kolbeck, R., Korte, M., Barde, Y.A., 2008. Biosynthesis and processing of endogenous BDNF: CNS neurons store and secrete BDNF, not pro-BDNF. Nat Neurosci 11, 131-133.

McMahon, E.J., Bailey, S.L., Castenada, C.V., Waldner, H., Miller, S.D., 2005. Epitope spreading initiates in the CNS in two mouse models of multiple sclerosis. Nat Med 11, 335-339.

McTigue, D.M., Horner, P.J., Stokes, B.T., Gage, F.H., 1998. Neurotrophin-3 and brainderived neurotrophic factor induce oligodendrocyte proliferation and myelination of regenerating axons in the contused adult rat spinal cord. J Neurosci 18, 5354-5365.

Medana, I., Martinic, M.A., Wekerle, H., Neumann, H., 2001. Transection of major histocompatibility complex class I-induced neurites by cytotoxic T lymphocytes. Am J Pathol 159, 809-815.

Meldolesi, J., Sciorati, C., Clementi, E., 2000. The p75 receptor: first insights into the transduction mechanisms leading to either cell death or survival. Trends Pharmacol Sci 21, 242-243.

Merrill, J.E., Kono, D.H., Clayton, J., Ando, D.G., Hinton, D.R., Hofman, F.M., 1992. Inflammatory leukocytes and cytokines in the peptide-induced disease of experimental allergic encephalomyelitis in SJL and B10.PL mice. Proc Natl Acad Sci U S A 89, 574-578.

Meyer-Franke, A., Wilkinson, G.A., Kruttgen, A., Hu, M., Munro, E., Hanson, M.G., Jr., Reichardt, L.F., Barres, B.A., 1998. Depolarization and cAMP elevation rapidly recruit TrkB to the plasma membrane of CNS neurons. Neuron 21, 681-693.

Michalski, B., Fahnestock, M., 2003. Pro-brain-derived neurotrophic factor is decreased in parietal cortex in Alzheimer's disease. Brain Res Mol Brain Res 111, 148-154.

Miller, F.D., Kaplan, D.R., 2001. Neurotrophin signalling pathways regulating neuronal apoptosis. Cell Mol Life Sci 58, 1045-1053.

Mitsumoto, H., Ikeda, K., Klinkosz, B., Cedarbaum, J.M., Wong, V., Lindsay, R.M., 1994. Arrest of motor neuron disease in wobbler mice cotreated with CNTF and BDNF. Science 265, 1107-1110.

Moalem, G., Gdalyahu, A., Shani, Y., Otten, U., Lazarovici, P., Cohen, I.R., Schwartz, M., 2000. Production of neurotrophins by activated T cells: implications for neuroprotective autoimmunity. J Autoimmun 15, 331-345. 
Moalem, G., Leibowitz-Amit, R., Yoles, E., Mor, F., Cohen, I.R., Schwartz, M., 1999. Autoimmune $\mathrm{T}$ cells protect neurons from secondary degeneration after central nervous system axotomy. Nat Med 5, 49-55.

Morgan, M.E., Sutmuller, R.P., Witteveen, H.J., van Duivenvoorde, L.M., Zanelli, E., Melief, C.J., Snijders, A., Offringa, R., de Vries, R.R., Toes, R.E., 2003. CD25+ cell depletion hastens the onset of severe disease in collagen-induced arthritis. Arthritis Rheum 48, 1452-1460.

Muhallab, S., Lundberg, C., Gielen, A.W., Lidman, O., Svenningsson, A., Piehl, F., Olsson, T., 2002. Differential expression of neurotrophic factors and inflammatory cytokines by myelin basic protein-specific and other recruited $\mathrm{T}$ cells infiltrating the central nervous system during experimental autoimmune encephalomyelitis. Scand J Immunol 55, 264-273.

Nakajima, K., Honda, S., Tohyama, Y., Imai, Y., Kohsaka, S., Kurihara, T., 2001. Neurotrophin secretion from cultured microglia. J Neurosci Res 65, 322-331.

Neumann, H., Misgeld, T., Matsumuro, K., Wekerle, H., 1998. Neurotrophins inhibit major histocompatibility class II inducibility of microglia: involvement of the p75 neurotrophin receptor. Proc Natl Acad Sci U S A 95, 5779-5784.

Niino, M., Bodner, C., Simard, M.L., Alatab, S., Gano, D., Kim, H.J., Trigueiro, M., Racicot, D., Guerette, C., Antel, J.P., Fournier, A., Grand'Maison, F., Bar-Or, A., 2006. Natalizumab effects on immune cell responses in multiple sclerosis. Ann Neurol 59, 748-754.

Nilsson, A.S., Fainzilber, M., Falck, P., Ibanez, C.F., 1998. Neurotrophin-7: a novel member of the neurotrophin family from the zebrafish. FEBS Lett 424, 285-290.

Noseworthy, J.H., Gold, R., Hartung, H.P., 1999. Treatment of multiple sclerosis: recent trials and future perspectives. Curr Opin Neurol 12, 279-293.

Noseworthy, J.H., Lucchinetti, C., Rodriguez, M., Weinshenker, B.G., 2000. Multiple sclerosis. N Engl J Med 343, 938-952.

Nye, S.H., Squinto, S.P., Glass, D.J., Stitt, T.N., Hantzopoulos, P., Macchi, M.J., Lindsay, N.S., Ip, N.Y., Yancopoulos, G.D., 1992. K-252a and staurosporine selectively block autophosphorylation of neurotrophin receptors and neurotrophin-mediated responses. Mol Biol Cell 3, 677-686.

Oemichen, M., 1978. Mononuclear phagocytes in the central nervous system. Origin, mode of distribution, and function of progressive microglia, perivascular cells of intracerebral vessels, free subarachnoidal cells, and epiplexus cells. Schriftenr Neurol 21, I-X, 1167.

Olerup, O., Hillert, J., 1991. HLA class II-associated genetic susceptibility in multiple sclerosis: a critical evaluation. Tissue Antigens 38, 1-15.

Oppenheim, R.W., Prevette, D., Yin, Q.W., Collins, F., MacDonald, J., 1991. Control of embryonic motoneuron survival in vivo by ciliary neurotrophic factor. Science 251, 1616-1618.

Parrens, M., Dubus, P., Groppi, A., Velly, J.F., Labouyrie, E., de Mascarel, A., Merlio, J.P., 1999. Differential expression of NGF receptors in human thymic epithelial tumors. Pathol Res Pract 195, 549-553.

Peng, S., Wuu, J., Mufson, E.J., Fahnestock, M., 2005. Precursor form of brain-derived neurotrophic factor and mature brain-derived neurotrophic factor are decreased in the pre-clinical stages of Alzheimer's disease. J Neurochem 93, 1412-1421.

Perez-Perez, M., Esteban, I., Garcia-Suarez, O., Hannestad, J., Naves, F.J., Vega, J.A., 1999. Expression of the neurotrophin receptor TrkB in rat spleen macrophages. Cell Tissue Res 298, 75-84.

Perez-Perez, M., Garcia-Suarez, O., Esteban, I., Germana, A., Farinas, I., Naves, F.J., Vega, J.A., 2003. p75NTR in the spleen: age-dependent changes, effect of NGF and 4- 
methylcatechol treatment, and structural changes in p75NTR-deficient mice. Anat Rec A Discov Mol Cell Evol Biol 270, 117-128.

Pershadsingh, H.A., Heneka, M.T., Saini, R., Amin, N.M., Broeske, D.J., Feinstein, D.L., 2004. Effect of pioglitazone treatment in a patient with secondary multiple sclerosis. $\mathrm{J}$ Neuroinflammation 1, 3.

Pesini, P., Kopp, J., Wong, H., Walsh, J.H., Grant, G., Hokfelt, T., 1999. An immunohistochemical marker for Wallerian degeneration of fibers in the central and peripheral nervous system. Brain Res 828, 41-59.

Phillips, H.S., Hains, J.M., Armanini, M., Laramee, G.R., Johnson, S.A., Winslow, J.W., 1991. BDNF mRNA is decreased in the hippocampus of individuals with Alzheimer's disease. Neuron 7, 695-702.

Piccirillo, C.A., Tritt, M., Sgouroudis, E., Albanese, A., Pyzik, M., Hay, V., 2005. Control of type 1 autoimmune diabetes by naturally occurring CD4+CD25+ regulatory $\mathrm{T}$ lymphocytes in neonatal NOD mice. Ann N Y Acad Sci 1051, 72-87.

Polman, C.H., O'Connor, P.W., Havrdova, E., Hutchinson, M., Kappos, L., Miller, D.H., Phillips, J.T., Lublin, F.D., Giovannoni, G., Wajgt, A., Toal, M., Lynn, F., Panzara, M.A., Sandrock, A.W., 2006. A randomized, placebo-controlled trial of natalizumab for relapsing multiple sclerosis. N Engl J Med 354, 899-910.

Porritt, M.J., Batchelor, P.E., Howells, D.W., 2005. Inhibiting BDNF expression by antisense oligonucleotide infusion causes loss of nigral dopaminergic neurons. Exp Neurol 192, 226-234.

Purves, D., Snider, W.D., Voyvodic, J.T., 1988. Trophic regulation of nerve cell morphology and innervation in the autonomic nervous system. Nature 336, 123-128.

Ransohoff, R.M., 2005. Natalizumab and PML. Nat Neurosci 8, 1275.

Redford, E.J., Kapoor, R., Smith, K.J., 1997. Nitric oxide donors reversibly block axonal conduction: demyelinated axons are especially susceptible. Brain 120 ( Pt 12), 21492157.

Rios, M., Fan, G., Fekete, C., Kelly, J., Bates, B., Kuehn, R., Lechan, R.M., Jaenisch, R., 2001. Conditional deletion of brain-derived neurotrophic factor in the postnatal brain leads to obesity and hyperactivity. Mol Endocrinol 15, 1748-1757.

Robinson, R.C., Radziejewski, C., Stuart, D.I., Jones, E.Y., 1995. Structure of the brainderived neurotrophic factor/neurotrophin 3 heterodimer. Biochemistry 34, 4139-4146.

Rosa, A., Cuesta, M.J., Fatjo-Vilas, M., Peralta, V., Zarzuela, A., Fananas, L., 2006. The Val66Met polymorphism of the brain-derived neurotrophic factor gene is associated with risk for psychosis: evidence from a family-based association study. Am J Med Genet B Neuropsychiatr Genet 141B, 135-138.

Rose, C.R., Blum, R., Pichler, B., Lepier, A., Kafitz, K.W., Konnerth, A., 2003. Truncated TrkB-T1 mediates neurotrophin-evoked calcium signalling in glia cells. Nature 426, 74-78.

Roux, P.P., Barker, P.A., 2002. Neurotrophin signaling through the p75 neurotrophin receptor. Prog Neurobiol 67, 203-233.

Ruddle, N.H., Bergman, C.M., McGrath, K.M., Lingenheld, E.G., Grunnet, M.L., Padula, S.J., Clark, R.B., 1990. An antibody to lymphotoxin and tumor necrosis factor prevents transfer of experimental allergic encephalomyelitis. J Exp Med 172, 11931200.

Sakaguchi, S., 2005. Naturally arising Foxp3-expressing CD25+CD4+ regulatory T cells in immunological tolerance to self and non-self. Nat Immunol 6, 345-352.

Santambrogio, L., Benedetti, M., Chao, M.V., Muzaffar, R., Kulig, K., Gabellini, N., Hochwald, G., 1994. Nerve growth factor production by lymphocytes. J Immunol 153, 4488-4495. 
Sariola, H., 2001. The neurotrophic factors in non-neuronal tissues. Cell Mol Life Sci 58, 1061-1066.

Schenone, A., Gill, J.S., Zacharias, D.A., Windebank, A.J., 1996. Expression of high- and low-affinity neurotrophin receptors on human transformed B lymphocytes. J Neuroimmunol 64, 141-149.

Schuhmann, B., Dietrich, A., Sel, S., Hahn, C., Klingenspor, M., Lommatzsch, M., Gudermann, T., Braun, A., Renz, H., Nockher, W.A., 2005. A role for brain-derived neurotrophic factor in B cell development. J Neuroimmunol 163, 15-23.

Schwartz, M., Kipnis, J., 2001. Protective autoimmunity: regulation and prospects for vaccination after brain and spinal cord injuries. Trends Mol Med 7, 252-258.

Schwartz, M., Moalem, G., Leibowitz-Amit, R., Cohen, I.R., 1999. Innate and adaptive immune responses can be beneficial for CNS repair. Trends Neurosci 22, 295-299.

Screpanti, I., Meco, D., Scarpa, S., Morrone, S., Frati, L., Gulino, A., Modesti, A., 1992. Neuromodulatory loop mediated by nerve growth factor and interleukin 6 in thymic stromal cell cultures. Proc Natl Acad Sci U S A 89, 3209-3212.

Sendtner, M., Kreutzberg, G.W., Thoenen, H., 1990. Ciliary neurotrophic factor prevents the degeneration of motor neurons after axotomy. Nature 345, 440-441.

Sendtner, M., Schmalbruch, H., Stockli, K.A., Carroll, P., Kreutzberg, G.W., Thoenen, H., 1992. Ciliary neurotrophic factor prevents degeneration of motor neurons in mouse mutant progressive motor neuronopathy. Nature 358, 502-504.

Serpe, C.J., Coers, S., Sanders, V.M., Jones, K.J., 2003. CD4+ T, but not CD8+ or B, lymphocytes mediate facial motoneuron survival after facial nerve transection. Brain Behav Immun 17, 393-402.

Shibayama, E., Koizumi, H., 1996. Cellular localization of the Trk neurotrophin receptor family in human non-neuronal tissues. Am J Pathol 148, 1807-1818.

Shull, M.M., Ormsby, I., Kier, A.B., Pawlowski, S., Diebold, R.J., Yin, M., Allen, R., Sidman, C., Proetzel, G., Calvin, D., et al., 1992. Targeted disruption of the mouse transforming growth factor-beta 1 gene results in multifocal inflammatory disease. Nature 359, 693-699.

Shults, C.W., Kimber, T., Altar, C.A., 1995. BDNF attenuates the effects of intrastriatal injection of 6-hydroxydopamine. Neuroreport 6, 1109-1112.

Sleeman, M.W., Anderson, K.D., Lambert, P.D., Yancopoulos, G.D., Wiegand, S.J., 2000. The ciliary neurotrophic factor and its receptor, CNTFR alpha. Pharm Acta Helv 74, 265-272.

Smith, K.J., Kapoor, R., Hall, S.M., Davies, M., 2001. Electrically active axons degenerate when exposed to nitric oxide. Ann Neurol 49, 470-476.

Sospedra, M., Martin, R., 2005. Immunology of multiple sclerosis. Annu Rev Immunol 23, 683-747.

Stadelmann, C., Albert, M., Wegner, C., Bruck, W., 2008. Cortical pathology in multiple sclerosis. Curr Opin Neurol 21, 229-234.

Stadelmann, C., Kerschensteiner, M., Misgeld, T., Bruck, W., Hohlfeld, R., Lassmann, H., 2002. BDNF and gp145trkB in multiple sclerosis brain lesions: neuroprotective interactions between immune and neuronal cells? Brain 125, 75-85.

Stankoff, B., Aigrot, M.S., Noel, F., Wattilliaux, A., Zalc, B., Lubetzki, C., 2002. Ciliary neurotrophic factor (CNTF) enhances myelin formation: a novel role for CNTF and CNTF-related molecules. J Neurosci 22, 9221-9227.

Stockli, K.A., Lillien, L.E., Naher-Noe, M., Breitfeld, G., Hughes, R.A., Raff, M.C., Thoenen, H., Sendtner, M., 1991. Regional distribution, developmental changes, and cellular localization of CNTF-mRNA and protein in the rat brain. J Cell Biol 115, 447459. 
Stockli, K.A., Lottspeich, F., Sendtner, M., Masiakowski, P., Carroll, P., Gotz, R., Lindholm, D., Thoenen, H., 1989. Molecular cloning, expression and regional distribution of rat ciliary neurotrophic factor. Nature 342, 920-923.

Storer, P.D., Xu, J., Chavis, J., Drew, P.D., 2005. Peroxisome proliferator-activated receptorgamma agonists inhibit the activation of microglia and astrocytes: implications for multiple sclerosis. J Neuroimmunol 161, 113-122.

Strasser, A., 2005. The role of BH3-only proteins in the immune system. Nat Rev Immunol 5, 189-200.

Tachibana, K., Nakajima, T., Sato, A., Igarashi, K., Shida, H., Iizasa, H., Yoshida, N., Yoshie, O., Kishimoto, T., Nagasawa, T., 1997. CXCR4/fusin is not a species-specific barrier in murine cells for HIV-1 entry. J Exp Med 185, 1865-1870.

Tao, X., West, A.E., Chen, W.G., Corfas, G., Greenberg, M.E., 2002. A calcium-responsive transcription factor, $\mathrm{CaRF}$, that regulates neuronal activity-dependent expression of BDNF. Neuron 33, 383-395.

Tapley, P., Lamballe, F., Barbacid, M., 1992. K252a is a selective inhibitor of the tyrosine protein kinase activity of the trk family of oncogenes and neurotrophin receptors. Oncogene 7, 371-381.

Tessarollo, L., 1998. Pleiotropic functions of neurotrophins in development. Cytokine Growth Factor Rev 9, 125-137.

Testi, R., Pulcinelli, F., Frati, L., Gazzaniga, P.P., Santoni, A., 1990. CD69 is expressed on platelets and mediates platelet activation and aggregation. J Exp Med 172, 701-707.

Thoenen, H., Sendtner, M., 2002. Neurotrophins: from enthusiastic expectations through sobering experiences to rational therapeutic approaches. Nat Neurosci 5 Suppl, 10461050.

Timmusk, T., Belluardo, N., Metsis, M., Persson, H., 1993. Widespread and developmentally regulated expression of neurotrophin- 4 mRNA in rat brain and peripheral tissues. Eur J Neurosci 5, 605-613.

Timmusk, T., Palm, K., Lendahl, U., Metsis, M., 1999. Brain-derived neurotrophic factor expression in vivo is under the control of neuron-restrictive silencer element. J Biol Chem 274, 1078-1084.

Torcia, M., Bracci-Laudiero, L., Lucibello, M., Nencioni, L., Labardi, D., Rubartelli, A., Cozzolino, F., Aloe, L., Garaci, E., 1996. Nerve growth factor is an autocrine survival factor for memory B lymphocytes. Cell 85, 345-356.

Turrini, P., Zaccaria, M.L., Aloe, L., 2001. Presence and possible functional role of nerve growth factor in the thymus. Cell Mol Biol (Noisy-le-grand) 47, 55-64.

Vega, J.A., Garcia-Suarez, O., Hannestad, J., Perez-Perez, M., Germana, A., 2003. Neurotrophins and the immune system. J Anat 203, 1-19.

Veldhoen, M., Hocking, R.J., Atkins, C.J., Locksley, R.M., Stockinger, B., 2006. TGFbeta in the context of an inflammatory cytokine milieu supports de novo differentiation of IL17-producing T cells. Immunity 24, 179-189.

Veldhoen, M., Uyttenhove, C., van Snick, J., Helmby, H., Westendorf, A., Buer, J., Martin, B., Wilhelm, C., Stockinger, B., 2008. Transforming growth factor-beta 'reprograms' the differentiation of $\mathrm{T}$ helper 2 cells and promotes an interleukin 9-producing subset. Nat Immunol 9, 1341-1346.

Viglietta, V., Baecher-Allan, C., Weiner, H.L., Hafler, D.A., 2004. Loss of functional suppression by CD4+CD25+ regulatory T cells in patients with multiple sclerosis. J Exp Med 199, 971-979.

Villoslada, P., Hauser, S.L., Bartke, I., Unger, J., Heald, N., Rosenberg, D., Cheung, S.W., Mobley, W.C., Fisher, S., Genain, C.P., 2000. Human nerve growth factor protects common marmosets against autoimmune encephalomyelitis by switching the balance 
of T helper cell type 1 and 2 cytokines within the central nervous system. J Exp Med 191, 1799-1806.

von Boehmer, H., 2005. Mechanisms of suppression by suppressor T cells. Nat Immunol 6 , 338-344.

Wang, S., Bray, P., McCaffrey, T., March, K., Hempstead, B.L., Kraemer, R., 2000. p75(NTR) mediates neurotrophin-induced apoptosis of vascular smooth muscle cells. Am J Pathol 157, 1247-1258.

Wardle, R.A., Poo, M.M., 2003. Brain-derived neurotrophic factor modulation of GABAergic synapses by postsynaptic regulation of chloride transport. J Neurosci 23, 8722-8732.

Wiese, S., Metzger, F., Holtmann, B., Sendtner, M., 1999. The role of p75NTR in modulating neurotrophin survival effects in developing motoneurons. Eur J Neurosci 11, 16681676.

Wiese, S., Pei, G., Karch, C., Troppmair, J., Holtmann, B., Rapp, U.R., Sendtner, M., 2001. Specific function of B-Raf in mediating survival of embryonic motoneurons and sensory neurons. Nat Neurosci 4, 137-142.

Wiesmann, C., de Vos, A.M., 2001. Nerve growth factor: structure and function. Cell Mol Life Sci 58, 748-759.

Winblad, B., Messamore, E., O'Neill, C., Cowburn, R., 1993. Biochemical pathology and treatment strategies in Alzheimer's disease: emphasis on the cholinergic system. Acta Neurol Scand Suppl 149, 4-6.

Yam, P.S., Takasago, T., Dewar, D., Graham, D.I., McCulloch, J., 1997. Amyloid precursor protein accumulates in white matter at the margin of a focal ischaemic lesion. Brain Res 760, 150-157.

Yamamoto, M., Sobue, G., Yamamoto, K., Terao, S., Mitsuma, T., 1996. Expression of mRNAs for neurotrophic factors (NGF, BDNF, NT-3, and GDNF) and their receptors (p75NGFR, trkA, trkB, and trkC) in the adult human peripheral nervous system and nonneural tissues. Neurochem Res 21, 929-938.

Yan, Q., Elliott, J., Snider, W.D., 1992. Brain-derived neurotrophic factor rescues spinal motor neurons from axotomy-induced cell death. Nature 360, 753-755.

Yoles, E., Hauben, E., Palgi, O., Agranov, E., Gothilf, A., Cohen, A., Kuchroo, V., Cohen, I.R., Weiner, H., Schwartz, M., 2001. Protective autoimmunity is a physiological response to CNS trauma. J Neurosci 21, 3740-3748.

Yoon, S., Lee, H.W., Baek, S.Y., Kim, B.S., Kim, J.B., Lee, S.A., 2003. Upregulation of TrkA neurotrophin receptor expression in the thymic subcapsular, paraseptal, perivascular, and cortical epithelial cells during thymus regeneration. Histochem Cell Biol 119, 55-68.

Ziemssen, T., Kumpfel, T., Klinkert, W.E., Neuhaus, O., Hohlfeld, R., 2002. Glatiramer acetate-specific T-helper 1- and 2-type cell lines produce BDNF: implications for multiple sclerosis therapy. Brain-derived neurotrophic factor. Brain 125, 2381-2391.

Zivadinov, R., Weinstock-Guttman, B., Benedict, R., Tamano-Blanco, M., Hussein, S., Abdelrahman, N., Durfee, J., Ramanathan, M., 2007. Preservation of gray matter volume in multiple sclerosis patients with the Met allele of the rs6265 (Val66Met) SNP of brain-derived neurotrophic factor. Hum Mol Genet 16, 2659-2668.

Zou, L.P., Abbas, N., Volkmann, I., Nennesmo, I., Levi, M., Wahren, B., Winblad, B., Hedlund, G., Zhu, J., 2002. Suppression of experimental autoimmune neuritis by ABR-215062 is associated with altered Th1/Th2 balance and inhibited migration of inflammatory cells into the peripheral nerve tissue. Neuropharmacology 42, 731-739. 


\section{Anhang}

\subsection{Abkürzungsverzeichnis}

$\begin{array}{ll}\% & \text { Prozent } \\ \times & \text { mal } \\ \alpha & \text { alpha }\end{array}$

Abb. Abbildung

AB Komplex

Avidin-Biotin Komplex

AK

Antikörper

Amp

Ampicillin

APC

Antigenpräsentierende Zelle

APC

Allophycocyanin

APP

Amyloid Vorläuferprotein

AS

Aminosäure

$\beta$

beta

Bcl-2

B-cell lymphoma 2

BDNF

Brain derived neurotrophic factor

bp

Basenpaare

BSA

Rinderserumalbumin

bzw.

beziehungsweise

ca.

circa

CD

cluster of differentiation

cDNA

complementary DNA

CFA

Komplette Freundsche Adjuvant

CNTF

ciliary neurotrophic factor

$\mathrm{CO} 2$

Kohlenstoffdioxid

Con A

Concanvalin A

ConAÜ

Concanvalin A Überstand

CTLA-4

cytotoxic T lymphocyte associated protein 4

CXCR4

CXC-Motiv-Chemokinrezeptor 4

\section{Cy5}

Cyanine 5

d

destilliert

DAB

Diaminbenzodin 


$\begin{array}{ll}\text { dATP } & \text { 3'-Desoxyadenosin-5'-Triphosphat } \\ \text { dCTP } & \text { 3'-Desoxyctidin-5'-Triphosphat } \\ \text { dGTP } & \text { 3'-Desoxyguanosin-5'-Triphosphat } \\ \text { DMEM } & \text { Dulbecco`s Modified Eagle Medium } \\ \text { DNA } & \text { Desoxyribonukleinsäure } \\ \text { dNTP } & \text { 3'-Desoxynukleosid-5'-Triphosphat } \\ \text { dTTP } & \text { 3'-Desoxythymidin-5'-Triphosphat }\end{array}$

EAE Experimentelle Autoimmune Enzephalomyelitis

E.coli Escherichia coli

EDTA Ethylendiamintetraessigsäure

ELISA Enzyme Linked Immunosorbant Assay

Epo Erythropoetin

et al. et alteri (und andere)

EtOH Ethanol

FACS Fluoreszenz aktivierter Zellsortierter

FCS Fötales Kälberserum

FITC Fluoreszeinisothiocyanat

g Gramm

GFP green fluorescent protein

Gy Gray

h Stunde

$\mathrm{H}_{2} \mathrm{O} \quad$ Wasser

HEK Humane Embryonale Nierenzellen

HIV human immunodeficiency virus

HLA human leukocyte antigen

HRP horseradish peroxidase, Meerrettichperoxidase

ICAM-1 intercellular adhesion molecule 1

IFN Interferon

Ig Immunglobulin

IgG Immunglobulin der Klasse G

IL Interleukin

iNOS inducable nitric oxide synthase

i.v. intra venös

JAK Janus Kinase 


\begin{tabular}{|c|c|}
\hline Kap. & Kapitel \\
\hline $\mathrm{kDa}$ & Kilo-Dalton \\
\hline LB & Luria Bertani \\
\hline LFA-1 & leukocyte function associated antigen 1 \\
\hline LIFR $\beta$ & Leukemia inhibitory factor receptor beta \\
\hline LPS & Lipopolysaccharid \\
\hline$\mu$ & Mikro \\
\hline MACS & magnetic bead-activated cell sorting \\
\hline MAG & Myelin assoziiertes Protein \\
\hline mBDNF & murine brain derived neurotrophic factor \\
\hline MBP & Myelinbasisches Protein \\
\hline$\mu \mathrm{Ci}$ & Mikrocurie \\
\hline $\mathrm{MHC}$ & major histocompability complex \\
\hline Min & Minuten \\
\hline $\mathrm{ml}$ & Milliliter \\
\hline$\mu l$ & Mikroliter \\
\hline$\mu \mathrm{m}$ & Mikrometer \\
\hline $\mathrm{mm}$ & Millimeter \\
\hline $\mathrm{mM}$ & Millimol \\
\hline MOG & Myelinoligodenrozytenprotein \\
\hline mRNA & messenger Ribonukleinsäure \\
\hline MRT & Magnetresonanztomographie \\
\hline MS & Multiple Sklerose \\
\hline $\mathrm{n}$ & Anzahl der Messwerte \\
\hline $\mathrm{Na}_{\mathrm{v}}$ & Natriumkanal \\
\hline NFאB & nuklear factor kappaB \\
\hline ng & Nanogramm \\
\hline NGF & nerve growth factor \\
\hline NK Zellen & Natürliche Killerzellen \\
\hline NO & Stickstoffmonoxid \\
\hline NT/NTR & Neurotrophin \\
\hline PBS & Phosphat-gepufferte Kochsalzlösung \\
\hline PCR & Polymerase-Kettenreaktion \\
\hline $\mathrm{PE}$ & Phycoerythrin \\
\hline
\end{tabular}




\begin{tabular}{|c|c|}
\hline PFA & Paraformaldehyd \\
\hline $\mathrm{pH}$ & negativer dekadischer Logarithmus der Protonenkonzentration \\
\hline PLP & Proteolipidprotein \\
\hline PMA & phorbol mystrate acetate \\
\hline PML & progressive multifokale Leukoenzephalopathie \\
\hline PNS & Peripheres Nervensystem \\
\hline POD & Peroxidase \\
\hline $\operatorname{PPAR} \gamma$ & Peroxysomproliferationsaktivierter Rezeptor gamma \\
\hline pTrkB & phosphorylierte Tyrosin Kinase B \\
\hline ReMed & Restimulationsmedium \\
\hline RNA & Ribonukleinsäure \\
\hline rRNA & ribosomale Ribonukleinsäure \\
\hline $\mathrm{rpm}$ & rounds per minute \\
\hline RT & Raumtemperatur \\
\hline RT-PCR & reverse Transkriptase PCR \\
\hline s & Sekunde \\
\hline STAT & Signal Transducers and Activators of Transcription \\
\hline TCGF & $\mathrm{T}$ cell growth factor \\
\hline TGF- $\beta$ & transforming growth factor- $\beta$ \\
\hline TNF & Tumornekrosefaktor \\
\hline Treg & regulatorische T-Zelle \\
\hline Tris & Trishydroxymethylaminomethan \\
\hline Trk & Tyosinkinase \\
\hline tRNA & transfer Ribonukleinsäure \\
\hline TZR & T-Zellrezeptor \\
\hline VLA-4 & very late antigen 4 \\
\hline z.B. & zum Beispiel \\
\hline ZNS & Zentrales Nervensystem \\
\hline
\end{tabular}




\subsection{Abbildungsverzeichnis}

Abbildung 1.1: $\quad$ Maus BDNF Genstruktur und Splice-Varianten

Abbildung 4.1: $\quad$ Amplifikation der mBDNF mRNA Splice-Varianten im Gehirn von C57BL/6 Mäusen

Abbildung 4.2: Durchschnittliche relative Expression der mBDNF mRNA SpliceVarianten im Gehirn von C57BL/6 Mäusen

Abbildung 4.3: Durchschnittliche relative Expression der mBDNF 3 mRNA in peripherem lymphatischem Gewebe und Immunzellpopulationen in C57BL/6 Mäusen

Abbildung 4.4: Durchschnittliche relative Expression der mBDNF 3 mRNA

Abbildung 4.5: $\quad$ Durchschnittliche relative Expression der mBDNF mRNA Splice-Varianten in Astrozyten von C57BL/6 Mäusen

Abbildung 4.6: $\quad$ Durchschnittliche relative Expression der mBDNF mRNA Splice-Varianten in Astrozyten im Vergleich zum Gesamthirn von C57BL/6 Mäusen

Abbildung 4.7: Durchschnittliche relative Expression der mBDNF 3 mRNA Splice-Varianten in gereinigten Astrozyten und Mikroglia von C57BL/6 Mäusen

Abbildung 4.8: $\quad$ Schematische Darstellung des Versuchsaufbaus

Abbildung 4.9: Restriktionsverdau lentiviraler Vektoren

Abbildung 4.10: Austestung des lentiviralen BDNF Vektors sowie des BDNF Virus an HEK-Zellen

Abbildung 4.11: Lentivirale Transduktion von T-Zellen einer MOG-spezifischen

\section{Zelllinie}

Abbildung 4.12: Lentivirale Transduktion mit dem GFP Virus

Abbildung 4.13: BDNF Cytospins unbehandelter und lentiviral transduzierter T-Zellen

Abbildung 4.14: BDNF Bioaktivitätstest mittels Überlebensassay mit murinen dorsalen Wurzelganglien

Abbildung 4.15: Detektion der GFP positiven T-Zellen in der Peripherie nach i.v. Injektion in C57BL/6 Mäusen

Abbildung 4.16: Nachweis der GFP positiven T-Zellen im ZNS nach i.v. Injektion in C57BL/6 Mäusen 
Abbildung 4.17: EAE Krankheitsverlauf i.v. injizierter und $\mathrm{MOG}_{35-55}$ immunisierter C57BL/6 Mäuse

Abbildung 4.18: Immunhistochemische Auswertung von Immunzellinfiltraten in C57BL/6 Mäusen nach i.v. Injektion

Abbildung 4.19: Immunhistochemische Auswertung von axonalen Dichten und APP Akkumulationen in C57BL/6 Mäusen nach i.v. Injektion

Abbildung 4.20: Immunhistochemische Auswertung der iNOS Expression in C57BL/6 Mäusen nach i.v. Injektion

Abbildung 4.21: Funktionelle Relevanz der BDNF Überexpression in situ anhand Fluoreszenzmikroskopischer Analyse der pTrkB Färbung

Abbildung 4.22: FACS Analyse der Aktivierungsmarker applizierter BDNF und GFP Virus transduzierter T-Zellen im Vergleich zu endogenen T-Zellen 


\subsection{Danksagung}

Zunächst möchte ich Herrn Prof. Dr. Ralf Gold dafür danken, dass er es mir ermöglicht hat diese Arbeit am Multiple Sklerose Institut in Göttingen anzufertigen.

Mein besonderer Dank gilt meinem Betreuer Herrn Dr. Fred Lühder für seine stete Diskussionsbereitschaft, Unterstützung und ausgezeichneten Betreuung.

Bedanken möchte ich mich auch bei Herrn Prof. Dr. Ernst Wimmer für die Übernahme der Erstkorrektur, sowie bei Herrn Prof. Dr. Detlef Doenecke, der bereit war, die Zweitkorrektur dieser Arbeit zu übernehmen.

Ganz herzlich bedanke ich mich auch bei Herrn Dr. Ralf Linker und Dr. Niels Kruse für die gute Zusammenarbeit, die Unterstützung und hilfreichen wissenschaftlichen Ratschläge.

Herrn Prof. Dr. Harald Neumann danke ich für die Bereitstellung des lentiviralen Vektors und Frau Dr. Ellen Gerhardt für die Generierung der Lentiviren und die überaus aufmunternden Gespräche.

Herrn Prof. Dr. Stefan Wiese danke ich für Hilfe beim Überlebensassay.

Ein riesengroßes Dankeschön geht an alle jetzigen und ehemaligen Mitarbeiter des IMSF für die tolle Arbeitsatmosphäre, die gute Stimmung, die Hilfsbereitschaft und die technische Unterstützung.

Mein Dank gilt außerdem meiner Familie, die mich immer unterstützt haben und immer für den nötigen Ausgleich während meiner Doktorarbeit gesorgt haben.

Ganz besonders danke ich meinem Ehemann dafür, dass er mein Leben stets bereichert und mir immer zur Seite steht. 


\subsection{Eidesstattliche Erklärung}

Hiermit erkläre ich an Eides statt, dass ich die vorliegende Arbeit selbstständig angefertigt und keine anderen als die angegebenen Hilfsmittel verwendet habe. Diese Arbeit hat weder in gleicher noch in ähnlicher Form in einem anderen Prüfungsverfahren vorgelegen. Ich habe in keinem früheren Verfahren einen akademischen Grad erworben oder zu erwerben versucht.

Göttingen, den 15-03-2010

Seray Demir 


\subsection{Lebenslauf}

Name

Geburtstag

Geburtsort

Familienstand

Staatsangehörigkeit

Schule

\section{Studium und Promotion}

Göttingen, den 15-03-2010
Seray Demir, geb. Cetin

07. Mai 1980

Rotenburg a.d. Fulda

verheiratet

deutsch

1986 - 1996: Grundschule und gymnasiale

Mittelstufe, Brüder-Grimm-Schule, Bebra

1996 - 1999: Gymnasiale Oberstufe,

Jakob-Grimm-Schule, Rotenburg a.d. Fulda

Abschluss: Abitur

1999 - 2005: Studium der Diplom-Biologie an der Universität Kassel

Vordiplom 2002

Diplom 2005 Schwerpunkte: Genetik, Zellbiologie, Tierphysiologie

Thema der Diplomarbeit: „Molekulargenetische Analyse testikulär exprimierter olfaktorischer Rezeptoren“ am Deutschen Primatenzentrum, Abt. Primatengenetik, Göttingen

Ab 2006 Promotion am Multiple Sklerose Institut in Göttingen

Thema der Doktorarbeit: „Brain derived neurotrophic factor (BDNF) - Untersuchungen zur Expression und Regulation in vitro sowie zur funktionellen Relevanz in der experimentellen autoimmunen Enzephalomyelitis (EAE)“ 